\title{
SOEMBANEESCHE VERHALEN.
}

In 't dialect van Kambera, met vertaling en aanteekeningen

vaN D. K. WIELENGA.

Missionair Predikant op Soemba.

\section{INHOUD.}

I. I Dari, de slimme aap.

II. Karoboe toenoe, Karoboe hămoe, de twee pompoenen.

III. I Rămboe Kahi dăngoe I O e mboe Ndiloe dăngoe I Mada, I Rămboe Kahi met de twee broeders.

IV. I Rămboe Kahi, na maloeri beli; I Ramboe Kahi in 't leven weergekeerd.

V. Maka Ihi Nāōē, de tol.

VI. Kabihoe Karoenggoe Watoe, het geslacht Karoenggoe Watoe.

VII. Tau Karita, de menschen van Karita.

VIII. Ihi Wawang, het geslacht Ihi Wawang.

IX. Na tawoeroe, de ring.

$\mathrm{X}$. Ana Manoe, het kuiken.

XI. Paraing Madita, de kampong Paraing Madita.

XII. Ndewa răndjăng, de geleide-geest.

XIII. Na tandánoe, de walvisch.

XIV. Na woeja, de krokodil.

XV. I Dai Karămbo'a, de karbouwen-hoeder.

XVI. I Rămboe Kahi, die een varken baarde.

XVII. II Rămboe Kahi en I Mili Kămi.

XVIII. I Rămboe Kahi zonder hoofd.

XIX. I Rămboe Kahi met den boschhaan.

XX. I Rămboe Kahi en de uien.

Dl. 68 . 


\section{I Dari.}

Toenanoe na pakiri na. Nindja da tau madoea, hina pa'ana ja ha'atoe na, anakeàda mini ja.

Toenakanoe bana dedi ka, ngalang tiloe mboea lodoe, meti na nja na ina na. Mandai ki hakoedoe meti na nja na ama na. Didi meha ki ja ka na ana rara. Toenanoe ngéa ngéa bana hì. Tau lihi oema da ndaningoe; marau. Da ina na da ama na ndaningoe matanindja, loepa hăla ha da ahoe.

Toenanoe na anakeàda noena, nggiki ma na ka ihoe! mbiha ma na nja; na ngalang hakamboeloe lima mboea lodoe, na ngalang be ja pa’ătăloe, kabeli nggoboe. Toenakanoe hili mandai na pingoe pabeli; ngăda na na ngeri ă, na pangga ndjoroe. Palăngăng hau woelang, na ătăloe ka papangga.

Toenanoe na kaka ja năhoe na pădăng mandjioe na. Toenanoe na piti mboăla pahăpa na na ina na hina boenggăhoe ja ; na tăngăroe ja, hau na na teànga; na piti ja hina lo'a pakē wănja watăroe, hau măngoe poălang. Toenanoe hina ngăndi ja la oema; bana tăka ka la oema, epi ndena pingoe papadoekoeloe; na watăroe noena na nga mata nja, hau lodoe halara..

Toenanoe bana hăla ja ka na watăr, na hili lo'a patăngăroe ja na mboăla pahăpa na na ina na; na ita ja hau na na ri malokoe.

Toenanoe hina lakoe, lo'a pahimboe watăr, wăna lăti. Toenanoe hi hamboeroe na nja na mangăndi boeti, hina pa’ărăng na madoekoe ja na boeti: ka nggi lo’a moe nja, wăna nja na anakeàda.

Tăka hina heàma na anakeàda: "lo’a nggoe nja pamandara, rimbang nggoe nja ka.» $\mathrm{Na}$ heàma njoena na boeti: "kē ka njoengga.» $\mathrm{Na}$ heàma na anakeàda: "nggăra ta toe kau ? rimbang ma doe dănja.

Tăka hina heàma na boeti: "kē ka!» Toenanoe hina karai ja na madángga nja na boeti: "pira wămoe nja na boeti?» $\mathrm{Na}$ heàma njoena na madángga nja: »hau ri malokoe, wănggoe nja.» Tăka hina heàma: măla ka! Toenanoe kē doe na nja ka na boeti; lakoe doe na nja ka la oema.

Toenanoe bana tăka ka la oema, na anakeàda noena, mahoeroe 
na, malidjang ka na ihi na, rimbangoe na. Tăka hiwăna njoena na boeti : "kanggiki na. oemboe, heàna!» Na heàma njoena naanakeàda: "rimbang nggoe nja jéa! lo’a nggoe nja pakē watăr, wănggoe kawai, kē ka njoengga, wămoe». Tăka na' heàma na boeti: "ămboe handoeka, ămboe hondoe mănoe mănoe ka, ka pekoe lakoe nggoe». Toenanoe hina pahăla ja; bana pahăla ja ka, lakoe doe na nja ka na boeti; na lo'a pamanganga watăr la woăka tau, na moeti oehoe, na păpoe karoboe, hina ngăndi ja la oema. Toenanoe hina padoekoeloe nja epi, toenoe ja watăr, manahoe ja karoboe hina wŏnja hina ngangoe noena na anakeàda. Hìna ka hina pingoe pangangoe pamémi.

Toenanoe hiwăna na boeti: »nggamoe ja na ngara moe, oemboe?» "Ndakoe pinja na ngara nggoe!» wăna na anakeàda.

Toenanoe hina heàma na boeti: "kanggiki na hi ndau pinja na ngara moe? Tăka hiwăna na anakeàda: "na ina nggoe, na ama nggoe ndakoe ita ha, ndakoe pindja, djăka da meti ka, djăka ndeda meti, ndakoe pindja. "Madja ka toena, wăna na boeti, măta kakoe toenggau ngara moe; Oemboe $\mathrm{Ndiloe}$ $\mathrm{mila}^{1}$ kau; djẻa ba njoengga I Dari, wămoe ngga.»

Ba toenakanoe bada papingoe ngara, lakoe doe na nja ka I Dari, wăna bana lakoe: "ha oemboe, djăka ndaningga, kanoăma wiki moe ka pangangoe; măta kakoe lo’a pambawa, koe lo'a patăngăroe ha da ndjara, da pawoeloe na na ama moe la padang.» Toenanoe hi lakoe na nja ka; palăngăng tiloe mboea roedoeng, patoe mboea roedoeng hina măngoe pabeli ja; ndena beli djoe’a ja, na lakoe li la woăka tau pamanganga oehoe, watăr.

1 In de Soemba-verhalen heet de "held" steeds I Oemboe Ndiloe, onderscheiden door verschillende adjectieven: $\mathrm{mila}=$ de arme; $\mathrm{k}$ atikoe $w \overline{\mathrm{e}}=$ varkenshoofd, etc. De "heldin" heet steeds I Ramboe Kahi, zoo noodig ook door een adjectief te onderscheiden. De "held" heeft langs allerlei moeilijke wegen de „heldin" te veroveren. Maar altijd „krijgen zij elkaar". 't Is hetzelfde onderwerp: „hoe I O emboe $\mathrm{Ndiloe}$ aan zijn vrouw, I Ramboe Kahi" kwam", maar steeds op een andere wijze behandeld.

Dit soort "volksroman" is zeer geliefd. Bij den oogst, 's avonds in de lichte maan, kan de verteller zijn hoorders in "verrukking" brengen met telkens nieuwe "verwikkelingen" te bedenken. Vooral als hij 't zoo weet te rekken, dat hij twee à drie avonden noodig heeft, dan is zijn naam als verteller voor goed gevestigd.

Dit verhaal van I Dari, is een der besten; vooral psychologisch mooi geteekend, hoe de aap de ouders van I Ramboe Kahi gunstig voor een huwelijk weet te stemmen. 
Toenanoe bana tăka ka la oema, hiwăna njoena I Oemboe Ndiloe: "Ka nggi'oe karai ningoe watăroe?» Na heàma njoena I Dari: "Kandí ka, da woăka nggoe njoengga laloe dangoe ha, da lima nggoe njoengga da madita ${ }^{1}$ bakoe boeta roemba.»

Toenanoe na kanoăma pangangoe; bana hăla ka pangangoe hiwăna njoena I Dari: "oemboe, măta kakoe lo’a pambawa!»

Toenanoe lakoe na nja ka la paraingoe, na pangeá na I Mbălăroe Kahiloe ${ }^{2}$; laloe woeloe ja na marămba noena, na bokoeloe na ndaningoe mahama na, da mata na hama wŏa kokoer, da kahiloe na laloe mbălăroe ha. Toenanoe na tăka ka la oema na, tăka hiwăna noena na marămba: "Ka heàna, Dari, nggăra mai moe?» Tăka hina heàma njoena I Dari: "mbawa ă nggoe nja; koe rongoe la tau, na mai I Dari pahikoe ha da tai kahiloe nggoe, wăna I Oemboe, wăda bakoe rongoe.» Tăka na heàma na marămba "lănga tăka, ba mai doe moe nja ka heàna kau hikoe ha.»

Hiwăna njoena I Dari: «ba ndokoe ${ }^{3}$ na nja na lodoe năhoe, haromoe ka bădi la mbaroe, ka patarakoe ${ }^{4}$ ndja lodoe mbaroe.»

Toenanoe todoe na nja ka I Dari lai noe; da kanoăma nja pangangoe, da wŏnja hina ngangoe. Ndedi bana harí ka, bana nanaroe ${ }^{5} \mathrm{ka}$ na lodoe, hiwăna njoena I Dari : «ha oemboe,

1 lima madita = lange vingers, heeft dezelfde bijbeteekenis als in het Hollandsch.

2 I Mbălăroe Kahiloe = breed oor. Een dergelijke reus, met oogen als klappernoten, komt in de meeste verhalen voor, met verschillende naam betiteld. Als een regel is hij 't, uit wiens handen de held zijn heldin moet verlossen.

s ndokoe $=$ de fout, de schuld van iets zịn: b.v. na ndokoe nja roedoeng hida maroămbang na ngarăngia = de nacht was de schuld, dat zij den weg verloren.

4 ta rakoe $=$ de eerste morgenstralen uitzenden. Een typische toepassing van 't praefix pa: vlg. Schets v/d Soemb. Spraakkunst, pg. 42.

${ }^{5}$ nanaroe $=$ de zon even zichtbaar zijn. 't Soemb. is rijk aan woorden om de verschillende "uren" van den dag aan te duiden, bv. bara kiri a wang $=$ de horizon wordt wit; nanaroe lodoe=de zon even zichtbaar; tarakoe lodoe $=$ de eerste stralen uitzenden; pera doea pah $\bar{e}=$ halverwege 't stijgen (9 uur); tidoeng lodoe $=$ de zon op 't hoofd dragen, (12 uur); pihil lodoe = de zon begint te draaien ( $t 1$ uur); hapoengoe kokoer djangga na $=$ zoo hoog als een klapperboom ( \pm 4 uur); hafoengoe kokoer pandakoe na $=$ zoo laag als een klapperboom ( 5 uur); tama loendoeng = geheel onder.

Dan zijn er nog vele woorden, welke meer „algemeen' zijn: had a roed oe $\mathrm{ng}=$ 's morgens vroeg als 't nog donker is; $\mathrm{mbaroe}=$ 's morgens vroeg (van 6-7 uur); maling $=$ avond; roedoeng $=$ nacht; mandalora $=$ middernacht, ete. etc. 
tarakoe na nja ka na lodoe, poeroe kau kakoe tăngăroe ha da kahiloe moe.»

Tăka hiwăna na marămba: "ka nggini koe mandapoe ningoe?»

* Mai kau noeloea, la ngadoe keàla ${ }^{1}$, ka pekoe ita nda ha da kahiloe moe.» Toenanoe lakoe da nja ka la hadidi keàla, hina mandapoe pangadoeng la keàla. Tăka njoena I Dari na mandapoe pali ditang. Toenanoe bana tăngăroe ha ka, "ndăhăroe ki nggau hakoedoe la ngadoe keàla, nde pekoe ita nggoe.» Toenanoe bana ndăhăroeng ka hina djoekăroe nja la keàla; meti doe na nja ka na marămba. Ndedi bana meti ka na marămba, na tau la paraingoe noena, na hadang ndăba, pameti ja I Dari, wăda, bana pameti ja na miri nda, wăda.

Toenanoe hiwăna njoena I Dari: "ha! păndjăng! rongoe ja na paní nggoe njoengga; na miri mi njimi jeàna laloe karaœ eti ja, laloe mbana pareàta ja; kai napa ja na miri nggoe njoengga haromoe, laloe hămoe eti ja, ndena bihoe pambana parèata na, na hămoe ndăba bana paní.» Toenanoe da heàma da tau lai noe: "lănga tăka ka i njoena, na mbana pareàta ma doe na.» Toenanoe hiwăna njoena I Dari: «da pawoeloe pawoeloe na na marămba jeàna na mameti, ămbi patabini ndja, pa'oehi ndăba ndja, kai pateà wănja na miri nggoe njoengga.»

Toenanoe lakoe na nja ka njoena I Dari, na lakoe li la woăka tau pahăpi watăroe, pamoeti oehoe hina ngăndi ja la oema. Toenanoe bana tăka ka la oema hiwăna njoena I Oemboe Ndiloe: "na lakoe moe njoemoe, nde papinggau pangéa palakoe moe.» Tăka na heàma njoema I Dari: "ho Oemboe Ndiloe, ndau pinja na papinggoe njoengga, napa haromoe kau tăngăroe ja.» Toenanoe bana kanŏama nja pangangoe, bada hăla ka pangangoe, hili lakoe na nja I Dari la marămba ha'atoe, na mawoeloe.

Tăka hininja na ana na, na ana karéa, kawini paki ma ja. Toenanoe bana tăka ka la oema noena, na marămba na mandapoe la bangga ${ }^{2}$, hiwăna nja: «Ka heàna. Dari, nggăra mai

1 la ngadoe keàla = waar men naar beneden ziet in 't ravijn; zoo zegt men ook la $\mathrm{ngadoe} l o k o e=o p$ den steilen oeverrand van een rivier.

$2 \mathrm{bangga}=$ is de \pm 1 meter hooge voorgalerij, waar men zit en bezoek ontvangt; $\mathrm{kaheli}=$ is de vloer in huis, $\pm 2 \mathrm{M}$. boven den grond. De vrouwen blijven in huis (d.w.z. op de kabeli), zittend in de deuropening. De gasten eten „binnen”. Vreemdelingen blijven in de voorgalerij eten en slapen. 
moe?» "Lo'a ki patadaloe ja, wăna i oemboe, i toeja ${ }^{1}$, wăna ngga nămoe, hikoe mai.»

Toenanoe hiwăna njoena na marămba: "wŏnja pahăpa na I Dari, na pingoe i bana wăngoe poeloeng.». Toenanoe hida wŏnja hina hăpa; bana hăla ka pahăpa, măta kakoe hē hoedita ${ }^{2}$ lai Rămboe, wăna.

Toenanoe bana hē ka, na mandapoe lihi nja njoena na kawini, hiwăna: "wŏnda tahăpa ${ }^{3}$, Rămboe!» Na heàma njoena na kawini: "lakoe hoeloea, Dari, ba miti-ndoera moe ka, mangădătoe i nggau!» Toenanoe na heàma I Dari: "ba ata doe ma doemoe ngga, nggiki na hioe mangădătoe ngga,» wăna. Na heàma na kawini: "djè ja njoena ndakoe pinggau djăka nggi pawelimoe.» Hina heàma I Dari : "papaleàwa na ngga na kalembi ma doemoe nămoe hikoe mai; ba peàka ă nda nja, kalembi lănga tăka mi, wăna I Dari, mata mi ndeda padjindjing, hama da paní mi, na pangga mi pahama, na riki mi pahama.»

Na heàma njoena na kawini: "ka nggikina, bau tăngăroe ka noe, Dari, hioe li ja noena; njoengga ndaningga kalembi; didi ma ka, bakoe dedi la ina nggoe la ama nggoe.» Toenanoe na heàma I Dari: “ămboe toemoenoe, Rămboe, lo’a kau rongoe ja, wăna dăngga nămoe, hikoe pangga londoeng, hikoe lakoe tăka nggau.» 4

Tăka na heàma na ama na la bangga, hiwăna: "nggăra wăna păkoe ka I Dari heàna, laloe dangoe ja bana paní.» Toenanoe na heàma na kawini: "Kalembi mi ka, na oemboe

1 toeja = noemt men zijn oom, getrouwd met een zuster van vader. En mijn zusters kinderen noemen mij ook zoo. Broers kinderen mogen niet met elkaar trouwen. Een huwelijk van kinderen van broer en zuster, is daarentegen zeer gewenscht; zonder buitengewone redenen mag hiervan niet afgeweken worden.

2 he hoedita (la kaheli) is een teeken van "vriendschap", en mag men nooit doen, dan na eerst verlof daartoe gevraagd en verkregen te hebben.

${ }^{3}$ hăpa = een sirihpruim kauwen. Zonder sirih kan er niets gedaan worden. Bij een bezoek, geeft men elkander eerst sirih, terwijl men praat over 't "mooie weer" en dergelijke onderwerpen. Heeft men zich van een pruim voorzien, dan eerst zal men 't doel van zijn bezoek vertellen.

4 hikoe pangga londoeng,

hikoe lakoe tăka nggau.

Dergelijk soort "panton" gebruikt de Soembanees gaarne, vooral als hij een "zaak" moet bespreken. Men heeft dan "bepaalde" uitdrukkingen, welke een "bepaalde" beteekenis hebben. Voor een "vreemdeling" lastig te leeren en te begrijpen. Maar een studie op zich zelf overwaard. 
nggoe», wăna. "Ka toena ka ka ihoe doena, wăna na ama na bana heàma, marau tana ja ka, nde papingoe pa năhoe dăngga angoe nda, wăna; batoenanoe bana pingoe papaní I Dari, kanoăma nja pangangoe kana ngangoe.»

Toenanoe hida kanoăma nja pangangoe, na memi ka năhoe da pangangoe, noe takoe doe da nja hida wonja, hiwăna njoena na kawini: "mai kau, kau ngangoe, Dari!» Na heàma I Dari: "njoengga ndakoe bihoe pangangoe meha, ta ngangoe doeang ${ }^{1}$ bădi hina hămoe.»

$\mathrm{Na}$ heàma njoena na kawinì: nde'a, wăna. Na heàma I Dari : «djàka toena, ndakoe bihoe pangangoe; djăka ta doeang bé ă la hau toboeng, koe ngangoe bé njoena." Toenanoe na heàma na kawini: "doeang bawămoe, ta doeang ka doena, nda ndokoe wa i nja noe!»

Toenanoe nga doeang da nja ka, loepa hăla da nja ka na oehoe da la hau toboeng. Bada hăla ka pangangoe, da wŏnja ka pahăpa; na hăla ka pahăpa, hiwăna I Dari: "măta :kakoe lakoe, na roedoeng doe bana marau na pangéa nggoe,» Toenanoe hî lakoe na nja ka.

Toenanoe bana tăka ka la oema hiwăna njoena I Oemboe Ndiloe: "ka nggi weli, Dari ?» Na heàma njoena I Dari: mbawa ă nggoe nja ka năhoe la marăda, ba boeti ka doekoe.» Na heàma njoena I Oemboe Ndiloe: "nggoemang palakoe ănga, pangangoe ndaningoe ma!» Na heàma njoena I Dari: «ămboe handoeka ni nja na pangangoe, năhoe tai ningoe.» Toenanoe hadang lakoe doe na nja ka, lo'a pahăpi watăr la woăka tau, ka nggăra ka ka doena pa'ita na, na ngăndi ndăba ja, na doekoe dira matiki. Toenanoe bana tăka ka la oema, kanoăma na nja pangangoe, toenoe ja watăr, manahoe na nja karoboe hina wornja hina ngangoe.

Tăka hiwăna njoena I Dari: "ninja na pakanandi nggoe njoengga, na pande pimoe, napa ngeri mandai ndai kau pinja ka.» Toenanoe hili lakoe na nja i la ngéa paweli na la pira na. Toenanoe bana ita ja ka na ama na I Rămboe Kahi, hiwăna: "hili nămoe nja i ka I Dari, nggăra wăna ihoe nămoe.» Toenanoe bana tăka ka hida wŏnja pahăpa na; bada hăla ka

\footnotetext{
1 ngangoe doeang = met zijn beiden uit één schotel eten. 't Is een bewijs dat men dan op zeer goeden voet met elkaar staat of met elkaar verloofd is. (Een dergelijk gebruik voor verloofden vindt men b.v. ook op Urk)
} 
pahăpa, tăka hiwăna njoena na ama na I Rămboe Kahi: "ka heàna, Dari, ka nggara mai ă moe?» Na heàma njoena I Dari : "mai nggoe nja pambawa ă.» Tăka na heàma njoena na ama na I Rămboe Kahi: "nde woekoe nggoe ${ }^{1}$ papa'ărănggau, napa hi papaleàwa na nggau na oemboe moe, wănggoe be a.» $\mathrm{Na}$ heàma njoena I Dari: "nde'a, napa mandai ndai ka bădi, djăka na paleàwa ka pamai lai njimi hikoe mai.» Tăka hiwăna na ama na I Rămboe Kahi: "kanoăma nja pangana I Dari kana ngangoe, laloe mboehanggoe nja bana paní, na pingoe pawotoe angoe na bana paní.» Toenanoe da kanoăma nja pangana, ba memi ka hida pa'aunja. Toenanoe hina hē la kaheli, tăka hiwăna njoena I Rămboe Kahi: "ha Dari, mai kau noeloea, ngangoe ningoe la lihi nggoe." Toenanoe hina lakoe ja hida wŏnja pangana. Toenanoe hiwăna I Dari: "ha Rămboe, ta ngangoe doeang bădi.» Tăka na heàma njoena I Rămboe Kahi: "ai ha, ndakoe bihoe panga doea dănggau.» "Kanggiki na hi ndau bihoe, Rămboe?» "Da lima moe da miting, na ihi moe ningoe woeloe na, djeà ja hi ndakoe bihoe.» Tăka hina heàma njoena I Dari: "njoemoe oepoe la hapapa, njoengga koe oepoe la hapapa, handăka djoe'ang ă bau oepoe.» Toenanoe hina dongoe.

Toenanoe bana hăla ka pangangoe, hiwăna njoena I Dari: «ha Rămboe, wŏnda tahăpa. Toenanoe hina wŏnja mbŏala pahăpa. Tăka hiwăna I Dari: "ha Rămboe, bakoe wăng papalakoeng mata nggoe, hama djè djeà ja ka na kaba mata na na oemboe nggoe; paní na pahama, riki na pahama, tăngăroe na pahama. Tăka na heàma njoena I Rămboe Kahi: "rongoe ja Dari, laloe paní ănga be ja ka, na oemboe moe mata ma na i doena, njoengga mata ma nggoe i doekoe, oepahama ndăba nja ka na tau.»

Tăka na heàma njoena I Dari: "lănga tăka ma nggoe, djăka na oemboe nggoe njoengga, ndjara, karămbo'a, ata, ămboe peàka ${ }^{2}$, laloe mawoeloe ja.» Tăka na heàma njoena I Kahi : «kana woeloe ki ka doena! noe bana woeloe, djeà mai mi patoengga ha,» Tăka na heàma njoena I Dari: napa haromoe

\footnotetext{
1 nde woekoe nggoe, meest gevolgd door nde ngaha nggoe, is een „beleefde" nitdrukking en beteekent: niet zonder reden, niet uit ijdele nieuwsgierigheid, er zit een bepaald doel achter, dat ik....

2 ămboe peàka = praat er me niet van, niet uit te spreken veel.
} 
djăka ndau pahămoe ha pa da pawoeloe na na oemboe nggoe, pandjiloe nja na tamoe nggoe, ${ }^{1}$ nde I Dari ă ka pa.»

Toenanoe hiwăna njoena I Dari: "măta kakoe lakoe ă.» Toenanoe lakoe na nja ka; na lakoe li la woăka tau, da oehoe, da watăr na tidoeng na doekoe.

Toenanoe bana tăka ka la oema, na kanoăma pangangoe hida ngangoe.

Toenanoe mandai-ndai ki ka, lakoe na nja ka njoena I Dari, hina lakoe li la woăka na I Mbălăroe Kahiloe, na ita ha da pănda djawa, na păpoe ha hina ngăndi nja na kawini noena. Toenanoe bana tăka ka: "jeàda da pănda djawa, lo’a patoe ndja, wăna I Oemboe.» Da heàma njoeda da tau lai noe: "ka nggăra ta toe ha nà, ama, da mamajiloe!» Na heàma njoena I Dari: "măla noe, kamang bera kai ngandja, laloe hămoe lănga tăka ha!»

Toenanoe bera doe da nja ka hida ngandja; bada ngandja ka năhoe, da hămoe i ka ihoe bada pakakandja. Toenanoe hiwăna na ama na I Rămboe Kahi: "ka nggini pănda djawa ningoe ha?» Tăka na heàma njoena I Dari: "pănda djawa la woăka na I Oemboe ha!» "Ka nde oekoe ${ }^{2}$ dangoe ma ha!» Na heàma njoena I Dari: "ai ha, ămboe peàka, hau woăka bokoel da.»

Tăka na heàma na ama na I Rămboe Kahi: "djăka toengoe be ka makanoăma ja na ana nggoe, laloe hămoe ja na eti nggoe, pamboeha ma nggoe ha da pănda djawa» $\mathrm{Na}$ heàma njoena na tau kawini: "măla noe, Dari, na oemboe moe, nde oekoe woeloe ma ja?» Wăna njoena I Dari: «ămboe peàka, banda dangoe. Tăka njoena na kawini hiwăna: "lănga tăka ma moe nja, Dari? napa hi ndena woeloe be ă.» "Noe ka ka doena, wăna I Dari, bai ita wănja mata ngeroe ngeroe.»

Tăka hiwăna na ama na noena na kawini: "kanoăma nja pangana I Dari kana ngangoe bana pingoe i papaní, laloe mboeha nggoe nja bana paní.» Toenanoe bana hăla ka pangangoe, bana hăla ka pahăpa, lakoe na nja ka I Dari.

1 pandjiloe nja na tamoe nggoe; iemands naam veranderen is voor den Soembanees geen zaak van geringe beteekenis. Zijn „tamoe", naam van een naamgenoot, meestal van een grootrader, doet hem kennen als lid van een bepaalde familie. Dat te veranderen wil dus zeggen, uit de familie uittreden en zich andere voorvaderen zoeken.

${ }^{2}$ oekoe = gewoonte, adat; nde oekoe, wat niet-gewoon, dus buitengewoon is. 
Toenanoe bana tăka ka la oema, hiwăna njoena I Oemboe Ndiloe: "Dari, laloe lakoe ănga kau, ná! rimbang ma nda bau lakoe, ndaningoe ma doe pangangoe, lakoe eànga moe ka; nggi weli ni păkoe moe?»

Na heàma njoena I Dari: "mbawa ă nggoe nja ka năhoe la woekoe oămang, ba boeti ka doekoe, nga nggoe nja woea ai», hiwăna njoena I Dari: "ka ndaningoe ma pa năhoe băla moe?» $\mathrm{Na}$ heàma njoena I Oemboe Ndiloe; "ndaningoe ndokoe ă pa!» Toenanoe lakoe doe na nja ka I Dari, na lakoe pamanganga watăr, oehoe, mamătoe na pa'ita na na ngăndi ndăba ja. Na kanoăma nja pangangoe, na wŏnja hina ngangoe. Na hăla ka pangangoe hiwăna njoena I Dari: "toenanoe ba pingoe ma doemoe nja patoenoe watăr, pamanahoe pangangoe, manahoe ka kau ngangoe ba ndaningga, măta kakoe lo'a pambawa.»

Toenanoe lakoe na nja ka la oema na na kawini. Toenanoe bana tăka ka hiwăna na ama na I Rămboe Kahi: "ka heàna, Dari ?» Tăka hiwăna njoena I Dari : "mai pakarai lăpoe, wănggoe, papaleàwa na $\mathrm{i}$ oemboe ka!» Taka na heàma njoena: "nggăra ihi wăngoe lăpoe?» Tăka na heàma njoena I Dari : "toe wăndja da ămăhoe, wăna I Oemboe, ndaningoe pa kanai da.» Toenanoe hida wŏnja lăpoe. Toenanoe bada wŏnja ka lăpoe, hi lakoe na nja i. Na tăka la ngarăngia hina kawinindja da lăpoe la woekoe roemba hina lakoe. Mandai ki ka hawoetoe hina hili beli ja hina lakoe li ha da lăpoe pakawini na la pira na, na piti ha hawiang. Toenanoe bana piti ha ka hawiang hina lo'a la paraing na I Mbălăroe Kahiloe. Toenanoe bana tăka ka lai noe, hiwăna: "loe wŏnda kadiroe hau roepi, ningoe pakē wăngoe, wăna I Oemboe.» Toenanoe hida wŏnja hau na na roepi; lakoe na nja ka. Tăka na roepi noena na pa'oenoe nja la koeloeroe lăpoe. Toenanoe bana tăka ka la oema na na kawini noena, hiwăna: "ndeda răkang da ămăhoe, wăna I Oemboe, laloe mărăhoe ha da lăpoe, wơnda lăpoe mabokoeloe, wăna, djeà ha da lăpoe koedoe, măta ndja, wŏnda mabokoeloe.»

Toenanoe bada wŏnja ka lăpoe mabokoel, lakoe na nja ka I Dari. Ndedi na marau bada piti ha da lăpoe hina kanaboe hau na na roèpi maweli la oenoe lăpoe. Toenanoe hida pa'aung pabeli I Dari: "mai kau kadiroe! djăka nggăra ămăhoe na mangeang la lăpoe?» Toenanoe hiwăna I Dari: "mahanggetoe ja ka ihoe!» Tăka hiwăna njoena na kawini: "ngăndi beli ja.» Na heàma I Dari: "wŏndja da anakeàda kada kē wăndja pa- 
hăpa.» Toenanoe lakoe na nja ka I Dari, bana tăka ka la padoea ngarăngia, na kawini ndja da lăpoe noeda la woekoe roemba. Toenanoe hina lakoe pangalang la oema na; bana tăka ka la oema hina kanoăma nja pangana I Oemboe Ndiloe. Toenanoe bada hăla ka pangangoe hiwăna njoena I Dari: "măta kakoe lo'a patăngăroe ha da ndjara pawoeloe na na ama moe la marăda.» Tăka hiwăna njoena I Oemboe Ndiloe: «ămboe lakoe ănga ănga, Dari!» Tăka na heàma njoena I Dari: "nde'a, lo’a nggoe nja patăngăroe ha da ndjara da pawoeloe na na ama moe handăka na.» Toenanoe lakoe na nja ka hina lakoe li ha da lăpoe pakawini na hina piti ha hawiangoe hina lakoe li la paraingoe noe kawai na mameti marămba na. Toenanoe bana tăka ka, hiwăna: "wŏnda hau rimalokoe, ningoe pakē wăngoe, I Oemboe.» Da wŏnja hau na, bana kē ja ka, na poehi ja la oenoe koeloeroe làpoe. Hili lakoe na nja i la oema na na kawini. Toenanoe bana tăka ka, hiwăna njoena na ama na na kawini: "Kanggikina Dari! handăka mai moe papiti lăpoe, ngăndi beli ha; handăka mai moe papiti lăpoe, hili ngăndi beli ha.» $\mathrm{Na}$ heàma njoena I Dari: "ha Oemboe, ndena manggawa nja na oemboe nggoe njoengga, na nggoemang padiha ha da ămăhoe, na tăngăroe ha dangoe da, nde dangoe da, nggănăpoe da, nde nggănăpoe da.»

Tăka hiwăna njoena na ama na: "pareàngganja pangana I Dari; laloe pingoe ja papaní.» Toenanoe kanoăma na nja pangangoe, da wŏnja, na ngangoe doe'ang dăngoe noena na kawini. Bada hăla ka pangangoe hiwăna njoena I Dari : "batoena năhoe, njoengga pa mangangoe doea dănggau, mandai ndai I Oemboe ka na mahiloe ka ba kalembi mi dimi, njoengga doekoe hau ngara ka, djeà ja hiwănggoe.»

Tăka na heàma na kawini: "lănga tăka, ka nde oekoe woeloe ma ja na oemboe moe?» Na heàma I Dari hiwăna: "ai ha, laloe mawoeloe lănga tăka ja na oemboe nggoe njoengga, la lăpoe la koeroeng na patapoe-tapoe ndja da ămăhoe na.»

Toenanoe bada hăla ka pahăpa hiwăna I Dari: "măta kakoe lakoe wa, piti ha da lăpoe!» Toenanoe lakoe na nja ka; ba talioe na ka hida piti ha da lăpoe, hìna da piti ha, na kanaboe hau na na ri malokoe. Tăka hiwăna na ama na I Rămboe Kahi: «ka nggăra pakarai nda, wăna ihoe na oemboe na I Dari!» 1

I wăna - de Soembanees gebruikt gaarne de zin constructie met wă, om een doel aan te duiden, dat men wil bereiken; bv. zij gingen heen om hem 
Njoena I Dari bana lakoe, na lakoe li pamanganga oehoe, watăr, katăbi, na ngăndi nja na oemboe na hina ngangoe. Bada hăla ka pangangoe: "ha Oemboe Ndiloe, poeroe kau la tana, lakoe nda la hoemoer!» Na heàma njoena $\mathrm{I}$ Oemboe Ndiloe: "ka pameti ja, wămoe ka, kau pa'aungga la hoemoer.» $\mathrm{Na}$ heàma I Dari: "nde tau makatoăba ka njoengga, mai kau kata ihoe kau, wănda nggămoe.» Toenanoe hina lakoe, na jila ja wai, na ihoe ja; na hăla pa'ihoe ja, "lakoe la mamarau hawoetoe. Kau ndoălăk kakoe tăngăroe kau.» Toenanoe hina lakoe la mamarau hawoetoe, na tăngăroe ja, hiwăna njoena I Dari: "laloe timbi ha da woetoe rara ${ }^{1}$ moe." Toenanoe hina pa'aunja hina hili ihoe ja, na piti nja kawita ai hina kori ja na woetoe rara na. Na hăla pakori ha hina ihoe ja: lakoe marau hawoetoe kakoe tăngăroe kau.» Toename hina lakoe marau, djăka ka, wăna, lakoe nda la oema. Toemanoe hida lakoe la oema; na "kanoăma pangangoe hida ngangoe. Na hăla ka pangangoe, hiwăna I Dari: "măta kakoe lo'a pambawa." Lakoe na nja ka I Dari, na lo papiti ha da hinggi komboe, da pawoeloe na I Mbălăroe Kahiloe, tera na, roehi bănggi na, kabeàla oeloe nggeding, kaloemboetoe pakamboeli ${ }^{2}$, kanai ${ }^{3}$ kapoe pakamboeli, likoe pakarăndja ${ }^{4}$, toăngăloe paboroe na, nimboe padoekoe na. Toenanoe hina ngăndi nja, hadang kau boroeng; na pabănggi nja kabeàla, na pahili kaloemboetoe, na papeàka nja patera; bana nggănăpoe ndăba ka la ihi na năhoe: malau poeroe kau la tana, kakoe tăngăroe kau. Na poeroe ja la tana I Oemboe Ndiloe, tăka I Dari na mandapoe la bangga:

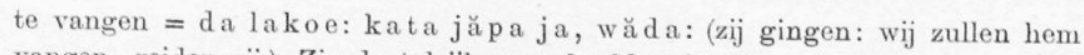
vangen, zeiden zij.). Zie de talrijke voorbeelden in dit verhaal.

1 woetoe rara $=$ een schurftige uitslag, waaran de zich nooit badende, maar zich met klappervet insmeerende Soembanees zeer veel lijdt.

${ }^{2}$ pakamboeli $=$ de sirihtasch van panda bladeren gevlochten, wordt versierd met rood en zwart garen, waarmee men heel aardige figuren op de tasch weet in te naaien.

${ }^{3} \mathrm{kanai}=' \mathrm{t}$ algemeene woord voor een voorwerp, waar men iets in kan doen, hoe groot of hoe klein ook. Echter altijd gebruikt voor een kalkpotje
of kalktaschje.

4 likoe pakarăndja $=$ om de 4 à 5 M. langen lendendoek, gewikkeld om zijn buik, vast te houden, maakt men een gordel van touw (likoe). Dit $\pm 20 \mathrm{M}$. lange dunne touw, wordt tot een streng gewonden, welke juist om 't lichaam past. Dit touw is aan de twee bochten met rotan omvlochten (pakarăndja), welke uiteinden dan met een touwtje aan elkaar gebonden
worden. 
măla palo'angoe maingoe la hangga nggoe, kakoe tăngăroe kau , djăkau parăka mining kakoe pinggau, djăka ndau parăka mining, kakoe hoekoetoe ja na eti nggoe.» Toenanoe palo'angoe maingoe I Oemboe Ndiloe, tăka hiwăna njoena I Dari: "ndjala hawoetoe na tera moe.» Toenanoe na hili patera ja hiwăna: djeà ja ka, na kăna la eti nggoe!» 1

Toenanoe hiwăna njoena I Dari: «rongoe ja na papaní nggoe njoengga, ningoe haätoe na na kawini, laloe manandăngoe ja, măla kata lo’a papiti ja.». Tăka na heàma na oemboe na: "djăka jéa păkoe, Dari, oehimboe himboe be ja lambongoe nge’a pakanaboe nda.» Tăka na heàma njoena I Dari: "ămboe handoeka nja lai noe, djăka talo'a, na wŏ be nda; napa doea modoeng kata lo'a.»

Toenanoe bana toăma ja ka na rehi, lakoe da nja ka. Toenanoe bada tăka ka lai noe, hiwăna na ama na I Rămboe Kahi: "toe ma na I Dari, mbăda kareà na nja na oemboe na, ndedi ningoe ă nggăra nggăra la oema nda.» Tăka na heàma njoena I Dari: "toena hikoe mai kareànja na oemboe nggoe, kana mai papiti ja I Rămboe Kahi, wănggoe.» Tăka na heàma na ama na: "ai ha, banda ndena ngăndi, ndjara ndena ngăndi, ata ndena ngăndi, ndakoe bihoe pawŏnja ja na ana nggoe.» Tăka hiwăna njoena I Oemboe Ndiloe: "djăka jéa păkoe, Dari, laloe pahandoeka ka njoengga, tau mila ma doeta.» Tăka na heàma njoena I Dari: "ha Oemboe, ămboe handoeka nja lai noe, njoengga matanggoe wŏngoe banda.» 2

Toenanoe hiwăna I Dari: "ha oemboe noedita, djăka djeà ha da banda, ămboe handoeka ndja lai noe, ndjara, ata, karămbo'a koe wŏnggau hau parangoe ata djoea, milioe patama nja la koeroeng ${ }^{3}$ na oemboe nggoe.» Tăka na heàma njoena

1 na kăna la eti nggoe = 't treft mijn hart, d.w. z. 't is geheel naar mijn zin.

2 banda $=$ goederen, bezittingen. Zoo zegt men: banda la oema, banda la marăda d.w.z. goederen in huis (goud en kleeren) en goederen op 't veld (paarden, karbouwen etc.)

Ook wordt 't gebruikt in de beteekenis van bruidschat, welke bestaat uit die twee soort goederen.

3 tama la koeroeng $=$ de kamer binnengaan, wil zeggen, met een vrouw afzonderlijk in een kamertje slapen. 't Groote Soemba huis is van binnen verdeeld in tal van kleine hokjes, met wanden van klapperbladeren of matten van pandan bladeren gevlochten. Deze zijn voor de getrouwde paren. Andere menschen slapen op lange bale bak's. De maagden worden ook in zoo'n kamertje opgeborgen, onder de hoede van een oude vrouw. 
na ama na I Rămboe Kahi: «toenanoe ba ngaroe na I Dari ja, koe patamanja la koeroeng na oemboe moe.»

Toenanoe hina patama nja la koeroeng. Toenanoe bana patama nja ka la koeroeng, lima mboea nomoe mboea roedoe na na mandai na, tăka hiwăna na ama na I Rămboe Kahi: "toenanoe ba mangoăma na nja ka na ana nggoe, ta kangărătoe ja hakoedoe, toboeng karămbo'a he'au na, doea ngioe da da wē, he'au kamămbi. » Toenanoe bana hăla ka patoboeng ${ }^{1}$, pahoendjoe $^{2}$, hiwăna njoena I Dari: "haromoe la mbaroe kai lo'a papiti banda la parai na i oemboe.»

Toenanoe bana hadang ka la mbaroe, lakoe da nja ka, na ama na I Rămboe Kahi, na ina na, na poelangéa na, da dawa na, da laleàba na, da bokoe na, lakoe ndăba. Tăka hiwăna njoena I Dari, na peàka nja na oemboe na: "ha oemboe, djăka ta lakoe, ndeta beli la pangéa nda ămăng; ninja na paraing na patoera nggoe, mbinoe tau, mbinoe ata na.» Tăka na heàma njoena I Oemboe Ndiloe: "koe kikoe-kikoeng be lai njoemoe, Dari, nde nggăra ndokoe papaní nggoe, pingoe ma moe nja doemoe. Tăka na heàma njoena I Dari: "djeà doe ja hiwănggoe, măta kakoe tanggoe wŏngoe banda la ama jera moe.»

Toenanoe lakoe da nja ka, bada tăka ka la paraingoe noena, hiwăna njoena I Dari: "pa'oehi tau dangoe dăngoe ata, kai rongoe bakoe pareàta, wăna I Dari.» Toenanoe mareni ndăba ka na tau. Tăka hiwăna njoena I Dari: "tăngăroe, na marămba ba wănggoe, ninja ka, laloe hămoe eti ja, ndena mbana na pareàta na; toenanoe hiwănggoe, pa'oehing banda, pa'oehing ata, ka wŏnja wili na na marămba kawini.»

Toenanoe hida pa'oehing ata, ndjara, karămbo'a, wē, kamămbi, ahoe, na pa'oehi ndăba ndja, hina wŏnja na ama jera na I Oemba Ndiloe Toenanoe bana hăla ka pawŏnja, na toboeng, na hoendjoe. Toenanoe bana hăla ka pangangoe, lakoe na nja ka na ama jera na I Oemboe Ndiloe.

Toenanoe bana lăpăhoe ka hiwăna njoena I Dari: «Oembòe Ndiloe, hăla nggoe nja ka palale ${ }^{3}$ kau, parada nggau; njoengga

I toboeng = slachten, d. w.z. met een kapmes de strot inhakken, bv. van een karbouw, paard.

2 hoendjoe = slachten d.w. z. steken met een mes, bv. van een varken. Zoo gebruikt men roeri = slachten van kippen, d. w. z. de kop af hakken.

s la $1 \bar{e}=$ trouwen (van den man). $1 \bar{e}=$ echtgenoot. la $\overline{\mathrm{e}}=$ tot echtgenoot worden.

paha $=$ trouwen (van den man) mangoăma = trouwen (van de vrouw.) Hiervoor gebruikt men ook wel kanoăma = klaar maken. 
doekoe lakoe nggoe nja ka palalē.» Tăka na heàma njoena I Oemboe Ndiloe: "ămboe lakoe, măta kakoe paha nggau ka kawini lai jehoe.» Tăka hiwăna njoena I Dari bana heàma: "ai ha, oemboe, ndakoe bihoe, njoengga tau ningoe woeloe ihingoe ka, na tau lai jehoe na kadoădăhoe na manoela na; na palingoe ki pa djăka koe himboe hama nggoe, banda ndakoe wŏngoe, woăka ndakoe toengoe.»

Toenanoe lakoe na nja ka I Dari la angoe na paboeti la woekoe oămang. 
I. I Dari, de slimme aap.

Aldus is 't begin. Er waren eens twee menschen en zij baarden één kind, een jongen was 't. Toen 't geboren was, na drie dagen, stierf zijn moeder. Korten tijd daarna stierf zijn vader. De zuigeling bleef nu alleen over. En 't bleef maar huilen. Menschen in de buurt, waren er niet; ver weg (waren zij). Er was niemand die zijn ouders begroef; totdat de honden ze geheel (opgegeten) hadden.

Wat dit kind betreft, hoe zou 't daarmee zijn! dat was wonder-machtig; 't werd 15 dagen, 't werd wat sterker, 't kon zich op zijn rug keeren. Na verIoop van tijd, 't kon zich omwentelen; vervolgens langzamerhand, struikelend liep hij. Na verloop van een maand, hij was sterk genoeg om te stappen.

Toen meende hij dat hij honger voelde. Hij nam de sirihmand van zijn moeder en maakte die open; hij keek er in, een halve gulden; hij nam dien en ging er maïs voor koopen, één klos. En hij bracht 't thuis; toen hij thuis gekomen was, vuur wist hij niet te maken; die maïs at hij rauw, iederen dag een rijtje.

Toen hij de maïs op had, ging hij wederom de sirih-mand van zijn moeder nazien; hij zag één rijksdaalder. En hij ging; maïs gaan zoeken, zeide hij maar. En hij ontmoette iemand, die een aap bij zich had; en hij, die den aap droeg, vroeg: waar gaat gij heen, zeide hij tot den knaap. En de knaap antwoordde: «ik ga eten zoeken, ik lijd honger». De aap antwoordde: koop mij. De knaap antwoordde: wat moet ik met je doen? 't is hongerlijden met je. Maar de aap antwoordde: koop mij. Toen vroeg hij hem, die den aap verkocht: hoeveel zegt gij voor den aap? En hij, die hem verkocht, antwoordde: één rijksdaalder, zeg ik er voor. En hij antwoordde: in orde! Hij nam den aap en ging naar huis. Toen hij thuis gekomen was, ging de knaap slapen, zijn lichaam was slap, hij leed honger. Toen zeide de aap: wat scheelt u daar toch, heer! De knaap antwoordde: ik hier heb zoo'n honger! ik ga maïs koopen, zei ik zooeven; koop mij toch, zeidet gij! Toen 
antwoordde de aap: wees niet bezorgd, bind mij niet voortdurend vast, maak mij los opdat ik gaan kan. En hij maakte hem los, toen hij hem losgemaakt had, ging de aap heen; hij ging maïs stelen in een anders tuin, hij sneed padi, hij plukte pompoen en hij bracht 't naar huis. Toen maakte hij vuur, roosterde maïs, kookte de pompoen en hij gaf 't en de knaap at. $\mathrm{Nu}$ voor 't eerst leerde hij kennen gekookt (eten) te eten.

En de aap zeide: hoe is uw naam heer? "Ik ken mijn naam niet», zeide de knaap. En de aap antwoordde: hoe is 't, dat gij uw naam niet kent? Toen zeide de knaap: mijn moeder, mijn vader, ik zie ze niet, ik ken ze niet, of ze dood zijn of zij niet dood zijn, ik ken ze niet. "Laat dat maar zoo, zeide de aap, ik zal u wel een naam geven; Oemboe Ndiloe mila zijt gij; wat mij betreft I Dari, zult gij tot mij zeggen.

Toen zij aldus elkaars namen kenden, ging I Dari heen; bij zijn gaan zeide hij: Nu heer! als ik er niet ben, maak dan zelf 't eten klaar; laat mij even gaan wandelen, ik ga de paarden bezien, de bezittingen van uw vader in 't veld.

En hij ging heen; er gingen 3 à 4 nachten voorbij, toen eerst keerde hij terug; hij kwam niet ledig terug; hij ging aan in de tuinen van (andere) menschen, om te stelen rijst, maïs.

Toen hij thuis gekomen was, zeide Oemboe Ndiloe: waar hebt gij rijst gevraagd? I Dari antwoordde: zwijg maar, mijn tuinen zijn veel in getal, mijn handen zijn lang wanneer ik onkruid wied.

Toen maakte hij eten klaar; toen hij gegeten had, zeide I Dari: heer, laat mij gaan wandelen. En hij ging naar de Kampong, de plaats van I Mbălăroe Kahiloe; zeer rijk was deze vorst, er was niemand zijns gelijke in grootte, zijn oogen waren als klappernoten, zijn ooren waren verbazend breed. Hij kwam nu in zijn huis en die vorst zeide: he daar, Dari, wat komt ge doen? Toen antwoordde I Dari: ik ben aan 't wandelen; ik hoorde van de menschen: I Dari moet eens komen om 't vuil uit mijn ooren te peuteren, zegt de vorst, zeide men naar ik hoorde. En de vorst antwoordde: 't is waar, en nu gij daar toch gekomen zijt, zult gij 't er uit peuteren. En I Dari antwoordde: daar 't nu mis is met de zon, moet 't maar morgen ochtend zijn, opdat wij ze (de ooren) richten naar de stralen van de morgen zon.

En I Dari overnachtte aldaar; men maakte eten voor hem Dl. 68 
klaar, gaf 't hem en hij at. 't Was nog niet licht, terwijl de zon pas even zichtbaar was, toen zeide I Dari: heer de zon zendt haar eerste stralen uit, kom naar beneden opdat ik bezie uwe ooren. Toen zeide de vorst: waar moet ik gaan zitten? "Kom daarheen, op den rand van 't ravijn, opdat ik kan zien uwe ooren.»

Zij gingen nu naar den rand van 't ravijn en hij ging zitten naar beneden kijkend in 't ravijn. Maar I Dari ging iets meer boven zitten. Toen hij ze bezien had: schuif nog een beetje dichter bij den rand van 't ravijn, ik kan niet zien! Toen hij nu dichter bij schoof, duwde hij hem in 't ravijn en de vorst stierf. De vorst was nog niet dood of de menschen in de Kampong, vlogen allen op om I Dari dood te slaan, want hij heeft gedood onzen heer, zeiden zij.

Maar I Dari zeide: ha, wacht even! hoor naar mijn woord; deze ruwe heer, was zeer toornig, zeer warm (streng) was zijn regeeren; gij moet maar eens wachten op mijn heer, zeer goed is hij, hij wil niet streng regeeren, al wat hij zegt is goed. De menschen aldaar antwoordden: dat is waar hij regeerde streng. En I Dari zeide: de bezittingen van dezen gestorven vorst, moet gij niet verbergen, verzamelt alles opdat gij er mee opwacht mijn heer.

I Dari ging heen, hij liep aan in de tuinen van (andere) menschen om djagoeng te plukken, om padi te snijden en hij bracht ' $t$ in huis. Toen hij thuis gekomen was zeide I Oemboe Ndiloe: wat uw gaan betreft, men weet niet waar gij heen gaat. I Dari antwoordde: ha Oemboe Ndiloe, gij weet niet wat ik weet, naderhand zult gij 't zien. Toen hij eten voor hem klaar gemaakt had en zij gegeten hadden, ging I Dari wederom, naar een anderen vorst, die rijk was. Hij had een kind, een maagd, 't was een schoone vrouw. Toen hij in dat huis gekomen was, zat de vorst in de voorgalerij en hij zeide tot hem: he daar, Dari, wat komt gij doen? "Ga eens kijken, zeide (mijn) heer, naar oom, zeide hij mij daar, en zoo kom ik.» En de vorst zeide: geef I Dari zijn sirih, hij weet hoe hij een zaak moet aanvatten. En men gaf hem en hij kauwde sirih; toen hij sirih gekauwd had, zeide hij: laat mij naar boven gaan naar de Ramboe. Toen hij naar boven gegaan was, ging hij zitten naast die vrouw en hij zeide: laat mij eens sirih kauwen, Ramboe. En die vrouw antwoordde: ga weg, Dari, want je 
bent zoo pik-zwart, ik ben bang voor je. I Dari antwoordde: en terwijl ik toch uw slaaf ben, hoe zijt gij dan bang voor mij? De vrouw antwoordde: dat is, ik ken je niet, van waar gij gekomen zijt. En I Dari antwoordde: ik ben gezonden door uw familie ginds en zoo ben ik gekomen; ik moet zeggen, gij zijt waarlijk familie, zeide I Dari, uwe oogen verschillen in niets, gelijk ook uw praten, uw stap is dezelfde, uw lachen is hetzelfde. En de vrouw antwoorde: hoe is 't toch, terwijl gij mij ziet, Dari, spreekt gij zulke dingen; ik heb geen familie; ik ben maar alleen geboren aan mijn ouders. En I Dari antwoordde: niet alzoo, Ramboe, ga eens hooren, sprak hij daarginds met mij, en zoo ben ik door gestapt en zoo ben ik tot u gekomen.

En haar vader in de voorgalerij antwoordde: wat zegt die Dari daar toch, hij praat veel te veel. En de vrouw antwoordde: 't is familie van $u$, mijn heer, zegt hij. Misschien is 't dan wel zoo, zeide haar vader terwijl hij antwoordde, 't land is zoo ver, wij kennen elkaar tegenwoordig niet meer, zeide hij; daarom dat I Dari zoo goed kan praten, maak eten voor hem klaar, opdat hij ete.

Toen maakte men eten voor hem klaar; en toen het eten gaar was, schepten zij 't op en gaven 't en die vrouw zeide: kom eten Dari! I Dari antwoordde: ik wil niet alleen eten, als wij te zamen eten dan is 't goed. En die vrouw antwoordde: neen, zeide zij. En I Dari antwoordde: als dat zoo is, dan wil ik niet eten; maar wanneer wij te zamen uit één schotel eten, dan zal ik wel eten. En die vrouw antwoordde: met zijn beiden, zegt gij, laten wij 't dan maar tesamen doen, daar steekt tocht geen kwaad in! En zij aten te samen, totdat zij opgemaakt hadden hun rijst in één schotel. Toen zij gegeten hadden, gaf men sirih; na 't sirih kauwen zeide I Dari: laat ik gaan, 't is al donker en ver is mijn woonplaats. En hij ging heen.

Toen hij thuis gekomen was, zeide I Oemboe Ndiloe: waar van daan, Dari? I Dari antwoordde; ik ben eens aan 't wandelen geweest op de vlakte, want ik ben toch een aap. En I Oemboe Ndiloe antwoordd: je bent maar bezig met onzinnig te loopen, en eten is er niet! I Dari antwoordde: wees toch niet bezorgd over dat eten, zoo meteen is 't er. En hij stond op en ging heen, hij ging djagong plukken in de tuinen van een ander; al wat hij maar zag, hij bracht 't alles, onnoemlijk veel droeg 
hij. Toen hij thuis gekomen was, maakte hij eten klaar, hij roosterde maïs, hij kookte pompoen, hij gaf 't en hij at.

En I Dari zeide: ik heb iets bedacht, wat gij niet weet, langzamerhand na verloop van tijd, dan zult gij 't weten. En wederom ging hij naar de plaats waar hij vroeger van daan gekomen was. Toen de vader van I Ramboe Kahi hem zag, zeide hij: daar komt I Dari wederom aan, wat zou hij nu toch te zeggen hebben. Toen hij aangekomen was, gaf men hem sirih; toen men sirih gekauwd had, zeide de vader van I Ramboe Kahi: he daar, Dari, wat komt gij doen? I Dari antwoordde: ik kom zoo maar eens wandelen. De vader van I Ramboe Kahi antwoordde: 't is niet zonder reden dat ik je vraag, misschien is hij wel door zijn heer gezonden, zeide ik maar. I Dari antwoordde: dat zal eerst na verloop van langen tijd gebeuren; en als hij mij dan zendt om tot u te komen, dan zal ik komen. En de vader van I Ramboe Kahi zeide: maak 't eten klaar van Dari opdat hij ete; ik mag hem zeer gaarne (hooren) spreken, hij weet een ander te prijzen als hij spreekt. Men maakte nu zijn eten klaar, toen 't gaar was riepen zij hem. Hij klom nu in huis en I Ramboe Kahi zeide: ha Dari, kom jij daar, en eet hier aan mijn zijde. En hij ging en men gaf hem zijn eten. En I Dari zeide: ha Ramboe, wij moeten te samen eten. En I Ramboe Kahi antwoordde: ai ha, ik wil niet te samen eten met jou. "Waarom wilt gij niet, Ramboe?» "Uwe handen zijn zwart, op je lichaam zitten haren, daarom is 't dat ik niët wil. En I Dari antwoordde: gij schept aan den eenen kant, en ik schep aan den anderen kant, één keer slechts zult gij scheppen. En zoo deden zij 't tesamen.

Nadat hij gegeten had, zeide I Dari: ha Ramboe, geef mij sirih. En zij gaf een sirih-mand. En I Dari zeide: ha Ramboe, als ik mijn oogen zoo eens laat gaan, dan is dit precies hetzelfde als 't aangezicht van mijn heer, zijn spreken hetzelfde, zijn lachen hetzelfde, zijn kijken hetzelfde. En I Ramboe Kahi antwoordde: hoor dien Dari eens, wat praat hij toch voor onzin; uw heer heeft zijn eigen oogen, en ik heb mijn eigen oogen, gij maakt alle menschen gelijk. Maar I Dari antwoordde: ik ben in ernst, wat mijn heer betreft: paarden, karbouwen, slaven, praat er niet van (zooveel zijn er), verbazend rijk is hij. I Kahi antwoordde: laat hem maar rijk zijn! en als hij zoo rijk is, dan moet gij mij 't komen brengen. En I Dari antwoordde: nader- 
hand als gij 't niet zijt, die de bezittingen van mijn heer bewaren zult, verander dan mijn naam, ik zal dan niet meer I Dari zijn. En I Dari zeide: laat mij gaan. En hij ging heen en liep aan in de tuinen van anderen, padi en djagong hij droeg 't op zijn hoofd en droeg 't over zijn schouder. Toen hij thuis gekomen was, maakte hij eten klaar en zij aten.

$\mathrm{Na}$ verloop van korten tijd ging I Dari heen en hij liep aan in den tuin van I Mbălăroe Kahiloe, hij zag de ananassen, hij plukte ze en hij bracht ze aan die vrouw. Toen hij aangekomen was: deze ananassen, ga ze hun brengen, zegt mijn heer! En de menschen aldaar antwoordden: wat moeten wij daar mee doen, vadertje, zij zijn zuur. En I Dari antwoordde: wel aan, probeer ze open te maken en te eten, zij zijn werkelijk zeer goed. En zij maakten ze open en zij aten ze; en terwijl zij ze nu aten: ze zijn toch wel goed, overdachten z.e. En de vader van I Ramboe Kahi zeide: waar komen die ananassen van daän? I Dari antwoordde: 't zijn ananassen uit den tuin van mijn heer. "Zijn er buitengewoon veel? En I Dari antwoordde: ai ha, praat er niet van, een groote tuin (vol) er van. En de vader van I Ramboe Kahi antwoordde: als zoo is hij, die mijn dochter trouwt, dan ben ik zeer blijde, ik houd zoo veel van ananassen. En de vrouw antwoordde: wel aan, Dari, uw heer, is hij buitengewoon rijk? I Dari zeide: praat er niet van, veel bezittingen! en de vrouw zeide: spreek je in ernst, Dari? misschien is hij wel niet eens rijk! Dat is hij wel, zeide I Dari, gij zult 't naderhand met uw eigen oogen zien.

De vader van die vrouw antwoordde: maak eten klaar voor I Dari, opdat hij ete, want praten kan hij, ik mag hem gaarne (hooren) praten. Toen hij gegeten had en sirih gekauwd had, ging I Dari heen. Toen hij thuis gekomen was. zeide I Oemboe Ndiloe: Dari, wat loop jij onzinnig heen, jij daar! ik lijd honger terwijl gij gaat, er is volstrekt geen eten, onophoudelijk gaat gij maar! waar kom je toch van daan? I Dari antwoordde: ik ben maar eens aan 't wandelen geweest in 't dichte bosch, want ik ben toch een aap en ik at boomvruchten; en I Dari zeide: hebt gij heden geen etensvoorraad meer? I Oemboe Ndiloe antwoordde: er is heelemaal niets meer. En I Dari ging heen, hij ging stelen maïs, padi, al wat hij maar zag, hij bracht 't allemaal. Hij maakte eten voor hem klaar, hij gaf en hij at. $\mathrm{Na}$ 't eten zeide I Dari: daar gij 't nu kent mais roosteren, 
eten koken, kook dan om te eten, wanneer ik er niet ben, laat mij gaan wandelen.

En hij ging naar 't huis van de vrouw. Toen hij daar gekomen was, zeide de vader van I Ramboe Kahi: hei daar, Dari! En I Dari antwoordde: ik kom zakken vragen, ik ben gezonden door mijn heer! En hij antwoordde: wat moet er in die zakken? En I Dari antwoordde: om er geld in te doen, zegt mijn heer, er zijn geen manden meer. En zij gaven hem zakken. Toen zij hem zakken gegeven hadden, ging hij heen. Hij kwam op den weg en hij verborg de zakken in 't dichte gras en hij ging heen. Na korten tijd, ging hij weer terug en hij ging aan bij de zakken, vroeger door hem verborgen, en hij nam een gedeelte. Toen hij er een gedeelte van genomen had, ging hij naar de Kampong van I Mbălăroe Kahiloe. Toen hij daar gekomen was, zeide hij: vlug, geef mij even een gulden, ik moet er iets voor koopen, zegt mijn heer. En zij gaven hem een gulden, en hij ging. En deze gulden stak hij tusschen de opgerolde zakken in. Toen hij bij 't huis van die vrouw gekomen was, zeide hij: het geld kan er niet in, zegt mijn heer, de zakken zijn veel te klein, geef mij groote zakken, zegt hij, hier zijn de kleine zakken, laat maar, geef mij grooten.

Toen zij hem groote zakken gegeven hadden, ging I Dari weg. Hij was nog niet ver, toen men de zakken opnam en er viel een gulden binnen uit de zakken. En men riep I Dari terug; kom even hier! wat voor geld is dat, dat in de zakken gebleven is? I Dari antwoordde: 't is er misschien aan blijven hangen. En die vrouw zeide: breng 't terug. I Dari antwoordde: geef 't maar aan de jongens, om er sirih voor te koopen. En I Dari ging heen; toen hij halverwege gekomen was, verborg hij die zakken in het dichte gras. Vervolgens ging hij recht door naar huis, thuis gekomen, maakt hij eten klaar voor I Oemboe Ndiloe. Toen zij gegeten hadden, zeide I Dari: laat mij de paarden eens gaan bezien, de bezittingen van uw vader op 't veld. I Oemboe Ndiloe antwoordde: loop niet onzinnig overal heen, Dari. En I Dari antwoordde: neen, ik ga bezien de paarden, de bezittingen van uw vader op 't veld eertijds. En hij ging en hij liep aan bij de zakken, door hem verborgen, en hij nam er een gedeelte van en hij ging aan in die kampong van daareven, waarvan de vorst dood was. Toen hij daar gekomen was, zeide hij: geef mij een rijksdaalder, ik moet er 
wat voor koopen, zegt mijn heer. $\mathrm{Zij}$ gaven hem er één, toen hij 't genomen had, stopte hij 't tusschen de opgerolde zakken. Wederom ging hij naar 't huis van de vrouw. Toen hij daar gekomen was, zeide de vader van de vrouw: hoe is 't Dari? de eene keer komt gij zakken halen en brengt ze weer terug; een andere keer komt gij zakken halen en gij brengt ze weer terug. En I Dari antwoordde: o heer, mijn heer heeft zelf geen tijd (om te komen), hij is bezig met geld te tellen, hij kijkt of er veel is of niet veel; of 't voltallig is of niet voltallig. En haar vader antwoordde: maak vlug 't eten klaar voor I Dari, wat kan hij toch praten. Men maakte eten klaar, men gaf het en hij at te zamen met die vrouw. Toen men gegeten had, zeide I Dari: zooals 't nu is, ben ik 't nog die te samen met u eet, na verloop van tijd neemt mijn heer mijn plaats in, want hij is familie van u, ik ben van een anderen naam, daarom zeg ik het. En de vrouw antwoordde: werkelijk, is uw heer verbazend rijk? En I Dari antwoordde en zeide: ai ha, mijn heer is werkelijk erg rijk, in zakken in kamers stapelt hij zijn geld maar op.

Madat men sirih gekauwd had, zeide I Dari: laat mij nu gaan, neem de zakken! En hij ging; hij was juist weg of men nam de zakken; men had ze pas genomen, daar viel een rijksdaalder. En de vader van I Ramboe Kahi zeide: wat zou hij ons toch willen vragen, de heer van I Dari?

Toen I Dari heen ging, liep hij aan om te stelen padi, maïs, aardvruchten, hij bracht 't aan zijn heer en hij at. Toen men gegeten had: ha Oemboe Ndiloe, kom hier op den grond, laten wij naar den put gaan. I Oemboe Ndiloe antwoordde: je wilt mij dooden, daarom roept gij mij naar den put. I Dari antwoordde: ik, ik ben geen gek, kom dan zullen wij u baden, zeg ik u. En hij ging, hij putte water, hij baadde hem; na 't baden: ga een eindje weg, blijf staan dat ik u bezie. En hij ging een eindje weg, hij bekeek hem en I Dari zeide: al te dik is uw schurftige uitslag. Hij riep hem en hij baadde hem wederom; hij nam een stukje hout en hij begon zijn schurftige uitslag af te krabben. Toen hij klaar was met krabben, baadde hij hem: ga een eindje weg opdat ik u bezie. Hij ging een eind weg; klaar is 't, zeide hij, laten wij naar huis gaan. Zij gingen naar huis, hij maakte eten klaar en zij aten. Na 't eten zeide I Dari: laat mij gaan wandelen. I Dari ging heen, hij 
ging halen de gekleurde mannendoeken, de bezittingen van I Mbălăroe Kahiloe, zijn hoofddoek, zijn lenden doek, 't kapmes met ivoren heft, de versierde sirihtasch, het versierde kalkzakje, het buiktouw, 't houten geldbakje, dat hij omdeed en de lans, die hij droeg. Hij bracht 't hem: sta op, kleed u aan; hij deed hem 't kapmes aan, hij hing hem de sirihtasch om, hij leerde hem een hoofddoek omdoen; en toen alles compleet aan zijn lichaam was: ga nu naar beneden op den grond, dat ik u bezie. I Oemboe Ndiloe ging naar beneden op den grond, en I Dari zat in de voorgalerij: ga nu eens heen en weer hier vóór mij, dat ik $u$ bezie, of gij op en top een man zijt, dat ik 't wete van u, of gij 't niet zijt, dat ik 't overwege in mijn hart. En I Oemboe Ndiloe ging op en neer, en I Dari zeide: uw hoofddoek is een weinig verkeerd. Hij deed opnieuw de hoofddoek om en hij zeide: dat is 't, 't treft mij in 't hart.

En I Dari zeide: hoor naar mijne woorden; er is een vrouw zeer schoon is zij, laten wij haar haan halen. Maar zijn heer antwoordde: als dat 't is, Dari, gij zoekt maar altijd een kuil, waarin wij moeten vallen. Maar I Dari antwoordde: maak u daarover maar niet bezorgd, als wij gaan, dan geeft hij haar ons; over twee dagen zullen wij gaan.

Toen de bepaalde tijd gekomen was, gingen zij. Toen zij daar gekomen waren, zeide de vader van I Ramboe Kahi: zoo is die I Dari, hij brengt reeds mee zijn heer, en wij hebben nog niets in huis. Maar I Dari antwoordde: dat is 't dat ik mijn heer meebreng, opdat hij kome hale I Ramboe Kahi, zeg ik. Maar haar vader antwoordde: ai ha, goederen brengt hij niet, paarden brengt hij niet, slaven brengt hij niet, ik wil hem mijn dochter niet geven. I Oemboe Ndiloe antwoordde: als dat 't is, Dari, 't brengt mij zeer in moeite, wij zijn arme menschen. Maar I Dari antwoordde: ha heer, maak u daarover niet bezorgd, ik neem 't op mij de bruidschat te geven.

En I Dari zeide: ha heer daarboven (in huis) als 't de bruidschat betreft, maak u daarover niet bezorgd, paarden, slaven, karbauwen, ik zal u geven één kampong van uitsluitend slaven, als gij mijn heer maar in de kamer laat (laat trouwen). En de vader van I Ramboe Kahi antwoordde: omdat I Dari 't zegt, zal ik uw heer in de kamer laten.

En hij liet hem in de kamer. Toen hij hem in de kamer gelaten had, na vijf à zes nachten, toen zeide de vader van 
I Ramboe Kahi: daar mijn dochter nu getrouwd is: zullen wij een heetje offeren, en slachten één karbauw, twee varkens en een geit. Toen men klaar was met het slachten, zeide I Dari: morgen vroeg moet gij de bruidschat gaan halen in de kampong van mijn heer.

Toen men 's morgens vroeg opgestaan was, gingen zij heen, de vader van I Ramboe Kahi, haar moeder, haar oom, haar nichten, haar neven, haar grootvader, allen gingen. En I Dari zeide, hij sprak tot zijn heer: heer als wij gaan, wij keeren niet terug naar onze vroegere plaatsen; er is een kampong door mij gesticht, vol met menschen, vol met slaven. En I Oemboe Ndiloe antwoordde: ik zal je maar volgen, Dari, ik zal niets zeggen, gij alleen weet het. En I Dari antwoordde: daarom zeide ik: laat mij 't op mij nemen de bruidschat te geven aan uw schoonvader.

En zij gingen; toen zij in die kampong gekomen waren, zeide I Dari: verzamelt u gij allen en gij slaven, opdat gij hoort mijn bevelen, zeide I Dari. Al de menschen kwamen dicht bij. Toen zeide I Dari: kijk de vorst waarvan ik sprak, hier is hij, hij is zeer goed, zijn bevelen is niet streng; daarom zeg ik: verzamel goederen, verzamel slaven, opdat wij de prijs van de vorstin betalen.

En zij verzamelden slaven, paarden, karbauwen, varkens, geiten, honden, zij verzamelden alles en men gaf 't aan den schoonvader van I Oemboe Ndiloe. Toen men 't gegeven had ging men slachten. Nadat men gegeten had, ging de schoonvader van I Oemboe Ndiloe heen.

Toen hij weg was, zeide I Dari: Oemboe Ndiloe, ik heb u nu uitgehuwelijkt, ik heb u opgevoed; wat mij betreft ik ga ook trouwen. Maar I Oemboe Ndiloe zeide: ga niet, ik zal u laten trouwen met een vrouw van hier. I Dari zeide en antwoordde: ai ha, heer, ik wil niet, ik ben een harig mensch, de menschen hier hebben een glad vel; 't is veel beter, dat ik mijns gelijke zoek, een bruitschat geef ik niet, een tuin leg ik niet aan.

En I Dari ging naar zijn mede apen in 't dichte bosch. 
II. Karoboe toenoe. Karoboe hămoe ${ }^{1}$.

Toenanoe ninja haätoe na na marămba, laloe woeloe ma ja. Toenanoe na paha ja na haätoe na kawini. Toenanoe ba ndaningoe ana na, tăka na hili paha ja na haätoe; ndaningoe mboe ana na. Da ngara da da kawini noeda, na haätoe I Wa ndăloe ja, tăka na haätoe I Leà m ba ja.

Toenanoe hiwăna njoena na marămba: papoeroendja da ana mongoe kata tondoendja; lo pahimboe ana manoe ${ }^{2}$ kata pinja. Tăka hi ninja haätoe na na ata na, mini ja, I Kaka ja na ngara na. Tăka noena hina lakoe, lo’a pakarai ana mañoe, wăna. Toenanoe bana lakoe ka hina tăkạ la ana woăka; la woăka noena ninja haätoe na na kawini, I Kăhi ja na ngara na. Na kawini noena laloe mbodoekoe ja.

Toenanoe hina piti ja na woeroeng, hina tidoenja hina lakoe hina hamboeroe ja I Kaka, na malo'a pakarai ana manoe, na papaleàwa na na marămba. Tăka hiwăna njoena I Kăhi: ka nggi lo’a moe nja, Oemboe Kaka? Tăka na heàma njoena I Kaka: lo’a pakarai ana manoe, wăna ngga I Oemboe.

Tăka na heàma njoena I Kăhi Mbodoekoe: Kanggăra toe wămoe? "Tatăngăroe ja na oera na na manoe, wăna I Oemboe, kakoe itandja hiloe da ${ }^{3}$ I W o.eriding dăngoe I Wo ehă no moeng».

1 karoboe toenoe = laboe air; karoboe hămoe=laboe manis. De derde soort pompoen, waarvan men kalkpotjes en flessehen maakt, heet Katiti.

2 ana manoe $=$ een "kipje"; is een "euphemistische" uitdrukking en kan elk beest beteekenen, tot een karbouw toe. Elk geschenk of offerande is echter niet compleet, zonder een kuikentje, waarvan de darmen worden nagezien. De mensch wil echter ook wel wat eten en daarom komt er een grooter dier bij.

3 hiloe da I Woeriding dăngoe I Woehănomoeng: de vorst gaat offeren, om uit de ingewanden te zien, of hij nog kinderen zal krijgen of niet, nl. de opvolgers van I Woeriding en I Woehănomoeng d.w. z. de namen van de voorouders moeten voortleven in 't nageslacht - en een kleinzoon heet naar zijn grootvader. Zonder kinderen te zijn is voor den Seembanees bijna onmogelijk; desnoods adopteert hij een zoon. Dit staat natuurlijk in verband met zijn "voorvaderen-dienst"; want wie moet straks zijn graf verzorgen en hem telken male eten geven, als hij zonder kinderen sterft? 
Tăka hina heàma njoena I K. Mb.: "djăka njoengga, koe ngalang papa'anandja hiloe da I Woeriding, I Woehănomoeng». Tăka hiwăna njoena I Kaka: "măta kakoe lakoe ă». Toenanoe hina lakoe.

Toenanoe bana ngalang ka na ana manoe hina beli ja.

Tăka njoena I K. Mb. : "ha O emboe Kaka, ămboe peàka doe nja na Oemboe moe na papăní nda kawai, tangedji ă nggoe doekoe.»

Toenanoe hina lakoe I Kaka, hina tăka nja na Oemboe na, hiwăna nja: "ha Oemboe, ninja haätoe na na kawini noewawa, wăna ngga kawai, djăka njoengga, koe ngalang papa'ana ndja hiloe da I Woeriding dăngoe I Woehănomoeng, wăna ngga.»

Tăka hina heàma njoena na Oemboe na, hiwăna: ṇapa haromoe la mbaroe, koe lo'a pajăpa ja, pamamoha nja ${ }^{1}$, kareà nja jehoe la paraingoe. Toenanoe hadang la mbaroe, na hoenga ka na lodoe, tăka na marămba noena na padoendang; bana tăka ndăba ka na tau hina lakoe pajăpa ja hina kareà nja la paraingoe. Toenanoe bana tăka ka la paraingoe hida karai ja: "lănga tăka, wămoe njoemoe, koe ngalang papa'ana ndja hiloe da I Woeriding dăngoe I Woehănomoeng, ba wăna I Kaka, na ata nggoe?» Tăka hina heàma I K. Mb. : lănga tăka!

Toenanoe hina paha ja, bana paha ja ka patoe mboea woelang lima mboea woelang malăpăhoe, toemboe ma da nja da anakeàda. Toenanoe na ngeri bokoel na kamboe na I K. Mb.

Tăka hiwăna na marămba: ndaningoe kokoeroe paroehi ndja da anakeàda, djăka da dedi. Tăka hina piti ja na loeloe kamba, hau kabokoeloe na na loeloe kamba miting, hau kabokoeloe na na loeloe kamba wingiroe. Tăka hina hondoe ha da hoepoe da la koeroeng, pangia na I K. Mb., hiwăna njoena na marămba: "lakoe nggoe nja la hapapa tana ${ }^{2}$, lo'a pakē kokoeroe;

$1 \mathrm{mamoha}=$ een jong meisje, dat als "slavinnetje" de bruid vergezelt, en altijd bij haar blijft. Gedurende de trouwfeesten, blijft zij mooi aangekleed en gesluierd in huis zitten, als 't ware de bruid voorstellend, die zelf vrij
rond loopt.

Ook wordt eene mamoha wel gegeven als verzoeningsgeschenk en bij 't sterven van een radja, wordt zij door andere verwante radja's gegeven, aan de familie van den overledene. Vroeger werden zij ook wel gedood om den vorst in 't doodenrijk te vergezellen.

${ }^{2}$ la hapapa tana ='t land an de overzijde der zee. Hoewel de Soembanees zich nooit op zee waagt, is toch in de verhalen steeds sprake van reizen naar overzee. De Soembaneezen zijn dan ook naar de legende, van
overzee hier aangekomen. 
toenanoe djăka da dedi da anakeàda, djăka kawini ha, kădoekoe nja na loeloe kamba miting; djăka mini ha, kădoekoe nja na loeloe kamba wingiroe, kakoe pindja dedi da, kakoe wotoe pareànggang kokoer, kakoe beli ka.»

Toenanoe ba' talioe na ka pihoe mboea woela na mandai na, hida dedi ha da anakeàda noeda, mini djoea ha.

Tăka hina kădoekoe nja na loeloe kamba wingiroe; tăka na marămba na malakoe hoepapa la hapapa tana, na pinja ka. Tăka da papaha woenga na hida piti nja karoboe toenoe dăngoe karoboe hămoe hida băndjăloe ha la lihi na I K. Mb.; tăka da anakeàda hida piti ha; na haätoe la hau katiti hida poehi ja, na haätoe hamang, hida lakoe pawăroendja la lokoe.

Tăka njoena I. K. Mb. hiwăna: na kapătang na mata nggoe, ndakoe pinja pa djăka nggamoe na madandandja da ana nggoe hida băndjăloe ngga karoboe toenoe dăngoe karoboe hămoe.

Tăka hininja haätoe na na makaweàda, I Apoe Kămi ${ }^{1}$ ja na ngara na, na marada nja I K. Mb. Toenanoe hina lakoe la wai hina ita ha dămboe da da katiti, tăka hiwăna: nggăra h a titi ha ihoe ha jeàda? ta ha piti ha ha njoeda, ta $h$ a takoe ha wăngoe ha wai.

Tăka hina piti ha, tăka hina tăngăroe ha noedaloe la katiti, ningoe ana rara, tăka hiwăna: ha, ha lahoe ha ama da, ha nggăra ha daloe ha titi, djeà ha ha oemboekoe ngga ha ihoe?

Tăka hina paloehoe ha, hina ihoe pahămoe hămòe ndja, hina ngăndi ha la oema na. Na tăka la oema na hina pohoe ndja wai hoehoe kamămbi, hina pa'oenoe ndja hau lodoe hau lodoe; noewang naingoe ${ }^{2}$ ma na bana pa'oenoe ndja wai hoehoe kamămbi.

Toenanoe bana pindja ka dedi da da ana na, na marămba na wotoe ma nja liroe na na teàna na, tăka hina hărăngoe la mananga ${ }^{3}$ Toenanoe bana tăka ka la mananga, tăka da

1 I A poe $\mathrm{Kămi}$, speelt in de verhalen steeds de rol van „beschermster der onschuld" en geeft aan belanghebbenden te kennen geheimen, misdaden en verborgen zaken. Dat 't geen gewoon menschenkind is, blijkt uit haar taaltje; overal voegt zij ha vóór of tusschen de woorden.

2 noewang naingoe ma na=een samenstelling van noewang = aanlasschen en naingoe=onafgebroken voortzetten, en is geworden tot een vaststaande uitdrukking in de beteekenis van "voortdurend, onophoudelijk".

3 mananga $=$ is de monding der rivier in zee, afgesloten door zandbanken of koraalriffen; $\mathrm{ngaroe}$ mananga is de eigenlijke riviermond. 
papaha woenga na da lakoe panapa ja la ngaroe mananga. Toenanoe bana poeroe ka na marămba noena, tăka hiwăna: măla da ana nggoe, nde doe da meti ? Tăka hida heàma da papaha na da tau madoea, hiwăda: nggăra ka na pa'anang, karoboe toenoe dăngoe karoboe hămoe. Tăka hina heàma njoena na marămba, hiwăna: lănga tăka? Da heàma njoeda da kawini: lănga tăka! "Kani, hina kădoekoe nja na loeloe kamba wingir, mini ha, hăla pawăna ngga! ha Kaka, lakoe papoenggoe au, kata tăka tai kata paharikanja ${ }^{1}$ la awang; laloe kambălikoe ja I K. Mb.», hiwăna noena na marămba.

Tăka njoena na marămba lakoe woengang la oema, tăka njoena I Kaka na lakoe li papoenggoe au. Toenanoe bana tăka ka na marămba la oema, tăka hiwăna: "ha Ka h i M bo d o e k! nggini ha ka da ana moe da hiloe da I Woeriding dangoe I Woehănomoeng, bawămoe ngga ba la hapapa tana ka. » Tăka njoena I K. Mb. ndena heàma. Toenanoe bana tăka ka I Kaka, hiwăna njoena na marămba: "ha Kaka, ăki nja na au kau pahada nja. Toenanoe bana hăla ka pa’ăki nja, tăka hina pahada nja, na paharikandja da au noeda, doea mboengoe da. Tăka njoena na marămba hina he toămanja hoedita la oema hina jăpa ja na loenggi na hina jăbăhoe nja la bangga hina ndoeha ja la tana, hiwăna njoena na marămba: "ha Kaka, piti ja I K. Mb. jeàna, kau wotoe ja noedita la kapoeka au.» Tăka njoena I Kaka hina piti ja hina hē pawotoe ja, na padjăngăloe nja la kahanga au na loenggi na, na papohoe dăngoe tau na.

Toenanoe njoena I A poe Kămi bana kaboeboeloe ha noeda da anakeàda, da kabeli nggoboe ka; hili hau woelang da pangga ndjoroe ka; tiloe mboea woelang da pingoe ka papa'ina papa'ama. Tăka hiwăna njoena I. A. K. : "da ha oemboekoe $\mathrm{h}$ a nggoe $\mathrm{ha}$ jeàda, da $\mathrm{h}$ a toetoeroe, $\mathrm{h}$ a njoengga $\mathrm{h}$ a leàwa ha ndeda ha bihoe ha tarang.

Toenanoe bana ngeri kaboeboe-boeboeloe ha, ngalang hau ndaung da pingoe ka papadjoeloe, da pingoe ka papamakang, da pingoe ka papadjoeki, da pingoe ka papawoei. Toenanoe bada pingoe toedanoe ka, tăka hiwăda da anakeàda: "ha Apoe, măta kama lo'a hoedita la paraingoe." Tăka na heàma njoena I A. K. : "ha napa kadiroe, napa doena i ngeri matoea toea

' harikang = kruiselings, in den vorm $\operatorname{ran} \times$ teeken. 
ki hakoedoe.» Tăka hida heàma da anakeàda noeda: "lănga tăka na papaní na I Apoe, djăka ta loa năhoe, ndena mangădătoe nda tau.» Tăka hina heàma njoena I A. K.: "djè doe ja, hiwănggoe nggămi.» Tăka njoena I A. K. na kaboeboeboeboeloe ha. Toenanoe papohoenja na ndaung na kawoenga kaboeboeloe ha, dămboe ndaung wăngoe. Toenanoe bana ita ka năhoe, na paleàwa ha lai noe lai noe; da anakeàda noeda da kikoenja na pareàta na I A. K., ndeda bihoe papatarang.

Toenanoe ba laloe toetoeroe ha, tăka hiwăna njoena I A. K. : "ha oemboekoe nggoe, Oemboe ha Woe ha riding dăngoe Oemboe ha Woehă ha nomoeng, ha rongoe ja na pa ha pèaka nggoe $h a$ doea $h a$ modoeng njoemoe dăngoe $h a$ eri moe ha loa ha dita ha raingoe la ha rămba ha băkoel.» Tăka da heàma da anakeàda noeda: "ba wămoe njoemoe ma doe, Apoe, ka loa doe na.»

Toenanoe bana ndjăpoe ka na rehi na papeàka na $\mathrm{I} \mathrm{A}$. $\mathrm{K}$. hadang la mbaroe, "Apoe!» hiwăda nja. Na heàma njoena I A. K.: "ha nggăra ja?» Tăka hiwăda njoeda da anakeàda: "wăda modoeng wămoe njoemoe Apoe, doea modoeng njoemoe dăngoe eri moe, ba wămoe nggăma, loa hoedita la marămba bokoel, hăla pawămoe.»

Tăka hina heàma njoena I A. K.: "măla kai loa wa na!» Tăka njoeda da anakeàda hiwăda: «ha Apoe, ka nggăra wăngoe hinggi ma? tera ma ndaningoe, kalembi ndaningoe, karăndja lima ${ }^{1}$ ndaningoe, tawoeroe la lima ma ndaningoe, maka ndaningoe, loenga maka ndaningoe.» Tăka hina heàma njoena I A. K.: "ha hadang ha kikoengga ha njoengga.»

Toenanoe bada hadang ka hida kikoenja hida tama ha la koeboe watoe. Tăka hiwăna njoena I A. K.: «ha ninja ha koembang $\mathrm{h}$ a hau la $\mathrm{h}$ a leàngoe $\mathrm{h} \mathrm{a}$ jeàna; djăka $\mathrm{ha}$ tăka $\mathrm{h} \mathrm{a}$ tai, ai loeloe ha boenggăhoe ja, ămboe ha nggoemang ha teàngoe.»

Toenanoe bada tăka ka noedaloe la leàngoe, njoena I Wo eriding ndena nggoemang papateàngoe, na ai loeloe boenggăhoe ma ja. Toenanoe bana hăla ka paboenggăhoe ja hina ngadoe ja na koembang, na ita ha noedaloe la koembang, laloe hambila ja na ngaroe na na koembang. Tăka njoena I Woeriding: "ha Apoe, ka nggăra ha noedaloe da madoeroe?»

\footnotetext{
1 karăndja lima=armband van gevlochten (karăndja) rottan.
} 
Tăka na heàma njoena I A. K. : "nggăra ha ana ha keàda kămoe, laloe ha mbănga kămoe, ka ha piti ha nde wămoe, da ha hinggi tai ha ămăhoe ${ }^{1}$, da ha tera $\mathrm{h}$ a tai ha ămăhoe, da ha nggeding ha ningoe noedaloe la ha koembang.»

Toenanoe njoena I Woeriding hina lo'a hina pahaunja na lima na la ngaroe koembang, hina piti ha da hinggi, tera, tawoeroe, nggeding ămăhoe ${ }^{2}$; loenga koera moeki ${ }^{3}$, maka ihi naoe 4 ningoe, mătoe ma ningoe ningoe ja la koembang noena, na nggănăp ndăba.

Toenanoe bana hăla ka papiti ha da ihi na na koembang hina pandăbi beli nja na koembang noena. Toenanoe bana hăla ka papandăbinja, tăka hiwăna njoena I A. K.: «ha măla nda, ha talakoe, ta ha tăka ha tai la ha oema, ha lamboeng hinggi, ha wotoe ha da $\mathrm{h}$ a tera $\mathrm{mi}$, ha toendja ha nggéding h a ămăhoe la ha koekoe ha lima mi.

Toenanoe bana hăla ka pawăna ndja ${ }^{5}$ năhoe la ngarăngia , bada tăka ka la oema, hiwăna njoena I A, K.: "rongoe pahămoe njimi, ba toenanoe napa ${ }^{6}$ hi ndai pinja na hiloe nggoe njoengga, napa koe paní hiloe mi njimi, hiwăna, rongoe, hinggi padoekoe mi ningoe, hinggi pakalamboeng mi ningoe, ndea hinggi tera ha, hinggi tai ămăhoe ha, tawoeroe ămăhoe rara, nggeding ămăhoe rara, panggănăp ndăba ndja da lima mi njimi.» Toenanoe bana hăla ka papaní, tăka hina wŏndja hinggi da, tera da, tawoeroe, nggeding ămăhoe rara. Toenanoe bada hăla ka papaki, tăka hiwăna njoena I A. K. "măla lo’a

1 tai ămăhoe=verguld, met goud overtrokken.

2 $\mathrm{ng}$ geding=ivoor, van 't Maleische gading=olifantstand, ivoor. Daar

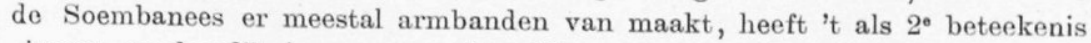
„ivoren armband", ja men spreekt zelfs van "nggeding ămăhoe" d. w. z. gouden armband, zoodat 't begrip ,ivoor" geheel vervallen is.

" loenga koera moeki=een "onmogelijke" samenstelling van loeng a = touw voor een tol, èn koera moeki=vergulde ketting.

" maka ihi naoe $=$ "mooie" tol; de bijvoeging "ihi naoe" is mij onverklaarbaar.

5 na hăla ka pawăna ndja=De uitdrukking wăna=zijn (haar) zeggen, wordt dus zuiver verbaal gebruikt en als zoodanig geconstrueerd met pa, als volgend op „hăla=klaar zijn met iets, vlg. Schets Soemb. Gramm. pag. 45 .

6 napa= wachten, en dat gebruikt wordt tot aanduiding van 't futurum, heeft de bijbeteekenis van „misschien”, br. napa na lo'a=hij zal gaan, hij zal wel eens gaan, misschien zal hij gaan. Als een nadverbium" wordt 't dan ook geconstrueerd met hi bv. napa hi ndai pinja=misschien weet gij niet. 
hoedita la paraing, na tidoeng na lodoe, mai beli kămi, " hiwăna ndja. Da heàma da anakeàda noeda: măla ka.

Toenanoe hida hē la paraingoe hida pamakang la talora ${ }^{1}$, talora noena, talora bokoeloe ma ja. Tăka njoena na marămba hina poeroe ja la bangga hina ita ha da anakeàda noeda. Tăka hiwăna njoena na marămba: "Ka nggamoe ana da ha ihoe noeloa da mapamakang?» Tăka da heàma da tau hawiang "ihi ndja ka ni!» Tăka hiwăna njoena na marămba: "djăka toengoe be ka lăti ana nggoe, na hămoe ka eti nggoe; djăka nina păkoe noedita I Rămboe Kahì Mbodoèk, koe pa'ana, wăna ngga, hi ndena pa'ana be, na pa'ana be ndja na karoboe toenoe dăngoe na karoboe hămoe; ka nggiki paleàwa nda ha ka nida ba karoboe be ha!»

Toenanoe hina pa'aundja da anakeàda noeda: "ha oemboe ${ }^{2}$ anakeàda, mai nămoe!» Tăka da heàma da anakeàda noeda : "ma mangădătoe doema, hé miri, ndema bihoe.» Tăka hina heàma na marămba: "mai ka wa njoena! njoengga ndakoe bihoe paléoe, njoengga koemboehang ndăba ndja da anakeàda, djăkai njimi ă ma ki ka, laloe mboehanggoe nggămi.» Tăka da heàma da anakeàda noeda: «lănga tăka njoena, oemboehang nggăma, mboehang. nggăma la ngaroe ă ka doena, na eti moe karaoe!»

Tăka na heăma na marămba: ndea, wănda nggămoe, njimi wiki ma kai mai kai hoăwăkoe ja na kamboe nggoe, kai tăngăroe ja na eti nggoe, djăka na karaoe djăka ndena karaoe.»

Toenanoe bana tidoeng ka năhoe na lodoe, tăka hiwăda njoeda da anakeàda: "ha Oemboe, măta kama lakoe kadiroe, napa haromoe kama hili mai ka.» Toenanoe lakoe da nja ka doeda.

Toenanoe bada tăka ka la oema na I A. K. hida mandapoe la bangga, hiwăda njoeda da anakeàda: "ha Apoe, ningoe tau

${ }^{1}$ talora $=e e n$ open ruimte tusschen de twee rijen huizen van een kampong. In 't Savoen. heeft 't nog de beteekenis van "tusschen in, in 't midden"; en in 't Soemb. vindt men 't nog in mandalora=middernacht.

$\mathrm{Al}$ is er geen huis aan de overzijde, bv. bij een tuinhuis, dan heet toch de open ruimte vóór 't huis talora.

${ }^{2}$ oemboe=de titel van oemboe=heer, gebruikt voor menschen van "adel", geeft men ook an kleine kinderen bv. oemboe koedoe=kleine mijnheer; oemboe anakeàda=jongeheer! Een slaaf sprekend van of tot zijn heer, gebruikt steeds „oemboe. 't Is geworden als ons „Jhr.", want iemand heet: Oemboe Toenggoe Namoe Paraing, en wanneer men dit "oemboe" zou weglaten, zou 't als een beleediging of minachting worden opgerat. 
arijá noewawa la bangga!» Tăka hina heàma njoena I A. K. "nggăra arijá ha!» Tăka da heàma njoeda da anakèada: »arijá ana rara mamila.» Tăka hina heàma njoena I A. K. : «ma wănja na hiloe na doena I A. K., hiwăna, ămbi ha laloe ha anggaloeng mi pa'ita la ha koeboe ha titi.» Toenanoe bana hăla ka papaní I A. K. tăka da anakeàda noeda da hē ha la oema.

Tăka hiwăda nja na ăpoe da: «wŏnda tangangoe, Apoe, laloe mandjioe kăma, ndena wŏngoe pangangoe na tau noedita la paraingoe kawai.

Toenanoe hina wŏndja pangangoe. Toenanoe bada ngangoe ka bada mbihoe ka, tăka hiwăda nja: «hăla ma ja ka pangangoe, măla kama loa papamakang hoeloea la boeloe woăka. Tăka hina heàma I A. K. : "ămbi lakoe doe hoeloea la woăka, napa ningoe kataroe moeroe, na witoe kămi, napa ningoe oelăroe, na woendjoeloe nggămi, ămbi pamajila ka pahimboe kămi. »

Tăka hida heàma njoèda da anakeàda: "mădja ka toena , măta kama pamakang la talora lai jehoe.» Na heàma na ăpoe da: măla ka, lakoe ă. Toenanoe bada hăla ka papamakang, tăka I A. K. hina pa'aundja: "ha anakeàda, mai kai wa, kai ngangoe kai mahoeroe, haromoe la mbaroe kai loa hoedita la paraingoe.» Tăka hiwăna njoena I A. K.: «djakai hili lo’a haromoe, karai pahămoe hămoe nja na marămba lai noe, nggi paweli na I Kahi Mbodoek, ka wămi nja. Toenanoe na ngia paweli na, djăka wăna, tăka njimi heàma: njoema ana I Kahi Mbodoek kăma, na ama ma ndema pinja.» Toenanoe bana pandjăpoeng ka papaní I A. K. tăka hina heàma I Oemboe Woeriding: "lănga tăka, Apoe, na banda na pawoeloe na na marămba lai noe, koe ngalang papiti ndăba ha haromoe, kiring bana pameti ja na ina nggoe.s

Toenanoe mahoeroe da nja ka, hadang la mbaroe hada roedoeng ${ }^{1}$ hina wŏndja pangangoe pambihoe $\mathrm{ma}$ ha; loloekoe pahămoe tai, ămboe bihoe pawawa. Na heàma njoena I W o eriding: "loepa koe taloe ma bădi tai.» Toenanoe da poeroe ha hida lakoe; bada tăka ka la paraingoe, da toăma la talora.

Tăka na marămba noena hina ita ha, hina piti pareànggang

1 hada roedoeng='s morgens vroeg, als 't nog nacht is; samenstelling van $\mathrm{h}$ adang=opstaan, dat de uitgang $\mathrm{ng}$ geeft aan 't volgende woord roedoeng = nacht.

Dit "verplaatsen" van de uitgang $\mathrm{ng}$, vindt men regelmatig; zoo spreekt men van hada beling = weder opstaan (van een doode.)

D1. 68 . 
topoe bara ${ }^{1}$ hina palăkăroe nja la bangga, hiwăna ndja: "mai kămi wa la jehoe, Oemboe, kai mandapoe.» Tăka njoena I Woeriding: "ndakoe bihoe pamandapoe, tau ndaningoe ina ngga, tau ndaningoe ama ngga, tau mamila ka.» Tăka na heàma njoena na marămba: "mai kau wa njoena, kau mandapoe la bangga, ta ngeri paní-ní ka.» Tăka njoena I Woeriding: măla ka; tăka hina mandapoe la bangga. Tăka hiwăna njoena nà marămba: "măla paní wa noe kata rongoe kămoe.»

Tăka njoena I Woeriding hina paní hiwăna: "toenanoe na parongoe nggoe la kange'au la wăda modoeng, la tau; na pakiri na hina pamaingoe ja lai jehoe I Kahi Mbodoek..... (en nu volgt bijna woordelijk 't verhaal van de verwisseling der kinderen etc, I Woeriding eindigt dan aldus....) Toenanoe na parongoe nggoe njoengga la tau na mapalo'angoe na mapamaingoe. Toenanoe ba miri da nggămoe, ba marămba bokoeloe kămoe, ba woeja rara kămoe, kara woelang kămoe ${ }^{2}$, ngia patangara da nja lai njoemoe, laloe rihi kămoe, batoenanoe hoekoe-hoekoetoe ja na eti moe, timba timbanja ${ }^{3}$ na eti moe, hiwăna nja.»

Tăka njoena na marămba ndena pingoe ndokoe papaní, bana piti weli pakiri ma nja loepa na patoăma nja la hoepoe bana paní ja. Tăka njoena na marămba hina hadang, hina lakoe toăma ha hina mandapoe papera dăndja. I Woeriding la kawana na nja, I Wo ehănomoeng, la kalai na nja. Toenanoe hina rohoe ha, hiwăna: "djăka hăngga păkoe mi ngga dimi, malangoemi!» Tăka hina heàma njoena I Woeriding: "malangoem, wămoe ka ka njoena, na ina nggoe oewotoe ja la awang, na ngiangoe ka la lodoe mahambăti, la mboeroe ma mandiri, la ngiloe ma maringoe, djeà doe ja na răka pakarai nggoe lai njoemoe.»

Tăka hina heàma njoena na marămba pakareàngoe hī na, hiwăna «djăpa ndakoe poeha ndăba nggămoe ha, da banda la marăda mboendăba da, da banda la oema, ndakoe handoeka ă djăka koe wŏnggau ha; njoemoe ba ana ma doe nggoe nggau, mili ngiangoe njoena la karaha nggoe.»

1 topoe bara: een beleefde Soembanees zal nooit voor iemand een vuile, gebruikte, maar steeds een nieuwe, witte schoone mat uitspreiden.

2 woeja rara=roode krokodil en kara woelang =doorschijnend, helder schildpad, zijn termen gebruikt om een vorst van „edelen bloede" aan te duiden.

3 timbang =afwegen, is Maleisch en alleen bekend aan de Soembaneezen, in aanraking gekomen met handelaren. 
Tăka na heàma njoena I Woeriding: "lănga tăka moe nja?» Hiwăna nja: "lănga tăka ma nggoe nja, djăka koe kambălikoe koe meti ma la lodoe năhoe!» Tăka hiwăna njoena I Woeriding: ka măla noe, na ina nggoe ndau toenja dănga ${ }^{1}$ na ba hīna na meti?" Tăka na heàma njoena na marămba: "ndedi. »

"Djeà doe ja kata pinja.» Tăka hiwăna njoena I Woeriding: "paleàwa ha da ata moe kada păpa ja na harikang kana răndjăkoe la tana $\mathrm{i}$ ina.» Tăka hina paleàwa ha da ata na noena na marămba; da áki ja na tana na pangia na na au, na dedi ja watoe, ndeda măkanja pa'ăki ja. Da poenggoe ja na au, ndeda loehoe nja, na dedi ja băhi.

Tăka hiwăna njoena I Woeriding dăngoe eri na: "pahilang ndăba mboendăba mi, i pingoe paharikang tau, ndai pingoe papapoeroe ja.» Tăka hida poeroe njoeda I Wo eriding dăngoe eri na, hida lakoe la pingi na na au. Toenanoe bada hăla ka papahariang hida tila pambapa nja hina mbata na au. Toenanoe bana ndjoroe ka na au noena hida danda nja na ina da hida băndjăloe ja la padoea talora, da pawălăhoe nja hinggi tai ămăhoe hida pandăbi wănja hinggi tai ămăhoe hida pambatoeng bada winggiroenja. Toenanoe bada hăla ka pawinggiroe nja, tăka njoena I Woeriding hina boenggăhoe ja na tera na, tăka hina paloe wănja, na palimang bana paloe ja; hina wala ja na tera na la talora hina ndoălăkoe la toeba katikoe na hiwăna: «ha ina, ha ina, hadangoe wa, n!̣ngga ka ana moe jéa.» Toenanoe I Kahi Mbodoek hina ka’oeli; tăka hiná lakoe la wihi na, tăka na eri na lakoe la katikoe na. Tăka hiwăna njoena I-Woeriding: "ha ina, pawăla wa!» Tăka njoena na mama' eri: "ha ina, kanggiki na hoe pa'ana pamila ka, pangangoe ndakoe ngangoe, wai ndakoe oenoeng!s Tăka njoena na mamá' eri hina jăpa ja na lima na, tăka hina hadang, loeri beli na nja ka I Kahi Mbodoek noena. Da hinggi tai ămăhoe, da dedi ha la'oe na. Toenanoe hida loănda nja hida hē ngăndi ja la oema. Tăka hiwăna njoena na marămba: «ndedi koe ita hamang, na mameti da ngalang papahada nja, hiwăna.»

Tăka da papaha woenga na na marămba, napa kata kahili

1 dănga=noemt met alles, wat den doode moet vergezellen in 't hiernamaals: paarden, karbauwen, goud, kleedingstukken, etc.

Zoolang dit nog niet geschied is, kan de doode niet komen in 't zielenland, maar blijft de ziel in de buurt van 't lichaam rondzwerven. 
ja I Kahi Mbodoek, lo'a pa'ohoe ai ka wănda nja, tăka la oămang kata poeha ja la hoemoeroe.

Toenanoe bana rongoe ka na marămba tăka hiwăna: "ha Kaka, kareàndja jeàda da tau kawini kau lo'a kau paloe pameti ha kau poeha ha la hoemoer.» Toenanoe hina kareàndja, bada tăka ka la oămang, tăka njoena I Kaka hina ita ja na hoemoer hau na. Tăka hina pa'aundja: "ha! mai kămi noeloea la maningoe ai kai ohoe ningoe.» Toenanoe bada pamaingoe bada mareni nja ka na hoemoer, tăka njoena I Kaka hina jăpa ja na haätoe, na poeha ja la hoemoer; na hili jăpa ja na haätoe na hili poeha ja la hoemoer. Toenanoe bana hăla ka papoeha ha hina beli ja la oema: Koe kăla ha ka pawăroendja la hoemoer, hiwăna nja na miri na. $\mathrm{Na}$ heàma na miri na: nả hămoe doe, hiwăna.

Tăka njoena na marămba hiwăna: "da ana nggoe njoengga ndaningoe hama da; tau mameti na ngalang papahadanja; batoenanoe măta kana meha nja papareàta nja na tau na papareàta nggoe njoengga; njoengga djăka nggoe ka!» Toenanoe na kanandi na eti na na marămba noena: măta kakoe himboe ndja papaha da da ana nggoe.» Toenanoe hina himboe ndja, na itang tau mamanandang, hiwăna nja I Woeriding: "da kawini nida njoemoe dăngoe na erì moe, ndai mboehandja nida?». Tăka hina heàma njoena I Woeriding dăngoe I Woehănomoeng: ma mboehandja. Toenanoe bana hăla ka parongoe ha da ngaroe ${ }^{1}$ da da ana na, hina lo'a pangădăloe ja na ama da da kawini noeda. Toenanoe na ama da da kawini noeda hina mai la oema na na marămba, hiwăna njoena na marămba:- «da ana moe njoemoe, ămboe pamangoăma ha la tau hawiang.» Na heàma njoena na ama da: "djăkau wŏngoe ma doe banda, ndjara, karămboa, ka papohoendja ${ }^{2}$ doeda I Woeriding dăngoe na eri na, măra haätoe ha.» Na heàma njoena na marămba: "tiloe modoeng, loa kau tăka kata paní; pa'oehi mboe nja na kalembi moe kana nggănăpoe, ka pekoe wŏnggoe banda, ămboe ta hili paní la malamiri na, ta pameti ma ja na papaní wăngoe.»

Toenanoe hi lakoe na nja hina doenda nja na kalembi ha-

$1 \mathrm{ng}$ aroe $=$ mond, stem, uitgesproken meening.

${ }^{2}$ pohoe = uitwringen, uitdrukken; papohoeng $=$ bij elkaar drukken, bij elkaar doen; en wordt dan ook gebruikt voor: "wet elkaar doen huwen" of ,'t loslaten van een hengst bij een kudde." 
koedoe hakoedoe na. Toenanoe bana tăka ndăba ka bana toăma ja na rehi papeàka na na marămba hina lo'a. Toenanoe bana tăka ka hina wŏnja banda mboendăba na na kalembi na ${ }^{1}$. Toenanoe bana nggănăp ndăba ka banda, bana hăla ja ka hina pa'aunja na ata na njoena na marămba, hiwăna: "ha K a ka, lo’a kau jăpa ha da karămboa da tiloe ngioe kata toboe nja na kalembi da. Toenanoe bana jăpa ha ka hida toboendja hida hoăwăkoe ha hida paberindja tanggoe da mamata ${ }^{2}$.

Toenanoe bana nggănăp ka bada memi mboe ka da toloeng hina paberindja; na takoe mboe oehoe hina paberi ndăba ndja hida ngangoe.

Toenanoe bana hăla ka pangangoe: măla wa kama kanŏama, hiwăna na tau. Na heàma njoena na marămba: "măla kai lakoe ă; doea modoeng nangga, koe lo'a pajăpa ha ${ }^{3}$ da kawini.» Toenanoe bana deningoe ka na rehi hina lo'a pajăpa ha. Toenanoe bana jăpa ha ka hina kareàndja la oema na; na mama'aja tanggoe na I Woeriding ja, na mama'eri tanggoe na I Woehănomoeng ja. Toenanoe hina papohoendja. Toenanoe bana mandai ka năhoe hiwăna njoena na marămba: "lo'a padoendanja na tau mboendăba na kana pa'oehi kana rongoe ja na papareàta na I Woeriding kana tangara ningoe la I Woeriding, lai njoengga ămboe na tangara pa.»

Toenanoe bana tăka ka ndăba ka na tau hiwăna njoena I Woeriding: "rongoe ja na pareàta nggoe njoengga mboendăba moe; i ama na wăngoe iwi bana pareàta, njoengga koe wăngoe tamihikoe ${ }^{4}$; djăka ninja na mandebihoe pakē ja na tamihikoe la lima nggoe, njoengga koe kadipoe wănja kabeàla ; ndakoe bihoe bakoe pareàta "mai kau răma ja na mambotoe»

1 banda = bruidschat; moet niet alleen betaald an de ouders der bruid, maar ieder der familie moet wat hebben; een zwangere vrouw vraagt zelfs iets voor haar nog niet geboren kind.

2 tanggoe da mamata=na 't afhandelen en betalen van de bruidschat, wordt een varken geslacht en ieder krijgt dan een stuk vleeseh, dat hij rauw moet meenemen en thuis of onderweg opeten.

3 lo' a pajăpa ha da kawini=gan vangen, gaan grijpen, is de vaststaande uitdrukking voor „een vrouw, een bruid gaan ophalen". Een „overblijfsel" uit den tijd, dat men de vrouven schaakte, welke vorm van huwelijk soms nog voorkomt, vooral als men het over de bruidschat niet eens kan worden. De knoop wordt dan maar doorgehakt en men moet wel tot een conclusie komen.

4 ,mijn vader gebruikte rottan bij zijn regeeren, ik zal schorpioenen gebruiken" vlg. 1 Kon, 12:11, 
nde wănggoe, didi ă jang djăka na tăka ngga papa nggoe, mboendăba moe kau mareni kata kawăra mbeni ndăba.» Tăka na heàma njoena na tau mboendăba na: "na hămoe na papareàta moe, miri!» Tăka hiwăna njoena I Woeriding: "ha Kaka noeloea, lo'a kau jăpa nda nja na karămboa na he'au kana ngangoe na tau, da oehoe mbăda memi ha ka.»

Toenanoe hina toboenja na karămboa he'au na. Toenanoe bana hăla ka patoboenja, na hăla ka paropoe ja hina manahoe ja.

Toenanoe bana memi ka hina takoe hina paberi ndăba nja na tau na maninja. Toenanoe bana hăla ka pangangoe, hiwăna njoena I Woeriding: "noena na karămboa na panga moe, djăka nggamoe ja na mande mareni djăka na tăka na papa nda, dănga na nja ka na karămboa noena.» Toenanoe bana hăla ka parongoe ja na papareàta na I Woeriding hiwăna njoena na tau: "măla wa talakoe.» Toenanoe hina kanoăma ndăba; "măta kama lakoe wa, miri!» hiwăna na tau. Toenanoe hi lakoe na nja na tau mboendăba na. Tăka hiwăna njoena I Woeriding: "na tau na papareàta nggoe laloe dangoe ja.»

Tăka hi nindja da ahoe doea ngioe da, bai ahoe bokoeloe ma ha, hama ana ndjara ha bokoeloe da. Toenanoe hi lakoe na nja papatamang, hakamboeloe na kareănja. Toenanoe bana tăka ka năhoe la marăda, tăka hi ninja na bai wë bokoeloe, wē pa'ana ja, laloe mbeni ma ja. Tăka da ahoe noeda ba doea ngioe da, hida băngga ja na wē noena. Tăka njoena na wē na witoe ha da ahoe, na pameti ha. Njoena I Woeriding ndena pindja. Tăka hiwăda da kareà na: «ha miri, da ahoe moe da meti ka, na hăla ha ka wē pakaoe ha.» Toenanoe bana rongoe ka, ninja na likoe la boroe na, hiwăna njoena I Woeriding: "laloe namoe nggoe ha da ahoe noeda, ndaningoe hama bokoeloe da, ndaningoe hama mbeni da.» Toenanoe hina wăkăhoe ja na likoe hina hondoe nja la nggoroe na hina hē ja la ai hina kandila wiki na, meti na nja ka I Woeriding ${ }^{1}$.

Toenanoe da kareà na hida beli ha papeàka nja na ama na. Toenanoe bada tăka ka la oema hiwăda da kareà na: "ha miri, na meti ka na ana moe, na kandila wiki na la oămang, na

1 Zelfmoord is een niet ongewoon verschijnsel onder de Soembaneezen. $\mathrm{Al}$ is 't dan niet, dat hij 't doet om het sterven van een hond. Tijdelijke verstandsverbijstering komt meermalen voor. Iemand vermoordt zijn vrouw en kinderen, steekt 't huis in brand en verdwijnt zelf spoorloos, is een verschijnsel, dat meer dan eens voorkomt. 
namoe da ahoe na, bada meti ndăba.» Toenanoe bana rongoe ka na ama na, tăka njoena na ama na na piti nja epi na oema hina hoeloe ja; na hăla pahoeloe ja hina tama beli ja hoedaloe la oema, hina kandila wiki na hama na na ana na; da ri ana na da moetoeng hăla; I Woehănomoeng na moetoeng mboe; da mboeta ma. 


\section{De twee pompoenen.}

Er was eens een vorst; zeer rijk was hij. En hij trouwde een vrouw. Daar zij geen kinderen had, trouwde hij nog een andere; ook deze had geen kinderen. De namen dezer vrouwen waren: de eene I Wandăloe, de andere I Leàmba.

En de vorst zeide: breng de gongs naar beneden, dat wij ze slaan; ga een kipje zoeken, opdat wij 't weten. Hij had nu een slaaf, de man zijn naam was I Kaka. Hij nu ging om' een kipje te zoeken. Terwijl hij ging, kwam hij bij een kleinen tuin; in dien tuin was een vrouw, I $\mathrm{Kahi}$ was haar naam. Deze vrouw was zeer trotsch. Zij nu nam de kruik, zette die op haar hoofd en ging en zij ontmoette I Kaka, die een kipje ging vragen, gezonden door den vorst. En I Kahi zeide: waar ga je heen, Oemboe Kaka? En I Kaka antwoordde: ga een kipje vragen, zeide de heer tot mij. Toen antwoordde I Kahi mbodoekoe wat moet gij daarmee doen? \&Wij zullen eens bezien de teekenen van de kip, zegt de heer, opdat ik zie de opvolgers van I Woeriding en I Woehănomoeng». Toen antwoordde I K. Mb.: "wat mij betreft, ik zou kunnen baren de opvolgers van I Woeriding en I Woehănomoeng.» Toen zeide I Kaka: laat ik (verder) gaan. En hij ging. Toen hij 't kipje gekregen had, keerde hij terug. Maar I Kahi mbodoekoe zeide: ha, Oemboe Kaka, zeg 't niet tegen uw heer, wat wij zoo even besproken hebben, ik scherste maar.

En I Kaka ging en hij kwam bij zijn heer en hij zeide tot hem: o heer, daar ginds is een vrouw, zij zeide zooeven tot mij, als ik 't was, ik zou kunnen baren de opvolgers van I Woeriding en I Woehănomoeng, zeide zij tot mij.

En zijn heer antwoordde en zeide: wacht tot morgen vroeg, dan zal ik haar gaan vangen, haar een slavin geven en haar hier naar de kampong brengen. En 's morgens vroeg, de zon was al zichtbaar, verzamelde die vorst (zijn menschen); toen al de menschen gekomen waren, ging hij haar vangen en bragt haar in de kampong. En toen zij in de kampong gekomen was, vroeg men haar: hebt gij werkelijk gezegd: ik zou kunnen baren de opvolgers van I Woeriding en I Woehănomoeng, 
gelijk I Kaka mijn slaaf, zegt? En I Kahi mbodoekoe antwoordde: waarlijk.

En hij trouwde haar; toen hij haar getrouwd had, na 4 à 5 maanden toen groeiden de kinderen. De buik van I K. Mb. werd langzamerhand groot. En de vorst zeide: er zijn geen klappers om de kinderen in te wrijven, als zij geboren worden. En hij nam garen, één kluwen zwart garen, één kIuwen geel garen. Hij bond de uiteinden er van in de kamer, de plaats van I K. Mb. en de vorst zeide: ik ga naar 't land overzee, om klappers te koopen; als de kinderen geboren worden, als 't meisjes zijn, trek dan aan 't zwarte garen; als 't jongens zijn, trek dan aan 't gele garen, opdat ik wete hun geboren zijn, en snel de klappers oplaad en terugkeere.

Toen hij weg was, na zeven maanden, werden die kinderen geboren, uitsluitend jongens. En zij trok aan 't gele garen; en de vorst welke naar 't land overzee was gegaan, wist het nu. Maar zijn vroegere vrouwen, namen twee soorten pompoenen en zij legden die neer aan de zijde van I K. Mb., maar de kinderen namen zij weg; 't eene stopten zij in een kalebas en 't andere evenzoo, en zij gingen ze in de rivier werpen.

En I K. Mb. zeide: mijn oog is verduisterd, ik weet niet meer, wie mijn kinderen heeft opgenomen en twee socrten pompoenen bij mij neergelegd heeft. Er was nu een oude (vrouw), I Apoe Kămi was haar naam, die I K. Mb. had opgevoed. $Z$ ij nu ging naar 't water en zag de twee kalebassen en zeide: wat zouden dat voor kalebassen zijn? ik zal ze nemen en er water mee scheppen. En zij nam ze en zij keek in de kalebassen: er waren zuigelingen, en zij zeide: ha, mannelijk schaamdeel van een vader, wat is er in de kalebassen, zouden 't mijn kleinkinderen zijn?

Zij haalde ze er uit en baadde ze eens goed en bracht ze naar haar huis. Thuis gekomen, melkte zij de geiten en gaf ze iederen dag te drinken; onafgebroken was 't dat zij ze geitenmelk te drinken gaf.

Toen hij nu wist het geboren zijn van zijn kinderen, heesch de vorst 't zeil op zijn schuit en hij bleef liggen in den riviermond. Toen hij in de riviermonding gekomen was, gingen zijn vroegere vrouwen hem opwachten bij 't begin der riviermonding. Toen die vorst uitgestegen was, zeide hij: welaan mijn kinderen, zij zijn toch niet dood? En zijn beide vrouwen antwoordden en 
zeiden: wat heeft zij geboren, twee soorten pompoen. En de vorst antwoordde en zeide: waarlijk? De vrouwen antwoordden: waarlijk! Hoe is 't dan dat zij trok aan 't gele garen, jongens zijn 't, heeft zij tot mij gezegd! ha Kaka, ga bamboe hakken, als wij straks (thuis) komen dan zullen wij haar in de lucht ophangen: een groote leugenaarster is die I K. Mb., zeide die vorst.

En de vorst ging 't eerst naar huis, maar I Kaka ging ergens bamboe hakken. Toen de vorst thuis gekomen was, zeide hij: ha, Kahi Mbodoek, waar zijn uwe kinderen, de opvolgers van I Woeriding en I Woehănomoeng, gelijk gij mij zeidet, terwijl ik over zee was! Maar I K. Mb. antwoordde niet. Toen I Kaka gekomen was, zeide de vorst: Kaka, graaf een gat voor het bamboe en zet dien overeind. Toen hij een gat gegraven had, zette hij (het bamboe) overeind, hij zette 't kruizelings, twee stuks. En de vorst klom naar haar toe in huis, greep haar bij haar haren, smeet haar in de voorgalerij en wierp haar op den grond, en de vorst zeide: ha Kaka, pak op deze I K. Mb., hang haar in den top van het bamboe. En I Kaka nam haar en hing. haar op, hij hing haar bij de haren, met lichaam en al, in de mik van het bamboe.

En I A poe Kămi, terwijl zij die kinderen grootbracht, konden deze zich op den buik wentelen; na verloop van nog een maand liepen zij struikelend; na drie maanden konden zij "vader" en "moeder» zeggen. En I A. K. zeide: deze mijn kleinkinderen zijn gehoorzaam, ik beveel ze en zij willen niet tegenspreken.

Terwijl zij ze langzamerhand zoo groot bracht, na één jaar konden zij spelen, konden zij tollen, konden zij gekheid maken, konden zij stoeien. Toen zij dit alzoo kenden, zeiden de kinderen: ha grootmoeder, laat ons gaan naar boven naar de kampong. En I A. K. antwoordde: wacht eerst, tot gij langzamerhand een beetje ouder zijt geworden. En die kinderen antwoordden: naar waarheid is 't spreken van grootmoeder, als wij nu gaan, zijn de menschen niet bang voor ons. En I A. K. antwoordde: daarom zei ik 't $u$ ! En I A. K. voedde hen bij den voortduur op. En tesamen met 't eerste jaar, dat zij ze opvoedde, waren 't nu twee jaren. Toen zij ze nu zoo zag, zond zij ze hierheen en daarheen; die kinderen volgden op de bevelen van I A. K., zij wilden niet tegenspreken.

Daar zij zeer gehoorzaam waren, zeide I A. K.: mijn kleinzonen, Oemboe Woeriding en Oemboe Woehănomoeng, hoort 
mijn spreken, over twee dagen zult gij met uw jongeren broeder naar bcven naar de kampong van den grooten vorst gaan. En die kinderen antwoordden: daar gij 't nu zegt, grootmoeder, zoo zullen wij gaan.

Toen nu de tijd, gezegd door I A. K. voorbij was, 's morgens heel vroeg: ha grootmoeder! zeiden zij tot haar. En I A. K. antwoordde: wat is er? De kinderen zeiden: eergisteren hebt gij gezegd, grootmoeder, over twee dagen zult gij en uw jongere broeder, zoo hebt gij ons gezegd, naar boven naar den grooten vorst gaan, uit was uw spreken.

En I A. K. antwoordde: welaan gaat maar! De kinderen zeiden: grootmoeder, wat moeten wij als slimoet gebruiken? hoofddoeken hebben wij niet, noch baadjes, noch armbanden, noch ringen aar de hand, noch tollen, noch touw om te tollen. Maar I A. K. antwoordde: staat op en volgt mij.

Toen zij opgestaan waren, volgden zij haar en gingen een grot binnen. En I A. K. zeide: er is een groote pot in deze grot; als gij er straks bij komt, maak ze terstond open, blijf niet staan wachten.

Toen zij in de grot gekomen waren, bleef I. Woeriding niet staan wachten, terstond maakte hij hem open. Toen hij hem open gemaakt had, keek hij van boven af in den pot, hij keek in den pot, verbazend schitterde de opening van den pot. En I Woeriding zeide: grootmoeder, wat is er in dat zoo vlamt? En I A. K. antwoordde: wat ben jullie voor kinderen, groote stommelingen ben je, laat ik 't nemen, zegt gij niet! vergulde slimoets, vergulde hoofddoeken, ivoren armbanden zijn er in den pot.

En I Woeriding ging en stak zijn hand in de pot-opening en hij nam de slimoets, de hoofddoeken, ringen, gouden armbanden, gouden tol-touwen, prachtige tollen waren er, van alles was er in dien pot, alles was compleet.

Toen hij al den inhoud van den pot genomen had, sloot hij dien pot weer dicht. Toen hij hem gesloten had, zeide I A. K. : laat ons gaan, als wij straks thuis komen, zullen wij de slimoets aandoen, de hoofddoeken opzetten, en gouden armbanden aan uw polsen doen,

Terwijl zij dit zoo onderweg tot hen gezegd had, toen zij thuis gekomen waren, zeide I A. K.: luistert goed, omdat gij misschien mijn taaltje niet kent, zal ik uw taaltje spreken, zeide zij, hoort, een slimoet om over uw schouders te dragen is er, 
een slïmoet om aan te doen is er, 't zijn geen slimoets van goed, 't zijn vergulde slimoets, gouden ringen, gouden armbanden,' 't is alles compleet voor uwe handen. Toen zij gesproken had, gaf zij hunne slimoets, hun hoofddoeken, ringen, gouden armbanden. Toen zij zich mooi gemaakt hadden; zeide I A. K. : welaan ga naar boven naar de kampong, als de zon hoog boven 't hoofd staat, kom dan terug, zeide zij tot hen. Die kinderen antwoordden: welaan! En zij gingen op naar de kampong en zij tolden op 't plein; dat plein was een groot plein.

En de vorst daalde af in de voorgalerij en hij zag die kinderen. En de vorst zeide: wiens kinderen zouden dat zijn, die daar tollen. En sommigen antwoordden: weten wij 't! En de vorst zeide: als zóó mijn kinderen waren, wat zou ik blij zijn; wat die daar boven betreft, I Ramboe Kahi Mbodoek, ik zal baren, zeide zij mij, maar zij baarde niet, zij baarde twee soorten pompoen; hebben wij ze die dingen bevolen, dat 't pompoenen zouden zijn!

En hij riep die kinderen: ha heer-kinderen, kom hier! En die kinderen antwoordden: wij zijn bang: meester, wij willen niet.

En de vorst antwoordde: kom maar! ik wil geen afkeer (van je) hebben, ik houd veel van alle knapen, en wat jullie betreft ik houd verbazend veel van je. En die kinderen antwoordden: 't is waar, gij houdt van ons, maar 't is slechts met den mond dat gij van ons houdt, uw hart is boos! Maar de vorst antwoordde: neen, zeg ik je, kom zelf hier en hak open mijn buik en bekijk mijn lever (hart) of 't boos is of niet.

Daar 't nu twaalf uur geworden was, zeiden de knapen: heer, laat ons eerst heengaan, morgen dan zullen wij wederom komen. En zij gingen heen. Toen zij in 't huis van I A. K. gekomen waren, gingen zij zitten in de voorgalerij en de knapen zeiden: grootmoeder, er zijn vrienden hier beneden in de voorgalerij! En I A. K. antwoordde: wat voor vrienden? En de kinderen antwoordden : arme zuigelingen als vrienden! En I A. K. antwoordde: wij zullen maar weer gebruiken 't taaltje van I A. K. , zeide zij, wees niet al te ondeugend, gij die gezien zijt in de holte van een kalebas! Toen I A. K. uitgesproken had, klommen die kinderen in huis. En zij zeiden tot hun grootmoeder: geef ons te eten, grootmoeder, wij zijn zeer hongerig, de man zooeven daarboven in de kampong heeft ons geen eten gegeven.

En zij gaf hun te eten. Toen zij gegeten hadden en ver- 
zadigd waren, zeiden zij tot haar: 't eten is op, laat ons gaan tollen daar ginds op de schoone plek in den tuin. En I A. K. antwoordde: ga toch niet naar gindschen tuin, misschien is er een adder, die zal je bijten, misschien is er een slang, die zal je omkronkelen, mak mij toch niet moe door naar je te moeten zoeken. En de kinderen antwoordden: laat 't dan maar, laat ons tollen hier op 't plein. En hun grootmoeder antwoordde: 't is goed, ga maar! Toen zij klaar waren met tollen, riep I A. K. hen: Kinderen, kom toch, eet en ga slapen, morgen vroeg moogt gij naar boven naar de kampong gaan. En I A. K. zeide: wanneer gij morgen weer gaat, vraag dan eens goed aan den vorst daar; waar kwam I Kahi Mbodoek van daan, moet gij tot hem zeggen. En als hij zeggen zal haar plaats van afkomst, dan moet gij antwoorden: wij zijn kinderen van I Kahi Mbodoek, onzen vader kennen wij niet.

Toen I A. K. klaar was met spreken, zeide I Oemboe Woeriding: waarlijk, grootmoeder, de bezittingen 't eigendom van den vorst ginds, ik zal ze eenmaal allemaal nemen, omdat hij gedcod heeft mijn moeder.

En zij gingen slapen; 's morgens heel vroeg stonden zij op en zij gaf hun te eten tot verzadigings toe; bespreek straks uw zaak goed en laat je niet afdingen. I Woeriding antwoordde: (ik zal praten) totdat ik straks overwonnen zal moeten hebben. Zij klommen uit huis en gingen heen; toen zij bij de kampong gekomen waren, gingen zij tot op 't plein. En die vorst zag hen en nam snel een witte mat en spreidde die uit in de voorgalerij, en hij zeide tot hen: kom maar hier, heeren, ga zitten. Maar I Woeriding: ik wil niet gaan zitten, ik ben iemand zonder moeder, iemand zonder vader; ik ben een wees. En de vorst antwoordde: Kom toch hier, ga zitten in de voorgalerij, wij zullen er eens kalmpjes over praten.

En I Woeriding: wel aan! en hij ging zitten in de voorgalerij. En de vorst zeide: spreek nu maar, dan zullen wij naar u luisteren.

En I Woeriding sprak en zeide: aldus hoorde ik gisteren en eergisteren bij iemand de oorzaak er van dat I Kahi Mbodoek hier kwam..... (en nu volgt woordelijk 't verhaal van de verwisseling der kinderen, etc.; hij eindigt dan aldus: Zoo heb ik 't gehoord van den gaande en komende man. Daar gij hun meester zijt, daar gij een groot vorst zijt, een 
roode krokodil, en schitterende schildpad, de menschen naar u opzien, gij verre weg de meerdere zijt, daarom weeg 't af in uw hart, overweeg 't in uw hart, zeide hij tot hem.

Maar de vorst wist in ' $t$ geheel niets te zeggen, toen hij 't ophaalde van 't begin af, totdat hij kwam aan 't einde in zijn spreken. En de vorst stond op, ging naar hen toe en ging tusschen hen in zitten. I Woeriding aan zijn rechterhand, I Woehănomoeng aan zijn linker. Hij omhelsde ze en zeide: als gij vertoornd op mij zijt, hebt erbarmen! En I Woeriding antwoordde: erbarmen, zegt gij dáar, maar mijn moeder hebt gij in de lucht opgehangen, zij bleef in de gloeiende zon, in de druipende dauw, in de koude wind, daarom past 't dat ik $\mathrm{u}$ wat vraag.

En vorst antwoordde, terwijl hij er bij huilde, en hij zeide: al moest ik u ook alles toewerpen, de bezittingen allen in 't veld, de bezittingen in huis, 't zou mij niets spijten als ik ze u moest geven, daar gij toch mijn kinderen zijt, mits gij maar blijft aan mijn zijde.

I Woeriding antwoordde: zijt gij in ernst? Hij zeide tot hem: ik ben in ernst, als ik lieg, dan zal ik dezen dag nog sterven

Maar I Woeriding zeide: hoe is 't, hebt gij mijn moeder geen doodenoffer gegeven, toen zij pas gestorven was. En de vorst antwoordde: nog niet. "'t Is maar dat wij 't weten.» En I Woeriding zeide: beveel uw slaven dat zij 't kruis afbreken, opdat moeder op de aarde zitte. En die vorst beval zijn slaven; zij groeven in de aarde, waar het bamboe was, 't werd als steen, zij konden er niet in graven. Zij kapten op het bamboe; 't ging er niet in, 't werd als ijzer. En I Woeriding met zijn jongere broeder, zeide: gaat allen op zij, gij kunt wel menschen ophangen, maar gij kunt ze niet naar beneden halen! I Woeriding en zijn jongere broeder klommen naar beneden en gingen naar de bamboe stok. Toen zij er eerst tegen geleund hadden, schopten zij er van weerszijden tegen aan en het bamboe brak. Toen het bamboe gevallen was, namen zij op hun moeder en legden haar midden op 't plein, zij spreidden onder haar uit de vergulde slimoet en bedekten haar met de vergulde slimoet en toen liepen zij er viermaal omheen. Toen zij klaar waren met er om heen te gaan, maakte I Woeriding zijn hoofddoek los en hij sloeg er mee, vijfmaal sloeg hij haar; 
en hij spreidde open zijn hoofddoek op 't plein en hij ging staan vlak bij haar hoofd en hij zeide: moeder! moeder! sta toch op, ik, uw kind, ben het! En I Kahi Mbodoek rekte zich uit; toen ging hij naar haar voeten en zijn jongere broeder ging naar haar hoofd. Toen zeide I Woeriding: moeder, wórdt toch wakker! En de jongere broeder: moeder, waarom hebt gij mij als een wees geboren, eten eet ik niet, water drink ik niet! De jongere broeder nam haar bij de hand en zij stond op, I Kahi Mbodoek leefde weer! De vergulde slimoets werden haar tot een rok. En zij gelejdden haar en brachten haar in huis. De vorst nu zeide: zoo iets heb ik nog nooit gezien, een doode kunnen zij weer doen opstaan, zeide hij.

Maar de vroegere vrouwen van den vorst, zeiden: laten wij I Kahi Mbodoek in den val lokken; ga hout sprokkelen, zullen wij tot haar zeggen, maar in 't bosch zullen wij haar in een put werpen. Toen de vorst dat hoorde, zeide hij: ha Kaka, neem deze vrouwen mede, ga, sla ze dood en werp ze in een put. Hij nu nam ze mee en toen zij in 't bosch gekomen waren, zag I Kaka een put. Toen riep hij ze: ha! kom hier waar hout is en sprokkel hier. Toen zij kwamen en dicht bij den put waren, greep I Kaka er één beet en wierp hem in den put; wederom greep hij de andere, en wierp haar ook in den put, Toen hij ze er in geworpen had, keerde hij terug naar huis: ik heb ze reeds in den put gegooid, zeide hij tot zijn meester. Zijn meester antwoordde: dat is goed, zeide hij.

En de vorst zeide: de gelijken van mijn kinderen zijn er niet; dooden kunnen zij doen opstaan, daarom laat hem alleen bevelen de menschen van mijn rijk; ik houd er mee op. En die vorst dacht in zijn hart: laat ik vrouwen zoeken voor mijne kinderen. En hij zocht ze en hij zag schoone vrouwen, en hij zeide tot I Woeriding: die vrouwen zoudt gij en uw jongere broeder, ze niet graag hebben? I Woeriding en I Woehănomoeng antwoordden: wij hebben ze graag. Toen hij gehoord had den mond van zijn kinderen, ging hij den vader van die vrouwen roepen. En de vader van die vrouwen kwam in 't'huis van den vorst en de vorst zeide: uw kinderen, huw ze niet uit aan andere menschen. En hun vader antwoordde: als gij maar geeft een bruidschat, paarden, karbauwen, dan zullen wij ze geven aan I Woeriding en zijn jongere broeder, ieder één. De vorst antwoordde: over drie dagen, ga en kom, dan zullen 
wij praten; verzamel ook uw familie, opdat allen aanwezig zijn, opdat ik de bruidschat kan geven; wij moeten naderhand niet nog eens praten, wij moeten de bespreking laten afloopen.

Hij nu ging en riep tesamen zijn familie, tot de verst verwijderde toe. Toen men allen gekomen was en de tijd, door den vorst bepaald, was aangebroken, ging men. Toen men er gekomen was, gaf hij de bruidschat al de familie. Toen de bruidschat geheel compleet was, toen alles afgeloopen was, riep de vorst zijn slaaf, en zeide: Kaka, ga eens 3 karbauwen vangen, opdat wij ze slachten voor hun familie. Toen hij ze gevangen had, slachtten zij ze en hakten ze in stukken en verdeelden ze hun deel van rauw vleesch. Toen zij allen gehad hadden en ook het vleesch gaar was, verdeelde men 't onder hen; men schepte ook de rijst op, verdeelde 't onder allen en zij aten.

Toen men gegeten had: laten wij ons gereed maken, zeiden de menschen. En de vorst antwoordde: welaan gaat heen! over twee dagen ben ik er, kom ik de vrouwen halen. Toen de tijd vervuld was, ging hij ze halen. Toen hij ze gekregen had, bracht hij ze naar zijn huis; de oudere was 't deel van I Woeriding, de jongere was 't deel van I Woehănomoeng. En hij bracht ze bij elkaar. Toen 't nu een tijd geleden was, zeide de vorst: ga alle menschen bij elkaar roepen. dat zij zich verzamelen, dat men hoore naar 't bevel van I Woeriding, dat men opzie naar I Woeriding, en niet meer opzie naar mij.

Toen alle menschen nu gekomen waren, zeide I Wo e riding: gij allen hoort mijn bevelen; mijn vader gebruikte rottan in 't bevelen, ik gebruik schorpioenen; als er een is, die niet wil aannemen de schorpioen uit mijn hand, zal ik (zijn hand) afsnijden met het kapmes; ik wil niet bevelen: kom en werk dit zware, zal ik niet zeggen; alleenijk wanneer mijn vijand tot mij komt, dan zult gij allen naderen opdat wij allen te samen dapper zijn. En al de menschen antwoordden: uw bevelen is goed, meester! En I Woeriding zeide: he Kaka daar, ga mij eens vangen één karbauw, opdat de menschen eten, de rijst is reeds gaar. Hij nu slachtte een karbauw. Toen men met 't slachten klaar was en men hem gevild had, kookte men hem. Toen 't gaar was, schepte men op en verdeelde 't onder alle menschen, die aanwezig waren. Toen men gegeten had zeide I Woeriding: deze karbauw door u gegeten, al wie niet nadert, wanneer 
mijn vijand komt, die karbauw zal hem begeleiden naar het doodenrijk. Toen men gehoord had het bevelen van I Woeriding, zeiden de menschen: welaan laten wij gaan.

Er waren nu twee honden, 't waren zeer groote honden, zoo groot als veulens. Hij nu ging jagen, tien begeleidden hem. Toen men nu op 't veld gekomen was, was daar een groot wijfjes-varken, een varken met jongen, zeer woest was 't. Maar die honden, met hun tweeën, zij blaften dat varken aan. En dat varken beet de honden, 't doodde ze. I Woeriding wist 't niet. Maar zijn metgezellen zeiden: meester, uw honden zijn dood, 't varken heeft met bijten er een eind aan gemaakt. Toen hij 't gehoord had, er was een touw om zijn middel, zeide I Woeriding: ik heb veel medelijden met die honden, even grooten waren er niet, even dappere waren er niet. Hij maakt 't touw los, bond 't om zijn hals, klom in een boom en hing zich zelf op, en zoo stierf I Woeriding.

Zijn metgezellen keerden terug om 't aan zijn vader te zeggen. Toen zij thuis gekomen waren, zeiden zijn metgezellen: meester, uw zoon is dood; hij heeft zich zelf in 't bosch opgehangen, hij had medelijden met zijn honden, daar die allen gestorven waren. Toen zijn vader 't gehoord had, nam zijn vader vuur voor 't huis en stak 't aan; toen hij 't aangestoken had, ging hij wederom terug binnen in huis, en hing zich op evenals zijn zoon; zijn schoondochters verbrandden geheel, I Woehănomoeng verbrandde ook; zij stierven uit. 
III. I Rămboe Kahi dăngoe I Oemboe Ndiloe dăngoe I Mada.

Nindja da madoea da tau, da pakanoăma; na mini I Hadoe Hina ja na ngara na, tăka na kawini I Limba Băbăngoe ja na ngara na; na kawoenga ana da, I Ndiloe ja na ngara na. Toenanoe bana matoea ki ka hakoedoe hina pakamboe nja ${ }^{1}$ na haätoe. Toenanoe hina dedi, I Mada ja na ngara na. Toenanoe bana pa'ana nja ka, na kabeli nggoboe ka, meti na nja ka na ama na. Toenanoe ba talioe ${ }^{2}$ meti na ka na ama na, tăka njoena I Mada na ngeri matoea-toea ka.

Tăka hina pa'aunja na ana na I Ndiloe, njoena na tau kawini, hiwăna: ha Oemboe Ndiloe lakoe ă lăti, kai lo'a papárahoe nda oămang la woăka na na ama mi. Toenanoe lakoe da nja; bada tăka ka la oămang, njoena I O. Nd. na pandoī maka, na pandō̄ hai, na poeti loenga, na pandoī nggoenggi. Tăka njoena I Mada bana poenggoe ja na ana ai koedoe, na poenggoe weli mbaroe nja ${ }^{3}$ loepa na roedoeng;

${ }^{1}$ hina pakamboc nja na hä to e: en zij werd zwanger van een ander kind.

Opmerkelijk is in 't Soemb., dat men met de Dativ. eonstructie zoo veel kan uitdrukken. In vele gevallen, welke wij alleen met een praepositie kunnen zeggen, volstaat 't Soemb. met een Datief.

bv. na meti ka năhoe, wăna ngga ka=hij is nu dood, zult gij van mij zeggen.

hida pahăla nja na makaweàda da ahoe =en de honden hielden af van den oude. Terwijl: ,hida pahăla ja na maka we àda = en zijj lieten den oude los, (als hij bv. gebonden was) zou beteekenen.

hina tăka ngga njoengga=en hij kwam bij mij, (tot mij).

hina tăka la paraing =en hij kwam bij (of in) de kampong.

na mandapoe la lihi nggoe $=$ hij zit aan mijn zijde.

na lihi ngga njoengga=hij woont in mijn buurt, dicht bij mij.

2 ba talioe meti na ka=nadat hij gestorven was.

talioe $=$ juist vertrokken zijn, bv. ba talioe na ka, dergelijke verbaal constructie heeft men met:

t alăng a = juist met iets bezig zijn.

ba talănga pani i na pa=terwijl hij nog aan 't praten was.

en pekoe =mogelijk zijn

nde pekoe lakoe nggoe=ik kan onmogelijk gaan.

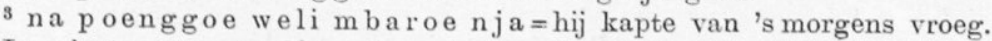

In plaats van "weling la mbaroe", wordt dikwijls gebruikt: „weli mbaroeng", zoodat de nasaal ng overgaat op 't volgende woord.

Zoo bv. ook weli ditang, voor weling la dita.

Daar 't adverbium terstond op 't werkwoord volgt, wordt $\mathrm{ng}$ met $\mathrm{ja}$ geassimileerd tot $n j a$.

Zoo zegt men bv. ook: koe ita marau ja ik zag hem van verre. 
hina măngoe pandjoroe. Toenanoe bana roedoeng ka, lakoe da nja ka la oema; bada tăka ka la oema hiwăna na ina da: măla noe kawai, pangalang doe? $\mathrm{Na}$ heàma njoena $\mathrm{I} \mathrm{O} . \mathrm{Nd}$.: mapangalang.

Toenanoe hili hadang la mbaroe, hili lakoe da nja; palo'a papárahoe.

Toenanoe bada tăkia ka la oămang, njoena I Mada na párahoe, tăka njoena I O. Nd. pandoī maka, pandoī hai, pandoī nggoenggi, poeti loenga. Tăka njoena I Mada na poenggoe weli mbaroe nja na ana ai loepa na roedoeng, hina măngoe pandjoroe. Toenanoe bana roedoeng ka hida lakoe la oema; bada tăka ka la oema, hiwăna na ina da: măla noe kawai, ana, bai párahoe, i pangalang ka doe? Na heàma njoena I O. N d.: djăka tondoe nja watăr dăngoe karoboe, pawŏngoe ma ja. ${ }^{1} \mathrm{Na}$ heàma na ina na: wŏa. Toenanoe hili hadang la mbaroe, hili lakoe da nja i; bada tăka ka la oămang, nj. I O. N d. pandoī hai, pandoī maka, poeti loenga, pandoī nggoenggi.

Tăka njoena I Mada, ba anakeàda ma ki ja doena, na poenggoe ja na ana ai hapoengoe ă nang; na poenggoe weli mbaroe nja loepa la maling hina ndjoroe. Toenanoe bana maling ka, lakoe da nja ka la oema; bada tăka ka la oema da, hiwăna na ina da: măla noe kawai, pangalang doe? Na heàma nj. I O. Nd.: na papárahoe ma njoema, nde'oekoe lérangoe ma ja. Tăka hiwăna na ina na: măla noe, haromoe kata lo'a patoe nja epi na. Na heàma nj. I $\mathrm{O} . \mathrm{Nd}$.: talo'a kadoe na! Toenanoe hadang la mbaroe hida lakoe kareàngoe dăngoe ina da; bada tăka ka la oămang, hiwăna na ina da: ka nggini ja ka na roekoe párahoe mi? Tăka na heàma njoena I Mada hiwăna: I Ndiloe doena na nggoemang papandoī maka, hai, nggoenggi, poeti loenga, ba didi ă ka njoengga mapoenggoe ha da ai jeàda. Toenanoe lakoe na nja ka la oema na na ina da; na tăka la oema na manahoe parèa-rèanggang. Toenanoe bana memi ka hina piti ja na tănga mboăla oehoe ${ }^{2}$ na I O. Nd., na piti ha da nggoenggi, maka, hai, loenga dăngoe na kahidi; na kahidi na toe kiri ja, na hai na toe ja la padoea; na toenja oehoe, na pităkoe nja; tăka na piti ja na loenga, na toe ja,

\footnotetext{
1 paw ŏngoe ma ja=verkorte spreekwijze van: ningoe pawöngoe $\mathrm{ma}$ ja d. w. z. er zal dan zeker een opbrengst ziju.

2 tănga mboăla oehoe=rijstmandje. De gekookte rijst wordt den gasten in mandjes roorgezet. Hoe "hooger" gast, hoe mooier en grooter mandje.
} 
na takoe ja oehoe, na pităkoe nja. Tăka na piti ja na maka, na toe ja, na takoe ja oehoe, na pităkoe nja. Tăka na piti ja na nggoenggi. na toe ja, na pităkoe nja oehoe. Tăka doe na nja ka I O. Nd. weling papárahoe, hina piti nja ja na oehoe na kawai, na patoengoe ihi, hina wŏnja ja hina ngangoe. Na handăkang pa'oepoe, na hoenggoe ja na nggoenggi, hiwăna: ha ina, ka jeàna na nggoenggi, kanggikina hoe toe ja ? $\mathrm{Na}$ heàma na ina na: kau pinja ka, kaweàda mboe ja ka năhoe, ndakoe ita mboe ja, makanaboe ja ka ihoe.

Tăka na hili oepoe handăkang, na ita ja na maka, hiwăna nj. I O. Nd.: ha ina, kanggikina hoe toe ja na maka la angoe oehoe nggoe? 1 "Kau pinja ka heàna, makanaboe ja ka ihoe ba ndakoe ita mboe». Tăka na hili oepoe handăkang, na ita ja na loenga, hiwăna: ha ina, kanggikina hoe toe ja na loenga la angoe oehoe nggoe? Tăka na heàma na ina na: kau pinja ka, nde njoengga ă matoe ja. Na hili oepoe handăkang, na hoenggoe ja na hai, hiwăna: kanggikina hoe toe ja na hai la angoe oehoe nggoe? $\mathrm{Na}$ heàma na ina na, hiwăna: ba djè ma doe ha hau lodoe hau lodoe da papandoī moe, tama wiki ma da la tănga mboăla oehoe moe. Toenanoe na hili oepoe handăkang, pandoe'angoe wăngoe, na hoenggoe ja na kahidi, da manoea ma da lima na; nj. I O. N d. ndena paní ndokoe, na piti ja na tănga mboăla, na wăroenja la tana. Toenanoe hina lakoe la pangéa na, mahoeroe mănoe mănoe ja na roedoeng na lodoe, ndena bihoe pahadang; ngangoe nde ngangoe ja, hăpa nde hăpa ja ${ }^{2}$. Toenanoe na hoeroeng ndăba na kalembi na, hiwănanja: ha Oemboe $\mathrm{Ndiloe,} \mathrm{nggiki} \mathrm{na} \mathrm{hi} \mathrm{ndau}$ ngangoe? Ndena bihoe paheàma. Oela eti na nja ka na kalembi na, lakoe beli na nja ka la parai na.

1 la angee oehoe $n g$ goe $=$ in mijn rijst

angoe $=$ "wat er bij behoort" dus: als behoorende tot mijn rijst.

De praepositie noedaloe ( $=$ in, binnen in; $)$ is alleen te gebruiken bij een kist, pot. huis, etc.

Zoo zegt men ook bv. na mandapoe kareàndja da oehoe hina $n$ gandja $=$ hij ging bij de rijst zitten en at 't op.

k a r è̀ng = volgen, begeleiden. Zou men zeggen: la oehoe, dan zou hij er tusschen in en er boven op zijn gaan zitten.

${ }^{2}$ ngangoe, nde ngangoe ja; hăpa nde hăpa ja=zonder te eten, zonder sirih te kauwen.

Men zegt ook: ngangoe ndena ngangoe, hăpa ndena hăpa=hij at niet, hij kauwde geen sirih. 
Tăka hiwăna na ina na: ha $\mathrm{O}$. Nd., măla noe, toăma ${ }^{1}$ ka doe? Na heàma nj: I. O. N.d.: nggi koe toăma ningoe? Tăka na heàma na ina na: djăkau toăma ja na ana poelangia moe, na pandengi na I Waloe mboea Katikoe? Tàka na heàma I. O. N. d. : koe toăma.

Toenanoe hina kanoăma nja bălang. Tăka nj. I. O. N.d. hina piti ja na koeta moeroe hau na, hiwăna: jeàna na koeta, djăka ndjăpa bé ja na moeroe na, nde nggăra ehi nggoe; djăka na mala’i ka, na meti mboe, maringoe na nja, wămi ngga; djăka na meti loendoeng, na meti ka năhoe, wămi ngga ka. ${ }^{2}$

Toenanoe lakoe na nja ka; bana tăka ka la woăka, hiwăna nj. I. O. N.d.: ka nggăra păkoe ja noedita la paraing, laloe remi ja? Na heàma na tau la woăka, hiwăna: djè ja I Wa lo e mboea Katikoe, na ndengi ja I Ramboe Kahi; wŏngga nja, wăna. Toenanoe lakoe na nja ka la paraing nj. I. O. Nd.; bana tăka ka la paraing, hiwăna njoena I. W. mb. K.: ka heàna, $\mathrm{O}$. Nd., nggăra mai moe? $\mathrm{Na}$ heàma nj. I $\mathrm{O} . \mathrm{Nd}$. : mai nggoe nija patăngăroe ja na ana poelangia nggoe. Tăka na heàma nj. I W. mb. K.: hai ă, ba njoengga ma doe $i$ doekoe! Tăka na heàma nj. I O. Nd.: noe ka na mataloe, djăka nggamoe ja na makăkoe. Na heàma nj. I W. mb. K. : măla ka, napa haromoe la mbaroe.

Toenanoe hadang la mbaroe, hiwăna nj. I W. mb. K.: koe wŏngga roe loenggi, kau hondoe wăndja da ndjaram, da nimboe moe, da ahoe moe, da wē moe, de kamămbi moe, da karambo'a moe. Tăka na heàma nj. I O. Nd.: măla ka; bana kē ha da roe loenggi noeda, na kē panaboe-naboe ha, ndena kambănga kana hondoe ha da ndjara na, da ahoe na, da nimboe na, da kabeàla na. Toenanoe bana hăla ka pawŏnja roe loenggi, hiwăna nj. I O. N d.: hăla nggoe ha ka pahondoe ha da ahoe, nimboe, ndjara. Tăka hiwăna nj. I W. mb. K. ${ }^{3}$ bau hăla doe ha ka pahondoe ha, ${ }^{4}$ mai kau wa, kau toengoe. Na tăkiloe ja na hau na katikoe na, na băbăroe ja; wăna nj. I W. mb. K.: ma

1 toămja = bereiken, ergens bij kunnen, iets kunnen verkrijgen, in staat zijn iets te verwerven.

2 Voor 't innige verband tusschen de zielestof van planten en menschen, vgl. Kruyt-A nimisme. pg. 136.

3 I Waloe mboea Katikoe beteekent: Mijnheer Acht-hoofd.

4 bau hăla doe ha ka pahondoe ha= daar gij ze allen gebonden hebt, (daar gij met allen klaar zijt ze te binden). Wil men uitdrukken: „daar gij klaar zijt met binden", dan zou 't zijn: bau hăla ka pahondoe ha. 
da pihoe! Na tăkiloe ja na hau, na băbăroe ja; wăna nj. I W. mb. K.: ma da nomoe! Tăka na tăkiloe ja na hau, na băbăroe ja; wăna I W. mb. K.: ma da haloētoe. ${ }^{1}$ Tăka na tăkiloe ja na hau, na băbăroe ja; wăna I W. mb. K.: ma da tiloe mboea! Tăka na tăkiloe ja na hau, na băbăroe ja; wăna $I$ W. mb. K: ma da dămboe! Tăka na tăkiloe ja na hau, na băbăroe ja; wăna I W, mb. K.: ma na hau! Tăka na tăkiloe ja na hau, na băbăroe ja, meti na nja ka I W. mb. K.

Toenanoe bana meti ka, nj. I O. Nd. kanŏama na nja I Rămboe Kahi. Toenanoe bana kanoăma ja ka, patoe mboea, lima mboea roedoeng ki na ka, hiwăna nj. I O. Nd.: ha Kahi, kokoeroe i ka, koe lo'a neloeroe la oema na na makaweàda. Tăka hiwăna njoena: nggăra ki ja na ngara na ? Makaweà da la Koeta 2 ja». "Ka ndaniıgoe koeta na, wăna nj. I O. Nd. Taka hiwăna nj. I. R. K.: ndaningoe ă kocta na, ngara ă na nja "la Koeta,» hiwănanja. Tăka na heàma ıj. I O N d. : kani hi ndaningoe koeta na, «la Koeta,» bawăna ma doe. Toenanoe kokoeroe na nja; bana hăla ka pakokoeroe ja, hiwăna nj. I. O. Nd.: wŏngga ha da tera nggoe, kaloemboet, kabeàla nimboe, na rapa.

Toenanoe hi lakoe na nja, na kaliti ja na ndjara na. Toenanoe bana lakoe ka, hina tăka "la Koeta». Toenanoe bana tăka ka "la Koeta» hina ita ha da oehoe, ndjăpa be ă bana takoe pandengi ${ }^{3}$ ha da oehoe. Toenanoe hina poeroe nj. I. O. Nd. weling la kadjea ndjara na, hina pa'aunja: ha ăpoe! ndi, wăna; ha ăpoe! ndi, wăna; ha ăpoe! ndi, wăna; ndena ita ndokoe ja. Toenanoe hina mandapoe kareàndja da oehoe

1 haloetoe $=$ een viertal. In andere dialecten: haliwitoe, haliwoetoe, ligoeta. Wordt steeds gebruikt bij 't tellen van voorwerpen, waar men anders "mboea” zou bezigen.

Als "spoor" van een 4tallig stelsel vindt men in West Soemba nog: 8 pondopata $(=2 \times 4) 9=$ banda diha (wat niet geteld wordt).

2 Koeta = sirih, is voor den Soembanees een heilige plant. Geen offerande is compleet zonder deze vruchten. Men eet niet de bladeren, maar de rruchten. Men kauwt van 'smorgens tot 's avonds, en alleen gedurende 't eten, legt men 't pruimpje naast zich neer.

Kinderen van 5 en 6 jaar ziet men reeds kauwen. Een Soembanees kan wel zonder een dag eten, maar niet zonder sirih.

3 bana takoe pandengi ha da oehoe $=$ men had de rijst opgeschept o $\mathrm{m}$ ze te laten staan.

I O. Nd. was bij de ,zielen" terecht gekomen. En nu wordt iemand, die van zulke rijst eet, een buit der "zielen". 
hina ngandja; péra doea ngangoe na, tăka hi nămoe nja na makaweàda, hiwăna: ha ha nggiki na hoe ha ngandja ha oehoe ha ndewa ha hoămba ${ }^{1}$ nggoe?

$\mathrm{Na}$ heàma nj. I O. N d. hiwăna: ha ăpoe, mandjóe nggoe nja hikoe ngandja. Tăka hiwăna njoena na makaweàda: toengoe bădi!

$\mathrm{Na}$ heàma nj. I O. Nd.; măla ka. Tăka na makaweàda na boeta ja na roe loenggi na, na boeta ja na hawala: jeàna kau hondoe wăndja da nimboe moe. Tăka na boeta ja na hawala: jeàna kau hondoe wăndja da ahoe moe. Tăka na hili boeta ja na hawala: jeàna kau hondoe wăndja da ndjara moe. Tăka na hili boeta ja na hawala: jeàna kau hondoe wăndja na kabeàla dăngoe na kaloemboet.

Toenanoe hina hondoe; bana hăla ka pahondoe ha: măla ta patăkiloe, hiwăna njoena I Apoe, toengoe woenga păkoe lai njoengga. Toenanoe hina toengoe; ndena loehoeng. Na hili toengoe, ndena loehoeng. Dira nggoe ka, hiwăna nj. I O. N d., toengoe wa njoemoe, wănanja na makaweàda. Toenanoe hina toengoe na makaweàda; na handăkang patoengoe, na meti meàmang. Toenanoe bana meti $\mathrm{ka}$, hina roeki ha da woea mata na, hina toe ha la kaba roăba; ${ }^{2}$ bana hăla ka paroeki ha da woea mata na, hina taninja.

Njoena doena I R. K. na pateàng, dira dira na. ${ }^{3}$

$\mathrm{Na}$ mandai ka năhoe hiwănanja na ama na: ha ina, laloe mandai ja năhoe I $\mathrm{O}$. N d., djăka nggi loa ningoe na nja, nde papinja. Toenanoe na ina na hina tăngăroe ja na koeta, na pawŏna I O. Nd.; na meti ka. Tăka hiwănanja I Mada: ha Mada, lo'a patăngăroe ja na ajamoe, napa hi nggiki ă na. Na heàma I M a da: măta kakoe lo'a ka. Toenanoe lakoe na nja ka; bana tăka ka la woăka, hiwăna bana pa'ărang: ka ndai ita ki ja I Ndiloe lai jehoe? Tăka da heàma da tau la woăka, hiwăda: na lakoe li njoena lai jehoe, lakoe ma na nja i la paraingoe, ndena mandai ă. Toenanoe hiwăna I Mada: madja ka toena, măta kakoe toăma la paraing. Toenanoe lakoe na nja; bana tăka ka la paraing, ndena poeroe weling la kadjéa ndjara na. Toenanoe hiwănanja nj. I. R. K., nămoe nja ka

${ }^{1} \mathrm{pahoămba}=$ offerplaats (aan den mond van een rivier of midden in een vlakte) voor de geesten, die gejieden over visschen en de dieren des velds.

$2 \mathrm{kaba}$ roăba =een klapperdop, welke niet als gewoonlijk middendoor is gedeeld, maar met een kleine opening van boven slechts voorzien.

dira dira $\mathrm{na}=$ zonder einde, eindeloos; van dira = uitscheiden. 
I. O. Nd., pareànggang, anakeàda, kai kē ja na ndjara na. $\mathrm{Na}$ heàma nj. I M a da: ha aja, I M a d a ja doekoe na ngara nggoe, I Ndilo e ja na aja nggoe. Tăka na heàma nj. I. R. K. : ba djeà ma doe kau noe, bau pandjiloenja na tamoe moe, ba I Ndiloe ma doe kau, I. Mada ka wămoe i.

Toenanoe bana taloe ka I Kahi ', njoena doena I Mada, kanoăma doe na nja i ka I Kahi. Toenanoe palăngang patoe lima; ha aja, kokoeroe ta kakoe lo’a néloeroe. Tăka hina kokoeroe ja; bana hăla ka pakakoeroe ja hiwăna njoena I M a da: wŏngga ha da kabeàla nggoe, da tera nggoe, da kaloemboetoe nggoe, da hinggi nggoe ${ }^{2}$. Toenanoe bana hăla ka pawŏnja ha, lakoe na nja, na kaliti ja na ndjara na pangăndi ma na. Toenanoe bana tăka [ka "la Koeta» hina pa'aung: ha ăpoe! ndi wăna; ha ăpoe! ndi wăna; ha ăpoe! ndi wăna. Mandapoe kareà na ha ka da oehoe, da patakoe pandenging; pera doea ngangoe păkoe na, djè tăka hăra bănda be na nja na makaweàda: ha ha nggiki na ha ngandja ha oehoe ha ndewa ha hoămba nggoe? Na heàma. njoena I Mada: oemboekoe ma doe moe ngga, ămboe mbeni doe! "Ai ndea, toengoe bădi». Na heàma njoena I Ma da: măla ka. Tăka njoena na makaweàda na boeta roe loenggi na, na boeta ja na hawala: jeàna kau hondoe wănja na ndjara moe. $\mathrm{Na}$ boeta ja hawala: jeàna kau hondoe wănja na kabeăla moe. Na boeta ja na hawala: jeàna kau hondoe wăndja da nimboe moe. Na boeta ja na hawala: jeàna kau hondoe wănja na kaloemboetoe moe. Tăka njoena I Mada na kē ha, na wăroendja. Tăka hiwăna na makaweàda: hăla ha ka pahondoe ha. Tăka njoena I Mada na heàma: hăla ha ka! "Măla, mai kau toengoe lai njoengga», wăna na makaweăda. Na toengoe handăkang, na meti meămang. Na hili hada beling: toengoe ki, wăna.

$\mathrm{Na}$ hili toengoe, ndena loehoeng pa. Na hili toengoe, ndena loehoeng. Tăka hiwăna na makaweàda : paheàngga wa doekoe kakoe toengoe, kakoe talandjir, wăna doe ka lăti; da ndjara

1 bana taloe ka I Kahi=daar I Kahi 't won; 't laatste woord had en hij zag dat tegenspreken niets meer gaf.

Wie in een Soemban. twistgesprek 't laatste woord heeft, is overwinnaar! Een goed prater, is een zeer gezien man.

2 wöngga ha da kabeàla nggoe, da tera nggoe, dakaloe. $\mathrm{mboetoe} n \mathrm{ggoe}=$ wanneer bij een verbum meerdere enkelvoudige substantiven worden gevoegd, gebruikt men gaarne 't lidwoord in 't meervoud. 
na, da nimboe na, da ahoe na da kanjoekoeloe nja hida kati ja; na tiki pameti ka ă mang. Hiwăna na makaweàda: ha ha ( emboekoe nggoe, ha paloe ha da ha ahoe moe ka ămboe ha da pameti ha ka. Tăka hiwăna njoena I Mada: djăka toenanoe, pahada beli nja I Oemboe $\mathrm{Ndiloe,} \mathrm{kakoe} \mathrm{ha-ha} \mathrm{da} \mathrm{ahoe.}$

Tăka na heàma na makaweàda: koe paloeri beli ja, miloe ha-ha njoena da ahoe moe. Toenanoe hina ha-ha da ahoe; bana ha-ha ka, hida pahăla nja na makaweàda. Toenanoe bada pahăla nja ka hina lo'a papiti ha da woea mata na I. O. Nd. la kaba roăba; hina lo'a hina ăki nja na tau na, na pahăla pataninja; hina toe beli ha da woea mata na; noe loeri na nja ka I O. Nd. Njoena na makaweàda, da ahoe na pamareni ha na ndjara na, nimboe na, na kabeàla na, na pamătoe ndăba hina wŏnja ha. Toenanoe bana hăla ka pawŏnja ha, lakoe da nja ka. Tăka la ngarăngia hiwănanja I Mada: papaleàwa na $\mathrm{i}$ ina ka, lo'a patadaloe ja na ajamoe, wăna ngga i ina; toenanoe hikoe pamaingoe; $\operatorname{dedi}^{1}$ koe tăka ka lai aja: djè I O. N d. wăna ngga, dedi koe heàma; ka doekoe njoengga : nde IO. Nd. ă ka, I Mada ja doekoe na ngara nggoe, aja nggoe nja I O. Nd., hiwănggoe nja. Toenanoe na taloe ma ka ka, hikoe kanoăma ja i aja.

Toenanoe bana rongoe ka I O. Nd., tăka hina koădja pameti ja.

Toenanoe bana meti ka, hiwăna bana hī: na eri nggoe, na eri nggoe, ndakoe boeti be nja pa; tangédji nggoe, hikoe pa lănga tăka ma ja ka bakoe koădja ja. Toenanoe mandapoe kareà doe na nja ka la ngea pameti na I Mada.

Tăka hi nindja da mbăra, patoe ngioe da, hida hawoeroeng hida răndjăkoe la kapoeka ai la ngea pamandapoe na I. O. Nd. Toenanoe hiwăda: ha angoe tamoe, ${ }^{2}$ măla kata păní li pangérang, na li pangérang noena laloe manandangoe ja, na malai mboe. Toenanoe na pakiri na: nindja da madoea da tau, na kawini I Limba Băbăngoe ja..... (en dan volgt 't geheele verhaal nog eens...... ${ }^{3}$ djăka na pingoe, kana hadang

$1 \mathrm{dedi}$ beteekent hier: vervolgens, en toen gebeurde 't dat - ; van dedi geboren worden, ontstaan...

${ }^{2}$ ha! angoe tamoe, $=$ ha mede naamgenoot! Uit deze anspraak blijkt, dat de duiven incarnaties zijn van gestorven familieleden, welke uoortdurend in 't lot der levenden belang blijven stellen en hen zoo mogelijk helpen.

${ }^{3}$ In dergelijke herhalingen van 't verhaal is de Soembanees sterk. 't Gebeurt soms tot 3 à 4 maal toe, dat men zoo hetzelfde nog eens te hooren krijgt. Anders is men ook zoo gauw uitverteld! 
hăra bănda kana kajămbăkoe nda, kata hawoeroeng kada tamboeta da woeloe ihi nda, kana piti ha noeda, kana toenoe ha kana pahangoedoe nja ha; bana hăla ja ka kana rămbăhoe wănja woeloe mata hinggi, na loeri beli be doe ja.

Toenanoe hina hadang hina kajămbăkoe ndja ; bada hawoeroeng ka hida tamboeta da woeloe ihi da. Toenanoe hina poetoe ha; bana hăla ka papoetoe ha, hina toenoe ha. hina pahangoedoe nja ha. Toenanoe bana hăla ja ka, hina rămbăhoe wănja woeloe mata hinggi. Toenanoe hadangoe na nja ka I Mada; lakoe da nja ka la oema ama da, la oema ina da. 
III. I Rămboe Kahi met de twee broeders.

Er waren eens twee menschen, zij waren met elkaar gehuwd; de man heette I Hadoe $\mathrm{Hina}$ en de vrouw heette I Limba Băbăngoe; hun eerste kind heette I Ndiloe. Toen hij wat ouder was geworden werd zij zwanger van een ander kind. En het werd geboren, I Mada was zijn naam. Toen zij hem geboren had en hij zich op zijn buik kon wentelen, stierf zijn vader. Na den dood van zijn vader, werd I Mad a langzamerhand ouder. En die vrouw riep haar zoon I Ndiloe en zij zeide: ha Oemboe $\mathrm{Ndiloe}$, gij moest eens gaan, en mij gaan openhakken 't bosch in den tuin van uw vader. $\mathrm{Z}_{\mathrm{ij}} \mathrm{nu}$ gingen; toen zij in 't bosch gekomen waren, makkte I O. Nd. tollen, hij maakte kammen, hij draaide tollentouw, hij maakte mondfluitjes. Maar I Mada terwijl hij hakte een klein boompje, hakte van den morgen tot den avond en toen pas viel 't. Toen 't nu avond geworden was, gingen zij naar huis; thuis gekomen zeide hun moeder: hoe was 't vandaag, hebt ge wat gedaan gekregen. I. O. $\mathrm{Nd}$. antwoordde: wij hebben wat gedaan gekregen. Wederom 's morgens vroeg opgestaan, gingen zij wederom bosch vellen. Toen zij in 't bosch gekomen waren, ging I Mada aan 't vellen, maar I O. Nd. maakte tollen, makkte kammen, maakte mondfluiten, draaide tollentouw. Maar I Mada hij hakte van 's morgens vroeg af een boompje, tot 't avond was en toen pas viel het. Daar 't nu avond geworden was gingen zij naar huis; thuis gekomen, zeide hun moeder: hoe was 't vandaag, kinderen, met 't hakken, gij hebt toch wat gedaan gekregen? I O. Nd. antwoordde: als men er maïs en pompoen op plant, dan zal 't wel wat opbrengen. Zijn moeder antwoordde: ja. Wederom des morgens vroeg opgestaan, gingen zij maar wederom; in 't bosch gekomen, maakte I O. $\mathrm{Nd}$. tollen, hij maakte kammen, draaide tollentouw, maakte mondfluitjes. Maar I Mada, terwijl hij toch maar een kind was, hakte een kleine boom, een stuks slechts; hij hakte er op van 's morgens vroeg, tot den avond en het viel. Daar 't nu avond geworden was, gingen zij naar huis, in hun huis gekomen, zeide hun moeder: hoe was 't vandaag, hebt gij wat gedaan gekregen? I O. Nd. 
antwoordde: wat door ons geveld is, is buitengewoon groot. En zijn moeder zeide: hoe is 't, zullen wij morgen 't vuur er in gaan brengen? I O. $\mathrm{Nd}$. antwoordde: laten wij maar gaan. 's Morgens opgestaan zijnde, gingen zij heen, vergezeld van' hun moeder; in 't bosch gekomen zeide hun moeder: waar is nu 't spoor van uw vellen? En I Mada antwoordde en zeide: wat I Ndilo'e betreft, hij was maar druk bezig met 't maken van tollen, kammen, mondfluitjes, met 't draaien van tollentouw, terwijl ik 't alleen ben, die dit hout hakte. Naar haar huis ging nu hun moeder, zij kwam thuis, zij ging snel aan 't koken. Toen 't gaar was, nam zij 't rijst-mandje van I O. N d., zij nam 't mondfluitje, den tol, den kam, 't touw en 't mes; 't mes deed zij onderin, den kam deed zij halverwege, zij deed er rijst bij en drukte 't goed vast; vervolgens nam zij 't touw, deed 't er in, schepte er rijst bij en kneedde 't vast. Toen nam zij den tol, deed dien er in, schepte er rijst bij en kneedde 't vast. Toon nam zij 't mondfluitje, deed 't er in en kneedde 't vast met rijst. En nu kwam I O. Nd. er aan, terug van 't bosch vellen, en zij nam hem zijn rijst van zooeven, waar zij het ingedaan had en gaf 't hem en hij at. De eerste maal schepte hij, hij vond 't mondfluitje en hij zeide: moeder, dit mondfluitje, waarom hebt gij 't er in gedaan? Zijn moeder antwoordde: weet $\mathrm{jij}$ ' $t$, ik ben nu ook al oud, ik zie ook niet, misschien is 't er in gevallen.

Hij schepte nog eens een keer, hij zag den tol, en I O. Nd. zeide: moeder, waarom hebt gij den tol in mijn rijst gedaan? "Weet jij 't daar, 't is misschien er in gevallen terwijl ik 't niet zag.» Hij schepte nog eens een keer, hij zag 't tollentouw, en hij zeide: moeder, waarom hebt gij 't tollentouw in mijn rijst gedaan? Maar zijn moeder antwoordde: weet jij 't? ik ben 't niet, die 't er in gedaan heeft. Wederom schepte hij nog eens, hij vond den kam en hij zeide: waarom hebt gij den kam in mijn rijst gedaan? $\mathrm{Zijn}$ moeder antwoordde en zeide: want dit zijn immers de dingen, welke gij iederen dag gemaakt hebt; van zelf zijn zij in uw rijst-mandje gegaan. Wederom schepte hij nog één maal, tweemaal deed hij 't en hij vond 't mes, zijn handen waren ook gewond; I O. Nd. zei heelemaal niets. hij nam het mandje, hij wierp 't op den grond. En hij ging naar zijn plaats, sliep voortdurend nacht en dag, hij wilde niet opstaan; eten at hij niet, sirih kauwde hij niet. En al zijn familie trok op 
en men zeide tot hem: Oemboe $\mathrm{Ndiloe}$, waarom eet gij niet? Hij wilde niet antwoorden. Zijn familie had er genoeg van, en ieder keerde terug naar zijn kampong.

Toen zeide zijn moeder: Oemboe $\mathrm{Ndiloe}$, hoe is 't kunt gij 't bereiken? I O. Nd. antwoordde, wat moet ik bereiken? En zijn moeder antwoordde: of gij kunt bereiken de dochter van uw oom, bewakt door I Waloe mboea Katikoe? I O. $\mathrm{Nd}$. antwoordde: ik bereik 't. En zij maakte reis-voorraad voor hem klaar. Toen nam I O. $\mathrm{Nd}$. één jonge sirih-vrucht en hij zeide: deze sirih-vrucht, als ze steeds groen blijft, dan mankeert mij niets; als ze slap wordt en ook droog: hij heeft de koorts, zult gij van mij zeggen; als ze heelemaal droog is: nu is hij gestorven, zult gij van mij zeggen.

$\mathrm{Hij}$ nu ging op reis; bij een tuin gekomen, zeide I O. Nd. wat is dat toch daarboven in de kampong, men viert er een groot feest? De menschen in de tuin antwoordden: dat is I W. mb. K., hij bewaakt I Ră mboe Kahi; geef haar mij, zegt hij. I O. Nd. ging nu naar de kampong; in de kampong gekomen, zeide I W. mb. K.: hei daar, O. Nd., wat komt gij doen? I O. Nd. antwoordde: ik kom eens zien naar de dochter van mijn oom. Maar I W. mb. K. antwoordde: hai a, ik ben er toch ook nog! En I O. Nd aniwoordde: die is 't die overwint, wie is 't die de nederlaag lijdt. En I W. mb. K. antwoordde: welaan morgen ochtend zal 't zijn.

's Morgens vroeg opgestaan, zeide I W. mb. K. : ik zal u geven haren, opdat gij er mee bindt uw paarden, uw lansen, uw honden, uw varkens, uw geiten, uw karbouwen. En I O. Nd. antwoordde: welaan; toen hij die haren aannam, liet hij ze tegelijkertijd vallen; hij was niet zoo dom, dat hij bond zijn paarden, zijn honden, zijn lansen, zijn kapmessen. Toen hij de haren gegeven had, zeide I O. Nd.: ik ben er mee klaar, met 't binden van de honden, lansen, paarden. Toen zeide I W. mb. K. : daar gij klaar zijt met ze te binden, kom dan maar, sla er op!

Hij sloeg met de vuist op zijn ééne hoofd, het was verbrijzeld; I. W. mb. K. zeide: er zijn er nog zeven! Hij sloeg met de vuist op een ander (hoofd), 't was verbrijzeld; I. W. mb. K. zeide: er zijn er nog zes. En hij sloeg met de vuist op een ander, het was verbrijzeld; I. W. mb. K. zeide: er zijn er nog vijf. En hij sloeg met de vuist op een ander, het was verbrijzeld; I W. mb. K. zeide er zijn er nog vier. En hij sloeg 
met de vuist op een ander; 't was verbrijzeld; I W. mb. K. zeide: er zijn er nog drie. En hij sloeg op een ander; 't was verbrijzeld; I W. mb. K. zeide: er zijn er nog twee. En hij sloeg met de vuist op een ander; 't was verbrijzeld; I W. mb. K. zeide: er is er nog één! En hij sloeg met de vuist op een ander, 't was verbrijzeld; en I W. mb. K. was dood,

Toen hij gestorven was, trouwde I O. Nd. met I Rămboe Kahi Toen hij haar getrouwd had, na verloop van vier à vijf nachten, zeide I O. Nd.: Kahi, wrijf mij eens in met klappervet, ik wil ginds heen gaan naar 't huis van de oude. Vervolgens zeide hij: wat is toch haar naam? "Oude la Koeta En er is daar geen sirih, zeide I O. Nd. En I R. K. antwoordde: daar is geen sirih, 't is haar naam maar "la Koeta.» Maar I O. $\mathrm{Nd}$. antwoordde: hoe is 't dat er geen sirih is, terwijl men toch zegt "la Koeta». Zij nu wreef hem in met klappervet; toen zij hem ingewreven had, zeide I O. Nd.: geef mij mijn hoofddoek, sirih-zak, kapmes, lans, het paardentoom. Hij ging en besteeg zijn paard. Toen hij gegaan was, kwam hij bij "la Koeta». Toen hij bij "la Koeta» gekomen was, zag hij de rijst, voortdurend bleef de rijst opgeschept staan wachten. I O. Nd. steeg van den rug van zijn paard en hij riep haar: ha grootmoeder! 't bleef stil; ha grootmoeder! 't bleef stil; ha grootmoeder! 't bleef stil; hij zag haar heelemaal niet. Hij ging nu naast de rijst zitten en begon te eten; halverwege zijn eten, daar kwam de oude aan en zeide: waarom eet gij de geestenrijst van mijn offerplaats!

I O. Nd. antwoordde en zeide: grootmoeder ik had honger en zoo at ik. Maar de oude zeide: (wij) moeten vechten! I O. Nd. antwoordde: welaan! En de oude trok zich de haren uit; zij trok er één uit: bind hiermee vast uw lansen. $\mathrm{Zij}_{\mathrm{ij}}$ trok zich een ander uit: bind hiermee vast uw honden. $Z_{i j}$ trok zich wederom er één uit: bind hiermee vast uw paarden. En wederom trok zij zich er één uit: bind hiermee vast uw kapmes en uw sirihzak.

En hij bond 't; toen hij ze gebonden had: welaan, laten wij met de vuisten op elkaar slaan, zeide I Apoe; sla maar eerst op mij. En hij sloeg, 't ging er niet in. Wederom sloeg hij, 't ging er niet in. Ik schei er mee uit, zeide I O. Nd. , sla gij nu maar, zeide hij tot de oude. En de oude sloeg; de eerste maal dat zij sloeg, was hij terstond dood. 
Toen hij dood was, stak zij hem de oogen uit en deed ze in een klapperdop met nauwe opening; toen zij hem de oogen uitgestoken had, begroef zij hem.

En zij, I R. K., wachtte maar zonder einde.

Toen 't nu reeds lang geduurd had, zeide zijn vader: moeder, I O. Nd. is nu al lang weg; waar hij toch heen gegaan is, weten wij niet. En zijn moeder bekeek de sirih-vrucht, door I O. Nd. gegeven. Ze was droog. Toen zeide zij tot I Mada: ha Mada, ga eens zien naar je oudere broer, hoe 't wel met hem zou zijn. I Mada antwoordde: welaan ik zal gaan. En hij ging; bij den tuin gekomen, zeide hij, terwijl hij vroeg: hebt gij soms $\mathrm{O}$. Nd. hier niet gezien? En de menschen in den tuin antwoordden: hij is hier wel aangegaan, maar hij ging (weer) naar de kampong; 't is niet zoo lang geleden. En I Mada zeïde: laat 't maar zoo zijn, ik zal wel doorgaan tot de kampong. Hij nu ging; in de kampong gekomen, ging hij niet van den rug van zijn paard af. En I R. K. zeide tot hem: daar komt I O. Nd. aan, vlug, slaven, neem zijn paard aan. I Mada antwoordde: ha oudere zuster, I Mada is mijn naam; I Ndiloe is mijn oudere broeder. I R. K. antwoordde: jij bent 't toch zelf, je hebt je naam veranderd, $1 \mathrm{Ndiloe}$ toch ben je, I Mada dat zeg je maar.

Toen I Kahi overwonnen had, trouwde $1 \mathrm{Mada}$ nu maar met I Kahi. Na verloop van 4 à 5 dagen (zeide hij,): ha oudere zuster, wrijf mij eens in met klappervet, dan ga ik ginds eens heen. En zij wreef hem in; toen zij hem ingewreven had, zeide I Mada: geef mij mijn kapmes, mijn hoofddoek, mijn sirih-tasch, mijn slimoet. Toen zij 't hem gegeven had, ging hij heen, hij besteeg 't paard, dat hij meegebracht had. Toen hij bij "la Koeta» gekomen was, riep hij: ha grootmoeder! 't bleef stil; ha grootmoeder! 't bleef stil.

Hij ging nu naast de rijst zitten, welke opgeschept stond te wachten; juist halverwege zijn eten, daar kwam plotseling de oude aan: waarom eet gij de geestenrijst van mijn offerplaats? I Mada antwoordde: ik ben toch uw kleinzoon, wees maar niet boos! "Neen toch, wij moeten vechten». I Mada antwoordde: welaan. De oude nu trok van haar haren uit; zij trok er één uit: bind hiermee uw paard. $Z_{i j}$ trok er één uit: bind hiermee uw kapmes. $Z_{i j}$ trok er één uit: bind hiermee uw lansen. Zij trok er één uit: bind hiermee uw sirih-tasch. Maar 
I Mada nam ze aan en wierp ze weg. En de oude zeide: hebt gij ze allemaal gebonden? En I Mada antwoordde: allemaal. "Welaan, kom en sla mij, zeide de oude. Hij sloeg éénmaal, zij stierf terstond. $Z$ ij stond wederom op: sla maar zeide zij. $\mathrm{Hij}$ sloeg wederom, hij vermocht niets meer. Hij sloeg wederom: hij vermocht niets. Toen zeide de oude: laat mij nu maar eens toe, dan zal ik slaan, dan zal ik er op los stormen, dat zeide zij maar, (want) zijn paard, zijn lansen, zijn honden, liepen op haar toe en beten haar; zij stierf er bijna van. En de oude zeide: o mijn kleinzoon, sla uw honden opdat zij mij niet dooden. Maar I Mada zeide: als 't zoo is, laat dan weer los I O. Nd., dan zal ik de honden wegjagen. Maar de oude antwoordde: ik zal hem weer in 't leven terugbrengen, mits gij maar uw honden wegjaagt. Hij nu joeg de honden weg; toen hij ze wegjoeg lieten zij af van de oude. Toen zij van haar aflieten, ging zij halen de oogen van IO. Nd. in den klapperdop met nauwe opening; toen ging zij zijn lichaam opgraven, dat reeds begraven was; en zij plaatste de oogen er weer in; en daar leefde I O. Nd. En de oude deed naderbij komen zijn honden, zijn paard, zijn lans, zijn kapmes, zij maakte 't alles compleet en zij gaf 't hem.

Toen zij 't hem gegeven had, gingen zij heen. Onderweg gekomen zeide I Mada: ik ben door moeder gezonden, ga eens naar uw oudere broeder zien, zeide moeder tot mij; en zoo ben ik hier gekomen; 't gebeurde toen ik bij de oudere zuster kwam: dat is I O. Nd., zeide zij tot mij; vervolgens antwoordde ik: ik ben toch niet I O. Nd., I Mada is mijn naam, I O. Nd. is mijn oudere broeder, zeide ik tot haar. Maar zij overwon toch en ik huwde met de oudere zuster.

Toen I O. N d. 't hoorde, toen stak hij hem dood. Toen hij dood was, zeide hij huilende: mijn jongere broeder, mijn jongere broeder, ik zal nooit meer een oog op hem kunnen slaan; ik scherts, zeide ik, maar ik heb 't werkelijkheid gemaakt terwijl ik hem stak. Hij nu ging naast hem zitten op de plaats, waar I Mada gestorven was.

Er waren nu duiven, vier stuks, zij vlogen en zetten zich neer boven in een boom, waar I O. Nd. zat. En zij zeiden: mede naamgenoot! laten wij eens een verhaal vertellen, dat verhaal is zeer mooi en ook lang. Aldus is 't begin er van: er waren eens twee menschen, de vrouw heette I Limba 
Băbăngoe ..... (en dan volgt 't geheele verhaal nog eens), als hij 't wist, dan zou hij plotseling opstaan en ons wegjagen, dan zouden wij wegvliegen en onze veeren uitvallen, dan zou hij die opnemen en ze verbranden en hem er aan doen ruiken; wanneer hij daarmee klaar was, dan zou hij hem slaan met de franje van de slimoet; hij zou dan wederom leven.

Hij nu stond op en joeg ze weg; terwijl zij wegvlogen vielen hun veeren uit. Hij raapte ze op; toen hij ze opgeraapt had, verbrandde hij ze en deed hem er aan ruiken. Toen hij dat gedaan had, sloeg hij hem met de franje van de slimoet. En hij stond weer op I Mada; zij gingen nu naar 't huis van hun vader en moeder. 


\section{I Rămboe Kahi, na maloeri beli.}

Nindja da anakeàda da mapa'ering, da mapa'ajang. ${ }^{1}$ Toenanoe bada matoea $\mathrm{ka}$, na ana wini na na mangoăma, na ana mini na na lalē. Tơnanoe hina pa'ana ja haätoe na na anakeàda mini. Na ana mini na ndaningoe ana na. Toenanoe bana matoea ka na anakeàda noena hida kăli paleàwa ja palo’a pakaoe oehoe ndjara. ${ }^{2}$ Toenanoe bana ngeri ndămang hina lakoe palo’a pakaoe oehoe ndjara la loemboe pingi wangga ${ }^{3}$, hina kaoe oehoe ndjara lai noe; ba hīna na handăkang ndena rongoe na paní lai noe la pingi wangga.

Toenanoe bana beli ja ka, da ina na da ama na da tangedji nja, hiwădanja: ha anakeàda, lo’a patoenja oehoe ndjara na toejam; djăka na pa'ana * haromoe, tanggoe moe njoemoe ja, djăka kawini ja, hiwădanja; djăka ndau lo’a patoenja oehoe ndjara, ndeda wŏnggau nja na ana da. Na heàma njoena na anakeàda: djăka ndeda wŏngoe, da djămang doeda.

Toenanoe hina hadang la mbaroe, na lo'a pakaoe oehoe ndjara. Na lăpăhoeng hau woelang, dămboe woelang hina hili lo’a pakaoe oehoe ndjara la pingi wangga, na ngéa palo'a na la pira na. Toenanoe na kaoe oehoe ndjara lai noe, bana paboendoendja ka da oehoe ndjara na hina păndjăng hakoedoe; tăka hina rongoe ha da tau da mapaní; tăka hina ita ja na tau noena la pingi wangga, haätoe na na makaweàda, hiwădanja: ha, ăpoe! «Ka nggăra wămoe , hiwăna na makawèada. "Lakoe li i nămoe», hiwădanja.

1 da mapa'ering, da mapa'ajang $n$ het praefix pa heeft hier dezelfde beteekenis als bv. in pa'ama = "vader" zeggen.

$\mathrm{pa}+\mathrm{ng}$ vormt reciproque verba. Bovenstaande uitdrukking is stereotiep, wanneer men wil zeggen: "dat zij broeders waren."

2 oehoe ndjara = paarden-voedsel.

oehoe dat in 't algemeen "voedsel" betcekent, bv. o ehoe w $\overline{\mathrm{e}}=$ varkensvoer, beteekent in 't bijzonder "rijst". Zoo spreekt men van oehoe pari rijst nog in den bast; o ehoe karohoe gebolsterde rijst.

3 wangga een waringin-soort, van welke de reusachtige exemplaren door den Soembanees worden gedacht bewoond te zịn door geesten. De knaap luistert hier dan ook een geestengesprek af, dat hij later ten eigen nutte weet te gebruiken.

4 pa'ana baren, kinderen krijgen; wordt zoowel van de vrouw als van den man gezegd. 
Toenanoe hina lakoe li, hida karai ja: kanggi weli ni moe, hiwădanja. Na heàma doena njoena na makaweada: weli nggoe padeàkanja ' na anakeàda noedita; hiwănggoe nja bakoe deàkanja: djăkau mangoăma haromoe, na kati kau kataroe, meti ma, wănggoe nja; nde'a —; koe hili deàkanja: djăka na ngăna kau oerang, pariti meti wăngoe ma moe nja, wănggoe nja; nde'a - ; hikoe hili deàkanja: haromoe djăkau mangoăma ka, na ama moe na lakoe papatamang, na mini le moe na kareà mboe nja; na tăka năhoe la marăda, koădja wē dira matiki; djăka da beli ha ka, mbăda meti moe ka, ndeda toăma mboe nggau la kaheli ${ }^{2}$, mbăda hăla dănggau patani nggau haätoe.

Toenanoe na anakeada kawai ndena pawoewang wiki na, na patingi pahămoe hămoe ndja bada paní. Tăka hiwăna njoena na makawèda: na mapaha ja haromoe, djăka na pingoe ma, na loeri beli be njoena; djăka na beli ja ka weli papatamang, ămboe na ngangoe oehoe la oema, na lakoe bădi la kaba aoe ${ }^{3}$, pangăndi na oehoe kadita dăngoe oehoe hajăla; na hajăla ba hina na tăka, na hăbăroenja la hingi lokoe la ngéa pa’ihoe na na tau la kaba aoe; tăka na oehoe kadita, na mătanja ka kadiroe.

Toenanoe pandjăpoeng da nja ka bada paní; njoena noe kawai

1 deàka=nam geven aan een pasgeboren kind. De „ceremonie” heeft aldus plaatst: met een scherp gepuntte bamboe wordt den navel doorgesneden en niet afgebonden. Men laat die van zelf uitbloeden. Intusschen geeft men een naam; is 't bloeden nog niet opgehouden, dan weer een andere naam, totdat er eindelijk geen bloed meer uitkomt en de laatst genoemde naam wordt dan de naam van 't kind.

Men stelt zich nu voor, dat de ,zielen" der voorouders bij dit namgeven tegenwoordig zijn, en als een soort "schikgodinnen" 't toekomstig lot van den kleine bepalen.

$2 \mathrm{kaheli}$ - de vloer in huis. Dáár is de plaats der vrouwen, terwijl de mannen steeds zitten op de „bangga“, de voorgalerij.

${ }^{3}$ kaba aoe=en klapperdop mat asch gevuld, waarin twee à drie kippenveeren worden gestoken. Na 't jaarlijksch bezoek der „zielen" aan de kampong (langoe paraing), wordt door elk huis een dergeiijke klapperdop buiten de poort neergezet of weggeworpen.

Meu gebruikt dit „kaba a o " nu ook, ter aanduiding van het zielenland. Een zwaar begroeide bergtop in Massoe heet dan ook kaba a oe, en wordt gedacht de verblijfplaats der gestorven voorvaderen te zijn. Méen stelt zich dit rzielenland" heel natuurlijk voor, waa.x dezelfde toestanden heersuhen als op aarde bij de levenden.

Omtrent deze "kaba aoe" zijn heel wat verhalen in omloop. Menschen, die er bij ongeluk verdwaald raken en een buit der zielen worden. Anderen komen er gelukkiger af en weten te ontsnappen. Ook sommigen "dooden" keeren weer terug. 
na anakeàda ba wănda, na pi hăla nja ka; na tidoendja da oehoe ndjara hina lakoe.

Toenanoe bana tăka ka la oema hina băndjăloe ha da oehoe ndjara, na paberindja oehoe da da ndjara.

Toenanoe bana ngeri matoea-toea ka ${ }^{1}$, tăka njoena na toeja na hina paleàwa ndja tau da ina na da ama na, hiwăna: poeli ngga ka ja wa na laleàba nggoe kakoe patama uja la koeroeng; wŏngga wa banda.

Toenanoe hida pa'oehi nja banda hida wŏnja hida palakoe ja na ana da. Toenanoe hina patama nja la koeroeng; hīna ă pa tiloe mboea roedoe na, tăka hiwăna na ama jera na: măla kata lo’a papatamang, hiwănanja na laleàba na.

Toenanoe hi lakoe da nja; bada tăka ka năhoe Ia marăda, tăka njoena na kawini ndena pawăla ndokoe; padoea pahē ma na ka na lodoe, tăka hiwăna na ina na bana paleàwa anakeàda: ha anakeàda ${ }^{2}$, loa kai benginja I Kahi noedita, kana toendja oehoe da da wē, na toendja păni da da manoe. ${ }^{3}$. Toenanoe hina hē haätoe na na anakeàda hina benginja: ndena pawăla. Tăka hina hē na ina na hína benginja; na tăngăroe pahămoenja, mbăda meti na ja ka, na halata ma ka. Toenanoe hina poeroe ja la bangga na ina na hina hī.

Toenanoe bana rongoe ka na tau na angoe koătăkoe na hida mai parongoe hiwădanja: kanggiki na, hiwădanja. $\mathrm{Na}$ heàma njoena: na ana nggoe na mamangoăma, mbăda meti na ka. Toenanoe hida pa'aung tau pataninja hida taninja.

Hadang la mbaroe hida măngoe patăka na ama na dăngoe na tau angoe na ${ }^{4}$. Toenanoe bana rongoe ka na ama na meti na na ana na, ndena bihoe ndokoe pangangoe; tăka na tau angoe na hina riki ja, na jădoe jădoe bana riki: ndakoe handoeka ă, wăna.

Toenanoe bana hăla ka pangangoe la ăpoe na; hiwănanja na

1 matoea oud, volwassen. Men zegt 't echter reeds van kinderen van \pm 14 jaar, welke dan den huwbaren leeftijd hebben bereikt. Kinderen verlaten bv. de school, omdat zij gaan trouwen.

2 anakeàda jongen, meisje; zoo noemt men in 't gewone gesprek de slaven (a ta).

3 De vaste uitdrukking voor een "goede huisvrouw" is dan ook: toetoeroe la toengoe oehoe wē,

I a toengoe păni manoe: d.w. z. ijverig in 't varkens voeren en in 't kippen eten geven.

t ta 11 agoe is zoowel echtgenoot als echtgenoote. 
ăpoe na: ha ăpoe, bai nda karohoe, hau ana lipitoe hajăla, hau ana lipitoe kadita, koe lo’a patăngăroe ha da ndjara. Toenanoe bana $k \bar{e}$ ha ka da oehoe papeàka na hina lakoe ja la oema na na ina wiki na hina paloehoe ja na ndjara kătoeng, hina kaliti ja, hi lakoe na nja.

Toenanoe bana tăka ka hoedija ', ndena hē la paraing, na napa ja noewawa la lokoe. Tăke hi nămoe ja haätoe na na tau kawini hina lakoe hina ihoe la lokoe lai noe, Njoena na tau na papaní nda noe kawai, na kawini parăpoe-răpoe wiki na, ndedi na pawoewang wiki na. Toenanoe bana hăla ka pa'ihoe hina piti ja na woeroeng hina boehi nja wai hina tidoenja hina lakoe. Na maringoe lodoe na hili beli ja; na tau kawini noena kawini pa'ana ja, na lakoe, na ihoe; na woeroengoe na na băndjăloe ja la mara. Tăka njoena na tau na makawining hina oepoe je na oehoe hajăla, hina hăbăroenja la wai, hina loehoe ja la ngarăngía. Tăka njoena na kawini hina ita ja na tau noena; nde nggăra papaní na na kawini; tăka njoena na tau makawining hina karai ja: ha rămboe ${ }^{2}$, nggăra ja parémi na noedita la paraing? Tăka na heàma njoena na kawini: mamoha $\mathrm{ja}^{\mathbf{3}}$; tiloe mboea roedoe ă na bana tama la koeroeng na mini lē na, tăka njoema hima jăpa ja na papaha na, wăda bakoe rongoe bada paní.

$\mathrm{Na}$ heàma njoena na tau mini: ka nggamoe ja na ngara na? Na heàma njoena na tau kawini: I Kahi ja na ngara na. Tăka

${ }^{1}$ hoedija - stroomopwaarts. De kaba a o e ligt, van de kust af gerekend, stroomopwaarts in 't binnenland.

2 rămboe=is de gewons aanspraak tot vrouwen. Tot vrouwen van radja's zegt men echter niet: rămboe =juffrouw, mar tamoe rămboe mevronw.

Een dergelijk onderscheid heeft men met oemboe en tamoe oemboe. Dit laatste "tam o e o mb o e", zegt een kleinzoon tot zijn gelijknamigen grootvader; zegt een onderdaan tot den zoon van zijn vorst; zegt een slaaf tegen den zoon ran zijn heer.

Tamoe rămboe, zegt een kleindochter tegen haar gelijknamiga grootmoeder en is de gewone aanspraak tegen rrouwen van een radja, welke den naam aannemen van haar schoonmoeder.

Zoo heeft men ook nog tamoe ina; zoo noemt mijn broer mijn vrouw, omdat ze de naam anneemt van mijn moeder. Ook de schoonvader noemt zijn schoondochter in plaats van ri ana, wel eens tainoe ina.

${ }^{3} \mathrm{mamoha}=$ een klein meisje, dat de bruid vergezelt en representeert. vig. aant. 4 van verhaal: De twee pompoenen.

Soms noemt men de bruid zelve ook wel mamoha en 't kleine meisje heet dan an a moha. 
hiwăna na tau mini: pirăngoe pa na poeroe tanang? 1 Na heàma njoena na tau kawini: bakoe rongoe la ama bokoel ${ }^{2}$ bada paní, haromoe la mbaroe, wăda, na mai pa'ihoe jehoe la lokoe.

Tăka hiwăna njoena na tau mini: boehi nja wai na woeroengoe moe.

Toenanoe na dandanja, ndena măka nja na woeroeng pawotoe ja la katikoe na, Tăka hiwăna: ha oemboe, mai kau patidoe i nda! Na heàma na tau mini: madja ka toena, djăka njoengga mapatidoe nggau, djăkau tăka la oema, pa'au păkoe nja na mamoha kana pandeàma ndja da lima na djăkau boeri ja na wai la mbăloe. Na tau mini noe kawai mbăda panaboe na nja na tawoeroe la woeroe wai. Na tau mini na mapatidoenja.

Toenanoe bana tăka ka la oema, hiwăna na tau kawini na maweling la lokoe: ha nedita! papoeroe i nja na wai. Toenanoe hida papoeroe nja, ndeda măka ndokoe ndja; mboendăba na na tau lai noe na nimbihoe wiki ha, ndeda măka ndokoe ndja. Tăka hiwăda njoeda da ama bokoel lai noe: na mamoha kana papoeroe nja na woeroeng; tai bana boeri nja la mbăloe kana baha ha da lima na. Tăka hina poeroe njoena na mamoha, hina papoeroenja na woeroeng noena, na măka be nja; hina ngăndi ja hoedita la oema hina pandeàmandja da lima na bana boeri ja la mbăloe. Toenanoe bana boeri ja ka, rehi ndjăpoe nja ka na wai weling la woeroeng hina hoenggoe ja na tawoeroe, tawoeroe noena tawoeroe ămăhoe rara ja. Na eti ${ }^{3}$ na noena I Kahi na hămoe ka bana ita ja na tawoeroe.

1 poeroe tanang of poeroe la tana op den grond komen, uit it huis gaan. De bruid, in 't huis van haar man gebracht, wordt feestelijk ontrangen. Enkele dagen duurt dat, terwijl 't meisje, dat de bruid voorstelt, gesluierd in huis moet blijven. Als slot van de feesten, welke nu een geheelen nacht geduurd hebben, gaat de bruid (d. w. z. het kleine meisje ook) vergezeld van alle vrouwelijke huisgenooten naar de rivier baden en haar eerste kruik water halen. Een teeken dat de feesten zijn afgeloopen en de gewone huiselijke werkzaamheden zijn begonnen.

" a ma bokoel letterlijk "groote vader", en is de de gewoue aanspraak tot hoofden van een familie of van een kampong. De radja vergadert met zijn "ama bokoel" tot 't bespreken van zaken van gewicht.

Een ama bokoel wordt niẹt officieel gekozen, maar bij onderling goedvinden als zoodanig erkend. Wordt hij wat te oud, dan komt van zelf langzamerhand een ander familie-lid in zijn plaats.

3 eti lever, welke door den Soembanees gedacht worden als de zetel van't denken en van 't gevoel. Daarom wordt ook bij offerdieren steeds de lever nagezien.

In uitdrukkingen derhalve als "goed van hart", „blij van gemoed", zal een Soembanees 't woord eti lever, gebruiken. 
Toenanoe bana hadang ka la mbaroe, bana hoenga ka na lodoe, hiwădanja da ama bokoel: mboeloendăba da da tau kawini kareànja na mamoha, kana lo'a patakoe wai. Toenanoe hida padjoeroeng ndăba; bada tăka ka la lokoe hida ihoe mboeloendăba da da tau, da poeroe ndăba la wai; tăka njoena I Kahi ndedi pa.

Tăka njoena na tau mini na makawining ndena pawoewang wiki na; hina piti pareàngganja na karohoe kadita hina hăbăroenja la wai, hamang la mamara. Toenanoe bana hăla ka pahăbăroenja, na tau na mamai pa'ihoe na meti hăla, hawiang na mili, hawiang la mara ja, dăngoe njoena na kawini na papaha na na meti mboe. ${ }^{1}$

Toenanoe bana meti ndăba ka, tăka hina lakoe hina piti ja na lima na: ha Kahi! pawăla wa kata lakoe, hiwănanja. Toenanoe ba ndena katătăkoe hina piti ja na oehoe hajăla hina hăbăroenja la pinoe ihi na, 2 hiwănanja: hawiangoe eti moe nja, hawiang woera moe nja, hawiang tanai moe nja, mboendăba na năhoe na oehoe hajăla na nggănăp ndăba na mandanindja la ihi moe.

Toenanoe hina kădoekoe nja: ha rămboe, hadangoe wa kata lakoe. Toenanoe hina hadang; bana hadang ka hina dandanja. Toenanoe bana tăka ka la oema, na tăka mandalora; hina tama ngăndi ja la koeroeng pangéa da ămang, ba hīna na tama la koeroeng. Na ama jera na dăngoe na ina jera na ndeda pinja, ninja na ana da, na tau kawini.

Tăka hi ninja na eri na noena na tau kawini, anakeàda mini ja; ndena pingoe pahămoeng papaní, ${ }^{3}$ padjoeloe be ja noewawa la tana. Tăka na anakeàda noena hina tama ja la loemboe pangéa na na aja na hina tangara; tăka na tau kawini hina padjoăla nja ja na kahidi kambăkoe koedoe ă ja. Toenanoe hina ngăndi ja hina pa’ita ndja ja da ina na da ama na. Tăka hida karai ja: ha anakeàda! ka nggini papiti ni moe nja na kahidi jeàna? Tăka njoena na anakeàda ndena pingoe papaní.

1 Dat de zielen, de afgestorven zelfs in het doodenrijk nog weer kunnen sterven, blijkt uit meer dan één verhaal.

't Hiernamaals is ook in dit opzicht een getrouwe afsp' cegeling van de aarde.

2 Het strooien van rijst, tot versterking van de zielestof, is ook den Soembanees niet onbekend.

${ }^{3}$ ndena pingoe pahămoeng papani=hij kon niet goed praten; hij was nog niet goed in staat om te praten. 
Toenanoe hiwădanja: ha, lo’a kau wăroenja, djăka nggini papiti ni moe nja; jéa la pira na bana meti na ajam bakoe toe ma doe ja la katikoe noela na noedaloe la lambongoe. ${ }^{1}$ Tăka na anakeàda hina hili lakoe la loemboe pangéa na na aja na hina wŏ pabelinja na kahidi.

Tăka njoena na tau kawini hina padjoălanja ja na hau na kăpoe kaninoe, hina ngăndi ja hina padjoeloe wănja la talora.

Tăka da ina na da ama na hida tandanja na kăpoe kaninoe noena, kăpoe kaninoe na na tau kawini na mameti. Toenanoe hiwăda: ha anakeàda, ka nggi papiti ni moe nja doemoe na, ba tani pa'angoe ma doe nja ha, kăpoe kaninoe, kahidi.

Noena na anakeàda: tau mawŏngga ha, wăna. Tăka hiwăda: lo’a kau wăroenja. Toenanoe hina lakoe la loemboe pangéa na na aja na hina wŏ pabeli nja na kăpoe kaninoe noena.

Tăka hi ninja na eri na na tau kawini na mameti, na aja na na anakeàda mini noena kawai, na mandepingoe papaní. Toenanoe hiwăna: ha aja, tau mini, wŏnda doeta tahăpa, hiwănanja. Na heàma na tau angoe na na tau kawini na ma kapandi la koeroeng, hiwănanja: lo'a kau himboe ja noedaloe la kaloemboetoe nggoe. Tăka hi lakoe na nja. Toenanoe bana bŏwa ja ka na koeroeng, tăka hina ita ja na aja na. Tăka hiwăna: djeà ja na aja nggoe, ni be nja ka. Da rongoe da ina da ama na; da kanjoekoel ndăba; hida lakoe hida rohoe ja hida poedoe-poedoekoe ja. Tăka na ama jera na hiwăna: hau mini lănga tăka kau ă ma, na loeri beli be ja na ana nggoe.

1 Niet alleen kleedingstukken en gouden versierselen, maar ook kleinigheden, persoonlijk eigendom van de(n) overledene, worden mede begraven. 
I. I Rămboe Kahi in 't leven weergekeerd.

$\mathrm{Er}$ waren eens kinderen, welke elkaar jongere en oudere broeder (zuster) noemden. Toen zij volwassen waren, trouwde zijn zuster en haar broeder huwde. Zij baarde een zoon, haar broeder had geen kinderen. Toen dit kind nu groot was geworden, zond men hem dikwijls om gras voor de paarden te gaan snijden, Toen hij langzamerhand er aan gewend was, ging hij om gras voor de paarden te gaan snijden onder een waringin boom en hij sneed aldaar gras voor de paarden. Toen hij pas de eerste maal er was, hoorde hij niet het spreken daar bij den waringin boom. Toen hij teruggekeerd was, schertsten zijn ouders met hem en zeiden tot hem: ha jongen, ga wat paarden-voedsel brengen aan uw oom, wanneer hij morgen een kind krijgt, is 't uw deel, als 't een meisje is, zeiden zij tot hem; wanneer gij hem geen paarden-voedsel gaat brengen geven zij $u$ hun dochter niet. En die jongen antwoordde: als zij 't niet geven, dan laten zij 't maar.

Des morgens vroeg stond hij op en ging paardenvoedsel snijden. Eén à twee maanden gingen voorbij en hij ging wederom paardenvoedsel snijden bij den waringinboom, waar hij vroeger gegaan was. En hij sneed paarden-voedsel aldaar; nadat hij zijn paardenvoedsel op een hoop had gebracht, rustte hij een weinig. Hij nu hoorde menschen, welke praatten en hij zag dat mensch bij den waringinboom, een zeer bejaarde en men zeide tot haar: ha grootmoeder! "Wat zegt gij? zeide de oude. "Kom hier eens aan», zeide men tot haar. En zij liep er aan en men vroeg haar: waar komt gij van daan, zeide men tot haar. En die oude antwoordde: ik kom terug van 't naam geven aan 't kind daarboven; ik zeide van haar, terwijl ik haar een naam gaf: wanneer gij eens zult trouwen, zal u een adder bijten, doodelijk, zeide ík van haar; 't was 't niet — ; ik gaf haar wederom een naam: wanneer de regen $u$ treft, dan zult gij door koortsen er van sterven, zeide ik van haar; 't was 't niet - ; en ik gaf haar wederom een naam: wanneer gij eens zult getrouwd zijn, dan zal uw vader op jacht gaan, uw echtgenoot zal ook meegaan; op de vlakte nu gekomen, steken zij ontelbaar veel 
varkens; als zij teruggekomen zijn, zult gij reeds dood zijn, zij zullen $u$ niet meer in huis aantreffen, een ander zal reeds klaar zijn met u te begraven.

De jongen van zooeven, liet zich zelf niet zien; hij luisterde zeer goed, terwijl zij spraken. Vervolgens zeide de oude: hij, die haar eens zal trouwen, als hij 't maar weet, dan zal zij wel weer in 't leven terugkeeren; wanneer hij wederkomt van 't jagen, dan moet hij geen rijst meer eten in huis, hij moet naar de Kaba Aoe gaan, en meebrengen kleefrijst en droogkokende rijst; de droogkokende rijst, wanneer hij pas is aangekomen, zal hij uitstrooien aan den oever der rivier; maar de kleefrijst, zal hij voorloopig nog laten.

Toen maakten zij een eind aan hun spreken; die jongen van zooeven, van wien wij spraken, wist nu alles; hij zette 't paarden-voedsel op zijn hoofd en ging heen. Toen hij thuis gekomen was, zette hij 't paarden-voedsel neer, hij verdeelde 't eten aan de paarden.

Toen zij nu langzamerhand groot was geworden, zond zijn oom menschen naar zijn ouders en hij zeide: sta mij toch af mijn neef, opdat ik hem late trouwen; geef mij toch goederen, (bruidschat).

En men verzamelde voor hem goederen en men gaf 't hem en zij lieten hun kind gaan. Hij nu trouwde, 't was nog pas 3 nachten, toen zeide zijn schoonvader: welaan, laten wij gaan jagen, zeide hij tot zijn neef.

Zij nu gingen; toen zij nu op de vlakte gekomen waren, wat betreft die vrouw, zij stond in 't geheel niet op; de zon was reeds halverwege haar klimmen, toen zeide haar moeder, terwijl ze slavinnen zond: ha slavinnen, gaat I Kahi daarboven eens wekken, opdat zij de varkens hun eten geeft en de kippen hun voedsel.

Eén der slavinnen klom (in huis) en wekte haar: zij werd niet wakker.

Toen klom haar moeder (in huis) en wekte haar; zij bekeek haar eens goed, zij was reeds gestorven, zij was al stijf. Haar moeder klom nu af ìn de voorgalerij en huilde. Toen de menschen, hare mede-kamponggenooten, 't hoorden, kwamen zij hooren en zeiden tot haar: hoe is 't? zeiden zij tot haar. $\mathrm{Zij}$ antwoordde: mijn kind, dat getrouwd is, is reeds gestorven. En zij riepen menschen om haar te begraven en zij begroeven haar. 
's Morgens vroeg eerst kwamen haar vader en haar echtgenoot. Toen haar vader hoorde den dood van zijn kind, wilde hij in 't geheel niet eten; maar haar echtgenoot lachte, hij schudde van 't lachen; ik ben niets bezorgd, zeide hij.

Toen hij gegeten had bij zijn grootmoeder, zeide hij tot zijn grootmoeder: ha grootmoeder, stamp mij rijst, één zakje droogkokende en één zakje kleefrijst, ik ga de paarden bezien. Toen hij ontvangen had de door hem bevolen rijst, ging hij naar 't huis van zijn eigen moeder en bracht naar buiten 't donkerbruine paard, besteeg het en hij vertrok.

Toen hij nu boven was aangekomen, ging hij niet in de kampong; hij wachtte beneden aan de rivier. En daar kwam een vrouw aan en zij ging en zij baadde in de rlvier aldaar. En die man, van wien wij zooeven spraken, verborg zich zorgvuldig, hij liet zich zelf nog niet zien. Toen zij gebaad had, nam zij haar kruik en vulde die met water en zette ze op haar hoofd en ging heen. Toen de zon koud was ('s middags) keerde zij weder; deze vrouw, was een vrouw met een kind; zij ging en zij baadde; haar kruik plaatste zij op 't drooge. En de man, die zich verborg, nam een handvol droogkokende rijst en strooide 't in het water en hij ging uit op den weg. En die vrouw zag nu dien man; volstrekt niets zeide de vrouw; maar die man, die zich verborgen had, vroeg haar: ha rămboe, wat voor feest heeft men daarboven in de kampong? En die vrouw antwoordde: een bruiloftsfeest is 't; drie nachten slechts is haar man met haar getrouwd, toen hebben wij zijn vrouw weggenomen, zegt men, naar ik hoorde terwijl zij spraken.

Die man antwoordde: hoe is haar naam? Die vrouw antwoordde: I Kahi is haar naam. En de man zeide: hoe lang nog komt zij uit 't huis? Die vrouw antwoordde: naar ik hoorde van de oudsten, terwijl zij spraken, morgen ochtend, zeiden zij, komt zij hier bij de rivier baden. En die man zeide: vul water in uw kruik. $Z_{i j}$ nam die op, zij was niet in staat de kruik op haar hoofd te zetten. En zij zeide: ha oemboe, kom en zet 't mij toch op 't hoofd. De man antwoordde: het zij zoo, als ik 't ben, die 't nu op uw hoofd zet, wanneer gij thuis gekomen zijt, dan moet gij de bruid roepen opdat zij haar handen ophoudt, wanneer gij 't water in den pot giet. De man van zooeven had reeds een ring in de waterkruik laten vallen. De man zet haar (de kruik) op haar hoofd. 
Toen zij thuis gekomen was: zeide de vrouw, die van de rivier kwam: ha daarboven! neem 't water eens af. Zij namen 't af, maar zij waren er volstrekt niet toe in staat; al de menschen aldaar ging zij zelfs langs, zij waren er volstrekt niet toe in staat. En de oudsten aldaar zeiden: de bruid laat haar de kruik afnemen; straks als men 't in den pot giet, laat zij dan haar handen nat maken. En de bruid kwam naar beneden en en nam die kruik af, zij was er toe in staat; en zij bracht 't naar boven in huis en hield haar handen op, toen men ' $t$ in den pot goot. Toen men aan 't gieten was, bijna was er een einde aan 't water uit de kruik, zoo vond zij den ring; die ring was een ring van goud. 't Hart van die I Kahi was blijde toen zij den ring zag.

Toen men 's morgens vroeg opgestaan was en de zon scheen, zeiden de oudsten tot haar: al de vrouwen zullen de bruid begeleiden, opdat zij water ga scheppen. $Z$ ij liepen nu allen achter elkaar op een rij; bij de rivier gekomen, gingen al de menschen baden, zij daalden allen af in 't water; maar I Kahi nog niet.

En die man, die zich verborgen had, liet zich zelf niet zien; hij nam vlug de kleefrijst en strooide die in 't water, evenzoo op het drooge. Toen hij klaar was met strooien, stierven al de menschen, welke waren komen baden, sommigen dreven af met den stroom, sommigen waren op 't drooge, en de vrouw, zijn echtgenoote, stierf ook.

Toen zij allen gestorven waren, ging hij en nam haar hand; ha Kahi! wordt toch wakker, opdat wij gaan, zeide hij tot haar. Daar zij zich niet bewoog, nam hij de droogkokende rijst en strooide die boven op haar lichaam en hij zeide tot haar: een gedeelte zij uw hart, een gedeelte zij uwe longen, een gedeelte zij uwe ingewanden, al deze droogkokende rijst nu make alles voltallig wat niet in uw lichaam is.

En hij schudde haar: ha ramboe, sta toch op, opdat wij gaan. $\mathrm{Zij}$ stond op; toen zij opgestaan was, tilde hij haar op (zijn paard). Toen hij thuis kwam, kwam hij te middernacht; en hij bracht haar binnen in de kamer, hun vroegere plaats, toen bij pas was getrouwd. Zijn schoonvader en zijn schoonmoeder wisten niet, dat hun kind, de vrouw, er was.

En er was nu een jongere broer van die vrouw, 't was een jongen; hij kon niet goed praten, hij speelde maar beneden op derı grond. Die jongen nu, ging onder de plaats van zijn oudere 
zuster en keek naar boven. En die vrouw reikte hem toe een knipmes, zeer klein slechts. En hij bracht 't en liet 't aan zijn ouders zien. En zij vroegen hem: ha jongen! waar hebt ge dat mesje vandaan gehaald? Maar de jongen kon niet praten. En zij zeiden tot hem: ha, ga 't wegwerpen, waar gij 't vandaan gehaald hebt; dit was 't vroeger, toen uw andere zuster stierf, dat ik toch gelegd heb aan 't hoofdeinde van haar hoofdkussen in het graf. En de jongen nu ging wederom onder de plaats van zijn oudere zuster en hij gaf haar 't mesje weer terug. En die vrouw reikte hem toe een spiegeldoosje en hij nam 't mee en speelde er mee op 't plein.

En zijn ouders herkende dat spiegeldoosje, 't spiegeldoosje van de vrouw, die gestorven was. $Z_{i j}$ zeiden: ha jongen, waar hebt gij dat toch van daan gehaald, daar wij 't te gelijkertijd met haar begraven hebben, 't spiegeldoosje, 't mesje. Dat kind: iemand heeft 't mij gegeven, zeide hij. En zij zeiden: ga 't wegwerpen. Hij ging onder de plaats van zijn oudere zuster en gaf haar dat spiegeldoosje terug.

Er was nu een jongere broeder van de vrouw, die gestorven was, een oudere broeder van dien jongen van zooeven, welke niet praten kon. Hij zeide: ha oudere broeder, man, geef mij toch sirih te kauwen, zeide hij tot hem. De echtgenoot van de vrouw, die zich schuil hield in de kamer antwoordde, zeide tot hem: ga 't maar zoeken in mijn sirihtasch. Hij nu ging.

Toen hij de kamer opende, daar zag hij zijn oudere zuster. En hij zeide: dat is mijn oudere zuster, daar is ze! Haar ouders hoorden het; zij kwamen allen toesnellen; zij gingen en omhelsden haar en zij zoenden, zoenden haar.

En zijn schoonvader zeide: werkelijk je bent me een kerel! mijn dochter is weer in 't leven teruggekeerd. 


\section{Maka Ihi Naoe.}

$\mathrm{Na}$ pakiri na na ana laloe: nindja da ana mamila, na meti wăroendja ina da ama da; ngara da noeda da ana mamila: I Oemboe Ndiloe ja na haätoe, tăka na kawini I Rămboe Kahi ja na ngara na; njoena I Rămboe Kahi mama'aja ja.

Toenanoe bana mandai ka bada hăla ka patanindja da ina da da ama da, tăka hi ninja na we bokoel, na parada da ina da da ama da; wē noena, wē talíhoe oeli ma ja. Tăka hina lakoe la woăka tau, na ngangoe watăroe, la mamarau ma ja. Tăka hina ita ja tau măngoe wŏakang, hina piti ja na nimboe dăngoe kabeàla na hina paloehoe ja ndjara na hini kaliti ja.

Toenanoe hina jauwoeloe ja na wē, tăka na wē na kateàkăl la palendi, na loendoeng na pinoe, tăka hina hili kamboeroeng la loălang, Tăka njoena na majauwoeloe ja, na loendoeng na pinoe, na tăngăroe ja, la palendi hau ninja na wē. Tăka hina hili kamboeroeng njoena na tau, kateàkăl beli, na loendoeng na pinoe, na tăngăroe ja, la palendi hau ninja na wē. Na hili kamboeroeng, kateàkăl beli, na tăngăroe ja, ninja la palendi hau na wē. Tăka hina kamboeroeng, na kateàkăl beli, na loendoeng na pinoe hina ngadoe la loălang, na ita ha da oema, tiloe mboea da. Tăka hina kamboeroeng, hina toăma la loălang, la pangéa da da oema. Na tăka la oema hina ita ja na wē, na pajauwoeloe na kawai; tăka hina koădja ja na wē noena; bana hăla ka pakoădja ja, bana meti ka na wē, tăka hina poeroe I Rămboe Kahi la bangga.

Tăka hiwănanja bana pa’ăranja: kanggikina hoe koădja ja na wē nggoe, ba wē ana mamila ja? Tăka hina heàma I Oemboe Ndiloe: "njoengga jeàna ana na I Taroe Tiboe ka, ana na ngga $^{1}$ na ana wini na na ama moe, toena hikoe mai pakoădja ja na wē, na hăla ja da watăr, da oehoe pangandja la woăka nggoe njoengga.

I ana na ngga na ana wini na na ama moe=de zuster van uw vader had mị als zoon.

a n a beteekent niet alleen „kind zijn", maar geconstrueerd met een D a ti v, beteekent 't: „als kind hebben" „iemand als kind beschouwen en aannemen".

Zoo zegt men ook "koe ata nggau" =ik mak u tot slaaf. 
Tăka njoena I Oemboe Ndiloe hina jila ja na wē hina toenoe ja; na hăla patoenoe ja hina dandanja hina băndjăloe ja la bangga. Tăka njoena I Rămboe Kahi hina hē papiti nja pahăpa na, hina wơnja; ndena bihoe. Tăka hina hili tama, na piti ja na kaba kaliangoe hina toe wănja "; na padjoălanja, ndena bihoe pahăpa.

Tăka hina lakoe I. R. K. papiti ja na patoe wăngoe pahăpa Marapoe, tanga watil ${ }^{2}$ ămăhoe rara, hina wŏnja.

Tăka njoena I O. Nd. hina kē ja hina hăpa.

Tăka I O. N d. hina wŏnja kaloemboetoe I R. K. ; tăka njoena I R. K., ndena bihoe pahăpa la kaloemboetoe na I O. Nd. Tăka hiwăna I O. Nd.: njoengga koe karéa nggau la oema nggoe, hiwănanja.

Tăka I R. K. é ndakoe bihoe. Tăka I O. Nd.: kanggiki na hi ndau bihoe, pangéa papiti ma nggoe nja papaha nggoe!

Toenanoe hina hadang I $\mathrm{O} . \mathrm{Nd}$., hina höawăkoe ja na wē; tăka hina bika padoea ja; bana hăla ka paberinja na we, tăka hina kadipoe ja la padoea na; na kahaundja da wihi malamiri na, na kahaundja da wihi mangiloe na; na katikoe na na kadipoe ja; na ri karaha na na ălindja; tăka hina paindja da wihi wē, wihi malamiri na dăngoe wihi mangiloe na, hina papapandja.

Tăka hiwăna I O. Nd.: poeroe wa, Kahi, talakoe. Tăka na heàma I R. K. hiwăna: ka na eri nggoe, oemboe, kareànja wămoe? Tăka na heàma I O. Nd.: piti ja na eri moe, kau doeha ja la tana kana meti; nggăra toe ja hi kareànja na anakeàda, tai woenggoe ndjara!

Tăka hina heàma I R. K.: napa kadiroe, oemboe, kakoe tăngăroe pahămoe ja na eri nggoe, hiwănanja. Toenanoe njoena I R. K. hina piti ja na kakoeta dăngoe na toloe wē doea lawăhoe da; na halawăhoe la kalai na nja, na halawăhoe na kadipoe ja; na hakadipoe na toe ja la kawana na, tăka na hakadipoe na tiwăloenja la toeba na. Tăka hina piti ja na maka ihi naoe ${ }^{3}$ dăngoe na loenga.koera moeki + hina băndjăloe

\footnotetext{
1 wănja = dit wăngoe heeft steeds een instrumentale beteekenis en wordt 't best vertaald door een praepositie: met, er op, er in, er mede, etc.

2 tanga watil = sierlijk gevlochten, plat mandje, als mpresenteer bordje" gebruikt. Men geeft er den bezoekers sirih in aan.

s maka ihi naoe= de tol , ihi naoe". De beteekenis van dit woord "ihi naoe is mij onbekend. 't Wordt echter in dit soort verhalen, steeds aan $\mathrm{maka}=\mathrm{tol}$, toegevoegd en schịnt dus een bịzonder, mooi soort aan te duiden.

4 loenga koera moeki: eigenlịk een onmogelijke samenstelling van loenga tollentouw en koera moeki fijne, dunne ketting.
} 
ha la karaha na. Tăka hiwăna I Oemboe Ndiloe na makoădja na wēe, hiwănanja: ha Rămboe Kahi, poeroe wa kata lakoe!

Tăka na heàma I R. K.: $\bar{a} \bar{a}$; bana hăla ndăba ja ka papamătoe ja na eri na, da papadjoeloe wăna, da pangangoe, tăka hina piti ha da woea kamănggihoe, ha'oepoe da. Na piti ja na tera rara, hakadipoe na, tăka hina poeroe li la kaheli bokoel. Na toăma la pindoe kaheli bokoel hina hira ja na tera rara: Oèmboe Ndiloe, ini ja na maoe nggoe,

$$
\text { dili ha da roekoe nggoe. }
$$

Tăka hina poeroe loendoeng la bangga; na hili hira ja na tera rara, hiwăna: Oemboe Ndiloe, in i ja na maoe nggoe,

dili ha da roekoe nggoe.

Tăka hina heàma na ana rara: $\bar{a}$, ōē.

Toenanoe hina poeroe loendoeng la tana, na tondoendja da woea kamănggihoe la toeba pangéa papoeroe na; bana hăla ha ka patondoendja, Oemboe Ndiloe, hiwănanja,

$$
\begin{aligned}
& \text { in i ja na maoe nggoe, } \\
& \text { dili ha da roekoe nggoe. }
\end{aligned}
$$

djăka nggini ka, koe hărăngoe ningoe; djăka tinoe nggoe nja, oe toekoe wăngga maka ${ }^{1}$; pata ja na wihi bai nggoe, na kamba tinoeng oe hira ja.

Tăka hina heàma na ana rara: $\bar{a}$, ōē, hiwăna.

Toenanoe na hili lakoe I R. K., na toăma la pindoe koătăk, tăka hina hira ja na tera rara: Oemboe Ndiloe, hiwănanja,

$$
\begin{aligned}
& \text { ini ja na maoe nggoe, } \\
& \text { dili ha da roekoe nggoe. }
\end{aligned}
$$

Tăka na heàma na ana rara: $\bar{a}$, ōe, wăna.

$\mathrm{Ka}^{2}$ lakoe da nja ka doeda ${ }^{3}$ I R. K. dăngoe I O. Nd.; da tăka ka doeda la pangéa da.

1 oetoekoe wăngga maka = werp mij met den tol. Dit instrumentale wăngoe trekt tot zich 't object, dat de handeling ondergaat en niet 't voorwerp, waarmede de handeling vorricht wordt.

iwi papaloe wăngoe = rottan om mee te slaan.

iwi papaloe wănja tau = rottan om menschen mee te slaan.

a ka, deze conjunctie beteekent hier: vervolgens, daarna.

s doe, dit bijwoord van nadruk, wordt, wanneer 't behoort bij een pronomen, steeds geconstrueerd met een pron. person. sufflix, als bij een verbum: wănggoe doekoe njoengga=ikzeg; wăda doeda njoeda= zij zeiden. imbéni ngga doekoe= gịj zijt boos op mij. wăna doe $\mathrm{ng} \mathrm{ga}=$ zeide hij tot mij.

Alleen bị njimi gebruikt mendi: wămi dimi njimi gijliedenzegt. 
Toenanoe ba talioe da ka doeda I R. K. dăngoe I O. Nd., tăka na kakoeta hina dedi ja tau, hina dandanja na anakeàda, hina pahoehoe ja; tăka na toloe wē na manahoe ja hina pahoăbanja.

Toenanoe bana ngeri matoea-toea ka hakoedoe, tăka na ina kakoeta na hi piti na nja na maka ihi naoe dăngoe na loenga koera moeki, hina wornja ja. Tăka I O. Nd. hina poeroe la tana, hina wingoe ja na maka noena, tăka hina laoenja la pindoe.

Tăka hina lakoe papiti beli ja, hina hē beli ja la kaheli, hina peàkanja na ina kakoeta na, hiwănanja: ina, koe pingoe ka doekoe pawingoe ja na maka nggoe. Tăka hina heàma na ina kakoeta na: na hămoe doe!

Toenanoe hili hau lodoe ${ }^{1}$ na hili poeroe ngăndi ja i na maka, na loehoe la ngaroe pindoe ${ }^{2}$ koătăk, hina ita ja he'au na na manoe.

Tăka I O. Nd. hiwăna: hō, djăka pawoeloe na i ina, i ama ja na manoe nina, koe handăka păkoe nja ${ }^{3}$ tai koe wănja maka. Tăka hina loenga ja na maka na, hina laoenja na manoe noena; na ngăna ja na manoe, na meti meàmang; bana tăngăroe ja na manoe noena, na kawérakoe ma na katikoe na bana ngăna ja maka.

Toenanoe hina piti ja na manoe noena, hina ngăndi ja la oema, hina pa'itanja na ina na. Tăka hiwăna na ina na: ka nggini manoe ningoe ja, ${ }^{4}$ oemboe? Tăka hina heàma $\mathrm{IO} . \mathrm{Nd}$ : manoe pawoeloe na $\mathrm{i}$ ina, $\mathrm{i}$ ama ja.

Tăka hili hau lodoe hina karai ja na ina na: ndaningoe bălang, kau bai nda, wănggoe lăti? Tăka hina heàma na ina na:

1 hili hau lodoe $=$ wederom op een anderen dag. 't Pron. indifin. hau, dat staat achter 't substantief, wordt alleen in de verbinding met een woord dat een tijdsbepaling te kennen geeft, er vóór geplaatst. Zoo zegt men la oema hau =in een ander huis; maar la hau ndaung $=$ in een ander jaar.

? ngaroe pindoe $=$ de deuropening; pindoe is de deur zelf.

3 koe handăka păkoe nja =ik zal 't straks maar eenmaal doen met hem (n.l. den tol) als ik gebruik den tol.

4 ka nggini manoe ningoe ja= waar komt de kip vandaan?

't Vragend bijwoord van plaats "nggini", wordt geconstrueerd met ningoe, wanneer men een beweging ergens heen of ergens vandaan wil te kennen geven. Zoo zegt men:

nggi lakoe ningoe moe = waarheen gaat gij ?

nggi papiti ningoe moe= waar hebt ge 't vandaan gehaald?

Dl. 68 . 
ninja hakoedoe dăng da loe'a ai ${ }^{1}$, măta kakoe bai nggau ha ka bălang. Tăka hina heàma I O. Nd. hiwănanja: hongoe nda ha da kambambang ${ }^{2}$, waloe mboea da.

Toenanoe bana hăla ka pahongoe ha da kambambang noeda, tăka hina peàkanja I O. Nd: da memi ka nida da bălang. Na heàma I $\mathrm{O}$. $\mathrm{Nd}$.: napa haromoe kakoe lakoe mbaroe palo'a patăngăroe ja na pada ${ }^{3}$ ndjara.

Toenanoe na hadang ka la mbaroe, hina kanoăma, tăka hiwăna na ina kakoeta na: ha ina, măta kakoe lo'a patăngăroe ja na pada ndjara, djăka ningoe doe ndjara na dăngoe karămbo'a.

Toenakanoe lakoe na nja ka njoena I O. Nd., hina tăka la ngarăngia; tăka hina ita ja na he'au na ndjara la karaha ngarăngia. Tăka hina woendjoeloe nja likoe na na maka na; tăka hiwăna: hō, djăka pawoeloe na i ina, i ama ja nina na ndjara, koe handăka păkoe nja tai koe wănja maka.

Tăka hina laoe nja na maka na, na ngăna ja, na meti meàmang ma na ndjara. Tăka hina lakoe njoena I O. Nd., hina hoăwăkoe wănja kahidi, hakoedoe ă bana hoăwăkoe ja; na piti ja na eti na; bana hăla ka papiti ja na eti na hina hili lakoe, na marau hakoedoe.

Na hili ita ja he'au na na karămbo'a, tăka hina woendjoeloe nja likoe na na maka na, tăka hiwăna: hō: djăka pawoeloe na i ina, i ama ja nina na karămbo'a, koe handăka păkoe nja, tai na meti meàmang, koe wănja maka.

Tăka hina laoenja na maka na, ngăna ja na karămbo'a, na katikoe na; na meti meàmang. Bana meti ka na karămbo'a hina lakoe njoena I O. Nd, na wanga ja na ngaroe na na karămbo'a, hina kadipoe ja na lăma na hina ngăndi ja.

Tăka na hili lakoe, na marau ki hakoedoe, na ita ja na paraing bokoel hau na *; tăka hina ita ha da tau da malo'a

1 ninja hakoedoe dăng da loe'a ai=er is een weinig van ze, de aardwortels. Dit dăng= genit. van 't pronom. plural., gesloten met een nasaal. Waarschijnlijk staat deze nasaal $\mathrm{ng}$ in verband met 't voorgaande ningoe. Zoo zegt men ook: măngoe oemang = eigenaar van 't huis. Een herhaling dus van de voorgaande $\mathrm{ng}$, vlg. Aant. 2, pag. 83.

${ }^{2} \mathrm{kambambang}=$ een soort gebak van rijst, maïs en pisang.

${ }^{3}$ pada ndjara = weidereld voor paarden. 't Woord padang heeft hier zijn nasaal laten vallen van de volgende nasaal $n d j$.

4 hau is hier hulptelwoord: één; wordt dus geconstrueerd als een substantief: hau na =één er van.

na paraing hau, zou beteekenen: een andere kampong. 
patakoe wai, hina karai ha: nggăra oela da da anakeàda noedita la paraing, hiwănandja.

Tăka da heàma da malo'a patakoe wai : anakeàda mapamakang ha doeda. Tăka njoena I O. Nd. hiwănandja: ka ni, djăka njoengga koe hê la paraing, na mbeni ihoe na marămba paraing?

Tăka da heàma da malo'a patakoe wai: kanggikina hina mbeni, lo'a pamanganga ndjara na bădi, hina mbeni.

Toenanoe hida lakoe ka da malo'a patakoe wai, tăka njoena I O. Nd. na lakoe pakawini ndja da ${ }^{1}$ hinggi na, da tera na, da kabeàla na; na kawinindja la koeboe watoe. Bana hăla ka pakawini ndja, tăka hina piti ja na katări, hina kalamboeng hama toena na tau na mandaningoe ndokoeng ${ }^{2}$ hinggi na.

Tăka hina piti ja na maka na, hina hē la paraing. Na tăka la kambata ${ }^{3}$ hina tăngăroe watoe madjangga pamandapoe ningoe; bana ita ka watoe madjangga hina tama loendoe ja; tăka hina mandapoe la pinoe watoe, hama toena na anakeàda na pahăla paroehing koemboer tana. Tăka hida ita ja da anakeàda da mapamakang, tăka hiwăda: nggamoe ja ihoe nedita la pinoe watoe, na haboenggoetoe mănoe mănoe. Tăka njoena na haätoe na anakeàda: ha, doe moe nā dita! mai kau, kata pamakang, hiwănanja.

Tăka na heàma I $\mathrm{O} . \mathrm{Nd}$ : ai, napa tai njimi i mbeni ngga doekoe; ndakoe bihoe, wăna I $\mathrm{O} . \mathrm{Nd}$. Tăka da anakeàda da mapamakang: ha, mai kau wa njoena! +

Toenanoe njoena I O. Nd. hina poeroe ja weli ditang la pinoe watoe, tăka hiwăna: măta kakoe wingoe mangiloe păkoe njoengga, njimi mboeloendăba mi kawăra toengoe ndăba. Toenanoe: $\bar{a} \bar{a}$, hiwăda da anakeàda dangoe.

Tăka hina wingoe ja njoena I O. Nd., tăka hida toengoe ndăba; ndeda ngăna ja na maka na njoena I $\mathrm{O} . \mathrm{Nd}$. bada toengoe.

$1 \mathrm{da}$ : wanneer bij een verbum meerdere enkelvoudige substantiva worden gebezigd, neemt men gaarne 't lidwoord in 't meervoud.

${ }^{2}$ na mandaningoe nd okoeng $=$ de nasale ng., vlg. aant. 1, pg. 82.

${ }^{3} \mathrm{kambata}=$ vóór elke kampong is een open ruimte, meestal omheind en iets lager gelegen, van waar men een ver uitzicht heeft, zoodat men vriend of vijand van verre kan zien naderen. Hier wachten vreemdeling of onderhandelaars, totdat zij toestemming krijgen om in de kampong zelf te komen.

' njoena = bijwoord van nadruk; evenals wa. 't Soembaneesch is zeer sterk in 't gebruik van dergelijke woorden. 
Tăka hiwăna I O. Nd.: ba tanggoe wa doekoe bakoe toengoe; tăka njoena I O. Nd. na marau ndja da maka hakoedoe, tăka hina toengoe, na ngăna ha da maka noeda, da mbera ndăba ma.

Toenanoe njoeda da anakeàda da măngoe makang da mbera kawai, hida jăpa ja njoena I. O. N d., hida hondoe wănja likoe, hida hondoe ja la loemboe aœ '; pangangoe ndeda wŏnja; djăka na manahoe ka măngoe oemang, na patihi ja na wai mbana, hina boerinja I O. Nd. la loembae aœ. Tiloe mboea lodoe, patoe mboea lodoe na, tăka njoena I $\mathrm{O} . \mathrm{Nd}$. bana pădăng ka katioe katilăk katikoe, tăka hiwăna: hē wa doemoe wai, kada halinding ndăba da aloe, da ngohoeng.

Tăka hina hē na wai hina taloemboer ndăba nja na paraingoe; mboeloendăba da da aloe, da ngohoeng, da ndjara, da wē, da kamămbi da halinding ndăba.

Tăka hiwăna njoena măngoe oemang: ha oemboe nedaloe la loemboe aœ, ămboe toemoenoe, na wawa ja na eti moe na makaraœ; djăka na wawa ja na wai jeàna na mahē, njoengga koe wŏnggau ata hau paraing. Tăka njoena I O Nd.: wawa beli kau doemoe wai. Bana wawa ka ja na wai, tăka hiwăna na măngoe oemang: măla năhoe koe wŏ meàma nggau ha da ata, da papeàka nggoe?

Tăka hiwăna njoena I $\mathrm{O} . \mathrm{Nd}$.: napa ka, djăka koe beli ka, kakoe lakoe li ka papiti ha. Toenanoe loehoe na nja ka weling la paraingoe noena. Tăka hina lakoe papiti ha da hinggi na, da kabeàla na, da tera na, da kaloemboetoe na dăngoe da bălăngoe na; pihoe mboea ki da ka da kambambang.

Toenanoe bana hăla ka patera, na kalamboeng, na hili lakoe. Na lakoe, na ita ja na hau na paraing, laloe bokoeloe ma ja. Toenanoe bana toăma ka la pamangahoe ${ }^{2}$; hina ita ha da malo'a patakoe wai.

Tăka hina pa'ărandja: ka nggăra oela na noedita la paraing, hi laloe remi bakoe rongoe ja. Tăka hiwăda njoeda da tau da

1 la loemboe aœ = onder de stookplaats. aœ is niet alleen a sch, maar wordt ook gebruikt voor de stookplaats zelve.

2 la pamangahoe=dit pa is plaats bepalend, en 't wil dus zeggen, de plaats waar men giet. (n.l. djagong, etc.) 't Wordt gebruikt in onderscheiding van de tuinen, welke gedurende den regentijd slechts bebouwd worden; pa nangahoe zijn dus de tuinen, gelegen aan den voet van een kampong, aan den oever eener rivier. Men gebruikt ook wel 't woord mondoeng dat eigenlijk beteekent; de lage rivier oevers, welke bij bandjir onder loopen; wat wij nuiterwaarden" zouden noemen. 
malo'a patakoe wai: ai, anakeàda mapamakang ha doeda. "Ka ni, djăka talo'a doeta, na mbeni ihoe măngoe paraing?

Tăka hida heàma njoeda da malo’a patakoe wai: ndé’ă, ndenă mbeni ă măngoe paraing.

Toenanoe njoeda da malo'a patakoe wai, lakoe da nja ka doeda, tăka njoena I O. Nd. hina lakoe pakawinindja na hinggi na, na tera na, na kabeàla na, na kaloemboetoe na, mboeloendăba da na kawinindja la koeboe leàngoe. Bana hăla ka pakawinindja, hina piti ja na katări na pakalamboe na la paraing na kawoenga tăka na. Tăka hina lakoe, na toăma la kambata, tăka hina ita ja na watoe poeda, hama mboăla jang bokoeloe na.

Tăka hina lakoe, na mandapoe haboenggoetoe lai noe.

Tăka njoeda da anakeàda la paraingoe noena hida ita ja njoena I O. Nd., hiwăda hawiangoe: tăngăroe ja neloea na anakeàda, hama toena na méo roemba, na pawoeloe ahoe! Tăka hiwăda hawiang: ămbi paní toenanoe, angoe nda patau ja, ămbi laloe pa’ănggaloeng mi njimi! Tăka hiwăda hawiang: ha eri, mai kau nămoe! Tăka hiwădanja: tapamakang, wăma doema hima pa'aunggau. Tăka hina heàma njoena I O. Nd.: bakoe pakakanja la eti nggoe, tai djăka pamakang, nda karaœ da eti mi njimi? Tăka hida heàma njoeda hawiang: kanggikina hita mbeni noe, pamakang wa njoena! Tăka hiwăna I O. N d.; măta koe bata mangiloeng, njimi mboeloendăba mi kawăra toengoe ndăba, ămbi pateànja bana mbăda. ${ }^{1}$

Tăka njoeda mboeloendăba da da anakeàda: măla ka.

Toenanoe njoena I O. N d. hina wingoe ja na maka na, da toe ja na maka noena, haätoe ndaningoe mangăna ja. Tăka hiwăna njoena I O. Nd.: bata wa ngga doekoe, kakoe toengoe.

Toenanoe njoeda da anakeàda hida wingoe ndăba ma ha da maka da. Tăka njoena I O. Nd. hina laœnja na maka na, da mbera ndăba ma da maka noeda. Bada hăla ka pambera da maka da, hida wăhi ja na maka na I O. N d. dăngoe na loenga koera moeki, hida băndjăloe ja la makawining.

Tăka hida jăpa ja, da painja, hida hondoe ja la ngéa papoeroe; djăka ningoe tau mapoeroe la tana, na dili ja; na mahē la

1 ămbi pateànja bana mbăda=wacht niet op hem, totdat hij uit (gedraaid) is. - Een typiseh gebruik van de conjunctie $\mathrm{b} a=$ terwijl. Men wil zeggen: terwijl hij draait en uitgedraaid is.

napa păkoe bakoe beli ka= wacht maar, tot ik teruggekeerd ben. 
kaheli na dili ja. Tăka na roedoeng hina loedoe njoena I O. Nd.: oe wŏngga nja

loe ma wŏngga nja

na maka ihi naœ nggoe,

na loenga koera moeki nggoe;

loemoe nggoe nja I Kahi

ana wini nggoe;

ini ja na maœ nggoe,

bawăna doe ngga;

dili ha da roekoe nggoe,

ba wăna doe ngga;

bana hira ja na tera rara,

bana tondoendja

da ha'oepoe kamănggihoe

la toeba papoeroengoe;

toena hikoe kapata nja roekoe na.

Tăka hina rongoe njoena măngoe oemang na anakeàda nina: ningoe pahimboe na, hămoe djăka tawŏnja ja na maka na, wăna.

Tăka hiwăna măngoe oemang: tapalohoe nja bădi, ata hau parai wăka.

Hida piti ja na maka na, hida wŏnja ja, dăngoe na loenga koera moeki na. Tăka hida karai ja hiwădanja: nggăra pamboehang moe njoemoe, djăka mapalohoe nggau? Tăka hina heàma njoena I $\mathrm{O} . \mathrm{N}$ d., hiwăna: na pamboehanggoe njoengga, rongoe $\mathrm{ja}$, ata hau parai wăka, patoekoe lomboe ${ }^{1}$ harata, ndjara hămoe lima băba, karămbo'a kalimboe mini tiloe băba, roeha da mandedi toemboe da kadoe da hakamboeloe lima; didi hang da pakarai nggoe, djăka măka doe kau palohoe ngga.

Tăka njoena măngoe paraing: ndjala ma nggoe nja doekoe, njoengga koepalohoe nggau, hama toeda da patiki moe kawai.

Tăka hida karai ja hiwădanja: măla năhoe palohoe ma ngga wămoe, na lodoe năhoe? Tăka hina heàma njoena $\mathrm{I} \mathrm{O} . \mathrm{Nd}$.: napa păkoe bakoe beli ka, kakoe lakoe li ha ${ }^{2}$ ka papiti ha.

\footnotetext{
1 patoekoe lomboe=gesmeed door Lomboe. Dit zijn oude mamoeli's (gouden oorhangers) van zeer ouden datum en door een zekeren legendarischen Lomboe vervaardigd. Ze hebben soms een waarde van 2 à 300 gulden.

2 kakoe lakoe li ha ka papiti ha = dan zal ik er bij aangaan, om ze te halen. Lakoe li=ergens aangaan; bij wie of wat men aangaat, wordt geconstrueerd met la: lakoe li la oema $\mathrm{ng}$ goe = ga bij mij thuis aan. Hier echter vinden wij een Accus-vorm van 't pronomen, ziende op 't object dat gehaald zal worden.
} 
Toenanoe na loehoe ja weling la paraingoe noena; hina lakoe li papiti ha da hinggi na, da tera na, da kabeàla na, da kaloemboetoe na, hina kalamboeng, na tera. Toenanoe na hili lakoe; na hili ita ja na paraing na hau, paraing tau mamila ja; noedaloe la paraingoe na dangoe na tau na, ' hakamboeloe nomoe ă ha, papohoeng kawini, tau mini dăngoe da anakeàda.

Tăka hina ita ja na tau kawini, ${ }^{2}$ na malo'a patakoe wai, makaweàda ja, da woea ngăndoe na da mbăpoe ka, na loenggi na na bara ka, hama toeda da kaka. Tăka hina karai ja: ha ăpoe, ka nggi lo'a moe nja nā? Tăka hina heàma njoena na makaweàda: e lo'a nggoe nja patakoe wai ă doekoe.

Tăka hiwăna njoena I $\mathrm{O} . \mathrm{Nd}$ : noedita la paraingoe laloe kahăna ja. Tăka njoena na makaweàda hina heàma: ndaningoe ă tau na noedita la paraingoe, anakeàda ningoe matiloe, ningoe mapatoe ă. Tăka hiwănanja njoena I O. Nd.: ka ni, djăka talakoe li, tapamakang, djăka wănda ndja? Tăka hina heàma njoena na makaweàda: kanggiki na hi ndeda bihoe, ba padjoeloe be ha năhoe.

Toenanoe lakoe na nja ka doena na makaweàda. Tăka njoena I O. Nd. hina lakoe li pakawini ndja da hinggi na, da tera na, mboeloendăba da da pangăndi na. Tăka hina piti ja na katări na pakalamboe na la kangéau la wăda modoeng Tăka hina lakoe; na tăka la pindoe hina tăngăroe ja hina ita ha da anakeàda da mapamakang, da doea ă. Tăka hina lakoe hina mandapoe la bangga. Na tăka njoena na măngoe oemang, na paní kanggoeroekoe la kaheli: " ka nggini ă na anakeàda ningoe ja ihoe? laloe manandangoe ja hinggi padoekoe na, hinggi komboe; hinggi pakalamboe na, hinggi wai ămăhoe. Tăka hida poeroe ngăndi ja pahăpa na: ka jéa ana marămba! Ka nggini lakoe ningoe moe nja? "Hălătoe nggoe nja tana.» Tăka njoeda da anakeàda da mapamakang: $\bar{a}$ ha oemboe! na maka moe laloe manandangoe ja; măla kata pamakang!

1 na dangoe na tau na = het rele-zijn der menschen er in; ('t aantal menschen er in.)

2 tăka hinaita ja na tau kawini =en hij zag een vrouw.

't Bepalend lidwoord na, wordt soms ook gebruikt als „onbepaald". Maar geheel "onbepaald" is die vrouw toch niet, want er volgt een heele beschrijving op.

$3 \mathrm{kaheli}=$ de vloer in huis, hooger gelegen dan de voorgalerij; $1 \mathrm{a}$ kaheli is dus 't best te vertalen door: "in huis", in onderscheiding van "la bangga", in de voorgalerij. 
Tăka hiwăna njoena I O. Nd.: na maka nggoe laloe madja ja, na reàngga na mbera. " $\mathrm{Ai}$ ha, măla kata kamanja!»

Tăka njoena I. O. Nd.: djăka toena, măta koewingoe mangiloe păkoe njoengga. Tăka hiwăda da anakeàda: măla ka, na maka moe njoemoe, tai na mbera kapoe-poerăkoe.

Toenanoe hina wingoe ja na maka na njoena I. O. Nd., tăka njoeda da anakeàda da madoea hida toengoe; ndeda ngăna ja. Tăka njoena I. O. Nd.: bata ngga wa doekoe kakoe toengoe, ba padjoeloe ă nda nja, ămbi mbeni doe, ai! Tăka njoeda hida wingoe ha da maka da; tăka njoena.I. O. Nd. hina toengoe, hida mbera ka da maka da da anakeàda noeda, de kaboe kapoe-poerăkoe ma. ${ }^{1}$

Tăka da anakeàda noeda da madoea: ai ha, mănăngoe ja ka na maka ihi naœ, laloe manandang ja ka, măla kata wăhi ja.

Tăka hida jăpa ja I. O. Nd., hida hondoe wănja likoe, hida ngăndi ja la toeba ngéa pahē na na tau. Na lodoe na roedoeng, na tau na mapoeroe la tana na dili ja, na tau na mahē la kaheli na dili ja.

Tăka na mandalora njoena I. O. Nd. na panawa hiwăna:

wŏngga nja na maka ihi naœ nggoe,

na loenga koera moeki nggoe;

wŏngga, loe ma wŏngga nja ;

kapata nggoe nja roekoe na,

kanoeka nggoe nja ji oe na; ${ }^{2}$

I Kahi na ana wini nggoe

ba ngaha moe pangiangoe

la lokoe li

la ănda pala.

Tăka njoena na măngoe oemang na katătăkoe ba mahoeroe i na nja. Tăka hina hadang hina patinginja, tăka njoena I. O. Nd. :

nde woekoe nggoe

pali lai jehoe;

ba ngaha na

pali patodoe

I Kahi na ana wini nggoe.

1 kapoe-poerăkoe $=$ kort en klein. Komt alleen voor in deze reduplicatievorm; evenals ka roe-roeng goetoe, dat ook beteekent „kort en klein".

${ }^{2}$ kapata $\mathrm{nggoe} \mathrm{nja}$ roekoe na,

kanoeka nggoe nja jioe $n a=$ het voetspoor naspeuren en (het spoor) van de tong, (waar 't beest gegeten heeft) nagaan. Vaste uitdrukking voor 't opsporen van verloren beesten. 
Tăka njoena na măngoe oemang na patingi pahămoenja; bana hăla ka parongoe ja, tăka njoena I. O. Nd. na păndjang ka papanawa.

Toenanoe hina hadang la mbaroe hina karai ja: ha oemboe, nggăra pahimboe moe? Na heàma njoena I. O. N d.: himboe nggoe nja I. Kahi, ana wini nggoe, hiwăna. "Djăka toena, măla kata wăkăhoe ja, hiwăna na măngoe paraing. Hina hoeroeng na haätoe na mini ătăl, na wăkăhoe ja, ndena măka nja $;{ }^{1}$ da likoe laloe djăritoe ha. Na hoeroe ndăbang na maninja la paraing lai noe, ndeda măka ndokoe nja pawăkăhoe ja. Tăka hi ninja na ama bokoel: kanggikina hi ndema măkandja da likoe pawăkăhoe ha? Tăka hina heàma njoena I. O. N d.: palohoe doe ngga bădi, hina măkandja pawăkăhoe ha.

Tăka hina heàma njoena na ama bokoel; nggăra papalohoe wănda nggau ka ba tau mamila ma doeta. Tăka hina heàma njoena I. O. N d.: djăka ndaningoe papalohoe wămoe, wŏngga bădi haätoe marămba loendoeng. Tăka njoena na ama bokoel: marămba na lai jehoe la paraing ndaningoe. Tăka na heàma njoena L. O. Nd.: madja ka toenanoe, mata kakoe ata nggau ka mboeloendåba moe mangéangoe la paraing lai jehoe. Táka njoena na ama bokoel na heama: $\bar{c}$ ndakoe bihoe djăka toenanoe; mboeloendăba ma njoema mapaloe pameti kămoe njoemoe. Taka njoena I. O. Nd. na heàma: ămboe paní toemoenoe. Taka hina heàma njoena na ama bokoel: madja ka toenanoe, pindi pamboehang moe, hỉwănanja. Tảka hina heàma njoena I. O. Nd.: wöngga ndjara miting katikoe, hiwănanja oengalang pawăkăhoe ha da likoe, da tawảkăhoe. Taka hina heàma na ama bokoel: ninja na ndjara miting katikoe la mboămang. Taka hina wakahoe ha da likoe, da tawăkăhoe. Tăka njoena na ama bokoel: măla wơ meàma nggau nja năhoe na ndjara miting katikoe? Tăka hina heàma njoena I. O. Nd.; măta koe beli ka bădi, kakoe lakoe li papiti ja.

Táka hina lakoe njoena I O. Nd., na loehoe ja weling la paraing.

Taka hina lakoe li papiti ha na hinggi na, na tera na, na kaloemboetoe na, mboeloendăba da ka doena da pangăndi na. Bana hăla ka patera, pakalamboeng, hina hili lakoe.

\footnotetext{
${ }^{1} \mathrm{mak}=\mathrm{k}=\mathrm{in}$ staat zijn (physiek); waartoe men in staat is, staat in den Datief-vorm.

na măka ndja da likoe pawhkhhoe ha=hij was in staat om de touwen los te maken.
} 
Tăka hina ita ja na paraing bokoel; na tăka la pamangahoe, tăka hina ita ha da ana karia, tau mapatoe ha, da malo'a patakoe wai. Da kawini nđeda bada lo'a patakoe wai, hīna da loehoe weling la pindoe, loedoe ma da nja, kakălăkoe ndeda păndjang.

Tăka hina karai ha: ha rămboe, nggi weli mi njimi? Tăka hida heàma da tau kawini: weling ma la paraing noedita, hiwădanja. Tăka hina heàma njoena I O. Nd.: la paraingoe jeàna bakoe rongoe, laloe remi ja. "Lănga tăka, hiwăda da tau kawini, noewang naingoe ma na ${ }^{1}$ bana remi, ndena păndjang. Tăka njoeda da tau kawini, lakoe da nja ka patakoe wai. Tăka njoena I O. Nd. na lakoe li la oămang bokoel, hina kawinindja da hinggi na, da tera na la koeboe ai; tăka hina piti ja na katări, na pakăli pakalamboe ma na, tăka hina hē la paraing.

Toenanoe njoena na tăka la pindoe hina ita ja tau na matondoeng ana mongoe, na mareàndja lamba. Tăka hina tama njoena I O. Nd.; na tăka hoedaloe la paraing, tăka njoeda hawiang da anakeàda pamakang da nja la hambeli oema. Tăka njoena I O. N d. hina lakoe la mapatondoeng, hina mandapoe lai noe. Tăka njoeda da anakeàda dangoe hida ita ja njoena I O. Nd., hida lakoe toăma ja hida karai ja: ka nggi weli ni moe njoemoe? Tăka njoena I O. N.d. hina heàma: weli nggoe pamangahoe, hiwănandja. Tăka da heàma da anakeàda dangoe: măla kata pamakang. Tăka njoena I $\mathrm{O} . \mathrm{Nd}$. hina heàma: ba remi i nā ja năhoe, da mbeni doe da mamatoea.

Tăka njoeda da anakeàda hida heàma: mătanja ka kana remi, njoeta tapamakang. "Măla ka kata pamakang ka doena, wingoe mangiloe păkoe njoengga bădi.» Da heàma da anakeàda dangoe: măla ka. Tăka hina wingoe njoena I $\mathrm{O} . \mathrm{Nd}$ : : mboeloendăba mi njimi kawăra toengoe handăkang. 'Tăka njoeda da anakeàda da kakikoenja na papaní na njoena I O. $\mathrm{Nd}$., da toengoe ndăba, ndeda ngăna ja. Tăka njoena I O. Nd. na piti ja na maka na: bata ngga wa doekoe. Mboeloendăba da da anakeàda hida wingoe nja; tăka njoena hina laœnja na maka na, da mbera hapăroe ma da maka da.

\footnotetext{
${ }^{1}$ noewang naingoe ma na= onafgebroken, zonder ophouden.

noewang = aanlasschen $-\mathrm{nai}=$ de lengte naad, van een stuk goed, dat aan elkaar genaaid is in de lengte. (niet in de breedte.) Deze vaste uitdrukking voor „onafgebroken", wil dus letterlijk zeggen: de lengte-naad van (een stuk goed) is zonder einde aungelascht.
} 
Toenanoe bada hăla ka pambera da maka da hida wăhi ja na maka na $\mathrm{I} O$. $\mathrm{Nd}$. dăngoe loenga koera moeki na hida ngăndi ja, da pa'itanja la ama da la ina da: jeàna na maka, ninja na anakeàda na mamăngoe makang. Tăka da heàma njoeda da mamatoea: lo'a kai pa'aunja na mamăngoe makang jeàna. Tăka hida pa'aunja hida karai ja njoeda da mamatoea: kanggiki na doemoe hoe bera ndăba ha da maka da da anakeàda lai jehoe la paraing?

Taka hina heàma njoena I $\mathrm{O} . \mathrm{Nd}$.: ka ihi ndja ka doeda hida bihoe papamaka dăngga. Tăka njoeda da mamatoea: anakeàda jeàna, anakeàda pamboeta maka.

Tăka hida jăpa ja, hida hondoe ja la pingi karoekoe; tăka hiwăda: ămbi wŏnja pangangoe, ămbi wŏnja wai pa'oenoeng, ămbi wakăhoe ja, măta nja kana meti, kana halata la mbana lodoe. ${ }^{1}$

Tăka njoena I $\mathrm{O} . \mathrm{Nd}$. bana rongoe ja njoena, tăka hina pani la eti na: ai, ka oekoe meti ă ka pa haromoe! "

Tăka njoena na măngoe oemang hina poeroe la tana; toenanoe hi ninja haätoe na na makaweàda na mamahoeroe la bangga, tăka hiwănanja: nggamoe kau năhoe mapoeroe?

Tăka njoena na tau na mapoeroe hiwăna; njoengga: ăpoe! "Djăka njoemoe doe, mai nămoe». Tăka njoena na makaweàda hina peàkanja na tau na mapoeroe la tana, hiwănanja: ămboe hē beli doe kămoe la kaheli, napa tai kau rongoe dăngga nja ${ }^{3}$ na mapanawa neloea la pingi karoekoe.

Tăka njoena I O. Nd. hina panawa:

hīna păkoe ka

bakoe tăka lai jehoe,

la pingi karoekoe

na hondoe kandila ka;

pangangoe ndeda wŏngga ,

1 la mbana lodoe= in de warme zon. Zoo zegtmen ook: la maringoc lodoe = in den namiddag (als de zon koud is.).

mbana wordt dus substantiviseh gebruikt in deze uitdrukking. Men kan echter niet zeggen: la mbana wai, maar alleen la wai mbana $=$ in 't warme water.

2 ka oekoe meti ă ka pa haromoe='t is de gewoonte (adat) wel eens een keer nog te sterven, d. w. z. ik moet wel eens sterven, maar nu nog niet; sterfelijk zijn wij allen!

${ }^{3}$ kau rongoe dăngga nja = luister met mij naar hem. Dit dăngoe, dat geassimileerd wordt met 't pronomen, wordt nooit instrumentaal gebruikt; dit geschiedt met wăngoe. 
wai ndeda wŏngga;

wŏngga, loe ma wŏngga nja, na maka ihi naœe nggoe

na loenga koera moeki nggoe;

himboe nggoe nja I Kahi, ana wini nggoe,

na mahira ngga

tera rara,

na matondoe ngga

woea kamănggihoe,

la toeboe papoeroeng;

djăka ndau wŏngga nja,

na maka ihi naœ nggoe,

mboeloendăba moe,

la paraing lai jehoe,

oemeti mboeta ma,

ndau bingoe kanănda moe. ${ }^{1}$

Tăka njoeda da mamahoeroe la bangga, da patinginja njoena bana panawa, na pahondoe la pingi karoekoe. Tăka njoena na haätoe, na mapoeroe la tana: ai lănga tăka, ăpoe! ningoe pahimboe na doena, lakoe li ă na nja.

Tăka hida hadang la mbaroe hida peàkandja da ama bokoel da mahondoe ja noena, na anakeàda. Tăka njoeda da ama bokoel hida heàma: paní ă ănga ka dimi năhoe! Tăka njoeda hida heàma, da marongoe ja bana panawa: madja ka toena, napa tai la roedoeng, njimi rongoe wiki mi nja bana panawa. Bada hăla ka pangangoe, tăka hida poeroe la bangga da ama bokoel, tau malima ha, hida patinginja bana panawa tai la mandalora. Tăka njoeda da pa'au mboe nja na makaweàda, na marongoe woenga ja: mai kau nămoe lai jehoe kata patinginja na papaní mi kawai la lodoe; mandalora ja ka năhoe.

Tăka hina hili panawa njoena I. O, Nd. hama toena ka i bana panawa kangéau roedoeng.

Tăka njoeda da ama bokoel hiwăda: napa haromoe la mbaroe kata wăkăhoe ja, kata karai pahămoe-hămoe nja, nggăra pahimboe moe doemoe, ka wăndanja bata karai ja.

1 ndau bingoe kanănda moe = gij zult niet bewaren uw overblijfsel; d.w. z. gij zult zonder nageslacht sterven. 't Grootste ongeluk dat een Soembanees kan overkomen; want wie moet dan voor zijn schim zorgen? 
Toenanoe hadang ka la mbaroe, pa'ita oera lima ja, tăka hida hadang; wăkăhoe ja, wăda be à lăti. Tăka njoena I. O. Nd.: ămboe wakahoe ha da likoe, măta kata pani păkoe tai bana hoenga na lodoe.

Toenakanoe bana hoenga ka na lodoe, bana hări ka na tana hida lakoe la pingi karoekoe da ama bokoel mboeloendaba da, tau malima ha, hida karai ja: măla noe, djăka tawăkăhoe ha da likoe, ndau pamădjandja?

Taka njoena I. O. Nd. hina heama: djăka ndau palohoe be ngga, ndau măka ă ndja pawăkăhoe ha da likoe, lăpăhoe djăritoe ha ka.

Taka njoeda da ama bokoel hida heàma: măla noe, nggăra papalohoe wăma nggau?

Tăka njoena I O. Nd. hina heàma: djăka palohoe wăngga, pihoe kamboeloe patoekoe lomboe bàdi, ndjara doea băba, karămbo'a tiloe băba, didi hang da pakarai nggoe.

Taka njoeda da ama bokoel hiwàda; pira da ka ka noeda, hawoetoe păkoe dang, palohoe doe nggau doena.

Tăka hina heàma njoena I O. Nd.: djăka matoebang doe ja, djăka matăndjing doe ja, mai kai wăkăhoe ha da likoe la ihi nggoe.

Tăka njoeda da ama bokoel hida hadang hida wăkăhoe ha da likoe mboendăbada la lima na, la wihi na, la nggoroe na. Bada hăla ndăba ha ka pawăkăhoe ha, da dandanja hida ngăndi ja la bangga hida wŏnja pahăpa. Toenanoe bana hăla ka pangangoe hida kạrai ja: măla năhoe, Oemboe, palohoe ma nggau ka năhoe?

Tăka njoena I O. Nd. na heàma: napa păkoe bădi, koe beli ka ${ }^{1}$ kakoe lakoe li papiti ha. Tăka njoeda da ama bokoel: kanggini lakoe ningoe nggoe nja, wămoe? Tăka hina heàma njoena I O. Nd.: himboe nggoe nja mandetoăma.

Tăka bana hăla ka papaní toenanoe hina lakoe; na lakoe li papiti ha da hinggi na, da tera na, da kaloemboetoe na, da kabeàla na, da bălang na. Toenakanoe bana hăla ka papiti ha hina hili lakoe.

1 koe beli ka=ik zal terugkeeren. Dit ka wordt niet alleen gebruikt bij een imperfectum en plusquamperfectum, maar duidt ook aan dat iets in de toekomst zal geschied zijn.

Zoo ook: măta ka kama papeàka nggau ka: welaan dan, wij zullen 't $\mathrm{u}$ wel leeren.

vlg. $\mathrm{ka}$ in aanteekening $2, \mathrm{pg} .86$. 
Tăka hina ita ja na tau na malo’a pahondoe ndjara la pamangahoe; tăka hina karai ja: ka nggi weli ni moe? hiwăna na tau noena. Tăka hina heàma njoena $\mathrm{I} O \mathrm{O}$. N .: weli nggoe la wara, hiwănanja. "Ka nggi lakoe ningoe nggoe nja, wămoe?» Tăka hina heàma njoena I O. N d.: lo’a nggoe nja papatamang. Tăka hina heàma na tau na mahondoe ndjara: ka nggini moe lakoe papatamangoe ningoe? Tăka hina heàma njoena I. O. Nd. : la-lakoe ka ka doena năhoe, djăka nggini ja na maningoe roehang.

Tăka njoena na mahondoe ndjara la pamangahoe, lakoe beli na nja ka hoedita la paraing. Tăka njoena I O. N.d. na lakoe li pakawinindja da hinggi na, da tera na la woekoe oămang. Tăka hina lakoe beli ja weli daloeng la woekoe oămang hina hē ja la paraing; na tăka la kambata hina ita ha da anakeàda da madjoengga la bangga. Tăka njoena I O. Nd, hina tama loendoeng hoedaloe la paraingoe, hina mandapoe la pinoe watoe ngoedoe. Tăka njoeda da anakeàda da madjoengga la

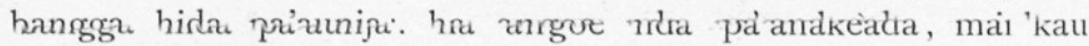
nămoe kata loedoe.

Tăka njoena I O. Nd.: e, ndakoe bihoe, ndakoe pingoe padjoengga, ndakoe pingoe paloedoe. Tăka njoeda da anakeàda: ha, mai kau wa njoena, djăka ndau pingoe paloedoe, djăka ndau pingoe padjoengga, măta ka kama papeăka nggau ka, ${ }^{1}$ kau pingoe padjoengga, kau pingoe paloedoe, hiwădanja.

Tăka njoena na haätoe na anakeàda hina poeroe, angoe da noe kawai da anakeàda da madjoengga la bangga; na lo'a paloănda ja I O. N d., na pamandanja. Tăka hina poeroe njoena I O. N d. hina pamaingoe la bangga; tăka hida wornja na djoengga: ha oemboe arijá, djoengga wa ná, kau loedoe. Na heàma njoena I O. $\mathrm{Nd}$, : ndakoe pingoe ă paloedoe.

Tăka njoeda da anakeàda da madjoengga kawai la bangga hida wăhi ja na djoengga hida paloe wănja ja; na mbera na djoengga.

Toenanoe bana hăla ka pambera na djoengga noena, da jăpa ja hida jăbăhoenja la tana. Tăka njoeda da mamatoea hida rongoe ha kanjawoeroe da da anakeàda la bangga. Tăka hida poeroe ha da mamatoea weli ditang la kaheli: ha nggăra ja na pakanjawoeroe mi njimi! Tăka hida heàma da anakeàda :

$1 \mathrm{ka}$, zie noot blz. 93. 
jeàna na anakeàda na bera ja na djoengga. Tăka njoena I O. N d., nde nggăra ndokoe papaní na.

Tăka njoeda da mamatoea: lo'a papiti nja likoe kata hondoe ja, kata toe ja loemboe bangga. Tăka njoeda da anakeàda hida hondoe ja; da hăla pahondoe ja, da poehi ja la loemboe bangga; da oăka noeda da wili winggiroe ${ }^{1}$ ndja da bangga ; da răpitoe ja na pindoe na na oăka noena.

Tăka hiwăda da mamatoea: na ita nja bădi hiloe na na djoengga, ka măngoe pawŏnja pangangoe, ka măngoe papahăla ja, hiwădanja.

Tăka njoena I O. N d. na heàma: nggăra koe wănja hiloe na! Ka pabera nggoe nja noe na djoengga moe? pabera da ana ma moe nja doemoe; ka ihi ndja doeda hida paloe wăngga nja hina mbera; djeà ma ja doekoe, ndakoe pingoe padjoengga , wănggoe ma, ndakoe pingoe paloedoe, wănggoe ma doekoe.

Tăka hida heàma da mamatoea: păndjang papaní doemoe noedaloe, piti doe nggau aloe tai pakiawerăkoe ja na katikoe, hiwădanja.

Toenakanoe ba mandalora ka năhoe, tăka hina panawa njoena I O. $\mathrm{Nd}$. hama toena ka i bana panawa la paraing hau.

Tăka hi ninja na bidi mini, na mamahoeroe la nggala djangga ; tăka hina rongoe ja bana panawa. Tăka hina hadang la mbaroe hina peàkandja da ama na da ina na: kamodoe na tau pahondoe mi njimi, na panawa la mandalora; ningoe pahimboe nggoe, wăna; ndakoe patingi pahămoe nja noe kamodoe bana panawa; tătik mboe nggoe nja hi mahoeroe be nggoe nja.

Tăka hida heàma njoeda da ama bokoel: ai, kambălikoem, hiwădanja.

Tăka njoena hina heàma: lănga tăka, djăka koe kambălikoe, koe meti.

Tăka hiwăda njoeda da ama bokoel: ai, matoebangoe ja ihoe na papaní na njoena.

Tăka hina hili roedoeng, tăka hida patingi wiki da nja njoeda da ama bokoel, hama toena na parongoe na na bidi mini la kangéau roedoeng. Tăka hida karai ja: toenanoe bana panawa kangéau roedoeng?

Tăka hina heàma njoena na bidi mini: toenanoe doe bana panawa, "Matoebangoe ja ka njoena na papaní moe».

1 wili winggiroe = geheel omringen. Dit wili, (niet wili=prijs) heb ik alleen in deze verbinding gevonden en is mij onverklaarbaar. 
Tăka njoena I O. Nd. na hili panawa, ndena panawa padangoe; hiwăna bana panawa: djăka ndau pahăla ka, tau lai jehoe haromoe, na tăka na tai ria, oemboeta, ndau bingoe kawe moe. ${ }^{1}$

Tăka njoeda da ama bokoel: rongoe ja bana panawa noe, ta meti mboeta ka haromoe, djăka ndeta pahăla ja; napa haromoe la mbaroe kata wăkăhoe ha da likoe na, kata pahăla ja.

Toenanoe hadang ka la mbaroe, hida paloehoe ja weling la oăka la loemboe bangga: kanggiki na wămi jéa, hiwăna I $O$. $\mathrm{Nd}$. Tăka hida heàma da ama bokoel: wăkăhoe ha da likoe, wăma doe.

Tăka hina heàma njoena I $\mathrm{O}$. N d.: măta nja, ămboe wăkăhoe ha da likoe, palohoe păkoe ngga bădi, hiwăna, măngoe pawăkăhoe ha da likoe.

Tăka hida heàma njoeda da tau: ha oemboe, pira ma ka papalohoe wănggau, hiwădanja. Tăka na heàma njoena I $\mathrm{O}$. $\mathrm{Nd}$.: wŏngga matembi ngaroe ${ }^{2}$ djoea, patoe kamboeloe pihoe mboea; mamoeli pangening, ${ }^{3}$ hakamboeloe pihoe mboea; ndjara ndakoe bihoe, karămbo'a ndakoe bihoe, wē mopoe ndakoe bihoe; wē roemba talíhoe oeli, lima ngioe; roeha kamboeroeng kadoe, pihoe ngioe; didi ă hang da pakarai nggoe; djăka bihoe doe papalohoe ngga, kai wăkăhoe ha da likoe la ihi nggoe.

Tăka hida heàma njoeda da ama bokoel: ndokoe ma nda nja ka, ndănga ma nda nja ka, ${ }^{+}$palohoe nja ka bădi; djăka ndeta palohoe nja, tameti mboeta ja haromoe; măla wa njoena palohoe nja.

Tăka hida wăkăhoe ha da likoe na la lima na, la nggoroe

${ }^{1}$ ndau bingoe kawe noe= gij zult zonder nageslacht sterven.

vlg. aant. pg. 92. $-\mathrm{Kaw} \mathrm{e}=$ schoon op maken, schoon leeg maken in een pan.

2 matembi ngaroe $={ }_{\text {}}$ met dikken mond", d.w. z. mamoeli's, zoo geheeten naar den vorm, waarin zij van onderen uitloopen.

$s$ mamoeli pangening = licht vergulde oorhangers; niet van goud, maar van blik of zilver gemaakt en daaraan even laten nzwemmen" (n g e ni) in verguldsel.

4 ndokoe ma nda nja ka,

ndănga ma nda $\mathrm{nja}$ ka=een vast staande uitdrukking van schuldbelijdenis; $\mathrm{ndokoe}=$ schuldig zijn aan 't overtreden van de adat; $\mathrm{ndănga=afdwalen} \mathrm{van} \mathrm{den} \mathrm{rechten,} \mathrm{goeden} \mathrm{weg.}$ 
na, la wihi na; da wăkăhoe ndăba ha. Tăka hiwăda nja: ningoe pa pangéa palakoe nggoe, wămoe?

Tăka hina heàma njoena I O. N d.: ningoe ngéa palakoe nggoe, himboe nggoe nja na mandetoăma; djăka ${ }^{1}$ noeda da papeàka nggoe, napa koe beli ka, kakoe lakoe li ha ka papiti ha.

Toenanoe na loehoe ja ka weling la paraingoe noena. Tăka hina lakoe li papiti ha da hinggi na, da tera na, da bălăng na: tiloe mbăla ki da ka da bălăng na. Tăka hina kalamboeng, na tera; hina hili lakoe ja i la hau paraing; mareni ă ma ki na ka na pangéa na I Kahi, ana wini na.

Hina tăka la pamangahoe, na ita ha da tau da mapawang kamămbi la marăda mbila. Tăka hina karai ha: ha mapawang kamămbi, mai nămoe, ningoe pakarai nggoe la njimi. Tăka njoena I. O. N d. hiwănandja: Ka nggi anakeàda ningoe kămi 2 jéa?

Tăka hida heàma da anakeàda noeda: anakeàda la paraingoe lai jehoe kăma. Tăka njoena I. O. Nd.: măla noe, ba anakeàda lai jehoe kămi, măla kata pamakang la pamangahoe. Tăka hida heàma da anakeàda noeda: $\overline{\mathrm{e}}$, ha oemboe, ndema bihoe doema, pawang ma nja kamămbi doema; djăka ndema tăngăroe pahămoe ndja da kamămbi, da jăpa ha meo roemba. ${ }^{3}$

Tăka hina heàma njöena $\mathrm{I}$. $\mathrm{O}$. Nd.: ka nggini ha da pangéa da da meo roemba. Tăka hida heàma da anakeàdà noeda: năhoe ndja, 4 la woekoe oămang bokoel da pangéa da. Tăka hina heàma njoena I. O. Nd.: djăka koe ita ha njoengga, koe paloe pameti pamboeta ha da meo roemba, ka ămboe ningoe meo roemba la woekoe oămang noena.

Toenanoe bada pandjăpoeng ka papaní, njoeda da mapawang kamămbi, lakoe da nja ka doeda. Tăka njoena I. O. Nd. na lakoe li pakawinindja da hinggi na, da tera na, da koeloemboetoe na, la koeboe tana; tăka hina piti ja na katări na pakăli kalamboeng na.

$1 \mathrm{djăka}=$ wat betreft.

2 $\mathrm{kămi}=$ de Accus-vorm van 't pronomen vindt men bij nomina, welke praedicatief werden gebruikt.

Zoo in den volgenden zin: anakeàda la paraing lai jehoe kăma= kinderen van de kampong hier, zijn wij!

${ }^{3} \mathrm{meo}$ roemba $=$ boschkat, verwilderde kat.

4 năhoe $n d j a=z e$ zijn reeds weggegaan. Een beteekenis van 't woord $\mathrm{n}$ ăhoe, welke in 't Kamberaasch niet meer wordt aangetroffen; wel in ovcrig Midden-Soemba.

Dl. 68 
Tăka hina hẹ ja la paraing; tăka ka la pindoe, tama nggoe nja la pindoe, hiwăna. Tăka hi ninja I A poe Kămi ${ }^{1}$ la pindoe noena, hiwăna: ha oemboe ha Ndiloe, ka ha nggini ha lakoe ha ningoe moe nja? Tăka njoena I. O. Nd. hina heàma: ka nggini makaweàda ningoe kămoe doemoe? Tăka hina heàma I A poe Kămi: na pa ha ngéa nggoe ha lai ha jehoe ja, la karaha ha pindoe. Tăka njoena I. O. Nd.: djè doe ja kata pinja. Tăka hina lakoe hina tama la oema tau mamila. Ninja na ahoe bokoel lai noe, laloe mbeni ma ja. ${ }^{2}$

Tăka hina mandapoe njoena I. O. Nd. la bangga, ndedi ningoe tau ma'ita ja, didi jang na ahoe na ma'ita ja, hina bau, kati ma na nja, hina jăbăhoenja la tana. Tăka tau na mamăngoe oemang hina poeroe ja la bangga, hiwăna: ha kanggiki ă nda nja na anakeàda nina, na pameti ma ja ka ahoe. Tăka hida dandanja hida wotoe ja la bangga. Tăka njoena na măngoe oemang: napa haromoe la mbaroe kata taninja, hiwăna, tahăla pataninja, talakoe papa’ărang, djăka nggamoe ana da nja ${ }^{3}$ jeàna na mameti, na roekoe kati ahoe. *

Tăka njoena na măngoe oemang, ngangoe be na nja ka doena; tăka njoena na anakeàda na mameti, didi ă jang la bangga. Tăka njoena I A poe Kămi hina mai la bangga hina benginja njoena I O. Nd. hiwănanja: ha Oemboe ha Ndiloe ha hadang wa ma ha reni na ja ka na pa ha ngéa na I Kahi, ha ana wini ha moe, ha hadang na ha kau ha kē ja na maka ha ihi ha naœ moe, na loenga ha koera ha moeki moe,

1 I A poe Kămi = een oud vrouwtje, een oude „tooverfee”, welke steeds op een kritiek oogenblik verschijnt, om den held van 't verhaal te helpen of den weg te wijzen. Dat't geen gewoon mensch is, blijkt wel uit haar taaltje; overal zet zij ha voor, zoodat 't soms tamelijk onbegrijpelijk is.

2 la loe mbeni ma ja = zeer nijdig was hij. Deze zinsconstructie is kenmerkend Soemb.; waar wij een relatieve bijzin, beginnende met: die, welke, zouden gebruiken, construeert men in 't Soemb. met een zelfstandige zin. Het relatieve $\mathrm{ma}$, kan hier niet gebruikt worden: dus nooit: na malaloe mbeni. Dit la loe eischt steeds deze constructie.

s djăka' nggamoe ana da $n j a=$ wiens kind 't is; djăka leidt in een indirecte rede. Daar 't vragend pronom. geen verbuiging kent, omschrijft men aldus: wie 't kind van hen is hij $=$ wiens kind is hij.

4 na roekoe kati ahoe $=$ door 't bijten van een hond.

Dit roekoe $=$ spoor (roekoe wihi $=$ voetspoor) gebruikt men voor 't aanduiden van een zichtbare norzaak. Vraagt men b.v. hoe is hij gestorven, wat is de oorzaak? - dan antwoordt men : roekoe nimboe $=$ door een lans. De praepositie parai is hiervoor niet te gebruiken. 
haromoe ha la mbaroe kau ha lakoe, njoengga koe ha ndaki kau, ha tau ndena ha ita ka.

Taka hadang la mbaroe na măngoe oemang hina poeroe ja la bangga, taka njoena I O. Nd. mandapoe be na nja la bangga. Tăka njoena na măngoe oemang: ai, na loeri be $а$ a ka na anakeada, na pakati ahoe kangéau. Toenanoe hida karai ja: nggamoe ja na ngara moe, hiwădanja. Taka hina heàma njoena I O. Nd.: na ngara nggoe njoengga, ana mamila ka, pameti wăroeng ka ina nggoe ama nggoe; hinggiloe na i noe. ${ }^{1}$ Taka hiwăna: măla noe, pangerangoe ma moe njoemoe, oemboe, lai jehoe la paraing, djaka na kati ja ahoe na anakeada la hau kóatak, ndau palohoenja?

Taka hina heàma njoena măngoe paraing: palohoe doe nja.

Tăka hina heàma njoena $1 \mathrm{O} . \mathrm{Nd}$.: madja ka toena, njoengga ba kati pameti ma doe ka ahoe, palohoe doe ngga bădi, Taka hina heàma măngoe oemang: ba ndau meti pangalang ki noe, bau loeri beli doe à i ná! Taka hina heàma njoena I $\mathrm{O}$. Nd.: djăka ndau palohỏe ngga, jeàna na maka ihi naœ koe toekoe wănggau nja, oe meti. Tăka hina heàma njoena na măngoe oemang: ndea pangéa pamăka nda nja pa. Tăka njoena na măngoe paraing na lo'a papeàkanja na ama bokoel hau oema hau oema hina pa'oehi hina batang pa'oehing banda, tapalohoe wănja na anakeàda na pakati ahoe; na pawoetang ka bana kati ja ka na ahoe, wăda.

Da nggănăp ndăba ka da banda, hiwădanja: măla, kē ha wa da banda jéa, ămboe hili ningoe papaní ndja haromoe doea modoeng, hiwădanja.

Tăka hina heàma njoena I O. Nd.: măta nja kadiroe, lakoe ndedi păndjang nggoe nja, dămboe da pa da paraingoe, da pangéa palakoe nggoe; ba toenanoe napa bakoe beli ka, kakoe lakoe li ka papiti ha da banda jeàda.

Toenanoe bana hăla ka papaní: măta kakoe lakoe, hiwăna njoena I O. Nd.; tăka hina lakoe, na toăma la pindoe, tăka njoena I Apoe Kămi: ka ha lakoe moe nja ka ha Oemboe ha Ndiloe? Tăka hina heàma njoena I $\mathrm{O}$. N d.: wǒ'a i ăpoe, lakoe nggoe nja ka!

Bana hăla ka papaní, lakoe lăpăhoe na nja ka I O. Nd.

1 hinggiloe na i noe = genoeg hiervan. De vaststaande uitdrukking, wanneer men over een zaak niet meer wil spreken, en (hing giloe afzonderlijk.) op een ander onderwerp wenscht over te gaan. 
hina lakoe li papiti ha da hinggi na, da tera na, da kabeàla na, hina pandjiloeng.

Tăka hina hili lakoe; na ita ja na paraing, laloe djangga ja.

Tăka hina tăka la pamangahoe hina todoe ja lai noe. Mandalora ja ka năhoe, njoena $\mathrm{I} \mathrm{O} . \mathrm{Nd}$. mahoeroe be na nja. Tăka njoena I A poe Kămi ni be nja la karaha na I O. Nd., mandapoe na nja; tăka hina pambeling hina djoembăloe ni ja I A poe Kămi. Tăka hina hadang I O. Nd., hina karai ja: ka nggamoe kămoe doemoe jéa? Tăka hina heăma njoena I A poe Kămi: ha Oemboe ha Ndiloe, njoemoe ha roămbanja ka na pa ha ní nda kangéau ha wăda ha modoeng!

Tăka hina heàma njoena $\mathrm{I} O$. N d.: lănga tăka, hiwana, A poe Kămi be nggau năhoe, ai! Tăka hiwăna njoena I A poe Kămi: djăkau ha poeroe ha la paraingoe ha jehoe, djăkau $\mathrm{ha}$ hili ha ita ja na pa ha raingoe $\mathrm{ha}$ hau ka, djéa ja ka na pa ha ngéá na ha Kahi ha ana wini moe.

Tăka hina heàma njoena $\mathrm{I} \mathrm{O} . \mathrm{Nd}$.: mili koe ita ja noena na ana wini nggoe. Toenanoe ba harí na nja ka na tana, hoenga na nja ka na lodoe, tăka njoena I A poe Kămi na mboelang ka, nde pa'ita ja pa.

Tăka njoena I. O. Nd. hina lakoe la léang, na ita ja na koeboe watoe lai noe: tăka hina poehi ha da hinggi na, da tera na, da kabèala na, da kaloemboetoe na: Bana hăla ka pakawinindja hina loehoe ja hina he ja la paraing.

$\mathrm{Na}$ tau la paraing pa'oehi na nja, pamangoe na nja, na toboeng karămbo'a, na toboeng ndjara, na hoendjoe we, na roeri kamămbi, na roepoe manoe. ${ }^{1}$ Tăka hiwădanja: takoe wa oehoe! Tăka njoena I. O. Nd. bana ninja ka la pindoe, na rongoe ha bada paní: takoe oehoe, ba wăda. Toenanoe na tama loendoeng, na tăngăroe ja na oema bokoel, hina mandapoe ningoe ${ }^{2}$ la bangga.

Tăka hi ninja haätoe na na bidi mini, poeroe pahangiloe la bangga. Tăka hina ita ja I. O. Nd.: ha tau la kaheli, wŏnja pahăpa na na tau newawa la bangga. Tăka hida heàma da tau

1 't Woord "slachten" is verschillend naar gelang der methode van slachten: toboeng = van groote beesten met één slag den strot door slaan. hoendjoe=steken in 't hart, van varkens. roeri=den strot doorsnijden, van geiten en schapen. roepoe $=$ den kop afsnijden, van gevogelte.

${ }^{2}$ na mandapoe ningoe $=$ hij ging zitten. Dit ningoe duidt eene beweging aan, naar of van een plaats. 
kawini: ka nggăra tau ja noe, hi! Tăka njoena na bidi mini: tau doe ja, hi! wŏnja pahăpa na, hiwănggoe.

Tăka njoeda da tau kawini la kaheli hida toălanja: ka nggăra tau lahoe ja noe, hina tăka pamalamiri noe.

Tăka njoena I. O. Nd. na rongoe ja, hina heàma: ha rămboe nedita la kaheli, djăka ndau wŏngga nja pahàpa, kau djămang be doena, mili ămboe toălangoe lăti.

Tăka hida heàma njoeda da tau la kaheli: ka măla doemoe năhoe bau tăka pamalamiring, djè doe ja hima toălanggau. Tăka hina heàma njoena na bidi mini hiwăna: măla djăka ndaningoe pahăpa, djăka wămi lăti, na palingoe ki pa.

Tăka hina heàma njoena I. O. Nd.: ha bidi mini, ămboe tanggoe paní, măta kakoe paní ka doekoe. Tăka hiwăna njoena I. O. Nd. : ha rămboe noedita: ka napa doena năhoe hi mangăbang na nja oehoe, hi wămoe be ă; ndakoe mangăbang ă oehoe, ndakoe mangăbang ă toloe, lakoe li ă nggoe lai jehoe; djăka nde wŏngga moe nja i pangangoe, djămang.

Tăka hida heàma da ama bokoel noedita la kaheli, hiwădanja: Ka nggamoe păkoe ja noewawa la bangga, na karéaukoe ndena păndjang ndokoe. Tăka njoena I. O. N d. na kandí, ndena heàma.

Tăka njoena na bidi mini hina heàma: ka ihi nja ka, arijá ja ihoe! katări hinggi pakalamboeng na, ndena hămoe ndokoe; hinggi padoekoe na ndaningoe.

Tăka hida heàma njoeda da ama bokoel: ka pirang tăka ma na heàma? "Ka ihi nja ka, ndeta pinja.tăka na.» Tăka njoena I. O. Nd. hina heàma: tăka tidoe lodoe nggoe.

Tăka hida heàma njoeda da ama bokoel; tau mamai pamanganga, djăka ndea, tau mamai papatandangoe ja. Tăka hina heàma njoena I $\mathrm{O}$. $\mathrm{Nd}$.: djăka tau mapatandangoe ka doekoe, oemboeta doe jéa haromoe, bakoe mai pabera kau.

Tăka hida heàma njoeda da ama bokoel: pira ka ka parăpa moe? ${ }^{1}$ Tăka njoena I O. Nd. na heàma: didi ă jang hau na na maka.

Tăka hida heàma njoeda da ama bokoel: mawăhi ă ja ka na maka moe.

Tăka hina heàma njoena I O. N d.: djăka koe poeroe la tana, koe laœnja na maka, njimi i mboeta. Tăka hida heàma njoeda

1 pira ka ka parăpa moe = hoeveel kunt gij wel omspannen? waartoe zijt gij wel in staat. (răpa = vadem.) 
da ama bokoel: ămboe wănja nā wa, tai mapameti doe kau. Tăka njoena I O. Nd.: wă ma nggoe nja noe!

Tăka hida heàma njoeda da ama bokoel hiwădănja: hili pandoeang ki bau paní, njoema tai kama poeroe, makawita wănggau kabeàla.

Tăka hina heàma njoena $\mathrm{I} \mathrm{O} . \mathrm{N}$ d.: kanggiki na ka i ka noe, djăka koe paní, hiwăna.

Tăka mboeloendăba na na tau la kaheli hina poeroe hina oekoeroe nja, hida jăpa ja, hida tătăroe ja. Njoena I O. Nd. ndena loehoe nja kabeàIa; paloe wănja ai, ndena meti.

Tăka njoeda da ama bokoel: ka nggiki ă nda ja ka! tătăroe wănja kabeàla, ndena meti; paloe wănja ai, ndena meti; jăbăhoenja la tana, ndena meti; pai wănja likoe, ndena karităkoe ja; măla kata kamang patoenoe ja la epi.

Tăka hida pa'oehing ai dangoe; kawini, mini, anakeàda, makaweàda hada ndăbang. Toenanoe bada pa'oehing ka ai, hida paboendoendja; tăka hida piti nja ep̀i, hida toe ndja da ai noeda; bana doeroe ka na epi, hida piti ja njoena I O. Nd., hida ndoeha ja la epi; ndena moetoeng.

Tăka hiwăda njoeda da ama bokoel: nde nggiki nda pa. Tăka hida pa'aunja: ha oemboe marămba, mai kau nămoe la bangga, ndokoe ka njoema, ndănga ka njoema. Tăka hina heàma njoena I O. Nd.: djè doe ja, hiwănggoe kawai la mangiloe na, koe woenga nja na liting, koe hahanja na rehi ; ${ }^{1}$ djăka nde wŏngga moe nja i pangangoe, wănggoe ma doe, tăka njoemoe măngoe oemang, măngoe paraing, oembeni, oetătăroe ka, oepaloe ka, oetoenoe ka la epi, djè doe ja noena, palohoe ngga bădi.

Tăka hida heàma njoeda da ama bokoel: ndema padoea ja; tăka hiwăda: măla ba karaœ eti ma ja ka, nde papinja pa toeba na; măta kata ndokoe ka ka doena. Tăka hina heàma njoena I O. N d.: madja kau măka doe. Tăka hida heàma njoedą da ama bokoel: mălau tiki ha pa noe.

Tăka njoena I O. Nd. hina tiki ha: toenanoe wănggoe, mamoeli mapawihi, harata lima kamboeloe; ndjara tiloe băba; karămbo'a hamang; roeha pihoekamboeloe pihoe ngioe, kamboeroeng kadoe; kamămbi hakamboeloe tiloe ngioe, ha kawăloe da da kadoe da; didi ă hang da pakarai nggoe noeda.

1 koe woenganja na liting,

koe haha nja na rehi=ik heb 't van te voren wel gezegd. (ik was eerde: dan 't geschil, ik was den tijd vooruit.) 
Tăka hida heàma njoeda da ama bokoel: măla ka kadoena, ba ndjala ma nda nja. Tăka hida karai ja: măla noe, wŏma nggau ha năhoe? Tăka hina heàma njoena I $\mathrm{O}$. N d.: napa păkoe bana ndjănga na ndjara nggoe, bana beli na tau nggoe. ${ }^{1}$

Tăka hida heàma njoeda da ama bokoel: măla ka, madja ka toena, nganja na oehoe, oenoenja na wai, ka pekoe lakoe hămoe moe. Tăka hina heàma njoena I O. Nd.: eti moe ka, koe wŏnja kana ngangoe, djăka wămoe ngga; pa'oenoe nja wai, djăka wămoe doe ngga, njoengga ndea nde wănggoe.

Tăka hida jăpa ja he'au na na wē, kamboăka ă na nja; tăka hida hoendjoe ja. Toenakanoe bada hăla ka pahoendjoe ja hida toenoe ja; da hăla patoenoe ja, da hŏawăkoe ja, hida ăli ja na eti na, hida tăngăroe ja na oera na: na hămoe na oera wē, hiwăda. Băda hăla ka patăngăroe ja noena hida lătăkoe ja nà wê noena hida manahoe ja. Bada memi ka hida takoe, măngoe hida pa'aunja I O. Nd.: hē kau la kaheli, hjwădanja. Da pawălăhoe ndja topoe bara la nggala hina mandapoe wăngoe. Toenanoe bana hăla ka pangangoe hida pala ngăndi ja pahăpa na.

Toenanoe bana hăla ka pahăpa: măta kakoe lakoe wa, hiwăna njoena $\mathrm{I} \mathrm{O} . \mathrm{N}$.; ; hina poeroe ja weli ditang la oema, na poeroe ja la bangga; na hăla papoeroe ja la bangga, poeroe na nja ka la tana, lakoe na nja ka.

Tăka njoena I O. Nd. na toăma la pindoe, na păndjang lai noe hakoedoe; tăka njoena I A poe Kă mi: ha Oemboe ha Ndiloe; ha lakoe moe ha nja ka na, hiwănanja. Tăka na heàma njoena $\mathrm{I} \mathrm{O} . \mathrm{N} \mathrm{d}$.: lakoe doe nggoe ja ka. Toenanoe hina hadang, hina lakoe; na lakoe li papiti ha da hinggi na, da tera na, dă kaloemboetoe na, da kabeàla na. Tăka hina pandjiloeng; bana hăla ka papandjiloeng, tăka hina tăngăroe ja da kambambang la ndăni kaloemboetoe na: hau ki na ka.

Tăka hiwăna njoena I $\mathrm{O} . \mathrm{N}$ d. djămoe toăma nggoe ka.

Tăka hina loehoe ja weli daloeng Ia oămang; na hili lakoe, na kikoenja na ngarăngia bokoel.

Toenanoe bana tăka ka la pamangahoe, ndena ita tau. Tăka njoena I O. Nd. hina lakoe li pakawinindja da tera na, da hinggi na la koeboe lokoe, didi ă jang na maka ihi naœ na pangăndi na.

1 bana ndjãnga na ndjara nggoe,

bana beli na tau ng goe = tot dat ik teruggekeerd ben. (tot mijn paard halverwege is teruggekeerd, tot mijn lichaam is teruggekomen.) 
Tăka na londoeng ka hoedita la paraingoe, na tăka la pindoe, na ita ja na matinoeng. Tăka hina loenga ja na maka na, tăka hiwăna la pindoe la noe: jeàna tai, djăka djèa ma ja na paraing na pangéa na I Rămboe $\mathrm{Kahi}$, ana wini nggoe, koe lacenja na maka, ndea hangia ma na.

Toenanoe na tama loendoeng hoedaloe la paraing, tăka hina lakoe hina ita ja na matinoeng la loemboe mboămang, hiwăna: ho, djăka djèa ma ja I Kahi, ana wini nggoe, na matinoeng, hira ja na kamba tinoengoe na, pata ja na ngoăda na, pata ja na wihi bai na.

Tăka hina kandoeling hakoedoe, na marau nja; tăka hina lacenja na maka noena, na katoetoe ja na matinoeng noe la loemboe mboămang. Tăka hina ngăna ja I Rămboe Kahi, na pata ja na wihi bai na, na kamba tinoeng na hira ja, na ngoăda na pata ja, na woenang na bera ja.

Toenanoe bana ngăna ja ka maka I Kahi njoena, tăka hina hira mboe ja ka na kamba tinoeng. Tăka njoena I. R. K. laloe mbeni ma ja, na toălang mboe.

Tăka hiwăna njoena I. R.K.: lo'a ka jăpa ngga nja neloea na anakeàda kambănga lahoe, hiwăna, na mahira ja na kamba tinoenggoe, na mapata ja na wihi nggoe. Tăka njoeda da tau dangoe, hida jăpa ja. Tăka njoena $I$. $R, K$. na paloe $j a$, na wănja iwi manoe. Bana hăla ka papaloe ja, tăka hiwănandja, hida hondoe ja la toeba papoeroeng.

Tăka hiwăna njoena I. R. K.: măta kakoe toe ja panongoe, koe he wăngoe, koe poeroe wăngoe, bana mbata na wihi nggoe, ndakoe ătăl papangga.

Toenanoe bana hondoe ja ka lai noe la papoeroeng, tăka la roedoeng mboeloendăba da ndeda pawăla. Toenanoe njoena I. O. Nd., mandalora ja ka năhoe, tăka hina panawa:

hăla hoepoe li moe nja

bana hira ka nja

na tera rara,

bana tondoe ndja

da kamănggihoe ha'oepoe

la toeba papoeroeng.

Tăka njoena I. R.K. ndena pawăla; na lăpăhoeng ka năhoe hau woelang dămboe woelang, tăka hi ninja na haätoe na makaweàda, na makapoăla. Tăka njoena I. R.K. na poeroe ja la tana, lo'a la hambeli, wăna. Tăka hiwăna njoena na maka- 
weàda: ha rămboe Kahi, mai i nămoe, ningoe papaní nggoe hakoedoe; mahămoe ma ja.

Tăka na heàma njoena I R. K.: ē ndakoe bihoe, da wau da kapoăla moe. Tăka hina heàma njoena na makaweàda: ămboe toemoe noe, mai njoena nămoe, oengéangoe ka la pingi ngiloe.

Tăka njoena I R. K. na lakoe toăma ja, tặka hiwăna na makaweàda: ha rămboe Kahi, njama nda pahăpa. Toenanoe bana hăla ka panjamanja, tăka hina karai ja: măla noe, nămoe bau pamaingoe, ningoe anakeàda pawăroe moe? Tăka hina heàma njoena $\mathrm{I}$ R. K. : ningoe ka i njoena, na meti kadoena noe. Tăka hina heàma na makaweàda: batoenanoe, rongoe ja na papaní nggoe njoengga, lakoe tai kau mahoeroe wăngoe lodoe, tai la roedoeng kau pawăla.

Tăka njoena I R. K. : $\bar{a} \bar{a}$, wăna.

Toenakanoe na lakoe hina mahoeroe; na patoemboekoe ka na kálitoe hina pawăla. Toenanoe bana hăla ka pangangoe mboeloendăba na na tau, tăka hiwăna I R. K.: ha mahoeroe wa mboeloendăba mi, ămbi kanjangga; tătikoe mboe nggoe nja njoengga năhoe.

Toenanoe kē mandalora ja ka năhoe, tăka hina panawa njoena I O. $\mathrm{Nd}$ :

ka hăla era ki ja ka

bakoe tăka lai jehoe;

pangangoe ndakoe ngangoe

wai ndakoe oenoeng;

ma-lănga tăka ja ihoe

wănggoe be njoengga ,

bana hira ngga nja,

na tera rara,

bana tondoendja

da kamănggihoe ha'oepoe.

Toenanoe bana rongoe ja ka I R. K., na palai hadang weli ditang la kaheli, tăka hina lakoe toăma ja, hina rohoe ja, laloe hī ja njoena I R. K.

Tăka hiwăna njoena I O. Nd.: nde djèa ka! «Ndea, patăndjing, eri, kakoe pinja, njoengga lăpăhoe ndokoe nggoe ka, lăpăhoe ndănga nggoe ka»r.

Tăka hina heàma njoena I $\mathrm{O} . \mathrm{Nd}$.: djè doe ka jéa; karèanja, ba wămoe ngga ămang, tăka njoena i tamoe: wăroenja na 
anakeàda, tai woenggoe ndjara, ba wăna ngga; djè doe ka jéa.

Tăka njoena I R. K. laloe hī ma ja, laloe namoe ma na nja. Tăka hina pa'aunja na tau mini: wăkăhoe ha da likoe na na eri nggoe, hiwăna.

Tăka njoeda mboeloendăba da da tau lai noe, da poeroe ha: wăkăhoe ha da likoe, wăda. Toenanoe da wăkăhoe ha da likoe, ndeda . măkandja. Tăka hiwăna I R. K.: pata wa ngga ha da likoe, koe ndokoe pahoepoe bănggi, koe ndănga pahoepoe nggoroe.

Tăka hina heàma njoena I O. N d.: pinda ndja ka! Tăka hiwăna njoena I R. K.: mălau peàka pamboehang moe. "Tăka doe ndja djăka koe peàka ha». Tăka na heàma njoena I R. K. : mili oe peàka ha njoena! Tăka na heàma njoena $\mathrm{I} \mathrm{O} . \mathrm{Nd}$. da banda ndokoe pahoepoe bănggi, bawămoe, tanggoe nggoe ha noeda da banda; ndănga pahoepoe nggoroe, bawămoe, hama da ka i; didi ă jang na ndjara miting katikoe, kau wŏngga; da tawăkăhoe ha da likoe.

Tăka hina heàma njoena I R. K.: ninja na ndjara miting katikoe la loemboe mboămanggoe, koe wŏnggau nja.

Tăka hiwăna njoenả I $\mathrm{O}$. Nd.: wăkăkoe da likoe. Tăka hida lo'a, hida wăkăhoe ha; bada hăla ka pawăkăhoe ha, tăka njoena I R. K. hina piti nja topoe pabidi oenang, hina palăkăroenja la bangga. Tăka hina pa'aunja: ha oemboe, miri, mai kau nămoe la bangga.

Tăka njoena I O. Nd. ndena bihoe. Tăka njoena I R. K. hina pa'aung tau: lo'a kai dandanja na ana mimi nggoe néwa la tana, wotoe ja la bangga.

Toenanoe bada wotoe ja la bangga, tăka njoena I R. K.: koe ihoe ja na ana mini nggoe, bana hanggoboeng nămoe, bana pamaingoe, bana lăpăhoe ndăba ndja da paraingoe dangoe.

Tăka hina jăpa ja he'au na na kamboăka karămbo'a, ha kangădoekoe da da kadoe na; pamaringoe wăndja da wihi na, bawăna.

Toenanoe bana hăla ka patoboeng, bana hăla ka pangangoe, tăka njoena I R. K. hina piti ja na woeroeng, na lo'a patakoe wai.

Tăka njoena I O. N d. hiwăna: ha aja, napa takareàngoe, koe lo'a papa'oenoe nja wai na na ndjara, ${ }^{1}$ hiwănanja. "Mai kau, wăna .

I koe lo'a papa'oenoe nja wai na na ndjara=ik ga drinken geven aan hem zijn water het paard $=i k$ ga 't paard drinken geven. 
Tăka hina lo'a, hina iroe ja na ndjara. Toenanoe bana tăka ka la lokoe, njoena I R. K. takoe na nja ka wai. Tăka njoena I O. Nd. na toendoe lokoe hoedija; tăka hina ita ja, na ana winoe, ha pangga nang madita na. Tăka hina boeta ja, hina ngăndi ja la oema.

Toenanoe bana tăka ka la oema, bana hăla ka pahondoe ja na ndjara, tăka hina himboe parikoe. Na itang ka parikoe, hina ăki nja na winoe, hina pamoela ja na winoe la toeba toendoe pahoeloe, hina mangahoe ja na mbaroe na maling; djeà ma ja na pa'ihi oela na.

Toenanoe bana ngeri ana djangga $\mathrm{ka}$, hapoengoe ana tăda na, ${ }^{1}$ tăka hiwana njoena I O. Nd.: ha aja, bai ngga bălang, napa koe woeloe nja leàwatoe ${ }^{2}$ na na winoe jeàna, koe padjoeloe ningoe wănggoe.

Tăka hina bai nja bălang. Tăka njoena I O. Nd. hina woeloe nja leàwatoe na na winoe noena. Toenanoe bana hăla ka pawoeloe nja leàwatoe na, tăka hina karai ja I R. K.: ha aja, ningoe ka bălang, heàna, hiwănanja. "Ningoe ka, hiwănanja . "Pira mboea ana lipitoe da, hiwănanja. Tăka hina heàma njoena I R. K.: dămboe ana lipitoe da».

Tăka njoena I O. N d.: ndeda toăma, hiwănanja; hili bai ki ndja angoe da, waloe mboea ana lipitoe, hiwănanja.

Tăka hina heàma njoena I R. K.: ka napa, kata hili bai nggămoe ka doena. Toenanoe bana hăla ka pabai na bălang, bada patoetoeng ka da papeàka na, tăka hiwăna njoena I R. K.: djeà ha ka da bălămoe, da pakarai moe la kangé'au la wăda modoeng.

Tăka na heàma njoena $\mathrm{I} \mathrm{O}$. Nd.: ngăndi ha nămoe, hiwănanja.

Tăka hina ngăndi ha da bălang noeda; bana hăla ka pakē ha, hina hē ngăndi ha hoedita la leàwatoe.

Toenanoe bana loendoeng $\mathrm{ka}$ la leàwatoe noena, hau roedoeng ninja pa; hili hau roedoeng na winoe noena na ngeri djangga djangga. Hili hau roedoeng, hama toena na djangga kokoer.

Tăka njoena I R. K. hina poeroe ja la tana: kanggiki ă

1 ana tăda = zegt men van een jongen klapperboom, welke pas stam begint te krijgen. 't Hout is dan nog geheel bedekt door klappervezel, door bast ( $\mathrm{t}$ ă da).

${ }^{2}$ leà watoe $=$ boomhuisje, gelijk men veel in de tuinen aantreft. 
nggoe nja ka na ana mini nggoe, nde pekoe poeroe na pa, ' ba laloe djangga ja na winoe; laloe hī ja njoena I. R. K.

Tăka njoena I O. N d.: ămboe na handoeka na eti moe, ha rămboe Kahi, ana wini nggoe! hē nggoe nja palo'a papiti ja na ana na i toeja, noedita la awang.

Toenanoe bana hăla ka pawăna, na winoe noena na ngeri djangga djangga, kē toăma na nja ka na awang. ${ }^{2}$

Tăka njoena I R. K. na padoendang: ta poenggoe ja na winoe, hiwăna.

$\mathrm{Na}$ tăka ndăba na na tau; hau marămba, hau marămba, mboendăba na na kalembi na; na mătoe ndăba.

Tăka hiwăna njoena I R. K: deli ha da kataka mboendăba da, kata poenggoe ja na winoe jeàna, na makaraœ eti djangga na.

Toenanoe na hoeroeng na habandjar, na poenggoe ja ndena loehoe nja; hama toena i ba poenggoe băhi da angoe da pabăhi da kataka. ${ }^{3}$

$\mathrm{Na}$ pahilang noena na habandjar. Hili hoeroeng doea bandjar; na poenggoe ja, ndena loehoe nja; hama na na mapoenggoe woenga ja, ndena loehoeng.

Toenanoe na pahilang na doea bandjar; na hili hoeroeng na patoe bandjar; na poenggoe ja, ndena loehoeng ndăba. Na hili kandoeling na patoe bandjar; na hili hoeroeng na waloe bandjar, na poenggoe ja, ndena loehoe nja. Na kandoeli beling: măta nja kadoena, hiwăna, ndjăpoe na.

Toenancıe njoena I R. K. hiwănanja na tau padoendang na: măla năhoe, hoeroeng habandjar, ndena loehoe nja; hoeroeng mboendăba na, udena Ioehoe nja; beli kămoe la paraingoe njoemoe.

Tăka njoena I R. K. na jăpa ja he’au na na kalá, ${ }^{+}$hina

1 nde pekoe poeroe na pa $=$ hij kan niet meer naar beneden komen. pekoe $=$ mogelijk zijn; wordt steeds geconstrueerd als een verbaal substantief, evenals hoăda= genoeg van iets hebben; wă = zeggen. Ook enkele adverbia, wier plaats vóór 't verbum is, eischen zulk eene constructie: bidi tăka nggoe: ik ben pas gekomen; mbăda lakoe na=hij is reeds weggegaan.

${ }^{2} \mathrm{k} \overline{\mathrm{e}}$ toăma na nja ka la awang $=$ hij bereikte bijna (zoo ongeveer) den hemel. Men vindt dit $\mathrm{k} \overline{\mathrm{e}}$ ook in de uitdrukking: $\mathrm{k} \overline{\mathrm{e}} \mathrm{mandalora}=$ ongeveer middernacht. ( $\mathrm{k} \overline{\mathrm{e}}=$ aannemen - aanpakken.)

3 hama toena; ba poenggoe băhi da angoe da pabăhi da kataka=evenals wanneer ijzer hakt op mede-ijzer (zoo waren) de bijlen.

4 Kalá= castreeren. Men castreert de beesten alleen om ze vet te mesten en bij voorkomende gelegenheden te slachten. 
toboenja: kana ngangoe na tau na padoendanggoe, wăna. Toenanoe bana hăla ka pangangoe ndăba na na tau, hina lakoe ndăba na na tau na padoendangoe na.

Toenanoe na ana winoe noena, na ngéa pahē na njoena I O. Nd., na toăma ka la awang, na lăpăhoe nja na handăni; ningoe paraingoe na. Tăka na tau lai noe: ka nggi lakoe ningoe moe nja, Oemboe Ndiloe? hiwănanja. Tăka na heàma njoena I O. Nd.: lakoe nggoe nja lai toeja. Na heàma njoena na măngoe paraing: djăkau kareànja na ana na na toeja moe, lakoe li papiti nja ata ngăndi' na lai jehoe.

Tăka na hili djangga na winoe, hili toăma ja na handăni; ningoe paraingoe na. Tăka njoena na măngoe paraing: ha Oemboe Ndiloe, nggi lakoe ningoe moe nja njoemoe? Tăka na heàma njoena $\mathrm{I} \mathrm{O} . \mathrm{Nd}$.; lakoe nggoe nja pakanoăma ${ }^{2}$ ja na ana na i toeja. Tăka na heàma njoena na măngoe paraing: djăkau paha ja ka njoemoe, hau mini lănga tăka ma kau; oe lakoe li papiti nja na ndjara pakaliti na.

Tăka na heàma njoena I $\mathrm{O}$. N d.: măla ka.

Tăka na winoe noena na hili djangga, na toăma ja na handăni.

Tăka hiwăna njoena na măngoe paraing lai noe: ha oemboe Ndiloe, ka nggini lakoe ningoe? Tăka na heàma njoena I O. N d. : lo'a nggoe patoe nja winoe rara i toeja. ${ }^{3}$

Tăka na heàma nịoena na măngoe paraing: djăkau kareànja ka njoemoe na ana laleàba moe, hau mini lănga tăka kau; lakoe li papiti nja ahoe, kana dai ja na parai na. Tăka njoena I O. N d. : măla ka doena.

1 ata ngăndi=geleide-slaven, welke de bruid uit 't ouderlijke huis vergezellen en welke bij haar blijven als deel van de bruidschat.

${ }^{2}$ kanoăma kawini=een vrouw trouwen. Men zegt dit van iemand, die, hoewel de bruidschat nog nict geheel is betaald, toch reeds met de vrouw leeft in 't huis zijner schoonouders. Is alles betaald en in orde, dan heet het paha.

3 lo'a nggoe patoe $n j a$ winoe rara $i$ toeja=ik ga aan oom rijpe pinang brengen. In dergelijke „bloemrijke" uitdrukkingen is 't Soemb. sterk. Iemand sirih en pinang brengen, wil zeggen: met iemand over trouwen gaan spreken. 't Is gewoonte dat iemand, zijn aanstaande vrouw, steeds wat sirih en pinang komt brengen.

Zoo zegt b.v. een meisje:

na pangga ngga koeta,

na kakoămba ngga winoe = hij geeft mij sirih en

pinang, d. w. z. hij is mijn "verloofde". [sirih brengt men gedroogd in een rol van één span (pangga) breed; de gedroogde pinang is in een zakje van pinang-boom-bast, $\mathrm{k}$ a koă $\mathrm{m} \mathrm{b}$ a geheeten.] 
Tăka na winoe noena na hili djangga, na toăma ja na paraing; na paraingoe noena, djèa ka na pangéa na na toeja na. Tăka njoena I O. Nd. na lakoe, na todoe la pamangahoe, dămboe roedoe na, patoe mboea roedoe na. Tăka la mbaroe ningoe anakeàda, da malo’a patakoe wai, da doea. Tăka njoena I O Nd. hina ita ha, hiwăna: ha rămboe, ka nggi lo’a mi nja ná! Tăka hiwăda njoeda da anakeàda: lo'a ma nja patakoe wai. Tăka njoena I O. Nd.: lakoe li kadiroe nămoe. Tăka hina karai ha: ka nggăra oela na noedita la paraing; laloe kahăna ja, ndena kanjawoer.

Tăka hida heàma njoeda da. anakeàda: hidoe na nja i oemboe, noedita la paraing; na mătoe ndăba na tau lai noe, na ihi na na panggoeboeloeng awang; ${ }^{1}$ wăna noena i oemboe: djăka ningoe na maningoe tăda aingoe, djăka koe hămoe ma, koe wŏ ma nja ja na ana nggoe.

Tăka noeda da kawini da hili paní: ka ndaningoe pingoe tăda ai, hiwădănja. Tăka na heàma njoena $\mathrm{I} \mathrm{O} . \mathrm{Nd}$.: djăka njoengga noe, na hămoe be ja.

Tăka njoeda da anakeàda kawini: oemboe, măta kama lo’a patakoe wai, hiwădanja. Tăka njoena I O. N d.: lo’a wa ná patakoe wai.

Bada beli ha ka weling la patakoe wai: ha oemboe neloea, măta kama lakoe ă. Tăka njoena I $\mathrm{O} . \mathrm{Nd}$.: ha rămboe, djăkai tăka hoedita la paraing, ămbi kakikoenja na papaní nggoe kawai ; tangedji ă nggoe doekoe.

Tăka njoeda da anakeàda: 'măla kadoena, hiwăda. Tăka da anakeàda noeda da tăka hoedita la paraing, tăka hida peàka la tau, hiwăda: ninja noewawa na tau haätoe ă nang. "Ka nggini ja,» hiwădandja. Tăka da heàma: ninja la pamangahoe. «Kanggiki na, wana?» Da heàma da anakeàda kawini noeda: wăna nggăma bana pa'ărang: kanggiki na noedita la paraing ndena kanjawoer; tăka maheàma njoema, hiwămanja: hidoe na nja $i$ oemboe. "Ka nggiki hidoe», hiwăna. Tăka ma heàma njoema: hidoe na nggoroe na; mapeàka mboe nja njoena: mătoe mboendăba na panggoeboel awang, ndaningoe tăda ai na, ndena pingoe papahămoe nja; "djăka koe hămoe ma, koe wŏ ma nja na ana nggoe, wăna ma, hiwămanja.

${ }^{1}$ panggoeboeloeng awang = de heele wereld; nggoeboel zegt men van een pot, kist ete. welke omgekeerd met de opening op den grond stant. Al wat de hemel, als een omgekeerde pot, bedekt; de gansche aarde. 
Tăka hina heàma njoena I O. Nd.: ha, lo'a papa'aunja. Na paleàwa ja na ama bokoel na haätoe, hina lakoe la pamangahoe, na ita ja, tăka hiwănanja: ha oemboe, mai $\mathrm{i}$, wăna nggau $\mathrm{i}$ oemboe noedita la paraing. Tăka njoena I $\mathrm{O} . \mathrm{Nd}$. : măla kadoena. Tăka njoena I O. Nd. na piti ha da tera na, da hinggi na, da kaloemboetoe na, hina he ja la paraing.

Toenanoe bana táka ka hoedita la paraing, hida piti nja topoe bara hida palăkăroe nja la bangga, hida wŏnja pahăpa na. Toenanoe bana hăla ka pahăpa, njoena na tau na mahidoe hina paní noedita la kaheli. Tăka njoena I $\mathrm{O}$. $\mathrm{Nd}$. hina rongoe ja, hiwăna: djèa ma ja doekoe kawai, hiwănggoe, ămbi peàka doe ndja da tau noedita la paraing; tangedji ă nggoe doekoe, wănggoe ma. Batoenanoe ba lăpăhoe rongoe na nja na marămba ${ }^{1}$; măta kata kamang patăngăroe ja. Tăka njoena I $O . N d$. hina poeroe ja la loemboe mboramang hina wăkăhoe ja na likoe mangeàla, hina pakaloăngga ja; na nimbihoe ha da kambaniroe, na he ja la kaheli; na hăla ja la kaheli, na he ja la hindi oema dita, la talaroe, la hoekoe, loepa na poeroe toebanja noena na tau mahidoe. Bana toăma ja na tau mahidoe hina rau ja na ngaroe na, na ălinja na mangeàla; bana hăla ka pa’ălinja na mangeàla noena, hina băndjăloe ja la lihi na na tau na mahidoe.

Tăka hiwăna njoena I $\mathrm{O}$. Nd.: djè doe ja jeàna na likoe mangeàla na maharítoe, na mangeàla na katioe. Tăka hina heàma njoena na tau mahidoe: mili toe doena ka njoena, koe hămoe ka, koe wŏnggau ja na ana nggoe, hiwănanja. Tăka hina heàma njoena I $\mathrm{O}$. $\mathrm{N} \mathrm{d}$.: măla ka doena, hiwăna.

Tăka njoena I O. Nd. na kanandi nja na eti na; bana hăla ka pakanandi nja, tăka hina karai ja: pirang kakoe tama la koeroeng, ${ }^{2}$ toeja? Tăka hina heàma njoena na toeja: haromoe la maling. Tăka na heàma njoena $\mathrm{I} \mathrm{O}$. $\mathrm{N}$ d.: paleàwa nda anakeàda, lo'a papiti ha da winoe, nindja noewawa la pamangahoe, lima nggai da. Tăka njoena na toeja na hiwăna: măta kada lo'a da tau hakamboeloe, da kareàngoe.

Tăka njoena I O. Nd. na lakoe mangiloe ma. Toenanoe na

1 ba lăpăhoe rongoe na nja na marămba=daar de vorst 't nu toch eenmaal gehoord heeft. Een eigenaardig gebruik van lăpăhoe= voorbijgaan.

2 tama la koeroeng= den kamer ingaan, n.l. de slaapkamer van de vrouw. Is een vaste uitdrukking voor trouwen. Men zegt ook wel: le à m ba r la koeroeng=overstappen in de kamer. 
tăka ka la pamangahoe, hina pa'itandja ja na winoe: nida piti ha, hiwănandja, na hanggai tau madoea madoekoe ha. Toenanoe na tăka ka la paraing njoena I O. Nd.: toeja, hiwănanja, pawălăhoendja topoe parina, ka băndjăloe wăndja da winoe.

Toenanoe bana kikoenja na papaní na, hida pawălăhoenja topoe parina. Tăka hida băndjăloe ha da winoe noeda; bada hăla ka pabăndjăloe ha, tăka njoena I O. Nd.: ha toeja, poeroe kau la bangga, kau tăngăroe ha da winoe neloea. Tăka njoena na toeja na hina poeroe ja la bangga, hina mandapoe pahariangoe la panongoe.

Tăka hiwăna njoena I O. Nd.: tăngăroe ha neloea, toeja! Tăka njoena I O. Nd. hina pareàta ha da tau noeda, ba hakamboeloe ha; lo'a kai kadipoe ai, paloe wăndja da winoe noeda. Tăka njoeda da tau hida kakikoenja. Tăka njoeda hida lo'a papaloe ha la topoe parina. Na woea aja na, na dedi ja ămăhoe rara.

Tăka hida hili paloe ja na woea eri na, na dedi ja ri malokoe.

Tăka na woea eri pandăkingoe na, na dcdi ja patoekoe lomboe djoea.

Tăka na woea eri na na mahili pandăking, na dedi ja mata manoe djoea.

Tăka na woea eri ndau hoepoe na, na dedi ja ndoei djoea.

Da ranggoe da: kanataroe ha hawiangoe; loeloe ămăhoe bara ha hawiangoe; koera moeki ha hawiang.

Toenanoe bana ndjăpoe ndăba ka, tăka hiwăna njoena $\mathrm{I} \mathrm{O} . \mathrm{N}$ d. : toeja, tăngăroe ha noe, na pawoeloe nggoe njoengga.

Tăka hina heàma njoena na toeja na: lănga tăka, lănga tăka, ana! ndaningoe hama moe; ndedi ningoe mapalăkăr topoe parina hau 'marămba hau marămba, hīna njoemoe hikoe ita kau, bana palăkăroe ja na topoe parina hoewoetoe wănja.

Tăka njoena na toeja na hina kanandi nja na eti na, hiwăna la eti na: măta kakoe toenja nggeding, ana hida, na ana nggoe; koe wŏnja ata ngăndi na, kawini djoea, hakamboeloe madoea; anakeàda mini mapihoe; djăka ka, răka wili da ka da banda na nida. ${ }^{1}$

Tăka hina peàkanja I $\mathrm{O} . \mathrm{Nd}$ : ha oemboe Ndiloe, tai la

1 't Betalen van een bruidschat, geschiedt wel is waar door den man, maar de vrouw van haar zijde brengt een gelijke waarde mee terug. De man geeft hoofdzakelijk beesten en mamoeli's; de rrouw brengt slaven en kleeren en versierselen. 
maling tama la koeroeng. Hadang la mbaroe na hiroe nja karămboa tiloe ngioe da; hina remi,

Toenanoe pera doea pahē na na lodoe, tăka njoena na ama jera na I O. Nd., hina paleàwa ha da anakeáda, hida lo'a padoendang; na doenda ndăba nja na kalembi hawoetoe hawoetoe na. Toenanoe bana tăka ka na tau, hiwănanja na ama jera na I O. Nd.: rongoe ndăba kalembi nggoe, mboeloendăba moe: pamangoăma nggoe ja ka na ana nggoe. Tăka na kalembi na na heàma: ka nggăra jéa njoena, mili tau doe ja njoena.

Toenanoe bana hăla ka patoboeng njoena na toeja na hiwăna: toe ndăba nja tanggoe na, mboendăba na na tau na padoendang.

Tăka na he'au, tanggoe nda ja njoeta tau la jehoe la paraingoe.

Toenanoe bana hăla ka pangangoe, tăka njoena na toeja na hiwăna: papoeroe ndja da ana mongoe, kaboeloeloe hamawang; katala hamawang, nggaha hamawang ', pareàndja lamba hau , kabokang hau. Toenanoe bada papoeroe ndăba ndja ka da ana mongoe noeda, mboendăba da da tau na wotoe na paki na; na mini tera haurang, na kawini tera patang; na katanga ngingi, na tidoe hai na.

Toenanoe njoena I O. Nd. na poeroe ja la bangga, na wotoe ha da paki na, da hinggi na, hinggi ămăhoe bara; na roehoe bănggi na, roehoe bănggi hoetăroe, laloe paki ma ja; na likoe paboroe na, likoe marara ja; na tera na, tera ămăhoe rara djoea; na kaloemboetoe na hamang; kanai kapoe na, hamang; na kabeàla na oeloe ămăhoe rara.

Toenanoe hida tondoendja da tau da ana mongoe, bidi mini djoea. Tăka njoena I O. Nd: na mangiloe bana reàndja; bana ndjăpoeng ka pareàndja, hina mandapoe la bangga. Tăka hiwăna njoena na ama jera na: rongoe ndăba kalembi nggoe, kau tăngăroe ja noe na laleàba nggoe, na mapaha ja na ana nggoe! Mboendăba na na tau: ai, ha! lănga tăka, ndaningoe hama na la manandang.

Toenanoe bana hăla ka pawăna, mboendăba na na tau mini na reàndja, na kawini na ninggoe; patoe mboea woela na bana remi djoea djoea.

Tăka njoena na ana na noena na marămba, na poeroe ja paninggoe; da paki na hama da da paki na I O. Nd. Tăka

' kaboeloeloe, katala, nggaha zijn soorten gongs. Dl. 68. 
mboeloendăba na na tau: laloe manandangoe ja na kawini nina, laloe pingoe ja bana ninggoe.

Toenanoe bana hăla ka paninggoe hina hē ja la kaheli la angoe da I O. Nd. Tăka hiwăna njoena I O. Nd.: kalembi na i ama ja mboendăba na na padoendang? Tăka hina heàma na kawini noena: kalembi ndăba ma na nja, ndaningoe tau hawiang.

Tăka hiwăna njoena I O. Nd.: namoe ja, wănggoe. Tăka hina piti ha da ămăhoe, patoe mboea mbeàka da, hina poeroe ngăndi ha la bangga, hina oepoe ha hina hăbăroendja la talora. Tăka mboendăba na na tau na parambandja bana poetoe ha. Toenanoe bana hăla ka pahăbăroe ndja, bana hăla ha ka papoetoe ha ndăba na na tau, tăka hiwăna njoena $\mathrm{I} \mathrm{O} . \mathrm{Nd}$.: toe nggoe noe doe njoengga, ana mamila.

Toenanoe bana hăla ka paremi, na lăpăhoe na patoe mboea woelang, mboendăba na na kalembi na na lakoe ja la parai na. Tăka njoena I O. Nd.: ama, măla kakoe lakoe beli ka la paraingoe. Tăka hina heàma njoena na ama na; napa doea modoeng, hiwănanja. Tăka hina heàma njoena I $\mathrm{O} . \mathrm{Nd}$ : măla ka doena.

Toenanoe na ama jera na na hili hiroenja karămbo'a he'au, hina toboenja. Toenanoe bana hăla ka pangangoe hina kanoăma, lakoe na nja ka la pamangahoe, hina tăka nja na winoe hina hē; da kareà na da tau ata, da hē'ndăba la winoe noena la leàwatoe.

Tăka hiwăna njoena I O. Nd.: wawa kau, winoe! Tăka na winoe noena na ngeri wawa ja ka. Toenanoe hina lakoe li la paraingoe, na lakoe li papiti nja na ahoe.

Tăka hiwăna njoena I O. Nd.: hili wawa kau, winoe! Hina lakoe li papiti nja na ndjara he'au na.

Tăka njoena I O. Nd.: hili wawa kau, winoe! Hina lakoe li papiti nja na ata la paraing, na kawoenga tăka na.

Tăka hiwăna njoena I O. Nd.: hili wawa kau, winoe! kata tăka nja I Rămboe Kahi, ana wini nggoe la tana handădikoe.

Toenanoe na winoe hina wawa ja, loepa na pándakoe ka, hama toena ămang, bana wotoe nja leàwatoe. Toenanoe bana tăka ka, hiwăna njoena I R. K.: ni beli nja ka na ana mini nggoe, na weli ka papaha ja na ana na $\mathrm{i}$ toeja la paraing la awang madjangga. Tăka njoena $\mathrm{I} \mathrm{O} . \mathrm{Nd}$. hina heàma: nggiki na hoe poenggoe "ja na winoe?

Tăka hina heàma njoena I R. K. : na meti doe, wănggoe doe 
nggau, hikoe poenggoe ja ; njoengga bakoe tăngăroe ja na winoe, laloe mărăhoe ja na poăla na na winoe; napa na mbata doe, wănggoe doe hikoe poenggoe ja, hikoe padoendang tau. Tăka hi ndena loehoe nja $\mathrm{i}$; na oela ja ka papoenggoe ja hina djămanja.

Tăka na heàma njoena I $\mathrm{O} \mathrm{Nd}$ : batoenanoe na winoe ba ndena ndjoroe, djăkau papoeroe ngga weling la leàwatoe jeàna, ningoe bădi papapoeroe wămoe ngga.

Tăka na heàma njoena I R. K.: napa păkoe, tiloe modoeng kakoe papoeroe nggau ka. Tăka njoena I O. Nd. hina heàma beli: batoenanoe napa păkoe, kada lo'a pawelingoe karămbo'a da anakeàda. Tăka njoena I R. K. hina paleàwa ha: haätoe bidi mini, madoea makaweàda, haätoe ama bokoel, lo'a pawelindja da karămbo'a, hiwănandja.

Tăka hi ninja na he'au na karămbo'a, laloe mbeni ma ja. Toenanoe bana welindja ka năhoe la ngarăngia, da tăka la pamangahoe.

Tăka na he'au na karămbo'a na mbeni, na patidoeng pabeli ja, laloe hă-hăroe na nja, tăka hina hikoe ja na makaweàda na haätoe, na meti ma. Tăka da angoe na noena na makaweàda, tăka hida koădja ja na karămbo'a, da pameti ja la pamangahoe, hida mătanja; hida welindja hoedita la paraingoe da angoe na.

Toenanoe bada tăka ka, da patamandja la oăka. Tăka hiwăna njoena I R. K.: ha ama, nggini ja ka i bokoe, na haätoe?

Tăka hina heàma njoena na ama bokoel: na kaliti ja ka na he'au na karămbo'a; lakoe nggoe nja ka la kaba aoe ${ }^{1}$, wăna.

Tăka hina heàma njoena I R. K. : ha ama, peàka patăndjing! ămboe tangedji ngga. Tăka na heàma njoena na ama bokoel : na hikoe ja ka na karămbo'a kawai la pamangahoe. Tăka hina heàma njoena I R. K.: ka nggini ja ka na karămbo'a, na mahikoe ja?

Tăka na heàma njoena na ama bokoel: makoădja pameti ma ja noewawa la pamangahoe, kana dăngang na makaweàda, wăma.

Tăka hina heàma njoena I R. K. : lo'a papiti ja na makaweàda, ka ngăndi ja jehoe la paraingoe, ka taninja.

Toenanoe hida lo'a papiti ja hida ngăndi ja la paraingoe. Toenanoe bana hăla ka pataninja, tăka hiwăna njoena I R. K. : na karămbo'a noewawa la pamangahoe: măta nja ka, kana

\footnotetext{
${ }^{1} \mathrm{kaba}$ aoe $=$ 't hiernamaals. vlg. Aant. 7, verhaal IV.
} 
nganja nggangga, ikitoe, ngara mahawoeroeng mboendăba na, măta ka kana hăla ja.

Tăka hiwăna njoena na ama bokoel: pirang ka lo'a padoendang, wămoe, rămboe Kahi? Tăka hina heàma njoena I R. K.: tai la maringoe lodoe, hapoengoe kokoer pándakoe na; tau mapatoe kada lo'a papadoendang mboendăba na na mamai papoenggoe ja na winoe ămang, kirihoe ndăba ja.

Tăka njoeda da tau mapatoe hida lakoe. Toenanoe bada beli ha ka haromoe la mbaroe: nămoe nja na tau na padoendang, hiwăda. Tăka njoena I R. K. hina pareàta ja na tau la paraingoe noena, na kawini djoea, hiwăna: mai ndăba kămoe, mboendăba moe papoeroe ndja da oehoe la dandăkoe la talora, paoehi ndăba ndja da ngohoeng, da aloe, kalambaroe, tăpi, mboăla, tanga mboăla, mboăla kawoenga. Tăka hiwăna njoena l R. K.: bai pareàngganja na oehoe, haromoe la mbaroe papoeroe nja na marămba bokoel, na mawelingoe la awang.

Toenanoe mboendăba na na tau bai ja na oehoe; bana hăla ja ka pabai ja, na toe ja la mboăla kawoenga, hakamboeloe dămboe mboăla kawoenga da; bana hăla paboeri ja hina patangandja hina kabeli ha. Toenanoe bana hăla ka pakabeli ndăba ha hina wotoe ha la kaheli bokoel la toeba kambaniroe oerătoe.

Tăka hiwăna njoena I. R. K.: lo'a wa pa'ohoe nda ai moetoeng, ta manahoe wăngoe haromoe la marai romoe.

Toenanoe bada beli ha ka pa'ohoe ai, na roedoeng ka. Hadang la marai romoe, na wotoe ha da woeroeng kawoenga, bai woeroeng bokoeloe ma. Toenanoe bana harí loendoeng ka, pera doea pahē na na lodoe, mboendăba na na tau na tăka ka, da mătoe ndăba ka.

Tăka hiwăna njoena I. R. K.: ha ama bokoel, mai i nămoe. Tăka njoena na ama bokoel hina hadang hina lakoe toăma ja.

Tăka njoena I R. K.: ha ama, lakoe wa ná, hoepapa la kaheli bokoel, njoemoe tăngăroe wiki moe tau mahamajang.

Tăka njoena na ama bokoel hina pala ja la kaheli bokoel hina tăngăroe ja haätoe na na makaweàda, na mapingoe pahamajang.

Tăkạ hiwăna njoena na ama bokoel: ha rămboe Kahi, wŏnda pahăpa. Marapoe, ninja ka na matanggoe hamajang.

Toenanoe bana hăla ka pahamajang, toboendja da karămbo'a, hakamhoeloe tiloe ngioe da. Toenanoe bana hăla ka patoboeng, 
hida hoăwăkoe ha, hida tăngăroe ha da eti da da karămbo'a noeda, da pahăla patoboeng; tăka njoena na ama bokoel: da hămoe da eti karămbo'a, rămboe Kahi, hiwănanja. Tăka hina heàma njoena I. R. K.: mili toe doena njoena, ka da hămoe da eti da da karămbo'a.

Tăka njoena I R. K. hina pa'aunja I O. N d., ana mini na dăngoe na papaha na. Toenanoe hida lakoe patoăma ja noeloea la koeroeng, la toeba hanamba. Tăka njoena I R. K. hiwăna: ana mini nggoe njoengga, ndaningoe matoăma ja na papaha na, ndaningoe matoăma ja la manandang. Tăka na heàma njoena I O. N d.: lănga tăka ka i njoena, na papaha nggoe njoengga, nde tau lai jehoe ja, tau la awang ma ja doekoe.

Toenanoe bana memi ndăba ka da oehoe, da toloeng, tăka hiwăna njoena na ama bokoel: ha rămboe Kahi, takoe ă.

Tăka njoena I R. K. hina takoe, hiwăna: diha ja, djăka pira na na tau na padoendang. Tăka njoena na ama bokoel: napa kakoe diha ja ka. Toenanoe hina diha ja; bana hăla ja ka padiha ja, hiwăna: ha rămboe Kahi, tiloe ngahoe waloe kamboeloe madoea haätoe ha. Tăka na heàma njoena I R. K.: djè doe ja, kata pinja.

Toenanoe bana hăla ka patakoe, hina pakē mangiloe ndja da oehoe mangedjing, patoe mboea kawori da. Toenanoe bana hăla ka papakē ndja da oehoe mangedjing, njoena na matanggoe hamajang, hamajang na nja ka doena.

Na pakē mangiloe nja na oehoe na na matanggoe hamajang. Tăka hina pakē ndăba nja oehoe na tau dangoe. Toenanoe bana hăla ka papakē nja, bana ndjăpoe ndăba ka, tăka hina pakē nja tanggoe na toloeng.

Toenanoe ngangoe na nja ka mboeloendăba na na tau na padoendang na tau lai noe la paraingoe mboendăba na. Toenanoe bana hăla ka pangangoe, bana maringoe ka na lodoe, hiwăna na tau padoendang: ha rămboe Kahi, oemboe Ndiloe, ana mini na I R. K., mai kămi nămoe, kai hăpa, kama lakoe.

Tăka hida pala ngăndi ndja pahăpa da, hakawita mboăla da, na pambinoe waing na mboăla winoe; hina paberi ndăba nja na tau na padoendang. Toenanoe bana ndjăpoe ka hida hăpa; da hăla ka pahăpa: măta kama kanoăma wa, kama lakoe. Tăka hina heàma njoena I R. K.: măla kai lakoe ă.

Toenanoe bana lakoe ndăba ka na tau, tăka hiwăna njoena I O. N d.: ha aja, măta kakoe lo'a patăngăroe ja na ina kakoeta 
nggoe. Tăka hiwănanja I R. K.: peàka nja i tamoe, woeloe nja oema na na paraing na hau, kana lakoe na papaha nggoe lai noe, na kareà mboe ndja da ata na mboeloendăba da.

Toenanoe bana lakoe ka, tăka I R. K. hina peàka nja I O Nd. haätoe: lo'a pawoeloe nja oema na la paraingoe nina, wăna na tamoe moe. Tăka na heàma njoena $\mathrm{I} O \mathrm{O}$. N . noena: măla ka, măta kakoe woeloe nja ka. Tăka hina woeloe nja lima mboea da da oema; na wotoe nja kili mbatoe la paraingoe noena, na winggiroe ma nja. Na hăla ja na kilimbatoe, na na pandoi ja na pindoe, papakoe pali daloeng.

Toenanoe bana hăla ja ka hina peàkanja na papaha na na jera na: lakoe ă la paraingoe lai noe; mbăda hăla nggoe ha ka da oema pawoeloe ha, pindoe, kili mbatoe, koe hăla ndăba ha ka pawoeloe ha.

Tăka na papaha na I O. N d., na malakoe, hina lakoe ja la paraingoe noena.

Toenanoe I O. N d. bana tăka nja ka na ina kakoeta na, mbăda meti na ka, ndena toăma ma nja pa; na hakoeloeroe be ka bana mădoe ka. Tăka nioena I O. N d. hina piti ja, hina kamboeroenja, hina poeroe ngăndi ja la tana, la padoea talora, hina ăki nja hina tani nja. Toenanoe bana hăla ka patani nja, na oema noena na koehi nja epi hina hoeloe ja, hina lakoe.

Toenanoe bana tăka nja la paraing, na kawoenga tăka na ămang bana lakoe, hina pa'aung la pamangahoe, hiwăna: papoeroe ndăba nja da ata, da pahăla papeàka moe ămang, bakoe lakoe li.

Tăka la hau paraing, hamang; tăka la hau paraing, hamang; tăka la hau paraing, hamang; loepa da ndjăpoe da paraing da mapeàka nja palohoe. 


\section{De tol.}

Het begin van 't verhaal: er waren eens weezen, hun ouders hadden hen door hun dood achtergelaten; de namen van die weezen: I Oemboe Ndiloe de één, en 't meisje, I Rămboe Kahi was haar naam; zij, I Rămboe Kahi, was de oudere.

$\mathrm{Na}$ verloop van langen tijd, nadat men hun ouders had begraven, was er een groot varken, door hun ouders opgefokt; dat varken was een varken met uitstekende slagtanden. En het ging naar de tuinen van andere menschen, 't at de maïs op, reeds ver weg was het. En de eigenaar van den tuin zag het, en hij nam zijn lans en zijn kapmes en bracht zijn paard naar buiten en besteeg het.

Hij joeg 't varken achterna, en 't varken beklom een berg, 't kwam boven op den top en 't daalde wederom af in 't dal. $\mathrm{Hij}$, die het achterna joeg, kwam boven op den top, hij keek er naar; op een anderen berg was 't varken. En wederom klom die man naar beneden, hij klom weer naar boven, hij kwam op den top, hij keek er naar: op een anderen berg was 't varken. Hij klom weer naar beneden, klom weer naar boven, hij keek er naar: op een anderen berg was 't varken. En hij klom naar beneden, klom weer naar boven, hij kwam op den top en hij zag naar beneden in 't dal, hij zag huizen, drie stuks. En hij klom naar beneden en hij kwam in 't dal, de plaats der huizen. Hij kwam bij 't huis en zag het varken, door hem zoo even nagejaagd; en hij stak dat varken; toen hij gestoken had en 't varken dood was, daalde I Rămboe Kahi af in de voorgalerij.

Zij zeide tot hem terwijl zij hem vroeg: waarom hebt gij mijn varken gestoken, daar 't een varken van weezen is? I Oemboe Ndiloe antwoordde: $\mathrm{ik}$ hier ben een zoon van I Taroe Tiboe, ik ben een zoon van de zuster van uw vader, daarom ben ik gekomen om 't varken te steken, het heeft opgemaakt de mais, de rijst etende in mijn tuin.

En I Oemboe Ndiloe sleepte het varken en brandde (de borstels er) af; nadat hij 't afgebrand had, nam hij 't op en legde 't in de voorgalerij. En I Rămboe Kahi klom (in huis) 
om hem zijn sirih te halen en zij gaf 't hem; hij wilde niet. $Z_{i j}$ ging weer naar binnen, nam een bronzen bord en deed 't er op; zij reikte 't hem toe, hij wilde geen sirih kauwen. En I R. K. ging halen, waarop men de sirih voor den Marapoe deed, een gouden bordje, en zij gaf 't hem. En I O. Nd. nam 't aan en hij kauwde sirih.

En I O. Nd. gaf zijn sirihtasch aan I R. K.; maar I R. K. wilde geen sirih eten uit de sirih-tasch van I O. Nd. En I O. $\mathrm{Nd}$. zeide: ik neem u mee naar mijn huis, zeide hij tot haar.

Maar I R. K.: é, ik wil niet. Vervolgens I O. Nd.: waarom wilt gij niet, (hier) is de plaats, waar ik mijn vrouw van daan haal.

En I O. Nd. stond op en sloeg de buik van 't varken open; vervolgens deelde hij 't in tweeën; toen hij 't varken verdeeld had, sneed hij het in twee stukken; hij deed de achterpooten bij elkaar, hij deed de voorpooten bij elkaar; zijn kop sneed hij er af; zijn ribben haalde hij er uit; vervolgens bond hij de pooten van 't varken te samen, zijn achterpooten met zijn voorpooten, en hij bond 't aan elkaar.

Toen zeide I O. Nd.: kom toch naar beneden, Kahi, wij gaan. Maar I R. K. antwoordde en zeide: mijn jongere broeder, Oemboe, neem hem mee, zegt gij ? Maar I O. Nd. antwoordde: neem uw jongeren broeder, smijt hem op den grond, opdat hij sterve; wat hebben wij aan hem, als wij hem zouden medenemen, die schurftige paardennek!

En I R. K. antwoordde: wacht even, Oemboe, dan zal ik eens goed naar mijn jongeren broeder kijken, zeide zij tot hem. En I R. K. nam nu een pisang-bloem en twee stukken varkensvleesch; één stuk legde zij neer aan zijn linkerzijde, 't andere stuk sneed zij in tweeën; één stuk plaatste zij aan zijn rechterzijde, en 't andere stuk hing zij op recht tegenover hem. Toen nam zij den "mooie tol» en 't gouden tollentouw en legde 't neer aan zijn zijde.

En I Oemboe Ndiloe, die 't varken gedood had, zeide tot haar: ha Rămboe Kahi, kom toch naar beneden, wij gaan. En I R. K. antwoordde: ja; toen zij klaar was met alles voor haar jongeren broeder compleet te maken, zijn dingen om mee te spelen, het eten, toen nam zij $\mathrm{kamănggihoe} \mathrm{pitten,} \mathrm{één}$ handvol. $\mathrm{Zij}$.nam een stuk rood goed en zij ging naar beneden naar de groote vloer. $Z$ ij bereikte de deur van de groote vloer en zij scheurde een stuk af van 't roode goed: 
Oemboe Ndiloe, schuil in mijn schaduw treed in mijn voetsporen.

Vervolgens daalde zij geheel af in de voorgalerij; wederom scheurde zij een stuk van 't roode goed, en zij zeide:

Oemboe Ndiloe, schuil in mijn schaduw

treed in mijn voetsporen.

En de zuigeling antwoordde: ja'œ.

Toen daalde zij geheel af op den grond, zij plantte de kamănggihoe-pitten juist vóór de plaats waar men naar beneden gaat; toen zij ze geplant had, zeide zij:

Oemboe Ndiloe, schuil in mijn schaduw

$$
\text { treed in mijn voetsporen, }
$$

waar ik ook verblijf moge houden, als ik aan 't weven ben, gooi mij dan met den tol, breek mijn groote teen, 't weefgetouw zult gij scheuren.

En de zuigeling antwoordde: ja, œ, zeide hij.

Wederom ging I R. K., zij bereikte de deur van de kampong, vervolgens scheurde zij een stuk van 't roode goed: Oemboe Ndiloe, zeide zij tot hem: schuil in mijn schaduw,

\section{treed in mijn voetsporen.}

En de zuigeling antwoordde: ja, œ, zeide hij.

Vervolgens gingen zij heen, I R. K. met I O. Nd.; en zoo kwamen zij aan hun woonplaats.

Toen zij nu juist weggegaan waren, I R. K. met I O. Nd. daar werd de pisang-bloem een mensch, en zij nam 't kind op en gaf het te zuigen; en 't varkensvleesch kookte zij en stak't in zijn mond.

Toen hij nu langzamerhand wat ouder was geworden, nam zijn pisangbloem-moeder, den "mooie tol» en 't gouden tollenkoord, en zij gaf 't hem. En I O. Nd. daalde af op den grond en hij wond dien tol op en wierp hem naar de deur. Toen ging hij hem weer terug halen en hij klom weer in huis en hij sprak tot zijn pisang-bloem-moeder en hij zeide tot haar: moeder, ik kan mijn tol al opwinden. En zijn pisang-bloem-moeder antwoordde: dat is goed.

Wederom op een anderen dag, nam hij wederom zijn tol eens, ging naar buiten bij de deur van de kampong en zag een kip. En I O. Nd. zeide: ho! als deze kip 't bezit is van mijn ouders, dan zal ik 't maar éénmaal doen straks met den tol. Hij wond zijn tol op en wierp dien naar dien kip; hij raakte 
den kip, deze was terstond dood; toen hij den kip bezag, zijn kop was verbrijzeld door 't raken van den tol.

En hij nam dien kip op en bracht hem naar huis en liet hem zien aan zijn moeder. En zijn moeder zeide: waar komt deze kip van daan, oemboe? Toen antwoordde I O. Nd.: een kip van mijn ouders is 't.

Wederom op een anderen dag vroeg hij aan zijn moeder: is er geen teerkost, welke gij voor mij zoudt kunnen stampen? En zijn moeder antwoordde: er is een weinig van de aardwortels, laat ik ze voor je stampen als teerkost. En I O. Nd. antwoordde en zeide tot haar: bak voor mij kambambang, acht stuks.

Toen zij die kambanbang gebakken had, zeide zij tot I O. $\mathrm{Nd}$. : die teerkost is al gaar. I O. $\mathrm{Nd}$. antwoordde: morgen, dan zal ik vroeg weggaan, om te gaan bezien 't veld der paarden.

En hij stond 's morgens vroeg op en maakte zich gereed en hij zeide tot zijn pisang-bloem-moeder: moeder, laat mij gaan bezien 't weideveld der paarden, of er nog zijn paarden en karbauwen.

Aldus nu ging I O. Nd. en hij kwam op den weg; en hij zag een paard aan de zijde van den weg. Vervolgens wond hij 't touw om zijn tol en hij zeide: ho, als dit paard 't bezit is van mijn ouders, dan zal ik 't maar éénmaal doen met den tol. Hij wierp nu zijn tol, hij raakt het, 't paard was terstond dood. En I O. Nd. ging en sneed de buik open met een mes, een weinig slechts sneed hij 't open, hij nam de lever er van; toen hij de lever er van genomen had, ging hij wederom, een weinig verder.

Hij zag wederom een karbauw, en hij wond 't touw om zijn tol en hij zeide: ho, als die karbauw 't bezit is van mijn ouders, dan zal ik 't maar eenmaal doen, straks is hij terstond dood, (ik doe 't) met den tol.

En hij wierp zijn tol, hij raakte den karbauw, zijn kop; hij was terstond dood. Toen de karbauw dood was, ging I O. Nd., maakte den bek van den karbauw open en sneed zijn tong af en nam die mee.

Wederom ging hij een eindje verder en hij zag een groote kampong; vervolgens zag hij menschen, die water gingen scheppen en hij vroeg hen: wat doen de kinderen daarboven in de kampong, zeide hij tot hen. 
$\mathrm{Zij}$, die water gingen scheppen, antwoordden: kinderen, die aan 't tollen zijn. En I O.Nd. zeide tot hen: hoe is 't, als ik in de kampong klim, zal dan de kampong-vorst misschien boos zijn?

En zij, die water gingen scheppen, antwoordden: waarom zou hij boos zijn; als gij zijn paarden gaat stelen, dan is hij boos.

$\mathrm{Z}_{\mathrm{ij}}$, die water gingen scheppen, gingen heen en I. O. $\mathrm{Nd}$. ging verbergen zijn slimoet, zijn hoofddoek, zijn kapmes; hij verborg het in een steenholte. Toen hij 't verborgen had, nam hij een gescheurde doek en deed die om, evenals iemand, die in 't geheel geen slimoet heeft. Vervolgens nam hij zijn tol en klom naar de kampong. Hij kwam in de voorkampong en hij keek naar een hoogen steen om op te zitten; toen hij een hoogen steen zag, ging hij heelemaal naar binnen; vervolgens ging hij boven op den steen zitten, gelijk een jongen, die zich ingewreven heeft met stof. En de kinderen, die aan 't tollen waren, zagen hem en zij zeiden: wie zou dat toch zijn daarboven op den steen, hij zit voortdurend ineengebogen neer.

En één jongen zeide: ha, gij daar boven! kom, dan zullen wij tollen, zeide hij tot hem.

Maar I. O. Nd. antwoordde: ai, straks zult gij boos op mij zijn; ik wil niet, zeide I. O. Nd. En de kinderen, die aan 't tollen waren: ha, kom jij maar!

En I. O. Nd, kwam naar beneden van boven af den steen en hij zeide: welaan laat mij toch 't eerst den tol zetten, gij allen, werpt allen tegelijk. En de vele kinderen zeiden: ja.

I. O. Nd. zette nu den tol, en zij allen wierpen, maar zij raakten den tol van $\mathrm{I}$. O. $\mathrm{Nd}$. niet, in hun werpen.

Toen zeide I. O. Nd.: nu is 't mijn beurt om te werpen; en I. O. Nd. ging een eindje van de tollen af en hij wierp, hij raakt die tollen, zij waren allen stuk.

En die kinderen, eigenaars van de tollen, zoo even gebroken, zij grepen I. O. Nd. en zij bonden hem met een touw en zij bonden hem onder de stookplaats; eten gaven zij hem niet; als de menschen van 't huis kookten, als men 't warme water afgoot, dan stortte men 't op I. O. N d. onder de stookplaats. Drie dagen, vier dagen, en I. O. Nd., daar hij voelde pijnlijke hoofdklopping, zeide: stijg op, gij water, opdat drijven al de rijststampers en rijstblokken.

En 't water steeg en overstroomde geheel de kampong: alle 
rijststampers, de rijsiblokken, de paarden, de varkens, de geiten, zij dreven allemaal.

En de huiseigenaar zeide: ha oemboe, beneden de stookplaats, niet alzoo! laat bedaren uw hart, dat vertoornd is; als gezakt is dit water, dat stijgt, dan zal ik u geven slaven, een kampong vol. Vervolgens (zeide) I. O. N d.: zak weer terug, gij water! Toen 't water gezakt was, zeide de huiseigenaar: welaan zal ik u heden terstond geven de slaven, door mij beloofd?

Maar I. O. Nd. zeide: wacht maar, als ik terugkom, dan zal ik aankomen om ze te halen. En hij vertrok uit die kampong. Vervolgens ging hij halen zijn slimoet, zijn kapmes, zijn hoofddoek, zijn sirihtasch en zijn teerkost; er waren nu maar zeven stuks kambambang.

Toen hij zijn hoofddoek om gedaan had, zich gekleed had, ging hij weer. Hij ging en zag een kampong, zeer groot was die. Toen hij bereikt had de beneden-tuinen, zag hij menschen, die water gingen scheppen.

En hij vroeg hen: wat doet men daar boven in de kampong, dat er zoo'n feestgedruisch is, naar ik hoor. En die menschen, die water gingen scheppen, zeiden: ai, dat zijn maar kinderen, die aan tollen zijn. "Hoe is 't, wanneer men er heengaat, is dan het kamponghoofd soms boos? Maar zij, die water gingen scheppen, antwoordden: neen, 't kampong-hoofd zal niet boos zijn.

En zij, die water gingen scheppen, heen gingen $z \mathrm{ij}$, en I O. Nd. ging verbergen zijn slimoet, zijn hoofddoek, zijn kapmes, zijn sirihtasch, alles verborg hij in een rotsspelonk. Toen hij het yerborgen had, nam hij de gescheurde doek, door hem gedragen in de kampong, waar hij 't eerst gekomen was.

En hij ging, hij kwam in de voorkampong en hij zag een witte kalksteen, zoo groot als een mand. En hij ging en ging daar ineengebogen zitten.

En de kinderen in die kampong, zagen I O. Nd. en sommigen zeiden: kijk eens daar, die jongen, net als een wild varken, een schurftige hond! Maar sommigen zeiden: spreek niet alzoo, 't is een mede-mensch, gij moet niet al te ondeugend zijn. En sommigen zeiden: ha, jongere broeder, kom hier!

Vervolgens zeiden zij tot hem: laat ons tollen, zeggen wij, daarom roepen wij je. Maar I O. Nd. antwoordde: naar ik denk in mijn hart, straks als wij tollen, zal dan uw hart niet vertoornd zijn? Maar sommigen antwoordden: waarom zouden 
wij daarom boos zijn, laten wij maar tollen! En I O. Nd. zeide: laat mij den tol eerst plaatsen, gij allen moet allen tegelijk werpen, wacht niet totdat hij uit (gedraaid) is.

En al die kinderen: dat is goed.

En I O.Nd. wond zijn tol op, zij wierpen naar dien tol, er was niemand, die hem raakte. Toen zeide I O. Nd.: zet ze nu voor mij neer, dan zal ik werpen. En d!e kinderen wonden allen hun tollen op. En I O. Nd. wierp zijn tol, al die tollen waren stuk. Toen hun tollen gebroken waren, grepen zij I O. Nd. zijn tol af en 't gouden tollen-touw en legden 't op een verborgen plaats. Vervolgens grepen zij hem, bonden hem en bonden hem vast bij de plaats, waar men (uit 't huis) naar beneden gaat; al wie op den grond afdaalde, trapte op hem; die in huis klom, trapte op hem.

Maar des nachts zong I O. Nd.: geef mij hem, geef mij hem vlug; mijn mooie tol, mijn gouden tollen-touw; ik ben bezig met I Kahi, mijn zuster; schuil in mijn schaduw, daar zij toch tegen mij zeide; treed in mijne voetsporen, daar zij toch tegen mij zeide; terwijl zij scheurde 't roode goed, terwijl zij plantte, een handvol kamănggihoe, juist voor de plaats van nederdalen, aldus is 't dat ik naspeur haar voetspoor.

En de huiseigenaar hoorde dit kind: hij zoekt iets, 't zal goed zijn als wij hem zijn tol geven, zeide hij. En de huiseigenaar zeide: wij zullen hem boete moeten betalen, slaven, één kampong barstens toe vol.

Men nam zijn tol, en gaf 't hem en zijn gouden tollentouw.

En zij vroegen hem en zeiden tot hem: wat is uw verlangen, als wij $\mathrm{u}$ boete betalen? Toen antwoordde I O. Nd. en hij zeide: mijn verlangen, hoor het, slaven één kampong barstens toe vol; gouden oorversiersels : duizend; goede paarden : vijf kudden; volwassen mannetjes karbauwen: 3 kudden; herten, wier hoornen nog niet gegroeid zijn: vijftien; dit slechts is mijn vragen, als gij er toch.in staat toe zijt mij boete te betalen.

En 't kamponghoofd zeide: ik toch ben de schuldige, ik zal u boete betalen, zooveel als gij zooeven hebt opgenoemd.

En men vroeg hem en zij zeiden tot hem: welaan nu, betaal mij toch, zegt gij; op dezen dag? Maar I O. Nd. antwoordde: wacht maar, als ik terug gekeerd ben, dan zal ik aankomen om 't te halen.

Vervolgens vertrok hij uit die kampong; hij ging aan om te 
halen zijn slimoet, zijn hoofddoek, zijn kapmes, zijn sirihtasch en hij kleedde zich aan en deed zijn hoofddoek om.

En wederom ging hij; wederom zag hij een kampong, een kampong van arme menschen was 't; in de kampong was 't aantal menschen zestien slechts, vrouwen, mannen en kinderen te samen genomen.

Vervolgens zag hij een vrouw, die water ging scheppen, zij was oud, haar tanden waren reeds afgebrokkeld, haar haren reeds wit, evenals van de kakatoe. En hij vroeg haar: ha grootmoedertje, waarheen gaat gij daar? En die oude antwoordde: $\overline{\mathrm{e}}$, ik, ik ga maar water scheppen.

En I O. $\mathrm{Nd}$. zeide: boven in de kampong is 't zeer rustig. En die oude antwoordde: er zijn geen menschen daarboven in de kampong, kinderen drie of vier maar. En I O. Nd. zeide tot haar: hoe is 't, als men er aangaat, laten wij tollen, als men dat tot hen zegt? Die oude antwoordde: waarom zouden zij 't niet willen, daar zij nu toch maar aan het spelen zijn.

En zij ging heen de oude. En I O. Nd. ging verbergen zijn slimoet, zijn hoofddoek, al wat hij meebracht. Vervolgens nam hij 't gescheurde doek, door hem gisteren en eergisteren aangedaan. En hij ging; hij kwam bij de deur en hij keek en hij zag kinderen, die aan 't tollen waren, twee slechts. En hij ging en zat in de voorgalerij. De huiseigenaar kwam, hij sprak fluisterend in huis: van waar zou die knaap toch zijn; zeer schoon is zijn schouderdoek, een doek met figuren; zijn lendendoek, een doek met goud geweven. Vervolgens kwam men hem brengen zijn sirih: hier is 't, vorsten-zoon! waar gaat gij heen? "Ik ga 't land bezien». En de kinderen, die aan 't tollen waren: ha Oemboe, uw tol is zeer schoon, laat ons tollen.

Maar I O. Nd. zeide: mijn tol is zeer bros, hij is spoedig stuk. "Ai ha! laten wij 't maar probeeren!» Vervolgens I. O. $\mathrm{Nd}$ : als 't zoo moet, laat mij dan 't eerst den tol zetten. En de kinderen zeiden: dat is goed; uw tol, straks breekt hij in kleine stukjes.

En I. O. Nd. zette zijn tol, en die twee kinderen wierpen, zij raakten hem niet. Vervolgens I. O. Nd. : zet ze mij nu maar, dan zal ik werpen; daar wij maar spelen, moet gij niet boos zijn, ai! Zij nu zetten hun tollen en I O. Nd. wierp en zij braken, de tollen van die knapen, zij waren kort en klein.

En die twee knapen: ai ha, gewonnen heeft die "mooie" 
tol, erg mooi is hij, laat ons hem afnemen. Toen grepen zij I O. N.d. en zij bonden hem met een touw en zij brachten hem juist voor de plaats, waar men (in huis) klimt. Dag en nacht, ieder die afdaalde op den grond, trapte op hem, ieder die in huis klom, trapte op hem.

Maar des middernachts zong I O. $\mathrm{Nd}$. en hij zeide: geef hem mij, mijn "mooie» tol, mijn gouden tollen-touw, geef mij, geef 't mij vlug, ik speur na haar voetspoor, ik ga na ('t spoor) van haar tong, I Kahi mijn zuster, omdat 't uw wil is te blijven bij de rivier, welke men aandoet, bij den weg, welke men overtrekt.

En de huiseigenaar schrok, daar hij aan 't slapen was. Vervolgens stond hij op en luisterde, toen (zeide) I O. Nd.: 't is niet mijn eigen wil geweest, hier aan te gaan, want 't was haar verkiezing, (hier) te gaan overnachten, I Kahi mijn zuster.

En de huiseigenaar luisterde goed; toen hij 't gehoord had, hield I O. Nd. op met zingen.

's Morgens vroeg stond hij op en hij vroeg hem: oemboe, wat zoekt gij? I O. Nd. antwoordde: ik zoek I Kahi, mijn zuster, zeide hij: "Als 't zoo is, laten wij hem dan losmaken", zeide het kampong-hoofd. Men maakte zich op, de één, een sterke man, maakte hem los; hij was er niet toe in staat, de touwen waren te vastgebonden. Ieder, die in de kampong was, maakte zich op. zij waren heelemaal niet in staat hem los te maken. Er was nu één der familiehoofden: waarom is 't, dat wij niet in staat zijn de touwen los te maken? En I O. Nd. antwoordde: men moet mij boete betalen, dan is men in staat ze los te maken. En 't familiehoofd antwoordde: waar mee zullen wij u boete betalen, daar wij toch arme menschen zijn. Maar I O. Nd. antwoordde: wanneer gij niets hebt om mee te betalen, geef mij dan maar een vorst, van zuivere afkomst. Vervolgens het familie hoofd: een vorst van deze kampong hier, is er niet.

En I O. Nd. antwoordde: laat 't dan maar zoo, ik zal u allen, die in deze kampong hier wonen, tot slaven maken.

Maar 't familie-hoofd antwoordde: $\bar{e}$, zoo wil ik niet; wij allen, wij zullen u dood slaan. En I O. Nd. antwoordde: spreek niet alzoo. Maar het familie-hoofd antwoordde: laat 't dan maar zoo, kies uw verlangen, zeide hij tot hem.

En I O. Nd. antwoordde: geef mij een paard met zwarten 
kop, zeide hij tot hem, dan zult gij de touwen kunnen losmaken, zij zullen losgaan. En 't familie-hoofd antwoordde: er is een paard met zwarten kop, onder 't huis.

Men maakte de touwen los, zij gingen los. Toen (zeide) 't familiehoofd: zullen wij u nu terstond geven het paard met zwarten kop? Maar I O. Nd. antwoordde: ik moet eerst terugkomen, dan zal ik 't komen halen.

Vervolgens ging I O. $\mathrm{Nd}$. heen, hij vertrok uit de kampong.

En hij ging aan om te halen zijn slimoet, zijn hoofddoek, zijn sirihtasch, alles toch wat hij meegenomen had. Toen hij zijn hoofddoek om gedaan had en zich gekleed had, ging hij wederom.

En hij zag een groote kampong; hij kwam in de benedentuinen en daar zag hij jonge meisjes, vier waren er, die water gingen scheppen. Die vrouwen, terwijl zij water gingen scheppen, juist waren zij uit de poort gekomen, of zij zongen, zij hielden niet op met hun gillend geluid. En hij vroeg haar: ha ramboe, waar komt gij van daan? De vrouwen antwoordden: wij komen van boven uit de kampong, zeiden zij tot hem.

En I O Nd. antwoordde: in deze kampong, naar ik hoor, is men erg aan 't feestvieren. "Waarlijk, zeiden de vrouwen, onafgebroken viert men feest, men houdt niet op.» En die vrouwen, heen gingen zij om water te scheppen. En I O. Nd. ging aan in een groot bosch en hij verborg zijn slimoet, zijn hoofddoek in een boomholte; vervolgens nam hij 't gescheurde doek, zoo dikwijls door hem gedragen en hij klom naar de kampong.

Hij nu kwam bij de deur en bij menschen, die op de gongs sloegen, die dansten. En I O. Nd. ging naar binnen, hij kwam in de kampong en sommige kinderen waren aan 't tollen achter 't huis. Maar I O. Nd. ging naar hen die aan 't gong slaan waren en zette zich daar neer. Maar de vele kinderen zagen hem en gingen naar hem toe en vroegen hem: waar komt gij vandaan?- En I O. Nd. antwoordde: ik kom van 't (djagong) gieten, zeide hij tot hen. En de vele kinderen antwoordden: laten wij tollen. Maar I O. Nd. antwoordde: daar 't nu toch feest is, zullen de volwassenen boos zijn. Maar de kinderen antwoordden: laat men maar feestvieren, wij zullen tollen. «Laten wij dan maar tollen, ik zal mijn tol dan 't eerste zetten.» De vele kinderen antwoordden: welaan. En I O. Nd. zette zijn tol: gij allen, werpt allen op éénmaal tegelijkertijd. De knapen nu volgden 't woord van I O. $\mathrm{Nd}$., zij wierpen allen, zij raakten 
hem niet. Vervolgens nam I O. Nd. zijn tol: zet ze nu voor mij. Al de knapen wonden hun tol op, en hij wierp zijn tol; hun tollen gebroken waren ze tegelijkertijd

Toen hun tollen gebroken waren, grepen zij af den tol van I. O. Nd. en zijn gouden tollentouw en zij namen 't mee, zij lieten 't zien aan hun ouders: deze tol, de knaap, welke dezen tol bezit, is er. Toen riep men hem en de volwassenen vroegen hem: hoe is 't met je, dat gij al de tollen breekt van de kinderen hier in de kampong?

Maar I. O. Nd. antwoordde: dat zullen zij zelf wel weten, daar zij met mij tollen wilden. En de volwassenen: deze knaap is een knaap, die tollen opmaakt.

En men greep hem, en bond hem aan een Karoekoe boom, en zij zeiden: geeft hem geen eten, geeft hem geen water te drinken, maakt hem niet los, laat hem sterven, laat hem stijf worden in de brandende zon.

Maar I. O. Nd., toen hij hem hoorde, sprak in zijn hart: ai, ik zal wel eens moeten sterven (maar nu nog niet!)

De huiseigenaar nu daalde af op den grond; er was ook een oude (vrouw), die sliep in de voorgalerij en zij zeide tot hem: wie zijt gij, die daar naar beneden komt? En de man, die naar beneden kwam zeide; ik, grootmoeder. "Als gij 't zijt, kom dan hier. En de oude sprak tot den man, die afdaalde op de aarde, zij zeide tot hem: gij moet niet weer in huis terug klimmen, strakjes moet gij met mij even naar hem hooren, die daar bij den karoekoe boom zingt.

En I. O. Nd. zong; pas was 't maar - dat ik hier kwam aan een karoekoe boom - bond men mij hangend - eten gaf men mij niet - water gaf men mij niet - geef, vlug geef hem mij - mijn "mooie" tol - mijn gouden tollen-touw - ik zoek I Kahi - mijn zuster - die mij scheurde - rood goed die mij plantte - kamănggihoe pitten - juist voor de plaats, waar men neerdaalt - als gij mij hem niet geeft mijn "mooie» tol — gij allen — in de kampong hier — gij zult uitsterven - gij zult geen overblijfsel achterlaten.

En zij, die in de voorgalerij sliepen, luisterden naar hem terwijl hij zong, gebonden aan den karoekoe boom.

Vervolgens (zeide) de een, die afdaalde naar den grond: werkelijk, grootmoeder, hij heeft wat te zoeken, hij kwam maar eens aan.

Dl. 68 . 
En zij stonden des morgens op en vertelden 't aan de familie-hoofden, die dien knaap gebonden hadden. Maar die familie-hoofden antwoordden: gij spreekt nu maar wat onzin. En zij antwoordden, zij, die hem hadden hooren zingen: laat 't zoo zijn, straks in den nacht, zult gij zelf hem hooren zingen. Toen men gegeten had, daalden de familie-hoofden af in de voorgalerij, vijf warën 't, en zij luisterden naar hem of hij straks te middernacht zou zingen. En zij riepen ook de oude, die 't het eerst gehoord had: kom gij hierheen, dan zullen wij eens luisteren naar uw praten zooeven overdag; 't is nu middernacht.

En I O. Nd. zong wederom, hetzelfde was 't als hij gisteren nacht gezongen had.

Toen zeiden de familie-hoofden: morgen vroeg zullen wij hem losmaken, zullen wij hem goed ondervragen: wat zoekt gij toch, zullen wij tot hem zeggen, terwijl wij hem vragen.

En 's morgens vroeg, men kon de lijnen in de hand zien, toen stonden zij op: wij zullen hem maar losmaken, zeiden zij. Maar I O. Nd.: maak de touwen niet los, laten wij straks eerst eens praten, wanneer de zon schijnt.

Toen de zon nu scheen en de aarde zichtbaar was, gingen zij naar den Karoekoe boom, al de familie-hoofden, met hun vijven en zij vroegen hem: hoe is 't, als wij de touwen losmaken, staat gij 't dan niet toe?

Maar I O. Nd. antwoordde: als gij mij geen boete zoudt betalen, zoudt gij niet in staat zijn de touwen los te maken, meer dan vast zijn ze.

En de familie-hoofden antwoordden: welaan, waarmee zullen wij $\mathrm{u}$ boete betalen?

En I O. Nd. antwoordde: als gij mij met iets boete betaalt, dan moeten 't zijn 70 gouden oorhangers, twee kudden paarden, drie kudden karbauwen, dit slechts is mijn vragen.

De familie-hoofden zeiden: hoeveel is dit toch! een klein beetje maar, men zal u boete betalen.

Toen antwoordde I O. Nd.: als 't waarlijk is, als 't oprecht is, kom dan de touwen van mijn lichaam losmaken.

En de familie-hoofden stonden op en maakten al de touwen los, van zijn handen, van zijn voeten, van zijn hals. Toen zij ze allemaal los gemaakt hadden, tilden zij hem op en brachten hem in de voorgalerij en gaven hem sirih te kauwen. Toen hij 
gegeten had, vroegen zij hem: hoe is 't nu, oemboe, zullen wij $\mathrm{u}$ heden de boete betalen?

Maar I O. Nd. antwoordde: naderhand moet 't zijn, ik kom terug, dan zal ik 't komen aanhalen. Vervolgens de familiehoofden: waarheen wilt gij gaan? En I O. Nd. antwoordde: ik zoek de onbereikbare.

Toen hij aldus gesproken had, ging hij heen; hij ging aan om te halen zijn slimoet, zijn hoefddoek, zijn sirih-tasch, zijn kapmes, zijn teerkost. Aldus nu, toen hij 't genomen had, ging hij wederom verder.

En hij zag iemand, die paarden ging vastbinden in de beneden tuinen; en hij vroeg hem: waar komt gij vandaan, zeide die man, En I O. Nd. antwoordde: ik kom van 't strand, zeide hij tot hem. "En waarheen wilt gij gaan?» En I O. Nd. antwoordde: ik ga op jacht. De man, die paarden ging vastbinden, antwoordde: en waar gaat gij dan jagen?

En I O. Nd. antwoordde: ik ga zoo maar wat, waar ook maar herten zijn.

Hij, die paarden ging vastbinden in de benedentuinen, keerde nu terug naar de kampong. En I O. Nd. ging aan om te verbergen zijn slimoet, zijn hoofddoek, in 't dichte bosch. Hij ging weer terug uit 't dichte bosch, en hij klom naar de kampong; hij kwam in de voorpoort en hij zag kinderen, die aan 't djoengga-spelen waren in de voorgalerij. En I O. N d. ging nu geheel de kampong in en hij zette zich boven op een vasten steen.

De kinderen nu, die aan 't djoengga-spelen waren in de voorgalerij, riepen tot hem: ha mede-knaap, kom hier, dan zullen wij zingen.

Maar I O. Nd. (zeide): ē, ik wil niet, ik kan niet djoengga spelen, ik kan niet zingen. Vervolgens de knapen: ha, kom maar, als gij geen djoengga kunt spelen, als gij niet kunt zingen, laten wij 't je dan leeren, dat gij kunt djoengga spelen, dat gij kunt zingen, zeiden zij tot hem.

En één der knapen ging naar beneden, een makker van die knapen van zooeven, welke djoengga speelden in de voorgalerij; hij ging I O. Nd. aan de hand leiden, hij sprak hem vriendelijk toe. Toen klom I O. Nd. naar beneden en kwam in de voorgalerij; en zij gaven hem een djoengga: ha, hier vriend, speel nu op de djoengga en zing. I O. Nd. antwoordde: ik kan immers geen djoengga spelen. 
En de knapen, die zooeven djoengga speelden in de voorgalerij, grepen hem de djoengga af en sloegen hem er mee; de djoengga brak in stukken. Toen die djoengga stuk was, grepen zij hem en smeten hem op den grond.

En de volwassenen hoorden de knapen lawaai maken in de voorgalerij. De volwassenen klommen nu naar beneden van boven uit huis: ha, wat is dat een lawaai van jullie? Toen antwoordden de knapen: deze knaap heeft de djoengga in stukken gebroken. En I O. Nd.: zei heelemaal niets.

Vervolgens zeiden de volwassenen: ga hem een touw halen, dan zullen wij hem binden en hem onder de voorgalerij plaatsen. Toen bonden de knapen hem; nadat zij hem gebonden hadden, duwden zij hem onder de voorgalerij; de omheiningen liepen geheel rond de voorgalerij; de deur van die omheining sloten zij toe.

Toen zeiden de volwassenen: hij moet maar omzien naar een vervanger van de djoengga, dan pas geef hem eten, dan pas laat hem los, zeiden zij van hem. Toen antwoordde I O. Nd.: wat heb ik met een vervanger er van te maken! ben ik 't die uw djoengga heeft gebroken? door uw kinderen is ze gebroken; hoe is 't toch dat zij er mij mee sloegen en dat ze brak; wat mij betreft, ik kan geen djoengga spelen, zeide ik toch, ik kan niet zingen, heb ik toch gezegd.

Toen antwoordden de volwassenen: schei jij daar binnen uit met praten, men zal een rijststamper voor je halen, je zoo meteen je hoofd in stukken slaan, zeiden zij tot hem.

Toen 't nu middernacht was, zong I O. Nd., evenals hij gezongen had in de andere kampong.

Er was nu een jonge man, die sliep op een hooge balei ${ }^{2}$, en hij hoorde hem zingen. En 's morgens stond hij op en vertelde het aan zijn ouders: afgeloopen nacht heeft de man, die door ons is gebonden, gezongen te middernacht; ik heb iets te zoeken, zeide hij; ik heb niet goed naar hem geluisterd in den afgeloopen nacht, terwijl hij zong; ik knikkebolde ook van de slaap en zoo sliep ik maar.

Toen antwoordden de familie-hoofden: ai, je liegt, zeiden zij tot hem. Maar hij antwoordde: waarlijk, als ik lieg, zal ik sterven. Toen zeiden de familie-hoofden: ai, misschien is wel waar wat hij zegt.

En 't was wederom nacht en zij luisterden zelf, de familie- 
hoofden, hetzelfde als gehoord was door den jongen man gisteren nacht. Toen vroegen zij hem: was 't aldus, toen hij gisteren nacht zong? En de jonge man antwoordde: zoo was 't, toen hij zong. "Naar waarheid was toch uw zeggen."

En I O. Nd. zong wederom, hij zong niet veel; hij zeide in zijn zingen: als gij mij niet loslaat, de menschen hier morgen, dan komt buikloop met bloed, gij zult uitsterven, gij zult geen overblijfsel overlaten.

Toen (zeiden) de familie-hoofden: hoor hem daar zingen, wij zullen morgen uitsterven, als wij hem niet loslaten; wacht morgen vroeg, dan zullen wij zijn touwen losmaken en hem loslaten.

's Morgens vroeg nu, haalden zij hem uit de omheining onder de voorgalerij: wat bedoelt gij hier mee, zeide I O. Nd.

Toen antwoordden de dorpshoofden: wij willen de touwen losmaken.

Maar I O. Nd. antwoordde: laat toch, maak de touwen niet los, gij moet mij boete betalen, zeide hij, dan pas de touwen losmaken.

Toen antwoordden de menschen: ha oemboe, met hoeveel moeten wij u boete betalen, zeiden zij tot hem. En I O. Nd. antwoordde: geef mij uitsluitend met "dikken mond» 47 stuks; vergulde oorhangers, 17 stuks; paarden wil ik niet, karbauwen wil ik niet, tamme varkens wil ik niet; wilde varkens met uitstekende slagtanden, 5 stuks; herten met gladde hoornen, 7 stuks; dit slechts wordt door mij gevraagd; als gij mij dus boete wilt betalen, mak dan de touwen van mijn lichaam los.

En de familie-hoofden antwoordden: wij zijn schuldig, wij hebben gedwaald, men moet hem boete betalen; wanneer wij hem geen boete betalen, zullen wij morgen uitsterven; welaan, betaal hem boete.

Vervolgens maakten zij los de touwen van zijn handen, van zijn hals, van zijn voeten; zij maakten ze allemaal los. En zij zeiden tot hem: wilt gij nog ergens anders heengaan?

En I O. N d. antwoordde: ik moet nog ergens naar toe, ik zoek de onbereikbare; wat betreft deze dingen, door mij bevolen, ik kom naderhand terug, dan zal ik ze aan komen halen.

Aldus vertrok hij uit die kampong. En hij ging aan om te halen zijn slimoet, zijn hoofddoek, zijn teerkost: drie stuks 
waren er maar meer van zijn teerkost. Hij kleedde zich aan, hij deed zijn hoofddoek om; en wederom ging hij naar een andere kampong; nu was dan toch dicht bij de plaats van I Kahi, zijn zuster.

En hij kwam in de 'beneden tuinen, en hij zag menschen, die aan 't geiten hoeden waren op 't ruime veld. Toen vroeg 'hij hen: ha geiten-hoeders, komt hier, ik heb u wat te vragen. Vervolgens zeide I O. Nd. tot hen: gijlieden zijt kinderen waar vandaan? En die kinderen antwoordden: wij zijn kinderen van deze kampong hier. Vervolgens I O. Nd.: welaan, daar gij kinderen van hier zijt, laten wij wat tollen in de beneden-tuinen. Maar die kinderen antwoordden: $\overline{\mathrm{e}}$ oemboe, wij willen niet, wij moeten geiten hoeden; als wij niet goed op de geiten letten, dan pakken ze de boschkatten.

Toen antwoordde I O. Nd.: waar zijn de verblijfplaatsen der boschkatten. En die kinderen antwoordden: zij zijn reeds weg, in 't dichte groote bosch is hun plaats. Maar I O. Nd. antwoordde: als ik ze zie, sla ik de boschkatten, tot de laatste toe, dood, opdat er geen boschkatten meer zijn zullen in dit dichte bosch.

Toen zij een einde gemaakt hadden aan hun spreken, gingen de geitenhoeders heen. Maar I O. Nd. ging ergens aan om te verbergen zijn slimoet, zijn hoofddoek, zijn sirihtasch in een gat in den grond; daarna nam hij 't gescheurde doek, zoo dikwijls door hem aangedaan.

Vervolgens klom hij naar de kampong; bij de deur gekomen: ik zal de deur maar ingaan, zeide hij. Maar bij die deur was I A poe Kămi en zij zeide: Oemboe Ndiloe, waar gaat gij heen? En I O. Nd. antwoordde: een oude vrouw, waar thuis behoorende zijt gij toch? En I A poe Kămi antwoordde: mijn plaats is hier, ter zijde van de deur. Vervolgens I O. Nd.: 't is maar, dat wij 't weten. En hij ging verder en ging 't huis van een arme binnen. Er was een groote hond aldaar, zeer kwaadaardig was hij.

En I O. Nd. ging in de voorgalerij zitten, er was nog niemand, die hem gezien had, slechts de hond was 't, die hem zag, en hij blafte, beet hem en wierp hem op den grond. De eigenaar van 't huis daalde af in de voorgalerij, en zeide: hoe hebben wij 't met dit kind, de hond heeft hem gedood. En men nam hem op en tilde hem in de voorgalerij. Vervol- 
gens zeide de eigenaar van 't huis: morgenavond zullen wij hem begraven; als wij hem begraven hebben, zullen wij gaan onderzoeken, wier kind deze doode is, door 't bijten van een hond.

En de eigenaar van 't huis ging maar aan 't eten; maar de doode knaap was alleen slechts in de voorgalerij. Vervolgens kwam I Apoe Kămi in de voorgalerij en wekte I O. Nd. en zeide tot hem: Oemboe Ndiloe, sta toch op, dicht bij is de plaats van I Kahi, uw zuster, sta toch op, neem uw mooie tol en uw gouden tollen-touw, morgen vroeg zult gij heengaan, ik zal u volgen, niemand zal mij zien.

En des morgens vroeg daalde de huiseigenaar af in de voorgalerij, en I O. Nd. zat daar in de voorgalerij. Vervolgens zeide de huiseigenaar: ai, daar leeft de knaap toch; hoe is uw naam, zeide men tot hem. Toen antwoordde I O. Nd.: mijn naam, ik ben een wees, door den dood van mijn vader en moeder achtergelaten; dat is genoeg hiervan. Vervolgens zeide hij: welaan, hoe is 't, heer, is 't uwe gewoonte, hier in de hoofd-kampong, als een hond een knaap bijt in het een of andere dorp, betaalt gij hem dan geen boete?

Vervolgens antwoordde 't kampong-hoofd: men betaalt hem wel boete. Toen antwoordde I O. Nd.: zoo zij het, daar een hond mij toch heeft dood gebeten, moet gij mij boete betalen. Maar de huiseigenaar antwoordde: daar gij toch niet heelemaal dood zijt, daar gij nu toch wederom leeft! Maar I O. Nd. antwoordde: als gij mij geen boete betaalt, dan zal ik u met dezen "mooien» tol werpen, en gij sterft. En de huiseigenaar antwoordde: wij zijn niet sterk genoeg meer (om ons te verzetten). Het kampong-hoofd ging nu spreken met 't hoofd van ieder huis en men kwam bij elkaar en beraadslaagde over 't samenbrengen van goederen, om boete te betalen aan den knaap, door den hond gebeten; hij heeft een boete opgelegd, omdat de hond hem gebeten heeft, (zeide men).

De goederen waren geheel voltallig, en zij zeiden tot hem: welaan, neem toch deze goederen, opdat gij niet meer met ons te spreken hebt naderhand, zeide men tot hem.

Maar I O. N d. antwoordde: laat 't voorloopig, met reizen houd ik nog niet op, er zijn nog twee kampongs, waar ik heenga; daarom wacht tot ik terugkom, dan zal ik aangaan om deze goederen te halen. 
Toen hij klaar was met spreken: laat mij gaan, zeide I O. $\mathrm{Nd}$; ; vervolgens ging hij heen, hij bereikte de deur en I A poe Kămi (zeide): gaat gij heen, Oemboe Ndiloe? En I O. Nd. antwoordde: ja, grootmoeder, ik ga heen!

Toen hij klaar was met spreken, ging I O. N d. haar voorbij, en hij ging aan om te halen zijn slimoet, zijn hoofddoek, zijn kapmes en hij verkleedde zich.

Wederom ging hij verder; hij zag een kampong, zeer hoog gelegen was die. Hij kwam in de beneden tuinen en overnachtte aldaar. 't Was nu middernacht en I O. $\mathrm{N}$ d. was aan 't slapen. En I Apoe Kămi was daar aan de zijde van I O. Nd., zij was gezeten; toen draaide hij zich om en stootte tegen I A poe $\mathrm{Kămi}$ aan. Toen stond I O. Nd. op en hij vroeg: wie zijt gij toch? En I A poe Kămi antwoordde: Oemboe Ndiloe, hebt gij vergeten ons gesprek van gisteren en eergisteren. Toen antwoordde I O. Nd.: werkelijk, zeide hij, Apoe Kămi zijt gij, ai! En I A poe Kămi zeide: als gij uit de kampong hier naar beneden gaat, als gij dan wederom een kampong ziet, dat is de plaats van I Kahi, uw zuster.

Toen antwoordde I O. Nd.: als ik maar zie mijn zuster.

Toen de aarde nu zichtbaar was geworden, en de zon scheen, was I A poe Kămi verdwenen, zij werd niet meer gezien.

Vervolgens ging I O. Nd. naar een grot, hij zag daar een steenholte; vervolgens stopte hij er in zijn slimoet, zijn hoofddoek, zijn kapmes, zijn sirih-tasch. Toen hij 't verborgen had, ging hij naar buiten en klom naar de kampong.

De menschen in de kampong waren bijeen, 't was offerfeest, men slachtte karbauwen, men slachtte paarden, men slachtte varkens, men slachtte geiten, men slachtte kippen. En men zeide: schep de rijst op! I O. Nd., daar hij in de deur was, hoorde hen spreken: schep de rijst op, zeggende. Hij ging nu geheel naar binnen, hij keek naar 't groote huis en ging zitten in de voorgalerij.

Er was nu een jonge man, naar beneden gekomen om een luchtje te scheppen in de voorgalerij. En hij zag I O. Nd.: ha menschen in huis, geef sirih aan hem hier beneden in de voorgalerij. Toen antwoordden de vrouwen: wat voor man is dat, hé! Vervolgens de jonge man: 't is een mensch, hé! geef hem sirih, zeg ik.

Maar de vrouwen in huis scholden: wat voor mannelijk 
schaamdeel is dat toch, dat hij zoo achteraan komt. En I O. $\mathrm{Nd}$. hoorde het en hij antwoordde: ha mevrouw daarboven in huis, als gij mij geen sirih geeft, dan laat gij 't maar, mits gij maar niet scheldt.

En de menschen in huis antwoordden: daar 't met u nu zoo is, dat gij zoo achteraan komt, daarom schelden wij u. Toen antwoordde de jonge man en zeide: wel als er geen sirih is, a!s gij dat zoudt zeggen, dat zou vrij wat beter zijn.

Maar I O. N d. antwoordde: jonge man, neem gij niet op u te spreken, laat mij zelf maar spreken. Toen zeide I O. Nd.: mevrouw daarboven, misschien is 't nu zoo met hem, dat hij rijst begeert, dat zult gij misschien zeggen; ik begeer toch geen rijst, ik begeer toch geen vleesch, ik kom zoo maar eens hier aan; als gij mij geen rijst geeft te eten, laat 't dan.

Toen antwoordden de familie-hoofden boven in huis, en $z_{i j}$ zeiden tot hem: wie is dat toch daar beneden in de voorgalerij, hij schreeuwt en scheidt nooit uit. En I O. Nd. zweeg, hij antwoordde niet.

Maar de jonge man antwoordde: wie weet 't, misschien is 't wel een vriend, een gescheurde slimoet wordt door hem gedragen, welke heelemaal niet goed is; een schouderslimoet is er niet.

Toen antwoordden de familie-hoofden: wanneer is hij daar gekomen? "Wie weet 't, wij weten zijn aankomst niet». Maar I O. $\mathrm{Nd}$. antwoordde: midden op den dag ben ik gekomen.

Toen antwoordden de familie-hoofden: 't is iemand die komt stelen, en zoo niet, iemand, die komt spionneeren.

Maar I O. Nd. antwoordde: als ik toch iemand ben, die spionneert, zult gij hier morgen uitsterven, als ik u kom beoorlogen.

Maar de familie-hoofden antwoordden: waartoe zoudt gij in staat zijn? En I O. Nd. antwoordde: alleenlijk ééne tol.

Toen antwoordden de familie-hoofden: wij zullen uw tol even afnemen. Maar I O. Nd. antwoordde: als ik afdaal op den grond, dan zal ik den tol slingeren, en gij zult uitsterven. Maar de familie-hoofden antwoordden: gebruik daar niet (zulke groote woorden), wij zullen u even dood maken. Vervolgens I O. N d. : ik zeg 't dan toch maar.

Toen antwoordden de familie-hoofden en zij zeiden: als gij ten tweede male nog eens spreekt, dan zullen wij even naar 
beneden komen, en zullen $\mathrm{u}$ in stukjes hakken met kapmessen.

Maar I O. Nd. antwoordde: waarom moet dat zoo, als ik spreek, zeide hij.

En al de menschen in huis kwamen naar beneden en omringden hem en grepen hem en hakten hem. Maar 't kapmes vermocht niet tegen I O. Nd.; men sloeg hem met hout, hij stierf niet. Vervolgens zeiden de familie-hoofden: hoe hebben wij 't toch met hem! Wij hakken met kapmessen, hij gaat niet dood; wij slaan met hout, hij gaat niet dood; wij smijten hem op den grond, hij gaat niet dood; wij binden hem met touwen, 't blijft niet vast zitten; welaan laat ons trachten hem te verbranden met vuur.

En men verzamelde veel hout; mannen, vrouwen, kinderen, grijsaards, allen stonden op. Toen men hout bij elkaar gebracht had, stapelde men 't op; vervolgens haalde men vuur er voor en deden dat in dat hout; toen 't vuur opvlamde, greep men I O. $\mathrm{Nd}$. en men smeet hem in 't vuur; hij verbrandde niet. Toen zeiden de familie-hoofden: nu weten wij niets meer.

En men riep hem: heer vorst, kom hier in de voorgalerij, wij zijn schuldig, wij zijn van den rechten weg afgedwaald.

Maar I O. Nd. antwoordde: dat is 't, ik zeide 't zooeven van te voren, ik was eerder dan 't geschil, ik was den tijd vooruit; als gij mij geen eten zoudt geven, zeide ik toch, maar gij huis-eigenaar, kampong-hoofd, gij waart nijdig, gij hebt mij gehakt, mij geslagen, mij verbrand met vuur, dat is 't, men moet mij boete betalen.

En de familie-hoofden antwoordden: wij zullen niet dubbelhartig zijn; en zij zeiden: 't is omdat wij toornig waren, dat wij niet meer kenden den waren weg; welaan wij zullen schuldig zijn. En I O. Nd. antwoordde: als gij er maar in staat toe zijt (mij boete te betalen.). Toen antwoordden de, familiehoofden: welaan, noem 't maar op.

En I O. Nd. noemde 't op: aldus zeg ik, oorhangers met voeten, duizend en vijftig; drie kudden paarden; evenveel karbauwen; zeven en zeventig herten, met rechte hoornen; dertien geiten, met hoornen van twee vingergeledingen lang; dit is alles wat door mij gevraagd wordt.

En de familie-hoofden antwoordden: zoo zij 't, want wij zijn schuldig. Toen vroegen zij hem: hoe is 't, zullen wij' $t$ u heden geven? Maar I O. Nd. antwoordde: wacht maar, wanneer 
teruggekeerd is mijn paard, wanneer wederkomt mijn lichaam.

En de familie-hoofden antwoordden: welaan, zoo zij ' $t$, eet rijst en drink water, opdat gij in vrede kunt gaan. En I O. Nd. antwoordde: gelijk gij wilt; ik zal hem te eten geven, als gij tot mij zegt; te drinken geven, als gij tot mij zegt, dan zal ik niet «neen» zeggen.

Toen grepen zij één varken, 't was wel vet; en zij slachtten het. Toen zij 't aldus geslacht hadden, brandden zij het; toen zij klaar waren met branden, hakten zij 't open, en haalden den lever er uit en zij keken naar zijn teeken; goed is 't teeken van 't varken, zeide men. Toen zij dit bekeken hadden, hakten zij dat varken in stukken en kookten het. Toen 't gaar was, schepten zij op, toen pas riepen zij I O. $\mathrm{Nd}$.: $\mathrm{klim}$ in huis, zeiden zij tot hem. Men spreidde witte matten uit op de zitplaats en hij ging er op zitten. Toen hij gegeten had, bracht men zijn sirih naar hem toe.

Toen hij sirih gekauwd had: laat mij gaan, zeide I O. Nd.; en hij daalde af boven uit 't huis, hij daalde af in de voorgalerij; toen hij afgedaald was in de voorgalerij, daalde hij af op den grond en ging heen.

En I O. Nd. bereikte de poort en wachtte daar even; en I A poe Kămi zeide tot hem: Oemboe Ndiloe, gaat gij daar? En I O. N d. antwoordde: ik ga maar. Hij stond op en ging heen; hij ging aan om te halen zijn slimoet, zijn hoofddoek, zijn sirih-tasch, zijn kapmes. En hij verkleedde zich; toen hij zich verkleed had, keek hij naar de kambanbang onder in zijn sirih-tasch: er was er maar één meer. En I O. Nd. zeide: er is genoeg, tot ik 't bereik.

Hij ging nu uit 't bosch weg; hij ging weer verder; hij volgde den grooten weg.

Toen hij in de voor-tuinen gekomen was, zag hij niemand.

En I O. Nd. ging ergens verbergen zijn hoofddoek, zijn slimoet in een gat in den rivieroever, slechts de mooie tol werd door hem meegenomen.

Hij ging recht door naar boven naar de kampong, hij kwam bij de poort en zag iemand aan 't weven. En hij wond zijn tol op en hij zeide bij de poort daar: deze strakjes, als dit is de kampong, de plaats van I Rămboe Kahi, mijn zuster, dan werp ik haar met den tol en geen ander.

Hij ging nu de kampong geheel binnen, hij ging en hij zag 
iemand wevende onder 't huis, en hij zeide: ho, als dit I $\mathrm{Kahi}$ is, mijn zuster, die aan 't weven is, verscheur haar weefgetouw, verbreek haar weefklos, breek haar groote teen.

En hij ging een weinig achteruit, hij was ver van haar; toen wierp hij dien tol, hij mikte op haar, die daar aan 't weven was onder 't huis. En hij raakte I Ră mboe Kahi, hij brak haar groote teen, haar weefgetouw scheurde hij, haar weefklos brak hij, haar weef kam brak hij.

Toen de tol I Kahi geraakt had, scheurde hij ook haar weefgetouw. En I R. K. was zeer boos, zij schold ook.

En I R. K. zeide: ga mij eens grijpen daar ginds dien knaap, dat stomme manlijke schaamdeel, die mijn voet heeft gebroken. En de groote menigte greep hem. Toen sloeg I R. K. hem, zij gebruikte rottan. Toen zij hem geslagen had, zeide zij tot hen en zij bonden hem juist voor de plaats, waar men (uit ' $t$ huis) naar beneden gaat.

En I R. K. zeide: laat mij een ladder van hem maken, waar ik mee opklim en waar ik mee afdaal, want hij heeft mijn voet gebroken, ik ben niet sterk meer om te loopen.

Toen men hem gebonden had bij de afdaal-plaats, en de nacht gekomen was, zij allemaal werden niet wakker. En I O. $\mathrm{N}$, , toen 't nu middernacht was geworden, zong hij:

dit was 't einde van uw gesprek, toen $z$ ij verscheurde,

het roode goed, toen zij ze plantte, één handvol kamănggihoe, juist voor de afdaal-plaats.

Maar I R. R. werd niet wakker; er ging nu voorbij een maand, twee maanden, en toen was er een oude man, met vuile beenwonden. En I R. K. daalde af op den grond: ik ga naar achteren, zeide zij. Toen zeide de oude: ha Rămboe Kahi, kom eens hier, ik heb iets te vertellen, 't is wat goeds.

Maar I R. K. antwoordde: $\bar{e}$ : ik wil niet, je wonden stinken.

Toen antwoordde de oude: gij moet zoo niet zijn, kom maar hier, blijf dan boven den wind.

En I R. K. ging naar hem toe, en de oude zeide: ha, Rămboe Kahi, kauw mij een sirih-pruim. Toen zij die gekauwd had, vroeg hij haar: hoe is 't, toen gij hierheen zijt gekomen, is er toen door u een knaap achtergelaten? En I R. K. ant- 
woordde: er was er wel een, hij zal wel dood zijn, Toen antwoordde de oude: daarom, hoor wat ik te zeggen heb, ga straks en slaap overdag, straks in den avond, word dan wakker.

Vervolgens zeide I R. K.: ja.

Alzoo ging zij en sliep; de avondschemering viel en zij werd wakker. Toen al de menschen gegeten hadden, zeide I R. K.: gij allen, gaat slapen, kletst zoo niet, ik knikkebol nu al.

Tocn 't nu precies middernacht was geworden, zong I O. N d. : 't is tevergeefsch geweest, dat ik hier gekomen ben, eten, eet ik niet. water drink ik niet; 't zal misschien wel waar zijn, zeide ik toch, toen zij mij scheurde, het roode goed, toen zij plantte, één handvol ka măng gihoe.

Toen I R. K. 't gehoord had, stond zij vlug op, van boven uit 't huis, en zij ging naar hem toe, en omhelsde hem; zeer weende I R. K.

Maar I O. Nd. zeide: dat ben ik niet! "Neen, zeg de waarheid, broeder, opdat ik 't wete; meer dan schuldig ben ik, meer dan schuldig ben ik.

Toen antwoordde I O. Nd.: ik ben 't toch; neem hem mee, terwijl gij dat vroeger van mij zeidet, maar mijn naamgenoot: gooi dat kind weg, die schurftige paardennek, zeide hij van mij; die ben ik toch.

Maar I R. K. weende zeer, zeer veel medelijden had zij met hem.

Toen riep zij haar man: maak los de touwen van uw jongeren broeder, zeide zij.

En al die menschen aldaar, kwamen naar beneden: maak de touwen los, zeiden zij. Zij maakten de touwen los, zij waren er niet toe in staat. En I R. K. zeide: breek mij toch de touwen, ik ben schuldig tot aan mijn lendenen, ik ben schuldig tot aan mijn nek.

Toen antwoordde I O. Nd.: ik weet het! En I R. K. zeide: welaan zegt wat gij begeert. "Zijt gij er toe in staat, als ik het zeg?» Maar I R. K. antwoordde: als gij 't maạr zegt!

Toen antwoordde I O. Nd.: de goederen voor 't schuldig 
zijn tot aan de lendenen, naar gij zeidet, die goederen neem ik voor mijn rekening; schuldig tot aan mijn nek, naar gij zeidet, die eveneens; alleenlijk 't paard met zwarten kop, geef mij dat; dan zullen de touwen losgaan.

En I R. K. antwoordde: er is een paard met zwarten kop onder mijn huis, ik zal 't u geven.

Toen zeide I O. Nd.: maakt de touwen los. En zij gingen en zij maakten ze los; toen zij ze losgemaakt hadden, haalde I R. K. voor hem een pas gevlochten mat en spreidde die uit in de voorgalerij. En zij riep hem: Oemboe, meester, kom hier in de voorgalerij.

Maar I O. Nd. wilde niet. Toen riep I R. K. menschen: gaat mijn broeder daar beneden op den grond opnemen, tilt hem in de voorgalerij.

Toen zij hem in de voorgalerij getild hadden, zeide I R. K.: ik zal mij verzoenen met mijn broeder, daar hij zweette hierheen, daar hij gekomen is, daar hij voorbijgaande bezocht heeft al de vele kampongs.

En men ving één jonge karbouw, een handlengte waren zijn hoornen; om zijn voeten koud te maken (zijn vermoeidheid te doen ophouden), zeide men.

Toen men geslacht had, toen men gegeten had, nam I R. K. een kruik, zij ging water scheppen. En I O. Nd. zeide: ha zuster, wacht ik ga mee, ik ga de paarden drinken geven, zeide hij tot haar. "Kom dan, zeide zij». En hij ging en leidde 't paard aan een touw mee. Toen zij bij de rivier gekomen was, schepte I R. K. water. Maar I O. Nd. volgde de rivier stroomopwaarts; en hij zag een klein pinang-boompje, één span hoog maar. Hij trok 't uit en bracht 't naar huis. Toen hij thuis gekomen was, en zijn paard had vastgebonden, zocht hij een steekschoffel. Hij zag een steekschoffel en hij groef een gat voor den pinang en hij plantte den pinang recht voor den hoek van 't dak en hij goot 's morgens en 's avonds; dit was al de inhoud van zijn werk.

Toen 't langzamerhand een beetje hoog was geworden, als een jonge klapperboom, toen zeide I O. $\mathrm{Nd}$.: ha zuster, stamp mij reisvoorraad, ik zal een boomhuisje maken voor dezen pinang; ik zal er spelen, zeg ik.

En zij stampte hem reisvoorraad. En I O. Nd. maakte een boomhuisje in dien pinangboom. Toen hij 't boomhuisje ge- 
maakt had, vroeg hij I R. K.: ha zuster, is de reisvoorraad daar, zeide hij tot haar: "'t Is er, zeide zij hem». "Hoeveel kleine mandjes?» zeide hij tot haar. En I R. K. antwoordde: twee mandjes. Maar I O. Nd.: 't is niet voldoende, zeide hij haar; stamp er nog wat anderen bij, acht mandjes, zeide hij tot haar.

En I R. K. antwoordde: wacht maar, wij zullen wel wederom voor $\mathrm{u}$ stampen. Toen zij de reisvoorraad gestampt had, toen er evenveel waren als hij bevolen had, zeide I R. K.: dit hier is uw reisvoorraad, gisteren en eergisteren door u gevraagd.

En I O. Nd. antwoordde: breng 't hier, zeide hij haar. Zij nu bracht die reisvoorraad; toen hij 't aangenomen had, bracht hij 't naar boven in 't boomhuisje.

Toen hij gekomen was in 't boomhuisje, was hij er nog den volgenden nacht; weer den volgenden nacht was die pinangboom langzaam hooger geworden. Wederom een nacht, was hij zoo hoog als een klapperboom.

En I R. K. daalde af op den grond: hoe heb ik 't nu met mijn broeder, hij kan niet meer naar beneden komen, want zeer hoog is de pinangboom; zeer weende I R. K.

Maar I O. Nd. zeide: laat uw hart niet treuren, Ramboe Kahi, mijn zuster! ik ga naar boven om te halen de dochter van mijn oom, boven in den hemel.

Toen hij dit gezegd had, werd die pinang-boom langzaam hooger en hooger, bijna raakte hij den hemel.

Maar I R. K. riep menschen bij elkaar: wij zullen den pinang omhakken, zeide hij. Al de menschen kwamen, iedere vorst, al haar familie; allen waren voltallig.

En I R. K. zeide: slijpt al de bijlen, dan zullen wij dien pinang omhakken, die tot toornens worden toe hoog is.

De eene rij makkte zich op, men hakte, men vermocht er niets tegen; de bijlen waren alsof ijzer op ijzer hakte. Dit eene gelid week ter zijde. Wederom kwamen twee gelederen; men hakte, men vermocht er niets tegen; gelijk als zij die 't eerst gehakt hadden en niet vermochten.

De twee gelederen weken ter zijde; wederom maakten zich op vier gelederen; men hakte, geen van allen vermocht iets. De vier gelederen weken weer achteruit; acht gelederen makten zich weer op, men hakte, men vermocht niet. Men week weer terug: laat 't nu maar, zeide men, 't is afgeloopen. 
En I R. K. zeide tot de menschen, door haar verzameld: zoo is 't nu, de eene rij maakte zich op, men vermocht niets; allen hebben zich opgemaakt, men vermocht niets; keert terug naar uw kampong.

En I R. K. ving een gecastreerde karbouw en slachtte hem; opdat eten de door mij verzamelde menschen, zeide zij.

Toen al de menschen gegeten hadden, gingen al de door haar verzamelde menschen heen.

De pinang nu, waar I O. $\mathrm{Nd}$. in geklommen was, bereikte den hemel, hij ging voorbij de eerste verdieping; er was daar een kampong. En de menschen aldaar: waar gaat gij heen, Oemboe Ndiloe? zeide men tot hem. En I O. Nd. antwoordde: ik ga naar oom. 't Kampong hoofd antwoordde: als gij de dochter van uw oom meebrengt, kom dan hier aan om te halen haar geleide slaven.

En de pinang werd wederom hooger, en bereikte wederom een verdieping; er was een kampong daar. Het kampong-hoofd zeide: ha Oemboe Ndiloe, waar gaat gij heen? En I O. Nd. antwoordde: ik ga trouwen de dochter van mijn oom. Toen antwoordde het kampong-hoofd: als gij haar trouwt, dan ben je werkelijk een kerel; kom dan aan om haar rijpaard te halen. En I O. Nd. antwoordde; welaan!

Die pinang nu werd wederom hooger; hij bereikte een andere verdieping. En 't kampong-hoofd aldaar zeide: ha Oemboe Ndiloe, waar gaat gij heen? En I O. Nd, antwoordde: ik ga rijpe pinang brengen aan oom.

En 't kampong-hoofd antwoordde: als gij meebrengt uw nicht, dan ben je werkelijk een kerel; kom dan aan om een hond voor haar te halen, dat die bewake haar kampong. Vervolgens I O. Nd. : zoo zij 't.

Die pinang nu werd wederom hooger, hij bereikte de kampong; die kampong was de plaats van zijn oom, En I O. Nd. ging en overnachtte in de voortuinen, twee nachten, vier nachten. Des morgens waren er meisjes, welke water gingen scheppen, . twee. En I O. Nd. zag ze en hij zeide: dames, waar gaat gij heen? Toen antwoordden die meisjes: wij gaan water scheppen. Vervolgens I O. Nd.: kom eens even hier aan. En hij vroeg haar: wat doet men boven in de kampong, 't is zoo stil, men maakt geen gerucht.

Toen antwoordden de meisjes: hij is ziek, de heer, boven in 
de kampong; voltallig zijn alle menschen daar, de bevolking der geheele aạrde; de heer zegt: als er iemand is, die medicijn heeft, als ik beter word, dan geef ik hem mijn dochter.

En die meisjes spraken wederom: maar er is niemand, die een medicijn kent, zeiden zij tot hem. Toen antwoordde I O. $\mathrm{Nd}$. : als ik daar was, dan zou hij wel beter worden,

Vervolgens de meisjes: heer, laten wij water gaan scheppen, zeiden zij tot hem. En I O. Nd.: ga dan maar water scheppen. Toen zij teruggekeerd waren van 't water scheppen: heer daar, laat ons heengaan. En I O. Nd.: dames, als gij straks boven in de kampong komt, volgt dan niet mijn spreken van zooeven, ik schertste maar.

Toen zeiden de meisjes : 't is goed zoo. En die meisjes kwamen boven in de kampong en zij spraken tegen de menschen en zij zeiden: daar beneden is iemand, één maar. "Waar is hij?" zeide men tot haar. En zij antwoordden: hij is in de voortuinen. "Wat zegt hij?" Die meisjes antwoordden: hij zeide tot ons terwijl hij vroeg: waarom maakt men daarboven in de kampong geen gerucht; en wij antwoordden en zeiden tot hem: de heer is ziek. "Wat voor ziekte», zeide hij. En wij antwoordden: ziek in zijn keel; wij hebben hem ook verteld, de bevolking der geheele wereld is er voltallig, niemand heeft medicijn, of kan hem beter maken; "als ik beter word, geef ik hem mijn dochter, zegt hij, zeiden wij tot hem».

Toen antwoordde I O. N d. de oom : ha, ga hem roepen. Hij zond een familie-hoofd en deze ging naar de beneden-tuinen en zag hem en zeide tot hem: heer, kom toch, zegt tot $\mathrm{u}$ de heer boven in de kampong. Toen zeide I O. N d. : 't is goed. En I O. Nd. nam zijn hoofddoek, zijn slimoet, zijn sirih-tasch en klom naar de kampong.

Toen hij in de kampong gekomen was, haaIde men voor hem een witte mat, en spreidde die uit in de voorgalerij en men gaf hem zijn sirih. Toen hij sirih gekauwd had, sprak de zieke man boven in huis. En I O. Nd. hoorde hem en zeide: dit heb ik toch zooeven gezegd: vertelt 't niet aan de menschen boven in de kampong; ik scherts maar, zeide ik toch. Maar daarom, omdat de vorst 't nu toch reeds gehoord heeft:' laten wij trachten eens naar hem te zien. Vervolgens daalde I O. $\mathrm{Nd}$. af onder 't huis en maakte los 't hengelsnoer en hij liet 't vieren; hij ging langs al de palen, hij klom in huis; hij was klaar met den vloer, hij klom boven op het zoldertje, op de latten, op Dl. 68. 
de sparren, totdat hij neerdaalde juist voor den zieken man. Toen hij bij den zieken man gekomen was, stak hij zijn hand in diens mond en haalde de haak er uit; toen hij die haak er uit gehaald had, legde hij die naast den zieken man.

Toen zeide IO. N d.: dit was het, 't hengelsnoer dat geheel in de war was, de haak deed pijn. Toen antwoordde de zieke man: als 't dat dan maar is, ik ben beter, ik zal u mijn dochter geven, zeide hij tot hem. En I O. N d. antwoordde: zoo zij 't, zeide hij.

Vervolgens dacht I O. N d. na in zijn hart; toen hij nagedacht had, vroeg hij: wanneer zal ik de kamer ingaan, oom? En de oom antwoordde: morgen avond. Toen antwoordde I O. Nd.: zend mij slaven, ik ga pinang halen, ze zijn beneden in de beneden-tuinen, vijf trossen. Maar zijn oom zeide: laten 10 menschen gaan en u vergezellen.

En I O. N d. ging vooruit. Hij kwam in de beneden-tuinen en toonde hen de pinang: neem deze mee, zeide hij tot hen, één tros drage twee menschen. Aldus kwam I O. Nd. in de kampong: oom, zeide hij tot hem, laat de dorsch-matten uitspreiden, opdat wij er de pinang opleggen.

Terwijl men zijn woorden volgde, spreidde men uit een dorschmat. En zij legden die pinang er op; toen zij 't er op gelegd hadden zeide I O. N d.: ha oom, kom in de voorgalerij, bekijk eens die pinang, En zijn oom daalde af in de voorgalerij en zat leunend op de trap.

En I O. Nd. zeide: kijk er zoo meteen naar, oom! Toen beval I O. N d. die menschen, met hun tienen: gaat hout snijden, om die pinang er mee te slaan. En die menschen gehoorzaamden. Vervolgens gingen zij ze slaan op de dorschmat. De eerste vrucht, werd goud.

En wederom sloegen zij op de volgende vrucht, 't werden rijksdaalders. En de vrucht, welke er weer op volgde, werd louter gouden oorhangers. En de vrucht, welke er wederom opvolgde, werd louter dubbeltjes. En de laatste vrucht, werd louter centen.' De ranken: sommigen tot gouden kettingen; sommigen tot zilveren kettingen; sierkettingen werden sommigen.

Toen alles afgeloopen was, zeide I O. Nd.: oom, kijk dan eens, dat is mijn rijkdom.

En zijn oom antwoordde: werkelijk, werkelijk, kind! uws gelijke is er niet; er is nog nooit eenig vorst geweest die een 
dorsch-mat uitspreidde, gij zijt de eerste, welke ik zie, die uitspreidt een dorsch-mat om er iets in te bergen.

En zijn oom overdacht in zijn hart, en hij zeide bij zichzelf: laat ik haar geven ivoor, moeti sala, mijn dochter; ik zal haar geleide-slaven geven, alleen vrouwen, twaalf; zeven knapen; dat is genoeg, een voldoende prijs voor die goederen.

Toen sprak hij tot I O. Nd.: ha, Oemboe Ndiloe, straks in den avond, ga dan de kamer binnen. Des morgens vroeg strikte men hem drie karbauwen, en men vierde feest.

Toen de zon halverwege haar stijgen was, zond de schoonvader van $\mathrm{I} O \mathrm{O} . \mathrm{Nd}$. slaven uit, en zij gingen de menschen bij elkaar roepen; hij riep al zijn familíe, tot de verst verwijderde toe.

Toen de menschen gekomen waren, zeide de schoonvader van I O. $\mathrm{Nd}$.: al mijn familie hoort, gij allen! ik heb mijn dochter uitgehuwelijkt. En zijn familie antwoordde: wat zou dat zijn, als 't maar een man is.

Toen men geslacht had, zeide zijn oom: geef ieder zijn deel, alle de verzamelde menschen. Maar de eene, is 't deel van ons menschen hier in de kampong. Toen men gegeten had, zeide zijn oom: breng naar beneden de gongs, één stel $\mathrm{ka}$ boeboeloe, één stel katala, één stel $\mathrm{nggaha}$, één dans-trom, één hand-trom. Toen zij al die gongs naar beneden hadden gebracht, deden al de menschen hun mooie kleeren aan; de mannen hun hoofddoek met een punt van achteren afhangend, de vrouwen de hoofddoek met een punt omhoog stekend; men deed kin-banden om, men. stak kammen op 't hoofd.

En I O. Nd. daalde af in de voorgalerij, hij deed zijn mooie kleeren aan, zijn slimoets waren zilveren slimoets; zijn lendendoek was een zijden lenden-doek, zeer mooi was ze; zijn buiktouw was een rood touw; zijn hoofddoek was een hoofddoek van louter goud; eveneens zijn sirih-tasch; eveneens zijn kalkpotje; zijn kapmes had een gouden handvat.

En de menschen sloegen op de gongs, uitsluitend jonge mannen.

En I O. Nd. was de eerste die danste; toen hij geeindigd had met dansen, ging hij in de voorgalerij zitten. Toen zeide zijn schoonvader: hoort, al mijn familie, ziet daar mijn neef, die getrouwd heeft mijn dochter. En al de menschen zeiden: ai, ha, werkelijk, zijns gelijke in schoonheid is er niet.

Toen men dit gezegd had, dansten al de mannen, dansten 
de vrouwen; vier maanden deed men niets dan feestvieren.

En de dochter van dien vorst, kwam naar beneden om te dansen; haar kleederen waren als de kleederen van I O. Nd. En al de menschen zeiden: zeer schoon is deze vrouw, zij kan uitstekend dansen.

Toen zij gedanst had, klom zij in huis bij de metgezellen van I O. Nd. En I O. Nd. zeide: is 't familie van uw vader, allen, die hier verzameld zijn? Die vrouw antwoordde: 't is allemaal familie, andere menschen zijn er niet. Toen zeide I O. Nd.: ik houd van hem, zeg ik. En hij nam goud, vier manden en hij bracht ze beneden in de voorgalerij en hij schepte 't met zijn handen en strooide 't op het plein. Al de menschen plukhaarden, terwijl zij 't oppakten. Toen hij klaar was met strooien en al de menschen 't hadden opgeraapt, toen zeide I O. $\mathrm{Nd}$.: zoo doe ik nu, een arme jongen.

Toen men klaar was met feestvieren en de vierde maand verstreken was, ging de geheele familie naar hun kampongs. En I O. Nd. zeide: vader, laat mij teruggaan naar mijn kampong. Haar vader antwoordde: overmorgen, zeide hij tot hem. Toen antwoordde I O. Nd.: dat is goed.

En zijn schoonvader strikte wederom één karbauw en slachtte hem. Toen men gegeten had, maakte men zich gereed en ging naar de beneden-tuinen en men kwam bij den pinang-boom en klom er in; de slaven, die met hem meegingen, klommen allemaal in dien pinang-boom in 't huisje.

Toen zeide I O. Nd.: zak naar beneden, pinang! En die pinang-boom ging langzaam naar beneden. Hij nu ging aan in de kampong, hij ging aan om haar hond te halen.

Toen zeide I O. Nd.: daal wederom, pinang! En hij ging aan om haar een rijpaard te halen.

Toen zeide I O. Nd.: daal wederom, pinang. En hij ging aan om haar de slaven te halen in de kampong, waar hij 't eerst aangekomen was.

Toen zeide I O. Nd.: daal wederom, pinang! opdat wij komen bij I Ramboe Kahi, mijn zuster op de aarde, de eerste verdieping.

En de pinang-boom zakte, tot hij kort was, evenals vroeger, toen hij er 't huisje in gemaakt had. Toen men aangekomen was, zeide I R. K.: mijn broeder is teruggekomen, hij is wedergekeerd van 't trouwen van de dochter zijns ooms in de 
kampong in den hoogen hemel. Maar I O. N d. antwoordde: waarom hebt gij den pinang-boom willen kappen? Toen antwoordde I R. K. : hij zal sterven, zeide ik van u, daarom kapte ik hem; terwijl ik den pinang bezag, was de stam van den pinang zeer dun; misschien breekt hij, zeide ik, daarom kapte $i k$ hem en verzamelde menschen. Maar men vermocht er niets tegen; men had genoeg van 't kappen en men liet 't na.

Maar I O. Nd. antwoordde, daarom, omdat de pinang niet gevallen is, als gij mij uit dit boomhuisje doet nederdalen, moet er iets zijn om er mij mee te doen nederdalen.

En I R. K. antwoordde: wacht maar, over drie dagen zal ik u naar beneden doen dalen. En I $\odot . \mathrm{Nd}$. antwoordde terug: daarom laat ons wachten, opdat de slaven de karbauwen gaan opdrijven. En I R. K. zond ze heen: een jongen man, twee ouden, één familie-hoofd: ga de karbauwen opdrijven, zeide zij tot hen.

Er was nu één karbouw, welke zeer wild was. Toen men ze nu opdreef op den weg, kwam men in de beneden-tuinen. De ééne karbauw nu was wild, hij wilde met alle geweld terugkeeren, hij ging al sneller en sneller, en hij stak den éénen ouden man, hij stierf. En de metgezellen van den ouden man, staken nu den karbauw, zij doodden hem in de beneden-tuinen en lieten hem daar liggen; en de andere karbauwen dreven zij nu naar boven in de kampong.

Toen men daar gekomen was, dreef men ze in de omheining. En I R. K. zeide: vader, waar is toch grootvader, de eene? Maar 't familie-hoofd antwoordde: hij heeft bestegen den eenen karbauw: ik ga naar 't schimmen-rijk, zeide hij.

En I R. K. antwoordde: vader, spreek de waarheid! scherts niet met mij. Toen antwoordde 't familie-hoofd: de karbauw heeft hem zooeven gestoken in de beneden-tuinen.

En I R. K. antwoordde: waar is de karbauw, welke hem gestoken heeft? 't Familie-hoofd antwoordde: wij hebben hem doodgestoken beneden in de tuinen om den oude te begeleiden naar 't hiernamaals. Toen antwoordde I R. K.: ga hem halen den oude, breng hem hier in de kampong, dan zullen wij hem begraven.

Men ging hem halen en bracht hem in de kampong. Toen men hem begraven had, zeide I R. K.: de karbauw daar in de beneden-tuinen, laat hem maar liggen, dat hem opete 
kraaien, roofvogels, allerlei gevogelte, laat hem, dat ze hem op maken.

Toen zeide 't familie-hoofd: wanneer moet men gaan verzamelen, zegt gij, Ramboe Kahi? En I R. K. antwoordde: straks bij 't kouder worden van de zon, als ze zoo hoog is als een klapperboom; laat vier menschen gaan verzamelen alle degenen welke gekomen zijn om vroeger den pinang om te hakken, gaat bij allen aan.

En die vier menschen gingen heen. Toen zij den volgenden morgen teruggekeerd waren: de te samen geroepen menschen komen er aan, zeiden zij. En I R. K. beval de menschen in die kampong, de vrouwen alleenlijk, en zij zeide: komt gij allen; gij allen brengt naar beneden op 't plein de rijst uit de groote zakken; brengt te samen al de rijstblokken, de stampers, groote wannen, kleine wannen, manden, manden met deksel, offer-manden. En I R. K. zeide: stampt vlug de rijst, morgen vroeg zullen wij laten nederdalen den grooten vorst, die uit den hemel teruggekeerd is.

En al de menschen stampten rijst; toen men klaar was met stampen, deed men 't in de offer-manden, 12 offer-manden; toen men 't er in gegoten had, deed men 't deksel er op en keerde ze om. Toen men ze allen omgekeerd neergezet had, bracht men ze naar boven op den grooten vloer, juist vóór den offer-paal.

Tpen zeide I R. K.: gaat en verzamelt mij brandhout, om er morgen ochtend heel vroeg mee te stoken.

Toen men teruggekeerd was van 't hout sprokkelen, was 't reeds avond. 's Morgens heel vroeg opgestaan, zette men de offerpotten op 't vuur, dat waren nu groote potten.

Toen 't heelemaal licht was geworden, de zon halverwege gestegen was, waren alle menschen gekomen, allen waren voltallig.

En I R. K. zeide: familie-hoofd, kom eens hier. En dat familie-hoofd stond op en ging naar haar toe. Toen zeide I R. K.: vader, gaat daarheen, aan de overzijde van den grooten vloer, kijk gij zelf naar iemand, die zal bidden. En 't familie-hoofd ging naar de overzijde van den grooten vloer en keek naar een ouden man, die kon bidden. Vervolgens zeide 't familie-hoofd: Ramboe Kahi, geef sirih voor den Marapoe, hij is er, die op zich neemt te bidden. 
Toen men gebeden had, slachtte men karbauwen, dertien stuks.

Toen men ze geslacht had, hakte men ze open, en men bezag de levers van die karbauwen, welke geslacht waren; vervolgens zeide 't familie-hoofd: de levers der karbauwen zijn goed, Ramboe Kahi, zeide hij tot haar. En I R. K. antwoordde: als 't zoo maar is, dat de levers der karbauwen goed zijn.

Toen riep I R. K., I. O. N d., haar broeder en zijn vrouw.

En zij gingen naar haar toe ginds in de kamer, tegenover de plaats der vrouwen. Toen zeide I R. K.: mijn broeder, er is niemand, die uw vrouw evenaart, er is niemand, die haar in schoonheid nabij komt. En I O. Nd. antwoordde: zoo is 't werkelijk, mijn vrouw, is geen mensch van hier, 't is iemand uit den hemel toch.

Toen nu al de rijst gaar was en 't vleesch, zeide het familiehoofd: Ramboe Kahi, schep maar op. En I R. K. schepte op en zij zeide: tel eens hoeveel menschen er verzameld zijn. Toen zeide 't familie-hoofd: ik zal ze wel tellen. En hij telde ze; toen hij ze geteld had, zeide hij: Ramboe Kahi, er zijn er driehonderd drie en tachtig. En I R. K. antwoordde: 't is maar, dat wij 't weten.

Toen zij klaar was met opscheppen, reikte zij eerst over de offer-rijst, vier stel mandjes. Toen zij nu aangereikt had de offer-rijst, ging hij, die op zich genomen had te bidden, aan 't bidden.

Zij gaf nt eerst aan de rijst van den bidder. Vervolgens gaf zij aan al de rijst van de menigte. Toen zij 't overgereikt had, toen zij er mee klaar was, gaf zij aan ieder zijn deel vleesch.

Men ging nu aan 't eten, al de menschen, welke verzameld waren, en al de menschen daar in de kampong. Toen men gegeten had en de zon wat koud geworden was, zeide de verzamelde menigte: Ramboe Kahi, Oemboe Ndiloe, de broeder van I R. K., komt hier, kauwt sirih, wij zullen heengaan.

Men bracht nu hun sirih naar hen toe, de helft van een dubbele mand, vol als water was die mand met pinang, en men verdeelde 't allemaal onder de verzamelde menschen.

Toen men er mee klaar was, kauwde men sirih; toen men gekauwd had: welaan laat ons ons klaar maken en heengaan. En I R. K. antwoordde: gaat maar heen.

Toen al de menschen heengegaan waren, zeide I O. Nd.: 
zuster, laat mij eens gaan zien naar mijn pisang-bloem-moeder.

En I R. K. zeide: zeg uw naamgenoot, bouw huizen voor een nieuwe kampong, opdat mijn vrouw er heen ga, en zij ook meeneme al haar slaven.

Toen hij heengegaan was, zeide I R. K. tot I O. Nd., de andere: ga huizen bouwen in die kampong, zeide uw naamgenoot. En die I O. Nd. antwoordde: 't is goed, laat mij er maar een bouwen. Hij nu bouwde vijf huizen; hij richtte op een steenen muur bij die kampong, er heelemaal rondom heen. Toen hij de steenen muur af had, makkte hij de poort-deur, een deur, welke van binnen werd gegrendeld.

Toen hij er mee klaar was, zeide hij tot de vrouw van zijn zwager: ga maar naar gindsche kampong, ik ben al klaar met 't huizen bouwen; deuren, steenen muur, ik ben met 't bouwen heelemaal klaar.

En de echtgenoote van I O. Nd., die heengegaan was, ging naar die kampong.

I O. $\mathrm{Nd}$. nu, toen hij gekomen was bij zijn pisang-bloemmoeder, was zij reeds gestorven, hij ontmoette haar niet meer; zij was geheel verschrompeld van de droogte. En I O. Nd. nam haar, wikkelde haar in, bracht haar naar beneden op den grond, midden op 't plein, groef voor haar een gat en begroef haar. Toen hij haar begraven had, wreef hij vuur voor dat huis en stak ' $t$ in brand en ging heen.

Toen hij nu gekomen was bij de kampong, waar hij vroeger 't eerst gekomen was op zijn reis, riep hij van uit de benedentuinen en zeide: breng naar beneden al de slaven, welke gij vroeger beloofd hebt, toen ik hier aan ging.

Gekomen bij de andere kampong, deed hij evenzoo; gekomen bij de andere kampong, evenzoo; gekomen bij de andere kampong, evenzoo, tot dat geeindigd waren de kampongs, welke beloofd hadden boete te betalen. 


\section{Kabihoe Karoenggoe Watoe.}

Toenanoe handăka na; ninja anakeàda mamila, na meti wăroe nja ina na, ama na; na ngara na I Ndiloe ja. Toenanoe bana meti wăroe nja ka, bana ngeri matŏ-tŏa ka hakoedoe hina piti ja na parikoe hina lakoe la woăka paboeta roemba; hau lodoe hau lodoe ndena păndjang paboeta roemba; na tidoeng na lodoe ndena lakoe mboe la oema.

Toenanoe ningoe tau malakoe la ngarăngia la karaha woăka na, hiwănanja: »tăngăroe ja nina na anakeàda, koe lakoe ă kakoe mahoeroe, nde wăna; na pa'eànga-eàngang la mbana lodoe». Tăka hina pa'ăranja: "ha Oemboe Ndiloe, ndau lakoe ndokoe la mamaoe, haní moe ka la lodoe!» Tăka na heàma njoena: "taboeta $\breve{a}$ ka roemba; ămboe koe manganga, wănggoe doe, hikoe pa'eànga-eàngang la lodoe; djăka koe piti ja na watăroe tau, na pawoetang; dira na taboeta ma ka doeta roemba, ka ningoe nda watăroe nda, wănggoe».

Toenanoe mandai-ndai ki ka năhoe, hi ningoe I Oemboe Ndiloe la Katikoe lokoe; na kaliti na ndjara, ba rongoe marau ha nămoe lingoe langgiri, rŏngoe rŏngoe da. Toenanoe bana mareni nja ka na woăka na I Ndiloe mamila hina pa'aung: "ha tamoe noewawa!» Ndena rongoe. "Ha, tamoe!» hili wăna nja. "Wŏa i», hi măngoe pawăna. "Mai nămoe!» "Ka nggăra wămoe ka?» "Mai nămoe!» "Boeta nggoe nja roemba doekoe; tau pamehang ma ka jéa, ndaningoe angoe nggoe paboeta roemba». Na hili pa'aunja: "ha, mai na! ${ }^{1}$ ta lo'a hoeloeroe!» $\mathrm{Na}$ heàma njoena I N di loe mamila: "ndakoe bihoe, ndaningoe ndjara nggoe, ndaningoe hinggi nggoe, ndaningoe tera nggoe; tau mamila patăndjing ma ka!»

Tăka hiwăna I Ndiloe la Katikoe lokoe: ha, mai kau wa njoena, ndjara ningoe, pa'iroe dita ${ }^{2}$ nggoe; hinggi, tera

1 mai $\mathrm{na}=$ kom hier! Dit $\mathrm{n}$ a vindt men niet alleen als adverbium van plaats (lai na= daar), maar komt ook voor in uitdrukkingen als: $\mathrm{mai}$ na= kom hier, jij daar! Zoo zegt men ook: ni ngga=hier ben ik. (lai ni= hier.) en na ngga daar kom ik al aan.

2 iroe dita $=$ te paard zittende (dita $=$ boven op) een ander paard aan een touw mee trekken $=($ iroe $=$ aan een touw leiden. $)$ 
ningoe. Tăka hina lakoe hina wŏnja hina hăpa la kaloemboetoe na. Toenanoe bana hăla ka pahăpa: ta lo’a la I Ka h i, wănggoe ă noe, takaréang hiwănggoe nggau. Toenanoe hi lakoe da nja ka; bada tăka ka la oema na I Kahi, da todoe ha; dămboe roedoeng tiloe mboea roedoeng bada mandai. Toenanoe ba tiloe mboea roedoe da ka, hiwăna njoena I Ndiloe la Katikoe lokoe: "ma lakoe năhoe tai la maringoe lodoe».

Tăka hida wŏndja hida hăpa la mboăla pahăpa na I Kahi. Tăka njoena I NdiIoe la Katikoe lokoe, hina boenggăhoe ja na mboăla pahăpa na I Kahi, hina boetoehoe ja na ana kahoroe na na mboăla pahăpa na I Kahi. Tăka hina piti ja hau na na wŏa daloe kariri, hina toe ja la koeloemboetoe.na. Toenanoe bada memi ka da pangangoe hida wŏndja hida ngangoe; bada hăla ka pangangoe, bada hăla ka pahăpa, hiwăda: "rămboe Kahi, măta kama lakoe wa!» Na heàma njoena I Rămboe Ka hi: "măla i lo'a wa.»

Toenanoe lakoe da nja ka; bada tăka ka la pangéa na I Ndiloe mamila, njoena I Ndiloe la Katikoe lokoe hina wŏnja na kaloemboetoe na: «hăpa, wăna, kakoe lakoe.» Toenanoe bana hăpa ka hina ita ja na wŏa daloe kariri: "ha tamoe!» hiwăna. "Nggăra wămoe? "Wŏnda ja na wŏa daloe kariri, koe ngăndi ja kakoe tondoenja.» "Kau ngăndi ja ka doena.» Toenanoe hina ngăndi ja. I Ndiloe la Katikoe lokoe lakoe na nja ka.

Toenanoe I Ndiloe mamila lakoe pangalang ma na nja la wŏaka, ndena lakoe li la oema; na tăngăroe nja pangéa na na kariri hina tondoenja. Toenanoe pangalangoe ka na mandai na patoe mboea roedoeng hina lo'a patăngăroe ja.

Toenanoe bana ita ja ka toemboe na hiwăna: ai ha, na kariri nggoe, na toemboe ka!» Na heàma na kariri: “toăma răpa toemboe ma nggoe ' hikoe toemboe.»

Tăka mandai ki hakoedoe, hakamboeloe roedoe na, na hili lo’a patăngăroe ja. Toenanoe bana tăka nja ka, karoăka ${ }^{2}$ lima

${ }^{1}$ toăma răpa toemboe ma ng goe = bereikt den tijd van mijn groeien. răpa = vadem, bepaalde maat. Dus: de mant van mijn groeien bereikt hebbende.

2 karoăka lima=de lengte van top van den wijsvinger tot de buiging van den arm. Men zegt ook wel ,kaleàka lima".

Voor.' 't aangeven van een lengtemaat heeft men de volgende uitdrukkingen:

handalihoe =één geleding. (van de vingers of arm.) 
ja ka malai na. Tăka hiwăna: "ai ha, na kariri nggoe mbăda malai na ka, mbăda karoăka lima ja ka.» Tăka na kariri na heàma: "toăma răpa malai ma nggoe, hikoe malai.»

Toenanoe hila mandai hakamboeloe dămboe roedoe na, na hili lo'a patăngăroe ja; mbăda wăla katoăba ${ }^{1}$ na ka. Tăka hiwăna: "ai ha, na kariri nggoe mbăda wăla katoăba na ka, laloe reàngga ja ». Tăka na heàma na kariri: "toăma răpa wăla katoăba ma nggoe hikoe, wăla katoăba.»

Toenanoe hili mandai ki, na hili lo'a patăngăroe ja; mbăda moendjoe na ka na wăla katoăba na. Tăka hiwăna njoena I Ndiloe: "mbăda moendjoe be na na wăla katoăba na». Tăka na heàma na kariri: "toăma răpa moendjoe ma nggoe hikoe moendjoe.

Toenanoe lakoe na nja i la oema; tăka hili mandai ki, na hili lo'a patăngăroe ja; na kariri mbăda lidjoe ${ }^{2}$ na ka. Tăka hiwăna: "na kariri nggoe mbăda lidjoe be na ka.» Tăka na heàma na kariri: "toăma răpa lidjoe ma nggoe hikoe lidjoe.»

Toenanoe lakoe na nja i la oema; na mandai ka bana lo'a patăngăroe ja; ningoe hakamboeloe lodoe doeakamboeloe lodoe hina măngoe palo'a patăngăroe ja. Toenanoe bana lo'a pată-

hakangădoek = van top wijsvinger tot den pols. (kangădoek= buigeh, knikken.)

napoe nggeding = van top wijsvinger tot even boven den pols.

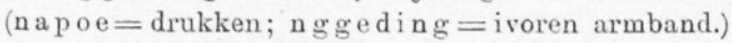

kambihoe lima= van top wijsvinger tot halverwege benedenarm.

( $\mathrm{k}$ a mbihoe $=$ vleezig gedeelte van beneden arm of been.)

kaleàka lima = van top wijsvinger tot elleboogsbuiging.

( $\mathrm{kaleàka}=\mathrm{krom}$; beteekent in vele dialecten: ellebóog.)

Meestal zegt men "karoăka lima"=de buiging van den arm van binnen. Zoo ook "karoăka wihi" = knieholte.

rau halili = van top wijsvinger tot schouder.

(rau (dialect. roe) $=$ blad, haar en halili $=$ oksel.)

bera koeroe= van top wijsvinger tot aan het borstbeen.

bera $=$ breken, in tweeën deelen; koeroe=borst.)

pala koendoe $=$ van top wijsvinger tot anderen schouder.

(pala $=$ overschrijden; koendoe $=$ schouder.)

hau răpa=één vadem.

1 wăla katoăba= (afvallende) bloesem. Van wăla=bloem en ka . to ăba $=$ gek.

: lidjoe=jonge kleine groene vrucht. De volgende stadiën hier genoemd zijn: bokoel=de vrucht is groot.

mábil = half rijp.

$n g$ géa $\mathrm{u}=$ zacht rood bruin.

rara $=$ donker bruin - rijp. 
ngăroe ja, mbăda bokoel be na. Tăka hiwăna: "na kariri mbăda bơkoeloe be na.»

Tăka na heàma na kariri: "toăma răpa bokoel ma nggoe hikoe bokoeloe.»

Toenanoe lakoe na nja i la oema, bana hăla ki ka paboeta roemba hakoedoe. Mandai-ndai na hili lo'a patăngăroe ja; na kariri noena mbăda matǒa mábiloe ${ }^{1}$ na. Tăka hiwăna: "ai ha, na kariri nggoe njoengga, mbăda matŏa mábiloe na!» Tăka na heàma na kariri: toăma răpa matǒa mábiloe nggoe hikoe matǒa mábiloe!»

Toenanoe lakoe na nja i la oema; mandai-ndai na hili lo'a patăngăroe ja; bana tăka nja ka na kariri, mbădă nggéau ${ }^{2}$ be na ka. Tăka hiwăna: "ai ha, na kariri ngoe mbăda nggéau be na ka.»

Tăka na heàma na kariri: "toăma răpa nggéau ma nggoe hikoe nggéau.»

Toenanoe lakoe na nja i la oema; mandai ki hakoedoe na hili lo'a patăngăroe ja, na tăka nja, mbăda rara na ka. Tăka hiwăna: "na kariri nggoe njoengga mbăda rara be na, ndena mandai ndokoe». Tăka na heàma njoena na kariri : "toăma răpa rara ma nggoe hikoe rara». Tăka hiwăna $\mathrm{I} O \mathrm{O} m b$ oeNdiloe: "kanggiki ă nda nja ka ihoe na kariri, ba mbăda rara na ka?» Tăka na heàma na kariri: "kau păpoe ka, kau ngăndi ka, kau pahămoe ka, la koeroe koewang ${ }^{3}$ kau băndjăloe ni ka.»

Toenanoe hina păpoe ja hina ngăndi ja la oema hina piti nja tera hina kamboeroe wănja hina băndjăloe ja la koeroe koewang.

Toenanoe hadang la mbaroe, lakoe na nja ka paboeta roemba la woăka; na mbana ka na lodoe, na beli ja la oema. Hili hau lodoe lakoe na nja ka la woăka. Toenanoe bana beli ja ka weling la woăka ba hīna na tăka, na wingoe nja na woeroe wai, koe lo'a patakoe wai, wăna na eti na. Toenanoe na tăka nja na woeroeng, na mbinoe be wai. Toenanoe hina poeroe

1 Zie noot ${ }^{2}$ blz. 155.

2 Zie noot 9 blz. 155.

3 la koeroe koewang = tusschen leege rijstaren.

koeroe $\equiv$ een kamertje; koewang=leege rijstaren. 't Wil dus zeggen: leg hem tusschen de rijst-aren in, als in een kamertje.

Een aparte schuur of afdeeling voor de leege rijst-aren kent een Soembanees niet. Men stapelt 't op in 't veld en laat 't zoo versteenen of men verbrandt 't. 
ja la tana hina piti ai, hina hē hina padoekoeloe ja na epi; bana doeroe ka na epi hina hadang, kakoe piti tanga mboăla, wăna.

Tăka na ita ni ja na oehoe bărăhoe hau tanga mboăla na. Tăka na hili boenggăhoe ja na tanga mboăla na hau; na ita ha da tiloe manoe padjoedjoekoe patoengoe wai kokoer. Tăka hiwăna: "nggamoe păkoe ihoe na mamai patoengga oehoe memi dăngoe tiloe manoe padjoedjoekoe; măta kakoe paloe wănja ${ }^{1}$, wăna ka ihoe, hina mai patoe ngga; koe ngandja doekoe, mili ămboe koe lo'a doe njoena la oema na pamanganga; ka ihi nja doena hina mai patoe ngga ha la oema nggoe.»

Toenanoe ngangoe na nja ka; na hăla ka pangangoe, mahoeroe na nja ka; na kanandi hili weli hili weli ja. Toenanoe bana oela ja ka pakanandi nja hiwăna: pateàng ka doena pameti wăngoe.

Toenanoe hili hadang la mbaroe, lakoe na nja i paboeta roemba; bana tidoeng $\mathrm{ka}$ na lodoe, na beli ja. Toenanoe bana tăka ka la oema, tăka hina hē ja la aoe; na tăngăroe ja na epi, ningoe; hina padoekoeloe ja; toenanoe bana hăla ka papadoekoeloe ja na epi, hina hadang, tăngăroe tanga mboăla, păpoe wăngoe watăroe, wăna. Toenanoe na ita ni ja i na oehoe memi hau tanga mboăla na dăngoe rī parănda. Nde nggăra ndokoe papaní na; na piti ha, na mandapoe kareàndja hina ngangoe. Toenanoe bana hăla ka pangangoe, na kanandi hili weli hili weli ja; bana oela ja ka pakanandi nja: pateàngoe ka pameti wăngoe, mili ămboé koe lo'a doe njoena pamanganga la oema tau, wăna bana paní méha.

Toenanoe na hili hadang la mbaroe, lakoe na nja i la woăka, lo'a paboeta roemba. Toenanoe bana lakoe ka, na toăma la padoea ngarăngia, tăka hi ninja I A poe Kămi ${ }^{2}$ la woekoe roemba, tăka hiwăna: "ha ha oemboekoe nggoe, nggi ha lo'a ningoe moe nja!» Tăka na heàma njoena $\mathrm{I} O \mathrm{emboeNdiloe:}$ "lakoe nggoe nja paboeta roemba.» " $\mathrm{Ha}$ lakoe $\mathrm{ha}$ li ha diroe nămoe, ha ningoe pa ha 'ní nggoe ha koedoe». Tăka na heàma njoena $\mathrm{I}$ Oemboe $\mathrm{Ndiloe}$ : "é ha, ndakoe bihoe palakoe li, da wau da kapoăla moe, ndéa hi!» "Ha lakoe ha li ha diroe, ningoe pa ha ní nggoe ha koedoe ha koedoe ă;

' măta kakoe paloe wănja=laat ik hem er mee slaan, d. w. z. ik zal hem er laten inloopen; een oorzaak zoeken tot twist.

"I A poe Kămi = „de tooverfee". vgl. pag. 98 , noot 1 verhaal V. 
mahămoe ha lănga ha tăka ja na pa ha ní nggoe.» Tăka na heàma njoena I Oemboe $\mathrm{Ndiloe:} \mathrm{"djăka} \mathrm{ndaningoe} \mathrm{be} \mathrm{ă}$ papaní moe tai, ndéa ndakoe djăma ă nggau. »

Toenanoe hina lo'a. "Ha ndapoe ha pingi ha ngiloe, kau ha njama nda.» Toenanoe bana hăla panjama nja, hiwăna njoena I Apoe Kămi: "măla, handăka tăka handăka tăka moe la oema, nggăra pa'ita moe la oema?» Tăka hiwăna njoena I $O$. Nd.: "lănga tăka kai njoena, handăka tăka nggoe, ningoe oehoe memi, wai la woeroeng ningoe.» Na heàma njoena I A. K. : "na! rongoe ja na papaní nggoe njoengga; măla noe, kanandi nja, napa hi ningoe pabăndjăloe moe»? Tăka na heàma njoena I O. N d.: "ningoe, kariri rara ja.» "Kanggini băndjăloe ni ja? "La koeroe koewangoe ja.»

"Na! djè doe ja na pabăndjăloe moe na mamanahoe pangangoe, na matakoe wai; batoenanoe pandapoe nja, kau lakoe beli ndjănga; na hori na, djăkau beli ndjănga, djăkau tăka la oema, pareàngang kau piti ja na haloămba na la koeroe koewang, kau piti ja kau toenoe ja la epi, bana kărang ka kau răba nja wai hau toboeng; toenanoe djăkau hăla ka pa'oerăkoe ja na kalátoe na la wai, kau mandapoe la ngaroe papoeroeng; djăkau ita ja ka, kau boeri weli katikoe nja ja.»

Toenanoe hina kakikoenja; na loehoe weling la woekoe roemba, na toăma la padoea ngarăngia, na beli ja. Toenanoe bana beli ja ka hina pangalang papiti ja na haloămba na, hama toena na papaní na I A. K. Toenanoe bana hăla ka patoenoe ja, hina răba nja wai hau toboeng hina lemi ja hina oeră-oerăkoe ja paka-kaboe ja. Tăka hina mandapoe ja la ngaroe pahē; na napa ja. Toenanoe tăka doe na nja ka I Kariri; hina boeri nja na wai. Toenanoe bana boeri nja ka na wai, păha wăna ma la tana bana meti widi. Toenanoe bana meti widi ka, tăka hina poeroe ja njoena I O. Nd. hina kata nja na hoepoe hinggi na, hina paloe wănja ja. Toenanoe ba hīna na handăkanja, ndedi na kambawăkoe; na pandoeanja, na pambatoenja hīna măngoe pahadang. Tăka hiwăna njoena I $\mathrm{O} . \mathrm{Nd}$.: "ai ha! laloe pingoe kămoe woeloe aka; handăka tăka nggoe la oema, ningoe pangangoe pamemi; handăka tăka nggoe hamang.» Toenanoe bana hăla ka pawăna: "nggamoe ja na ngara moe, hiwăna nja. Na heàma na kawini: I Kariri hă răka, hiwăna nja.

Toenanoe ka kanŏama na nja nja ka njoena I O. N d. 
Toenanoe mandai ki ka năhoe, ningoe dămboe woelang, tăka hiwăna njoena I O. N d.:- "măta kakoe lo’a patăngăroe ha da ndjara pawoeloe na i ama la padang; lakoe hau woela ă nggoe», wăna. Toenanoe ka lakoe na nja ka. Toenanoe ba tiloe mboea roedoe patoe mboea roedoe na ka mandai na, tăka na nja ka I Mbakoe ${ }^{1}$, na răndjăkoe la padoea talora, hiwăna: "ha oemboekoe nggoe, Kariri hărăkoe, poeroe kămoe nămoe, kau hikoe ha da tai kahiloe nggoe», hiwăna nja. Na heàma njoena I Kariri: "é, ndakoe, bihoe, koe mangădătoe.»

Tăka hiwăna njoena I Mbakoe: "ha, mai doemoe hi! kau beli ka tai!» Toenanoe poeroe doe na nja ka, na lakoe toăma ja, bana lihi nja ka. tăka njoena I Mbakoe hina padjămandja ka kahiloe na; toenanoe kakoe tăngăroe ha, wăna doe ka lăti; na napa ja, na poehi ja la koeboe kahiloe na, palai ngăndi na nja ka njoena I Mbakoe I Kariri, na ngăndi ma ja la kapoeka ai djangga.

Toenanoe bana mandai ka năhoe bana toăma ka hau woelang, beli na nja ka la oema I $\mathrm{O}$. Nd. Toenanoe tăka na nja ka la oema djoea. Toenanoe hina piti ha na tanggoe marapoe na ${ }^{2}$, na ngăndi ha. Toenanoe na tăka ndja da wē roemba, mangoering da nja kareha, hiwăna: "ha Oemboe wē, djăkai ita ja I Kariri, peàka ngga, koe wŏnggămi woenda mi. D Da heàma da wē roemba: "e, wăkoe be ja na ina moe, ămboe riau riau moe, malo'a tai, mahira wă-wăla kămoe; mangoering ma ja kareha doema, mandjoé mboe da ha da kamboe ma».

Toenanoe hili lakoe na nja $i$; na ita ha da ngganga: "djăkai ita ja I Kariri papaha nggoe, koe wŏnggămi woenda mi».

"Nggăra wămoe», wăda da nggangga. "Na papaha nggoe, wănggoe doekoe, na palai ngăndi ja tau, napa hi ita ă i ja.» Tăka da heàma dă nggangga hiwăda nja: «ha ănga, lakoe ma doemoe ka, ămboe ri-riau moe, tai kama lo'a, kama roeki ha da wŏa mata moe», wăda nja.

Toenanoe hili lakoe na nja i; na lakoe na ita ha da ndjara,

' I Mbakoe= naam van een grijs grauwen roofvogel.

2 na tanggoe marapoe na $=$ 't deel van zijn Marapoe.

Marapoe is de beschermgeest van de familie, die woont boven in huis en wiens deel ook daar neergezet wordt. 't Is meestal een klein houten kistje, waarin eukele schilfertjes goud.

Daar de Marapoe nu zoo slecht op zijn vrouw heeft gepast, neemt hij hem mee oin hem weg te geven. 
hiwăna njoena I O. N d.: "ha Oemboe ndjara!» Tăka da ndjara da heàma: "nggăra wămoe?» Tăka hiwăna njoena I $\mathrm{O} . \mathrm{Nd}$.: «himboe nggoe nja na papaha nggoe năhoe, na palai ngăndi ja tau; napa i ita ja, peàka ngga, koe wŏnggămi ha da tanggoe Marapoe nggoe.» Da heàma da ndjara: "nde djeà kau panggoemang ma! ănga lahoe moe! wăkoe ina moe! na jăpa kau woeja! măla ri-riau moe ná, tai malo'a matilăk kau ná, kau meti ka.»

Toenanoe hili lakoe na nja i; na ita ha da karămbo'a la hau kandjŏanga, hiwăna: "ha Omboe karămbo'a, ningoe pakarai nggoe lai njimi.» Da heàma da karămbo'a: "nggăra wămoe.» "Na papaha nggoe năhoe na palai ngăndi ja tau: djăkai ita ja, djăkai pinja na pangéa na, koe wŏnggămi woenda mi.» $\mathrm{Da}$ heàma da karămbo'a: "nggăra wămoe, ná!» Tăka na heàma njoena I O. Nd.: "himboe nggoe nja na papaha nggoe, djăka nggini ja ka na hanggang ningoe, ndakoe pinja.» Da heàma da karămbo'a hiwăda: "măla noe, njoema malo'a padai ja na papaha moe, tăka hioe karai kăma njoema?»

Tăka na heàma njoena I O. Nd.: "ná; napa hi ita ja, wănggoe doekoe hikoe pa'ărang.» Da heàma da karămbo'a: «hămoe kau păndjangoe ă papaní, djăka laloe paní moe, tai malo'a mandjoekoeloe nggămoe, kau meti ka, kana nganggau nggangga!»

Toenanoe hili lakoe na nja i; na tăka la hau kandjoănga. na ita ha da hapi: "ha Oemboe hapi!» "Wo i» wăda da hapi.

"Hi ita ă ja na papaha nggoe bana palai ngăndi ja tau?» Da heàma da hapi: "ngangoe nda roemba doeta, au au moe nămoe loea ${ }^{1}$; hili pa'aung ki, kama lo'a, kama pahikoe kămoe ná tai, kau meti kawé-wérăkoe.»

Toenanoe hili lakoe na nja i; na tăka la hau kandjoănga, hina tángara la pingi ai haki; na ita ja he'au na na lambakoe: "ha Oemboe lambakoe» hiwăna. "Wŏ i », wăna na lambakoe.

"Napa hioe ita ja na papaha nggoe, na palai ngăndi ja tau.» «Laloe kambănga kau noewawa ná! ngangoe nda i ja wŏa ai doeta, au au moe nămoe; djăkau hili pa'aung ná tai, koe poeroe toăma kau, koe kauri ma kau!»

1 a u a moe nămoe loea =en gij komt daar schreeuwen.

$\mathrm{au}$ a $\mathrm{u}=$ roepend geluid; pa' $\mathrm{a} \mathrm{ung}=$ roepen.

$\mathrm{n}$ ămoe $=$ er aankomen.

loea = adverbium van plaats: ginds. - Meest in den vorm: noe. loe $\mathrm{a}=$ ginds; en hoeloe $\mathrm{a}=$ gindsheen. 
Toenanoe lakoe na nja i; na tăka la kalimboe oămang, tăka hiwăna bana ita ha da mbăra nggeàla: "ha Oemhoe mbăra.»

Ndéa ndeda heàma. "Ha, oemboe mbăra.» Tăka hiwăda hawiăngoe da mbăra: "ha, rongoe ja ná, hama djè jéa I O. Ndiloe mamila.»

Tăka na hili pa'aung: "ha, oemboe mbăra.» «Wŏ i», hiwăda da mbăra, mai kau nămoe», wăda da mbăra bada pa'aunja. Toenanoe hina lakoe toăma ha, bana tăka ndja ka, "ka nggăra pahimboe moe?» Tăka na heàma njoena I O. Nd.: «himboe nggoe nja I Kariri papaha nggoe, na palai ngăndi ja tau.» Tăka da heàma njoeda da mbăra: "ha, ămboe handoeka nja lai noe, măla kata lakoe la marămba mbăra.» Toenanoe hida lakoe. Toenanoe bana tăka ka la oema na na marămba mbăra, hiwăda njoeda da mbăra: "ha oemboe, hijeàna I Ndiloe mamila, na mapaha ja na papalai ngăndi I Mbakoe.» Tăka na heàma njoena na marămba mbăra: "djeà doe ja kata pinja.» Tăka njoena I O. Nd. hiwăna: "ha oemboe mbăra, marămba, djăkau măka papiti beli ngga ja I Kariri, koe wŏnggau na patoekoe rara» ${ }^{1}$. Na heàma njoena na marămba mbăra: "Kandí kau! măla ndau pinja na pangéa na?» Na heàma njoena I O. Nd.: "ndakoe pinja.» "Napa tai na maringoe na lodoe kakoe pa'ita nggau ja.»

Toenanoe bana maringoe na lodoe hina patoedji nja ja, na káloe bana ita ja. Tăka hiwăna njoena na mbăra: "I Mbakoe, laloe mawoeloe lănga tăka ja; da banda hau tana hau tana, ri malokoe, kanătăroe, patoekoe lomboe, ana hida, halakoe loeloeng, mătoe ndăba na, bana lo'a pateàwa ha; djăka na dengi ha ka da hinggi na na tau la lodoe, na teàwa hăla ha. Toenanoe ndaninja năhoe I Mbakoe, năhoe ja la hapapa tana, lo'a pateàwa banda; wăna njoena na mbăra: «njoengga ndakoe măka, dira na lo'a papa'aunja I Kabira ${ }^{2}$, dira ma na na mamăhi, na măhi pamanganga, na măhi la kapoeka ai.»

Toenanoe hina lo'a papa'aunja; bana tăka ka hiwăna nja: "măla noe, Kabira, măka hē papiti ja I Kariri?» Na heàma njoena I Kabira: "wŏngga woenda nggoe bădi. » Tăka na heàma njoena na marămba mbăra: "wŏnggau doena woenda moe? Koe măka!»

\footnotetext{
${ }^{1}$ patoekoe rara= geslagen (toekoe) goud; platte dunne stukjes goud, welke men aan den Marapoe offert.

2 I Kabira = naam van een grooten aap.

Dl. 68 . 
"Napa tai hakoedoe.» Toenanoe mandai ki ka hakoedoe, tăka hina lo'a njoena I Kabira, na hē ja la kapoeka ai, na papoeroe ndăba ndja da banda hangia hangia, na hăla ndăba ma. Toenanoe bana hăla ha ka hina hili hē papapoeroe nja I Kariri, ngăndi doe na nja ka la oema na na marămba mbăra. Toenanoe bana tăka ka hiwăna njoena na marămba mbăra: "ha Oemboe Ndiloe mamila, ninja ka na papaha moe. $\mathrm{Na}$ heàma njoena I O. $\mathrm{Nd}$. mamila: "pira woenda nggoe, wăna I Kabira?» Tăka na heàma njoena na marămba mbăra: "măta kakoe tanggoe nja ka kakoe wŏnja.»

Toenanoe tăka doe na nja ka I Mbakoe; hīna na tăka: "ha Rămboe Kariri» wăna. Tăka hina hili pa'aunja: "ha Rămboe Kariri!» Tăka ba ndena heàma ja pa, na poeroe ja la bangga hina ka'oăka, hiwana bana ka'oăka: "djăka nggamoe ja na mapalai ngăndi ja I Kariri dăngoe da banda nggoe, hīna ka njoena, koe roeki ha da wŏa mata na.»

Toenanoe bana hăla ka paka'oăka hina pa'aung: "ha oemboe Mbăra noewawa, ndau ita ja năhoe I Kariri, na mapalai ngăndi ja?» Tăka na heàma njoena na marămba mbara: »hoekoetoe ja na eti moe, djăka nggini papiti ni moe nja!» «Papaha na I Oemboe Ndiloe mamila ja, bakoe wăhi ja.» $\mathrm{Na}$ heàma njoena I Mbăra: "madja ka toedoena, ninja I O. Nd. mamila.» Na heàma njoena I Mbakoe: "ai ha, napa haromoe la mbaroe ta patara.»

Tăka na heàma njoena na marămba mbăra: "măla ka!» Tăka hiwăna nja I O. Nd. mamila na Mbăra: «ămboe mangădătoe, napa koe wŏnggau hapanda; haromoe la mbaroe kai patara.»

Toenanoe hadang la mbaroe bana padoea pahē na na lodoe, tăka hiwăna I Mbakoe: "na ngga ka, napa ka!» Toenanoe hina hawoeroeng, ba hīna na hawoeroeng, na lakoe li hiwiroe ja I O. Nd. mamila; tăka njoena na na katăhi wănja hapanda na woeloe kăpa na, na mbata ma. Toenanoe păndjang na nja, lakoe na nja i la oema na; na tăka la oema na, na ka'oăka dira matiki; wăna bana ka'oăka: "napa haromoe, djeà ki ja ka na hapapa na woeloe kăpa nggoe, djăka koe tăba wănja ja, na meti meàmang.»

Toenanoe hadang la mbaroe, tăka hiwăna I Mbakoe: «na ngga ka, handăka djoea ngga ka — koe handăka djoea ă, na meti meàmang.» 
Toenanoe woeroe-roe wăna, lakoe li hiwiroe ja I O. Nd. mamila; na napa ja, na kadipoe ja na nggoroe na. Toenanoe bana meti ka, na padoekoeloenja epi hina toenoe ja, pakăra kăranja.

Toenanoe bana hăla ka pameti ja I Mbakoe, toenanoe ka beli da nja ka la pangéa da. Tăka njoena I Mbăra hina wŏnja woenda na I Kabira, na poetoe nja karoengga watoe hina wǒnja. Tăkă njoena I Kabira hina lakoe li la tau mapamehang, tăka hiwăna nja: «jeàda da tanda lima nggoe njoengga, djăka ningoe hama nggoe njoengga, toendja tanda da, ndeda bohoe ă, djăka tiki ja tau Karoenggoe Watoe ${ }^{1}$.

1 tau karoenggoe Watoe=menschen van Karoenggoe Watoe (d.i. kiezelsteenen.) De verschillende geslachten (K a b is o e) op Soemba hebben namen. Meestal weet men niet meer, war de naam van afkomstig is. Slechts in enkele gevallen is er een legende aan verbonden zooals bovenstaande.

Wanneer men iemand tegen komt op den weg, vraagt men niet naar zijn naam, maar naar zijn geslacht; n.l. nggăra tau kau? wat voor mensch zijt gij. - Men weet dan, van waar hij afkomstig is, want elk geslacht heeft zijn bepaalde landstreek.

Een eigenaardigheid van zulk een geslacht is dat men sommige dicren niet mag eten.

Meestal zijn 't er twee. De menschen van Karoenggoe Watoe eten geen apen en geen duiven; wat zij uit bovenstaande legende afleiden. Zoo heeft elk geslacht zijn eigen dieren. 


\section{Het geslacht Karoenggoe Watoe.}

Eertijds was er eens een wees; zijn ouders hadden hem door hun dood achtergelaten; zijn naam was I Ndiloe. Toen zij hem door hun dood hadden achtergelaten en toen hij langzamerhand wat ouder was geworden, nam hij een steekschoffel en ging naar den tuin om onkruid te wieden; dag na dag hield hij niet op met onkruid wieden; de zon stond recht boven zijn hoofd en nog ging hij niet naar huis.

Er was nu iemand die op den weg lang zijn tuin liep en hij zeide van hem: "kijk dien knaap eens; ik zal eens gaan liggen, zegt hij niet; hij houdt 't maar uit in de warme zon.» Vervolgens riep hij tot hem: ha Oemboe $\mathrm{Ndiloe}$, gij gaat heelemaal niet naar een schaduwrijk plekje, gij blijft voortdurend in de zon.»

Maar hij antwoordde: «laten wij maar onkruid wieden, opdat ik niet stele, zoo zeg ik; daarom houd ik 't maar uit in de zon; als ik mais van de menschen weg neem, legt men boete op; 't eenige is dus dat wij maar onkruid wieden, opdat wij onze (eigen) mais hebben, zoo zei ik».

Toen 't nu een korteren of langeren tijd geduurd had, was er I Oemboe Ndiloe la katikoe lokoe; hij besteeg een paard, terwijl men verre hoorde aankomen 't geluid der belletjes, 't gerinkinkel er van. Toen hij dicht bij den tuin van I Ndiloe mamila was, riep hij tot hem: "ha naamgenoot daar beneden!» Hij hoorde niet. "Ha naamgenoot!» zeide hij wederom tot hem: "Ja toch, zeide hij toen pas.» "Kom hier!» "Wat hebt gij te zeggen?» "Kom hier!» "Ik moet onkruid wieden; $\mathrm{ik}$ ben hier toch maar alleen, ik heb geen metgezel om onkruid te wieden.» Wederom riep hij tot hem: ha, kom toch, laten wij stroomaf gaan.» I Ndiloe mamila antwoordde: "ik wil niet, ik heb geen paard, ik heb geen slimoet, ik heb geen hoofddoek; ik ben werkelijk een arm mensch.»

Maar I Ndiloe la Katikoe lakoe zeide: ha, kom jij maar, een paard is er, ik neem je mee op paard; een slimoet, een hoofddoek is er.» Vervolgens ging hij, gaf hem en hij kauwde sirih uit zijn sirih-tasch. Toen hij sirih gekauwd had, 
wij gaan naar I Kahi, zeide ik daar, laten wij hem meenemen, zeide ik van u.

En men ging op weg; toen zij gekomen waren bij 't huis van I Kahi, overnachten zij; twee à drie nachten duurde 't. Toen 't nu drie nachten waren, zeide I Ndiloe la Katikoe lokoe: wij zullen nu straks weggaan als de zon "koud» is. En men gaf hen en zij kauwden sirih uit de sirih-mand van I Kahi. Vervolgens opende I Ndiloe la Katikoe lokoe de sirih-mand van I Kahi en trok uit 't schuiflaadje van de sirihmand van I Kahi. En hij nam één meloen-pit en deed die in zijn sirih-tasch. Toen het eten klaar was, gaf men hen en zij aten; toen zij gegeten hadden en sirih gekauwd hadden, zeiden zij: "ramboe $\mathrm{Kahi}$, laat ons nu gaan!» I Ramboe Kahi antwoordde: "welaan, gaat maar.»

En zij gingen heen; toen zij gekomen waren bij de woonplaats van I Ndiloe mamila, gaf I Ndiloe la Katikoe lokoe hem zijn sirih-tasch: "kauw sirih, zeide hij, dan ga ik heen." Toen hij sirih kauwde, zag hij de meloen-pit: ha, naamgenoot, zeide hij: "Wat hebt gij te zeggen? "Geef mij de meloen-pit, ik zal die gaan planten.» "Neem ze maar mee.» En hij nam ze mee. I Ndiloe la Katikoe lokoe ging nu heen.

En I Ndiloe mamila ging recht door naar den tuin, hij ging niet aan in huis; hij keek uit naar een plaats voor den meloen en plantte dien. Toen men bereikte den duur van vier nachten ging hij er naar kijken. Toen hij gezien had zijn ontkiemen, zeide hij: "ai ha, mijn meloen, ontkiemd is hij.» De meloen antwoordde: "(als) aangebroken is de tijd van mijn ontkiemen, dan ontkiem ik.»

$\mathrm{Na}$ verloop van korten tijd, tien nachten, ging hij er wederom naar kijken. Toen hij er bij gekomen was, een handgeleding lang was hij. En hij zeide: "ai ha, mijn meloen is al lang, reeds een handgeleding lang.» En de meloen antwoordde: "als aangebroken is de tijd van mijn lang zijn, dan ben ik lang.»

Wederom na verloop van twaalf nachten, ging hij er wederom naar kijken; er was reeds bloesem. En hij zeide: "ai ha, mijn meloen heeft reeds bloesem, zeer vlug is 't.» Maar de meloen antwoordde: "als aangebroken is de tijd van mijn bloesem, dan heb ik een bloesem.»

Wederom na verloop van langen tijd, ging hij er wederom naar zien; zijn bloempje was reeds afgevallen. En I N diloe 
zeide: "reeds is al afgevallen zijn bloesem." Maar de meloen antwoordde: "als aangebroken is de tijd van mijn afvallen, dan val ik af.»

Hij ging nu weer naar huis; wederom na langen tijd, ging hij er wederom naar kijken; de meloen had reeds jonge vrucht. En hij zeide: mijn meloen heeft al jonge vrucht. Maar de meloen antwoordde: "als aangebroken is de tijd van mijn jonge vrucht zijn, dan heb ik jonge vrucht.

Hij ging nu weer naar huis; 't duurde lang dat hij ging kijken; 't waren tien à twintig dagen, eer dat hij er naar ging kijken. Toen hij er naar ging kijken, was ie reeds groot. En hij zeide: "mijn meloen is al groot." Maar de meloen antwoordde: "als aangebroken is de tijd van mijn groot zijn, dan ben ik groot.»

Hij ging nu weer naar huis, nadat hij een weinig onkruid had gewied. Na langen tijd ging hij er wederom naar kijken; die meloen was reeds half rijp.» En hij zeide: "ai ha, mijn meloen is reeds half rijp.» Maar de meloen antwoordde: "als aangebroken is de tijd van mijn half rijp zijn, dan ben ik half rijp.»

Hij ging nu weer naar huis; na langen tijd ging hij er wederom naar kijken; toen hij bij den meloen gekomen was, was hij reeds zacht rood bruin. En hij zeide: "ai ha, mijn meloen is reeds zacht rood bruin.» Maar de meloen antwoordde: "als aangebroken is de tijd van mijn zacht rood bruin zijn, dan ben ik zacht rood bruin.»

Hij ging nu weer naar huis; na korten tijd ging hij er wederom naar kijken, hij kwam er bij en rijp was ie. En hij zeide: «mijn meloen is reeds rijp, 't duurde heelemaal niet lang." Maar de meloen zeide: "als de tijd van mijn rijp zijn is aangebroken, dan ben ik rijp. En I Oemboe Ndiloe zeide: "hoe heb ik 't toch met den meloen, dat ie reeds rijp is?» Maar de meloen antwoordde: "pluk mij, neem mij mee, bewaar mij, leg mij neer in rijst-aren.»

En hij plukte hem af, nam hem mee naar huis en nam hem een stuk goed en wikkelde hem er mee in en legde hem neer in rijst-aren 's Morgens vroeg ging hij onkruid wieden in den tuin; toen de zon warm was, keerde hij terug naar huis.

Wederom een anderen dag, ging hij naar den tuin. Toen hij teruggekeerd was van den tuin en pas was aangekomen, ging 
hij recht af op de waterkruik: ik ga water halen, zeide zijn hart. Hij kwam bij de kruik, ze was vol water. En hij daalde af op den grond en haalde hout en hij klom naar boven en stookte 't vuur op, toen 't vuur opvlamde, stond hij op om een mandje te halen.

En daar zag hij rijst, een mandje vol. Wederom opende hij een ander mandje; hij zag kippeneieren, gebakken met klapperolie. Toen zeide hij: "wie zou 't toch zijn, die mij kwam brengen gekookte rijst en gebakken eieren; laat ik hem er mee slaan, zeide hij misschien, en zoo kwam hij 't mij brengen; ik zal 't maar opeten, als ik maar niet naar zijn huis ga stelen; $z o o$ zal 't misschien zijn, dat hij 't mij in mijn huis is komen brengen.

En hij at; nadat hij gegeten had, ging hij liggen, hij dacht $n a$, nog eens en nog eens. Toen hij genoeg had van 't nadenken, zeide hij: men moet maar afwachten of men er van sterft.

Wederom des morgens vroeg, ging hij onkruid wieden; toen de zon boven zijn hoofd stond, keerde hij terug. Toen hij thuis gekomen waa, klom hij naar de stookplaats; hij keek naar 't vuur, 't was er; en hij stookte 't op; toen hij 't vuur opgestookt had, stond hij op; eens kijken naar een mandje om mais in te plukken, zeide hij. En daar zag hij gekookte rijst een mandje vol en gebraden toepijs. Hij sprak heelemaal niet, hij nam het, ging er bij zitten en at. Toen hij gegeten had, dacht hij na, nog eens en nog eens; toen hij genoeg had van 't nadenken: men moet maar afwachten of men er van sterft, als ik toch maar niet ga stelen in 't huis van een ander, zeide hij sprekende in zich zelf.

's Morgens stond hij weer vroeg op en ging maar naar den tuin om onkruid te gaan wieden. Toen hij wegging en halverwege was gekomen, was er I A poe Kămi in 't dichte gras en zij zeide: "ha, mijn kleinzoon, waar gaat gij heen?» En I Oemboe Ndiloe antwoordde: "ik ga onkruid wieden." "Kom dan eerst hier even aan, ik heb een beetje te vertellen.» Maar I O. $\mathrm{Nd}$. antwoordde: "é ha, ik wil niet aanloopen, uw wonden stinken, neen hoor!» "Kom toch even aan, ìk heb een heel klein beetje te vertellen; werkelijk goed is hetgeen ik te vertellen heb.» En I O.Nd. antwoordde: als gij straks niets te vertellen hebt, neen, dan laat ik 't je er niet bij.» 
En hij ging er heen. "Ga boven den wind zitten en kauw mij een sirih-pruim.» Toen hij er een gekauwd had, zeide I A poe Kămi: "welaan, telkens als gij in huis komt, wat ziet gij dan in huis?» En I O. Nd. zeide: «'t is werkelijk zoo, telkens als ik kom, is er gekookte rijst, is er water in de kruik.» I A. K. antwoordde: "dat is 't, hoor wat ik te vertellen heb; hoe is 't, denk eens na, misschien is er iets door u ergens neergelegd ?, Toen antwoordde I O. Nd.: er is wat, een rijpe meloen.». "Waar hebt gij dien neergelegd?» "Onder de padidoppen.» "Dat is 't, datgene wat door $u$ is neergelegd, is ' $t$, dat 't eten kookt, 't water schept; daarom ga 't opwachten, keer weer terug; dit is de adat er van, als gij terugkeert, als gij in huis komt, neem dan vlug de schil er van uit de padidoppen, neem 't, brand 't in 't vuur, als 't zwart gebrand is, giet er dan één schotel water op; als gij fijn gekneed hebt 't harde in 't water, ga dan zitten in de deur-opening; als gij haar ziet, giet 't haar dan boven op haar hoofd.»

En hij volgde 't op, hij ging weg uit 't dichte gras, kwam midden op den weg en keerde terug. Toen hij teruggekeerd was, ging hij recht door de schil halen, evenals I A. K. gezegd had. Toen hij 't gebrand had, goot hij er één schotel water op en hij weekte het en kneedde 't heelemaal fijn. Toen ging hij zitten in de deur-opening; hij wachtte. En daar kwam I Kariri aan; en hij goot 't water op haar uit. Toen hij 't water op haar uitgegoten had, viel zij met een slag op den grond, terwijl zij flauw viel. Toen zij flauw gevallen was, kwam I O. $\mathrm{Nd}$. naar beneden en hij pakte beet een tip van zijn slimoet en sloeg er haar mee. Toen hij 't pas éénmaal gedaan had, bewoog zij zich nog niet; hij deed 't tweemaal, hij deed 't viermaal, toen pas stond zij op. En I O. Nd. zeide: "ai ha! wat kent gij toch listige streken; telkens als ik thuis kwam, was er gekookt eten; telkens als ik kwam was 't hetzelfde.» Toen hij dit gezegd had: "hoe is je naam, zeide hij tot haar. De vrouw antwoordde: I Kariri Kăráka, ‘zeide zij hem.

Vervolgens huwde I O. Nd. met haar.

Toen 't nu een tijdje geleden was, 't waren twee maanden, zeide I O. Nd.: "laat ik eens gaan bezien de paarden, de erfenis van vader, in 't veld; ik ga voor één maand, zeide hij. . En hij vertrok. Toen 't drie à vier nachten geleden was, kwam daar I Mbakoe, hij streek neer midden op 't pleintje en hij 
zeide: "ha mijn kleinkind, Kariri hă rấkoe, kom eens hier naar beneden, peuter 't vuil uit mijn oor», zeide hij haar. I Kariri antwoordde: "é, ik wil niet, ik ben bang." Maar I Mbakoe antwoordde: "ha, kom toch hier! straks mag je terug.» En zij ging maar naar beneden, zij ging naar hem toe, toen zij aan zijn zijde gekomen was, hield I Mbakoe haar zijn ooren toe; zij nu wilde ze bekijken, maar hij wachtte haar op, duwde haar in zijn oorholte, en I Mbakoe schaakte I Kariri, hij bracht haar in den top van een hoogen boom.

Toen 't nu een tijd geleden was, toen één maand voorbij was, keerde I O. Nd, terug naar huis. En hij kwam in 't leege huis. Hij nu nam zijn marapoe-bezittingen en hij nam 't mee. Hij kwam bij de wilde varkens, zij waren aan 't gras wroeten, en hij zeide: "héeren varkens, als gij I Kariri gezien hebt, zeg 't mij, ik zal u uw belooning geven.»

De wilde varkens antwoordden: "é, schaamdeel van je moeder, - schreeuw zoo niet, wij zullen meteen even komen; wij zijn toch aan 't gras wroeten, onze buiken zijn zoo hongerig."

Hij ging wederom verder; hij zag kraaien: "als gij gezien hebt I Kariri, mijn vrouw, zal ik u uw belooning geven.» "Wat zegt gij», zeiden de kraaien. "Mijn vrouw, zeg ik toch, iemand heeft haar geschaakt, misschien hebt gij haar wel gezien.» Maar de kraaien antwoordden en zeiden tot hem: "ha dwaas, ga toch weg, schreeuw zoo niet, meteen komen wij en pikken u uw oogen uit», zeiden zij tot hem.

Hij ging wederom verder; hij ging en zag paarden, en I O. Nd. zeide: "heeren paarden!» En de paarden antwoordden: "wat zegt gij?" I O. Nd. antwoordde: "ik zoek heden mijn vrouw, iemand heeft haar geschaakt; misschien hebt gij haar gezien, zeg 't mij, ik zal u geven mijn marapoe-bezittingen.» De paarden antwoordden: "gij zijt niet degene, om wien wij ons druk maken! dwaas manlijk schaamdeel! schaamdeel van je moeder! de krokodil zal je grijpen! wel schreeuw daar nog eens, dan zullen wij je daar eens komen trappen, zoodat je dood gaat.

Hij ging wederom verder; hij zag karbauwen in een dal, en hij zeide: «heeren karbauwen, ik heb u iets te vragen.» De karbauwen antwoorden: "wat zegt gij.» "Iemand heeft heden mijn vrouw geschaakt; als gij haar gezien hebt, als gij haar verblijfplaats weet, zal ik u uw belooning geven.» De karbauwen 
antwoordden: "wat zeg je daar!» En I O. Nd. antwoordde: "ik zoek mijn vrouw, welke richting ze uit gegaan is, weet ik niet. ? De karbauwen antwoordden en zeiden: "hoe is 't, moeten wij op je vrouw gaan passen, dat gij 't ons vraagt?» En I O. Nd. antwoordde: "nou, misschien hebt gij ze gezien, zeide ik, daarom vroeg ik er naar.» De karbauwen antwoordden: «'t zou goed zijn, als je ophieldt met praten; als je te veel praat, dan zullen wij meteen komen met de hoornen steken, zoodat je dood gaat en de kraaien je zullen opeten.»

Wederom ging hij verder; hij kwam in een ander dal, hij zag sapi's: "heeren sapi's!» "Ja», zeiden de sapi's. "Hebt gij mijn vrouw gezien, terwijl iemand haar schaakte?» De sapi's antwoordden: "wij zijn aan 't gras eten, daar staat gij maar te roepen; roep nog eens, dan zullen wij gaan en u straks steken, dat gij in stukjes en brokjes dood gaat."

Wederom ging hij verder; hij kwam in een ander dal en hij keek op naar een haki-boom; en hij zag een civet-kat: "heer civet-kat», zeide hij. "Ja», zeide de civet-kat. "Misschien hebt gij mijn vrouw gezien: iemand heeft haar geschaakt." "Een verbazende stommeling ben jij daar beneden! ik ben aan 't vruchten eten en jij staat daar te schreeuwen; als gij daar nog eenmaal roept, zal ik eens naar beneden naar je toe komen en ik zal je dan krabben.»

Wederom ging hij verder; hij kwam in een op zich zelf staand bosch, en hij zeide, toen hij tortelduiven zag: "heeren duiven!" $\mathrm{Zij}$ antwoordden niet. "Heeren duiven!" En sommigen der duiven zeiden: "hoor hem daar, alsof 't I Oemboe Ndiloe mamila is.» En hij riep wederom: "heeren duiven!» "Ja», zeiden de duiven, kom hier heen», zeiden de duiven, terwijl zij hem riepen, En hij ging naar hen toe; toen hij bij hen was gekomen: "wat zoekt gij?» I O. Nd. antwoordde: "ik zoek I Kariri, mijn vrouw, iemand heeft haar geschaakt.» En de duiven antwoordden: "maak je daarover maar niet bezorgd, laat ons gaan naar den vorst der duiven.» $\mathrm{Zij}$ gingen. Toen zij in 't huis van den vorst der duiven gekomen waren, zeiden de duiven: "heer dit is I Ndiloe mamila, die hij getrouwd heeft is door I Mbakoe geschaakt, "En de vorst der duiven antwoordde: zoo is 't, dat wij 't weten. Toen zeide I O. N d.: "heer duif, duif, vorst, als gij in staat zijt mij terug te halen I Kariri, dan zal ik u geven geslagen goud.» De vorst der duiven antwoordde: "zwijg 
toch! weet gij haar (schuil)plaats niet?» I O. N. antwoordde: «ik weet 't niet." "Straks als de zon koud is, dan zal ik 't u wijzen.»

Toen de zon nu koud was, wees hij het hem, 't was slechts vaag dat hij 't zag. Toen zeide de duif: I Mbakoe, is werkelijk zeer rijk; de goederen van alle landen, rijksdaalders, gouden kettingen, gouden oorhangers, moeti sala, koperen kettingen, van alles heeft hij, doordat hij 't gaat wegrooven; wanneer de menschen hun slimoets droogen in de zon, hij rooft ze allemaal weg.

I Mbakoe was er nu niet, hij was vertrokken naar 't land overzee, om goederen te gaan rooven; en de duif zeide: "ik ben niet sterk, ga daarom I Kabira roepen, hij alleen is handig, handig in 't stelen, handig in de toppen der boomen.s

Men ging hem nu roepen; toen hij gekomen was, zeide men tot hem: "hoe is 't, Kabira, zijt gij in staat om I Kariri klimmend te halen? I Kabira antwoordde: "men moet mij een belooning geven.» De vorst der duiven antwoordde: «u uwe belooning geven? ik ben er toe in staat. "Wacht dan maar een poosje.» Na verloop van korten tijd, ging I Kabira, hij klom in den top van den boom, hij bracht alles naar beneden, allerlei soorten van goederen, hij maakte 't heelemaal leeg. Toen hij er mee klaar was, klom hij wederom naar boven om I Kariri naar beneden te brengen, hij bracht haar in 't huis van den vorst der duiven. Toen hij daar gekomen was, zeide de vorst der duiven: "ha Oemboe Ndiloe mamila! uw vrouw is er." En I O. Nd. anrwoordde: «hoeveel belooning wil I Kabira hebben?» De vorst der duiven antwoordde: "laat mij dat maar op mij nemen, om hem te geven.»

En nu kwam I Mbakoe er aan; pas was hij gekomen: "ha Ramboe Kariri», zeide hij. Toen riep hij haar wederom: "ha Ramboe Kariri.» Toen zij nog niet antwoordde, ging hij naar beneden in de voorgalerij en hij schreeuwde; schreeuwende zeide hij: "wie 't ook is die geschaakt heeft I Kariri en mijn bezittingen, dan eerst zal 't zijn, ik zal hem zijn oogen uitpikken.»

Toen hij klaar was met schreeuwen, riep hij: «ha heer duif daar beneden, hebt gij niet gezien I Kariri, wie haar geschaakt heeft?» En de vorst der duiven antwoordde: «overweeg in uw hart, waar gij haar vandaan gehaald hebt.» «'t Was de vrouw 
van I Oemboe $\mathrm{Ndiloe} \mathrm{mamila}$, toen ik haar roofde. En de duif antwoordde: "zoo is 't, en I O. Nd. is hier." Toen antwoordde I Mbakoe: "ai ha, morgen ochtend zullen wij vechten.» En de vorst der duiven antwoordde: "zoo zij 't.»

En de duif reide tot I O. Nd. mamila, wees niet bang, ik zal u een zwaard geven, morgen ochtend zult gij strijden.»

's Morgens vroeg toen de zon halverwege gestegen was, zeide I Mbakoe: "daar kom ik aan, wacht mij op!» En hij vloog, pas was hij aan 't vliegen, of hij ging rakelings langs I O. Nd. mamila heen; maar deze hakte met het zwaard zijn vleugel; die was gebroken. Men hield nu op en hij ging naar zijn huis; thuis gekomen schreeuwde hij zonder ophouden; schreeuwende zeide hij: "morgen, daar is nog één vleugel van mij, als ik hem er mee sla, sterft hij terstond.

's Morgens vroeg, toen zeide I Mbakoe: "daar kom ik aan, éénmaal slechts doe $\mathrm{ik}$ ' $t$, ik doe 't maar éénmaal en hij sterft terstond.» En hij vloog en ging rakelings langs I O. Nd. mamila; deze wachttte hem op en sneed hem zijn hals af. Toen hij dood was, stookte hij een vuurtje en verbrandde hem geheel en al.

Toen I Mbakoe dood was, keerden zij vervolgens naar hun plaatsen terug. En de duif gaf aan I Kabira zijn belooning; hij raapte wat kiezelsteenen op en gaf ze hem. Maar I Kabira ging nu aan bij iemand, die alleen woonde en zeide tot hem: "dit zijn teekenen van mijn hand, als er mijns gelijken zijn, geef hen hun teeken, en zij zullen niet roofzuchtig zijn, als men zich noemt: menschen van Karoenggoe Watoe. 


\section{Tau Karita.}

Toenanoe handăka na na pakiri na. Nindja da tau madoea; Oemboe Lapoe ja na haätoe, Oemboe Loetoeng na haätoe. Tăka njoena I O e mboe La poe ningoe mangeàla na. Toenanoe hina lakoe njoena I Oemboe Loetoeng hina piti léranja na mangeàla ${ }^{1}$ na; ndena karai ja.

Tăka hiwăna njoena I Oemboe La poe: «ămboe piti na mangeàla nggoe, na boăta doe ja ijang!» Tăka na heàma njoena I Oemboe Loetoeng, hiwăna: "djăka na mboăta ja, koe wŏnggau hiloe na.» $\mathrm{Na}$ heàma njoena $\mathrm{I} \mathrm{O}$ e mboe Lapoe: 'djăka hili hau băhi, ndakoe bihoe, djeà ma ja bădi na mangeàla nggoe.»

Toenanoe lakoe na nja ka I Oemboe Loetoeng, lakoe hina poeha la wai na mangeàla. Mandai ndai ki ka hakoedoe, boăta ma na nja ijang.

Toenanoe bana mboăta ka hina lakoe papeàka nja na măngoe mangeàlang, hiwăna bana peàka: "Oemboe, miri, na mboăta ka na mangeàla moe, ămboe mbeni doe!» Na heàma njoena I Oemboe Lapoe: "djeà ma ja, hiwănggoe, djăka na mboăta, ndakoe bihoe hăhi hawiang, djeà ma ja bădi kau ngăndi ngga ja; ndéa be njoena ndena karaoe na eti nggoe.»

Toenanoe lakoe beli na nja ka la pangéa pamangeàla na. Toenanoe hina tama ja la wai, na la-lakoe, loepa na lănga nja wai. Toenanoe bana lănga nja ka wai, hi mamara be ja, nde wai ă ja pa. ${ }^{2}$ Toenanoe hina ita ja hau na na oema koedoe, hiwăna bana pa'ărang: "ha rămboe, kanggikina dita la paraing, laloe toéndoengoe ja ana mongoe?» Tăka hina heàma na tau la oema koedoe: "toenoe nja manoe ${ }^{3}$, hidoe na nja

1 mangeàla = vischhaak; wordt ook gebruikt voor "vischsnoer", in on. derscheiding van 't vangen met een net.

${ }^{2} \mathrm{nde}$ wai ă ja pa='t was geen water meer. Volgens een Soembanees ziet ' $t$ er in den hemel en onder de aarde en onder de zee precies zoo uit als op de aarde. Alleen de „communicatie" is onderling niet zoo gemakkelijk en 't zijn slechts enkele menschen, dien een dergelijk reisje te beurt valt.

3 toenoe nja manoe= men offert voor hem. Dit "toenoe manoe" is een vaste uitdrukking voor alle offeranden, al worden er karbauwen en varkens geslacht; steeds zegt men "een kipje roosteren." 
na marămba, hidoe weli ngaroeng. ${ }^{1}$ Tăka hiwăna njoena : "djăka njoengga noe, na hămoe be ja!»

Toenanoe hi lakoe na nja ka na tau la oema koedoe la paraing. Toenanoe bana tăka ka hoedita: "ha Oemboe, hiwăna, ninja na tau noewawa, djăka njoengga, na hămoe be ja, wăna bana paní.»

Tăka na heàma na marămba na mahidoe: "pa'aunja, djăka koe hămoe ma năhoe tai, koe wŏ ma nja banda, ata, karămbo'a, ndjara, kamămbi, wē, manoe, ahoe.»

Toenanoe hina pa'aunja. Toenanoe bana pa'aunja hina lakoe la paraing. Toenanoe bana tăka ka, ndena bihoe pahăpa; «napa kadiroe» wăna. Toenanoe hi lakoe na nja la kambaniroe bangga, hina wăkăhoe ja na likoe apoeng, na paboăta ijang, bawăna. Toenanoe bana hăla ka pakaloăngga ja, hina hē ja la kaheli, hina rau ja la ngaroe na na mangeàla. Toenanoe bana hăla ja ka hina bănggi nja na mangeàla. ${ }^{2}$ Toenanoe hina mandapoe hina wŏnja hina hăpa; bana hăla ka pahăpa, hiwăna njoena na marămba: "măIa peàka wa pamboehăm!» Tăka na heàma njoena $\mathrm{I} \mathrm{Oem}$ boe Loetoeng: "didi jang na ngohoeng ămăhoe kau wŏngga nja.» Tăka na heàma njoena na marămba: "ndéa, ndakoe bihoe! ata, djăka wămoe ngga, koe wŏnggau dăngoe banda hangia hangia,»

Toenanoe ba ndena bihoe pa, lakoe hopoetoe na nja ka I Oemboe Loetoeng.

Toenanoe bana lakoe ka hina wonja ja na mangeàla la I Oemboe Lapoe; bana hăla ka pawornja, lakoe na nja ka njoena I Oemboe Loetoeng; lakoe hina lătikoe ha da hamba ${ }^{3}$, hakamboeloe mawa da, hina takoe ndja wai hina pawandaloe ndja bana tiwăloendja. Toenanoe bana hăla ha ka, tăka njoena I O emboe La poe hina weli ndja da karămbo'a, na weling la ramoekoe da, na hē ngăndi ha la tana dita. Tăka hiwăna njoena I O e mboe Loetoeng: "ha, mángga

1 hidoe weli ngaroeng= ziek van mond. Door dit weli...ng drukt men uit, dat de ziekte haar oorsprong had in den mond, daar begonnen is. Anders zou men eenvoudig zeggen: hidoe ngaroe.

2 hina bănggi nja mangeàla = hij stak de vischkaak in zijn lendendoek. bănggi=lendenen; (een kapmes) in de lendendoek dragen, b.v. na bănggi nja kabeàla = hij draagt een kapmes op zij.

$s$ hina lătikoe ha da hamba=van lontar-bladen een soort emmer maken. lătikoe= buigen, vormen. 
ndja da woloe ${ }^{1}$ nggoe, na bœdoe ndja karămbo'a!» Ndena rongoe njoena I Oemboe Lapoe. Toenanoe bada tăka ndja ka da wai la hamba, da oenoe ndja hawiang, da hikoe ha hawiang, da mbera hăla ma da hamba.

Toenanoe hiwăna njoena I Oemboe Loetoeng: "wŏngga bădi hiloe da da woloe nggoe; djeà ma ha bădi da woloe nggoe njoengga; djăka woloe hawiang, ndakoe bihoe» $\mathrm{Na}$ heàma njoera I Oemboe La poe: ămboe toemoe, ămboe na karaoe na eti moe!» $\mathrm{Na}$ heàma njoena I Oemboe Loetoeng: "ma njoengga bana mboăta na mangeàla moe, djeà ma bădi bawămoe, djeà ma ja bakoe pabeli nggau ja.»

Tăka njoena I Oemboe Lapoe hina lakoe la ngéa paboengoe da da wai hina kăndja kăndja ja na tana na mambaha. Toenanoe bana hăla ja ka pakăndja, palai na nja ka la Karita ${ }^{2}$, na lakoe ja lai năhoe, na toera parai na. Tăka njoena I Oemboe Loetoeng hina lakoe pakaninoe ${ }^{3}$ ja na ngohoeng ămăhoe hina kétoe ja hina padita ja. Noe, woeloe na nja ka banda dangoe.

1 woloe=legĕn; de gegiste drank, bereid uit 't vruchten-sap van den lontar.

2 Karita = landschapje in Midden-Soemba. De menschen van Karita beschouwen I O emboe Lapoe als hun stamvader, van wien men dezelegende vertelt.

Een panton, om de menschen van Karita te beleedigen is:

Karita kăndja woloe.

Kandiki bai bora=de menschen van Karita krabben legĕn, en paren zich met apen.

Een „verklaring" der tweede regel, heb ik niet kunnen krijgen.

$s$ kaninoe = spiegel; in 't water zitten kijken als in een spiegel en zoo visschen vangen. "Kaninoe ijang", zegt men steeds ran een "hengelaar", die op zijn dobber zit te turen. 
VII. De menschen van Karita.

Aldus was eertijds 't begin. Er waren twee menschen; Oemboe Lapoe was de eene, Oemboe Loetoeng de andere. En Oemboe Lapoe had een vischsnoer. Toen ging I Oemboe Loetoeng heen en nam zonder vragen diens vischsnoer; hij vroeg 't niet. Toen zeide I Oemboe Lapoe: "neem mijn vischsnoer niet, de visch zal 't stuktrekken.» Maar I Oemboe Loetoeng antwoordde en zeide: "als 't stuk is, zal ik je een ander geven." I Oemboe Lapoe antwoordde: "als 't een ander ijzer is, wil ik niet, 't moet zijn mijn (eigen) vischsnoer.»

En I Oemboe Loetoeng ging heen; hij ging en wierp het vischsnoer' in 't water. 't Duurde maar eventjes, een visch trok 't stuk. Toen 't stuk was ging hij 't zeggen aan den eigenaar van het vischsnoer; sprekende zeide hij: "heer, meester, uw vischsnoer is stuk, wees toch niet boos. I I emboe Lapoe antwoordde: "zoo is 't, dat ik zeide, als 't stuk is, wil ik geen ander ijzer, dit moet 't zijn, dat gij mij (terug) brengt; dan niet, dan ben ik niet toornig.»

Hij keerde nu terug naar de plaats van zijn visschen. En hij ging 't water in, hij liep en liep, totdat 't water hem bedekte. Toen 't water hem bedekte, was 't droog land, 't was geen water meer. En hij zag een klein huis en vragende zeide hij: "ha rămboe, wat is 't toch daarboven in de kampong, men slaat er erg op de gongs?»

En 't mensch in 't kleine huis antwoordde: "men offert, de vorst is ziek, ziek in zijn mond.» Toen zeide hij: "als ik daar was, dan zou hij beter worden.»

En 't mensch uit 't kleine huisje ging naar de kampong.

Daar boven gekomen: Oemboe, zeide zij, daar is iemand beneden: "als ik er was, dan zou hij beter worden, zeide hij terwijl hij sprak.» Toen antwoordde de zieke vorst: "roep hem, als ik straks meteen beter ben, zal ik hem geven goederen, slaven, karbouwen, paarden, geiten, varkens, kippen, honden.»

En men riep hem. Toen men hem riep, ging hij naar de kampong. Toen hij daar gekomen was, wilde hij geen sirih 
kauwen; "wacht eerst», zeide hij. Toen ging hij naar de paal in de voorgalerij en maakte de vischlijn los, door de visch afgebroken, naar hij gezegd had. Toen hij deze wat had laten vieren, klom hij in huis en haalde met zijn hand den vischhaak uit den mond. Toen hij daar mee klaar was, stak hij den vischhaak in zijn lendendoek. Toen ging hij zitten en men gaf hem en hij kauwde sirih; toen hij sirih gekauwd had, zeide de vorst: "zeg maar uw begeerte». En I O e mboeLoetoeng antwoordde: "alleenlijk 't gouden rijstblok, geef mij dat. " Maar de vorst antwoordde: "neen, ik wil niet; slaven, als gij mij dat zegt, zal ik u geven en allerlei soorten van goederen.»

Daar hij dit niet wilde, ging I Oemboe Loetoeng nijdig heen. Toen hij gegaan was, gaf hij den vischhaak aan I O e mboe Lapoe; toen hij dien gegeven had, ging I Oemboe Loetoeng heen; hij ging en vormde emmers van bladeren, tien paar, en hij schepte er water in en hij hing ze op één rechte lijn. Toen hij daarmee klaar was, joeg I Oemboe Lap.o e zijn karbauwen bij elkaar uit 't buffelwed en bracht ze naar hooger gelegen grond.

En I Oemboe Loetoeng zeide: "ha, pas op mijn gegisten drank, de karbauwen zullen 't uitstorten!» Maar I Oemboe Lapoe hoorde niet. Toen zij gekomen waren bij 't water in de "emmers», dronken sommigen, anderen stootten er met de hoornen tegen, allemaal gebroken waren de "emmers».

Toen zeide I Oemboe Loetoeng: "gij moet mij vergoeden mijn gegiste drank; 't moet mijn eigen gegiste drank zijn; als 't andere gegiste drank is, wil ik niet.» En I Oemboe La poe antwoordde: "wees niet alzoo, wees niet toornig." Maar I Oemboe Loetoeng antwoordde: «en ik, toen uw vischsnoer was gebroken: deze moet 't zijn, hebt gij gezegd; en dit (zelfde) was 't, dat ik u teruggebracht heb.»

En I Oemboe Lapoe ging nu naar de plaats, waar zij 't water uitgestort hadden en hij krabde en krabde op den vochtigen grond. Toen hij klaar was met krabben, vluchtte hij naar Karita, daar ging hij nu heen en stichtte er zijn kampong.

Maar I Oemboe Loetoeng ging 't gouden rijstblok kijkend opspeuren en hij haakte 't aan en bracht 't naar boven. Dit was 't, en rijk werd hij in vele goederen. 
VIII. Ihi Wawang.

Toenanoe handăka na na kawoenga bokoe ${ }^{1}$ na na Ihi Wawang.

"Lo'a patamang mananga» 2, wăda. Toenanoe bada tăka ka la mananga, tăka njoena I Bokoe hina hondoe ja la hadidi lokoe na ndjara na. Toenanoe tama doe da nja ka mananga; bada tama nja na mananga noena, laloe jăpa ja ijang bana woroe pa na ijang lai noe. Toenanoe bada hăla ka patama nja, tăka hida hē beli: "kama beli kăma la oema», wăda. Toenanoe da angoe na I Bokoe hida lo'a papiti ha da ndjara da; hawiang na tau mbăda lakoe na ka, hawiang ndedi.

Tăka njoena I Bokoe hina lakoe, na lo'a patăngăroe ja na ndjara na la pangéa pahondoe na nja kawai. Toenanoe bana tăka nja ka la pangéa na na likoe bana hondoe ja, tăka hina woelăkoe la kalai la kawana, ndena ita ja na ndjara na. Toenanoe hina himboe ha da roekoe na; toenanoe bana himboe ha ka da roekoe na, tăka hina ita ha da roekoe kamboeroeng ${ }^{3}$ la wai; hina kikoendja da roekoe na na ndjara noena. Toenanoe bana lakoe lakoe ${ }^{4}$, hoepoe kambăkoe ja na wai; na ita be ha da roekoe na na ndjara. Na hili lakoe, wai hoepoe bănggi ja, ndeda ngalang pamboelang da roekoe na na ndjara. Na hili lakoe lakoe, loepa na lănga nja wai. Toenanoe na la-lakoe ki hakoedoe, tăka hina ita ja hau na na koătăk, hama toena na

1 bokoe= grootvader, stamvader. Dit woord wordt in 't verhaal zelfs als persoonsnaam gebruikt; "want hoe de eerste stamvader heette, weten wij niet", zegt een Soembanees.

2 lo'a patamang mananga=in de riviermonding gaan visschen. tama = binnengaan, ingaan in 't water (om met een werpnet te visschen). mananga = de monding van een rivier in zee; terwijl de mond zelve der rivier ${ }_{n} \mathrm{ng}$ aroe mananga" heet.

${ }^{3} \mathrm{kamboeroeng}=$ naar beneden gaan langs een glooiende helling. Steil naar beneden gaan (uit een huis, een boom) heet poeroe. Zoo is ook: naar hoven gaan langs een glooiende helling (van een berg, een rivieroever)= kateàkăl; steil naar boven klimmen (in een huis, een boom) $=\mathrm{h} \bar{e}$.

4 bana lakoe-lakoe= terwijl hij maar steeds voortging.

De reduplicatie van een woord duidt aan een voortdurende, onafgebroken handeling. Meestal vormt men een reduplicatie aldus: la-lakoe; dus: de eerste lettergreep + het geheele woord. 
koătăk tau lănga tăka. ${ }^{1}$ Toenanoe hina tama ja la pindoe hina ita ja na ndjara na; na hondoe be ă la kambaniroe pangéa patinoeng na. Tăka hiwăna na kawini: "ka heàna, oemboe, hi djeà tăka be moe?»

Tăka hina heàma njoena I Bokoe: "himboe nggoe nja na ndjara nggoe; tăka na ndjara jeàna hi lai jehoe be ja.»

Tăka hiwăna na kawini na matinoeng: "ha oemboe, mandapoe păkoe la bangga, kau hăpa păkoe, kata măngoe papaní.»

Toenanoe hida wŏnja pahăpa na; bana hăla ka pahăpa, tăka hiwăna na kawini noena na majăpa ja na ndjara: "bakoe kaka ja, ningoe kiring ${ }^{2}$ lai njoemoe»

Tăka hina heàma I Bokoe: "ndaningoe papangga nggoe, ndaningoe padili nggoe.» ${ }^{3}$ Tăka hina heàma na kawini: "lănga tăka, ndaningoe lănga tăka? djăka koe paloehoe + ja tai, djeà ja wămoe.» Tăka hina heàma njoena I Bokoe: "măla ka.»

Toenanoe hina paloehoe ja: "handăka ndăka, pamangoăma ka, wănggoe nja $\mathrm{i}$ ama; na heàma $\mathrm{i}$ ama: ndakoe ita ja na laleàba nggoe, pateànja ka, wăna. Toenanoe na kiring hikoe jăpa ja na ndjara; matoea kaba mata ka ka, malai loenggi ka ka, koe pateà dira dirang, ${ }^{5}$ na oela be ka ka panapa kau; măla noe ndena ndjala?» hiwăna nja.

${ }^{1}$ Evenals in 't vorig verhaal reeds bleek, stelt zich de Soembanees voor, dat ook onder 't water menschen wonen.

Voor 't gewone oog zijn 't krokodillen, haaien etc., maar enkele „bevoorrechte" personen kunnen zien, dat 't werkelijk menschen zijn. Hij gelooft dan ook, gelijk uit dit verhaal blijkt, aan afstamming van menschen uit krokodillen, aan onderlinge verwantschap. Zoo heeft elke stam bijzondere "heilige" dieren, waarin de zielen der voorvaderen en der gestorvenen zich gaarne openbaren. De zielen der afgestorvenen komen dan ook dikwijls in dierengestalte, de menschen bezoeken en helpen in hun nood. Zoo b.v. in 't verhaal van I Dari, de slimme aap. - Wanneer men de versehillende Soemba-verhalen in dit licht beschouwt, zal men zien, dat hun animistisch geloof zich in deze legenden als 't ware gestalte heeft gegeven en ons een kijkje geeft in hun geloofswereld.

${ }^{2}$ kiring $=$ oorzaak van een perkara; aanleidende oorzaak.

s ndaningoe papangga nggoe, ndaningoe padili nggoe =ik heb niets overtreden (pangga=over iets heen stappen.) noch iets misdreven (dili=ergens op trappen). Een gewone uitdrukking van een Soembanees, wanneer hij wil zeggen, dat hij geen gebod heeft nagelaten te doen, noch met opzet met een gebod in strijd heeft gehandeld.

${ }^{4}$ paloehoe $=$ naar buiten brengen; uiten wat in iemands hart is, alles nauwkeurig verhalen.

${ }^{5}$ koe pateà dira dirang=ik wachtte zonder einde.

dira $=$ uitscheiden, een einde nemen. 
Tăka na heàma njoena I Bokoe: "kanggiki pinda nggau ka? tau la oema watoe, la wai mandjoloeng; ta mbiha pa doe noe kata pinggau!»

Toenanoe mandai ki ka hawoetoe bada pandjăpoeng ka papaní, toenanoe hina poeroe ja na ama na, bai ama bokoel patăki miring ' hina poeroe la bangga. Tăka hina wŏnja kaloemboetoe na I Bokoe, hina hăpa. Toenanoe bana hăla ka pahăpa hiwăna: "tăngăroe ja noe na laleàba nggoe, na panapa-napa, ba wănggoe nggămoe.»

Tăka na heàma njóena na ana na: "ná! djăka ndakoe jăpa lăti na ndjara, ndena mai ă.» Tăka na heàma njoena I Boko e: "wămoe ka ka njoena, ina nggoe ama nggoe, ndéa nggăra matoăma la lima nggoe, banda ndakoe ngăndi, kanătăr ndakoe ngăndi, patoekoe lomboe ndakoe ngăndi, ba mai nggoe nja patamang mananga ă.»

Tăka hina heàma njoena na ama na, hiwăna: "banda lai njoengga ndaningoe matoăma; watoe ja mamoeli ja, loeloe ai ja kanătăr ja.» Tăka na heàma njoena I Bokoe: "wămoe ka ka njoena; ${ }^{2}$ banda ndaningoe matoăma ka bawămoe, ningoe dóe bădi papaní wănda ${ }^{3}$, hina nggepi la ngaroe nda bata paní!»

Tăka na heàma njoena na ama na I Apoe Lodoe: "banda ămboe wŏngoe, didi jang na ndjara nina kau wŏngga nja, măta kata panoewanja na likoe na mamboăta, ai na mambata » ${ }^{4}$ hiwăna njoena na ama na I Apoe Lodoe.

Tăka na heàma njoena I Bokoe: "djăka djeá ja djăka wămoe doe, poelangia nggoe, diha păkoe ja na eti moe, wăngoe păkoe kokoe moe, djăka djeà ka njoengga, tăndjing ma na lai tamang mănanga.»

${ }^{1}$ patăki miring = een geweldig heer, een groot hoofd.

Samenstelling van tăki=gekko en $\mathrm{miri}=$ meester, heer.

? wămoeka ka njoena=dat zegt gij (nu wel ..... maar).

s ningoe doe bădi papani wănda=mar er moet wat zijn om mede te spreken.

Geen zaak kan besproken worden of er moet iets zijn (een doek, een stuk geld, een mamoeli etc.), dat tusschen de beide partijen in ligt, en waarover heen men spreekt. Zoo begint men dan gewoonlijk: nanja na ka mba na hawăla=daar is één stuk goed. Vervolgens zegt men, wat men te zeggen heeft.

4 panoewanja na likoe na mamboăta, ai na mambata=aanlasschen 't touw, dat stuk is, 't hout, dat gebroken is; d. w. z. afgebroken vriendschap, verwaarloosde -of vergeten familiebanden, wederom aanknoopen. 
Tăka hiwăna njoena I B ok o e: «djăka toena, poeli ngga kakoe lo'a kadiroe la watoe ngoedoe la tana mădoe. ${ }^{1}$ Tăka na heàma njoena na ama na I A poe Lodoe, hiwăna: "măla noe, Lodoe! ta poeli nja wămoe?» Tăka na heàma njoena I A po e Lodoe: "nà! ta poeli nja djăka wămoe njoemoe, napa na tăka nja oema na, kaheli na, ndena hili beli ă ja pa, koe pinja na ihi kamboe na. ${ }^{2}$ Tăka na heàma njoena na ama na: "djăka toenanoe, ămboe ta pamădja nja bădi.»

Tăka hiwăna njoena na ama na: "koe pandjiloenja na tamoe moe; I Ratoe ${ }^{3}$ ja na ngaram; na ngara meàmang na tiki ja tau la mara; djăka ningoe ana moe na mama'aja, na ngara na I Ratoe ja. Napa tiloe modoeng, lo'a papadoendang kana tăka ndăba na kalembi nda; djăka djeà djăka wăna doe mboeloendăba na na kalembi nda, ka papohoe nggămi * dăngoe I Lodoe.»

Toenanoe bana doendang ka tau hina batang, kawăra batang.

Toenanoe mbăda batang hiwăda: "nggăra ja i noe, djăka wăna na doe $\mathrm{i}$ ama, ama ndăba nda.s Toenanoe hina toboeng hina hoendjoe. Na mandai na I Bokoe la hiboe woeja, ${ }^{5}$ hau woela na.

$\mathrm{Na}$ tau la mara, da angoe na paloehoe I Bokoe, da leleàba na, da oemboekoe na, poei moăwăl, ${ }^{6}$ wihikoe

1 la watoe ngoedoe,

la tana $m$ ădoe=op den onbeweeglijken steen, op 't drooge land.

't Soembaneesch is rijk in dergelijke uitdrukkingen. Vooral bij 't bespreken van zaken worden zij gebruikt, en eischen een aparte „taalkennis", om 't te begrijpen.

${ }^{2}$ koe pinja na ihi kamboe na=ik ken de inhoud van zijn buik, d.i. zijn stille gedachten.

s ratoe=priester, leider van offerplechtigheden. Deze "waardigheid" is erfelijk in de familie. De oudste zoon volgt op. Hij is de man, die nauwkeurig de "gebeden" kent en weet hoe den Marapoe moet worden aangeroepen.

4 ka papohoe nggămi dăngoe I Lodoe= zullen wij u en I Lodoe bij elkaar doen, d. i. laten trouwen.

't Pronomen bij reciproque verba, staat in de pluralis.

${ }^{5}$ la hiboe woeja $=$ in 't nest der krokodillen.

Hier uit blijkt, dat hier met de bewoners van 't water, krokodillen worden bedoeld. I B okoe trouwt dus mét een krokodil.

${ }^{6}$ poei moăwăl='t orakelsnoer draaien. Het bestaat uit vier touwtjes. Twee er van, aan elk eind van twe e kraaltjes voorzien, heeten "vrouwelijk". De twee anderen, aan elk einde één kraaltje, heeten "mannelijk". Deze 
manoe, ${ }^{1}$ toboeng, hoendjoe, lo'a pahimboe ja la ngaroe mananga, la oămang, nde pahoenggoe ja; ita be ja la oera manoe, ita be ja la eti wē, na kateàkăl.

Toenanoe bana mandai ka ba hau woela na ka, hiwăda njoeda da tau la mara: toena ka, djămang ka pahimboe ja la moăwăl, la manoe; ămboe lo'a mboe pahimboe ja la mananga; măta nja ka kana wăngoe patăka wiki na ka.

Toenanoe bana hăla ka pahoendjoe, tăka hiwăna njoena na ama bokoel: "rongoe ndăba, mboeloendăba moe, oemboekoe nggoe, ana nggoe, laleàba nggoe, ana wini nggoe! djăka na lakoe ja I Lodoe la watoe ngoedoe la tana mădoe, ămbi maroămbanja, ămbi mboelanja, kăli lo’a pangădăloe ja.» Tăka da heàma mboendăba da, hiwăda: "na handoeka i ka ka noe, djăka lo'a pangădăloe ja i mamoe! djăka ta lo’a ba pangga pangga be doe nda.»

Toenanoe ba memi ka hida ngangoe mboendăba na na tau na padoenda na. Toenanoe bada hăla $\mathrm{ka}$, na roedoeng hida papohoe ndja. Toenanoe bana mandai-ndai ka, tăka hiwăna njoena I Bokoe: "ba toenanoe ba mandai doe nggoe nja ka, poeli ngga kakoe lakoe.»

Tăka na heàma noena na ama jera na: "djăka toenanoe, napa doea modoeng ${ }^{2}$ kai lakoe ka. Toenanoe hadang la mbaroe hina jăpa ja na wē he'au na, tăka hina piti ha da kapăna hau mboăla da; tăka hiwăna: «jeàda kau ngăndi ha, djăka ningoe oemboekoe nggoe kau paberi ndăba nja.» Tăka na heàma njoena I Bokoe: "ndea, wăna, jeàda djăka koe ngăndi ndăba ha ndena hămoe; tai la malamiri na da oemboekoe nggoe da oemboekoe moe njoemoe da paloemoe ndja, ${ }^{3}$

touwtjes worden over de vingers der beide handen gespannen en gedraaid (poei) en dan met een ruk uit elkaar getrokken. Naar gelang de touwtjes in elkaar zitten gedraaid, is de uitspraak van 't oordeel.

1 wihikoe manoe='t kuiken wordt met den nagel de buik opengescheurd ('t mag niet met een mes opengesneden worden). De darmen worden bekeken.

${ }^{2}$ napa doea modoeng $=$ over twee dagen.

Terwijl in 't dialect van Kambera modoeng slechts bekend is in de samenstellingen "over $2,3,4$ etc. dagen", beteekent "mădoeng" in andere dialecten "nacht". Een Soembanees rekent niet met "dagen", maar met "nachten".

3 da paloemoe ndja= zij zullen er over twisten.

loemoe $=$ zich met iets bezig houden. paloemoeng $=$ ergens over twisten. 
ba nindja noe da kapăna wăda, da pakoădja, da patătăroe; didi jang na pakarai nggoe njoengga, toe ngga ka la păti, ana păti koedoe ă.»

Tăka na heàma njoena na ama jera na: "măla ba pamboeha moe njoemoe ja, koe toe nggau ka la ana păti; ${ }^{1}$ ngăndi ndăba ha wănggoe nggămoe, ndau bihoe.» Tăka hina piti nja ana păti hau na, hina pa'ihi ndja hawiang, na măta nja hawiang; "jeàda bakoe pa'ihi ndja la păti, ămboe ningoe mabera-ja na păti», wăna. Tăka hina karăndja wănja loeloe kaleàngoe ; toenanoe bana hăla ja ka hina băndjăloe ha la pingi kambaniroe oeratoeng; djăkau tăka la oema, ămboe băndjăloe ha la bangga, la kaheli djămang, pangala ma ndja la hindi oema dita; djăkau hăla ka pabăndjăloe ha, kau poeroe beli kau, kau tăngăroè ndja kamboăka wē, wē mini.

Toenanoe hida hoendjoe ja na wē; toenanoe bada hăla ka, tăka hiwăna na ama na I Apoe Lodoe: "ha Lodoe, mai kămoe nămoe kan rongoe, djăka nggiki hama hamaja nggoe, kau kanandi nja, kau kăpoe ja.» Tăka hina pala ja la kaheli bokoel. Toenanoe bana hamajang: «I woeja makalítoe, kaperi mara langoe, ${ }^{2}$ mangga ngga la pahē, mangga ngga la papoeroe, paheàmba ngga mabara marara, hamang da oemboekoe, da tau da pawoeloe moe, da padji moe, ${ }^{3}$ da maningoe la wai, hamang $\mathrm{i}$ da mangéang la pinoe watoe ngoedoe la tana mădoe; heàma ja na li nggoe!»

Toenanoe mbăda memi ka da pangangoe, tăka hiwăna njoena na ama na I A poe Lodoe: «tăngăroe kaba kaleàng, patoe

\footnotetext{
1 la an a păti $=$ in een klein kistje.
}

Als medium voor 't verkeer met den Marapoe, dient een klein houten kistje, met koperdraad omwonden. it Wordt bewaard boven in den top van 't huis, tusschen de vier hoofdstijlen, boven den haard. Men weet niet wat er in zit, daar men 't niet mag open maken. Geschenken aan den Marapoe worden dan ook in een mandje er naast gezet.

${ }^{2}$ I woeja makalitoe.

kaperi mara langoe.

Zoo spreekt men den Marapoe van Ihi Wawang toe. Voor elken Marapoe heeft men een dergelijke vaste formule, waarvan in den regel de beteekenis vrij duister is. Woeja makalitoe $=$ krokodil met een huid; kaperi mara langoe= vet, droog, bericht!! (hier wordt bedoeld een slang).

s da tau da pawoeloe moe, da padji moe=de menschen door $u$ gemaakt, door u gevlochten.

Zoo noemt men den Schepper dikwijls: na mawoeloe, na madji tau= die de menschen maakt en vlecht. 
mboea kawori, kai takoe ndja oehoe mangédjing, kai ngăndi ha nămoe, kai băndjăloe ha la pingi kambaniroe oeratoeng. ${ }^{1}$ Tăka hiwăna na ama na I A poe Lodoe: "ha Oemboe Ratoe, hamaja ndja da oehoe mangédjing.» Tăka hiwăna njoena I Bokoe: "ningoe pakarai nggoe lai ama; djăka na tiki ja na ngara na hau kabihoe hau kabihoe, kanggiki na wăna nja?

Tăka na heàma njoena na ama jera na: wawang ${ }^{2}$ wăna nja, djeà ja ba weli na la wai; djeà ja na wawa ja $i$, na hē ja i na wai, wawang.»

Toenanoe hina hamajang njoena I Bokoe; bana hăla ka pahamajang, njoena I Bokoe hakawori da da oehoe mangedjing; ${ }^{3}$ I A poe Lodoe hakawori da, tăka na ama na hakawori; tăka hakawori hida wŏnja na tau la hanamba. Tăka hida pakē ndja da oehoe da bada nggănăp ndăba ka hida ngangoe.

Toenanoe bada hăla ka pangangoe, tăka hiwăna njoena I Bokoe: "haromoe ma lakoe hada roedoeng.» Tăka na heàma njoena na ama na: "măla ka, ămbi maroămbanja na hamajang la jehoe; djăkai hăla ka pawotoe ja na marapoe, ămboe ningoe matama la loemboe doe, manoe, ahoe, ndjara, ămbi hondoe nja la pingi kambaniroe oeratoeng; djăka ningoe matama, da meti.»

Toenanoe na roedoeng ka hiwăna njoena na ama: "djăka ningoe anakeàda malo'a, hinggi rara djoea pakalamboe da, tera rara patera wăda. ${ }^{*}$ Toenanoe bada hadang ka la mbaroe hida lakoe.

Toenanoe bada tăka ka la paraing hida kikoenja na papaní na na ama da.

Toenanoe bada hăla ja ka, tăka hida mai da angoe na pa-

1 kambaniroe oeratoeng $=$ offerpaal.

Een der 4 hoofdstijlen van 't huis wordt aldus genoemd, omdat men bij dien paal altijd bidt en de offeranden neerzet.

${ }^{2}$ wawang = elk kabihoe geslacht heeft een naam, welke naam dus ook dekt den naam van den Marapoe. Men kan dus spreken van den Marapoe Ihi Wawang, maar ook van 't geslacht Ihi Wawang.

3 oehoe mangedjing $=$ offer-rijst.

Nadat I Bokoe gebeden had en de rijst aan de geesten had aangeboden, worden deze verondersteld 't eten te gebruiken, n.l. 't essentieele geestelijk deel er van. De menschen mogen dan terstond de materie van de rijst opeten.

4 hing gi rara= roode slimoet; hieraan zouden de krokodillen kenbaar zijn als zij hun "tante" op de vaste wal eens kwamen opzoeken. 
loehoe, na I Bokoe, da ana na, da laleàba na, da ana wini na, hiwăda nja: "na meti ka ihoe, wăma be nggau ka!» Tăka hiwăda: "na ndjara moe nggini ja ka?» Tăka na heàma njoena I A poe Lodoe: "na băndjăloe ja ka i ama.» Tăka da heàma njoeda hawiang: "mili toe doena ka kana beli ja na ratoe, patandang dăngoe angoe nda; kata pabeli nja oera na, hamángoe na ${ }^{1}$ I Oemboe Ratoe, ka pekoe mangga na nda, na mangéang la koendoe na, la pinoe marăda na, ba kaliti marapoe ja. ${ }^{2}$

Toenanoe hida toboeng, da hoendjoe. Toenanoe hida tăngăroe ha da eti wē, da eti karămbo'a, da oera manoe; da hămoe.

Toenanoe na pakiri na na Ihi Wawang handăka na.

1 kata pabeli nja oera na, hamángoe na= wij zullen in hem doen terugkeeren zijn ingewanden, zijn geest.

Men veronderstelde, dat hij als uit de geestenwereld teruggekeerd zijnde, nu door offerranden weer moet ontvangen 't zuiver menschelijke, n.l. ingewanden en bewustzijn.

oera = vezel, spier, zenuw ; 't wordt ook gebruikt in den zin van „leven"„zielestof" en heeft dan dezelfde beteekenis als ndewa.

hamángoe= bewustzijn, van een mensch. Dieren b. v. hebben geen hamangoe, wel ndewa.

${ }^{2}$ ba kaliti Marapoe ja= want hij is door den Marapoe beklommen.

Men zegt van sommige menschen, dat de Marapoe op hun schoude. , op hun boofd zit, dat de Marapoe hen berijdt (kaliti.). Deze personen, als zijnde in onmiddelijk verkeer met den Marapoe worden zeer ontzien en gevreesd. Al wat zij vragen, moet hun gegeven worden, want anders zou de Marapoe zich wreken. 
VIII. Het geslacht Ihi Wawang.

Aldus eertijds de eerste stamvader van Ihi Wawang.

"In de riviermonding gaan visschen», zeiden zij. Toen zij bij de riviermonding gekomen waren, bond I Bokoe zijn paard vast aan den oever der rivier. En zij gingen de riviermonding in; terwijl zij die riviermonding ingingen, vong men veel visschen, want de visch aldaar vermenigvuldigde zich zeer.

Toen zij klaar waren met 't "ingaan», stegen zij weder op't land; laten wij naar huis terugkeeren, zeiden zij. En de metgezellen van I Bokoe gingen hun paarden halen; sommigen der menschen waren reeds vertrokken, sommigen nog niet.

En I Bokoe ging heen, hij ging naar zijn paard kijken op de plaats, waar hij 't zooeven gebonden had. Tỏen hij nu gekomen was op de plaats, waar hij 't touw gebonden had, keek hij om naar links en naar rechts, maar hij zag zijn paard niet. $\mathrm{Nu}$ zocht hij naar zijn sporen; toen hij zijn sporen gezocht had, zag hij, dat de sporen afdaalden in 't water; en hij volgde de sporen van dat paard. Toen hij zoo maar voortliep, kwam 't water tot aan zijn knieën; voortdurend zag hij de sporen van het paard. Wederom ging hij verder, 't water kwam tot aan zijn lendenen; de sporen van het paard raakten niet verloren. Wederom ging hij steeds verder, tot 't water hem bedekte. En hij ging en ging nog een weinig verder, daar zag hij een kampong, gelijk een kampong van menschen inderdaad. Hij ging de deur binnen en hij zag zijn paard; zij had 't gebonden aan de paal, waar zij weefde. En de vrouw zeide: hei daar, Oemboe, ben je daar gekomen?

Toen antwoordde I Bokoe: "ik zoek mijn paard; en dat paard, hier is 't toch.» En de vrouw, die aan 't weven was, zeide: "ha Oemboe, ga toch zitten in de voorgalerij, kauw toch sirih, dan eerst zullen wij praten». En men gaf hem zijn sirih; toen hij sirih gekauwd had, zeide die vrouw, welke 't paard genomen had: "naar mijn gedachte, ligt de oorzaak bij u».

Toen anlwoordde I Bokoe: "ik heb niet overtreden noch misdreven". Maar de vrouw antwoordde: "waarlijk, is er werkelijk geen (schuld)? als ik het straks uit, dan zult gij zeggen: dat is 't. 
Toen antwoordde I Bokoe: "welaan dan.» En toen vertelde zij: "heel vroeger zeide ik tot mijn vader: huw mij uit; maar vader antwoordde: ik zie mijn neef niet, wacht hem maar, zeide hij. Dat is de oorzaak, dat ik 't paard heb gegrepen; oud van gelaat ben $\mathrm{ik}$, lang van haren ben $\mathrm{ik}$, ik wacht maar zonder einde; men had er nu genoeg van op u te blijven wachten; welaan is er geen schuld? zeide zij tot hem.

Maar I Bokoe antwoordde: "hoe kon ik iets van u weten? gij (die woont) in de steenholen, in 't diepe water; zijn wij dan wonder-machtig, dat wij u zouden kennen!»

Korten tijd daarna, toen zij opgehouden hadden met spreken, kwam haar vader naar beneden - dat was me een familie-hoofd, een kolossaal heer! - en hij kwam in de voorgalerij. En hij gaf zijn sirih-tasch aan I Bok oe en hij kauwde sirih. Toen men sirih-gekauwd had, zeide hij: "kijk daar heb je mijn neef, (door u) te verwachten, naar $\mathrm{ik} u$ zeide.» Maar zijn dochter antwoordde: "nu, als ik 't paard niet gegrepen had, zou hij niet gekomen zijn». Toen antwoordde I Bokoe: zoo zegt gij; o mijn ouders, er is niets voldoende in mijn hand; goederen bracht ik niet, gouden kettingen bracht ik niet, mamoeli's bracht ik niet, daar ik slechts kwam visschen in de riviermonding."

Maar haar vader antwoordde en zeide: "ik heb ook geen goederen, welke voldoende zijn; een steen is een mamoeli, een boomwortel is een gouden ketting." Maar I Bokoe antwoordde: "zoo zegt gij; er zijn geen voldoende goederen, zegt gij, maar er moet wat zijn om mee te praten, dan is 't behoorlijk voor onzen mond, dat wij spreken *.

Maar de vader van I Apoe Lodoe antwoordde: goederen behoeft gij niet te geven, alleenlijk geef mij dit paard, en laten wij weder hechten 't touw dat gebroken is, het hout dat gebroken is:» zeide de vader van I A poe Lodoe.

Maar I Bokoe antwoordde: "als 't $\mathrm{u}$ daarom te doen is, mijn oom, overweeg dan uw hart, gebruik dan uw wil, maar wat mij betreft, waarlijk ik ging maar visschen in de riviermonding.»

En I Bokoe zeide verder: "als 't zoo is, geef mij verlof, dat ik eerst ga naar den vasten steen, naar 't droge land».

Maar de vader van I Apoe Lodoe antwoordde en zeide: "hoe is 't, Lodoe, zullen wij hem laten gaan, denkt gij?» Maar I Apoe Lodoe antwoordde: "nu, als gij zegt hem te 
laten gaan, als hij straks bij zijn huis en zijn zitplaats komt, dan zal hij wel niet meer terugkeeren; ik ken wel zijn diepste gedachten.» Toen antwoordde haar vader: "als dat zoo is, dan moeten wij 't hem niet toestaan».

Vervolgens zeide haar vader: «ik zal uw naam veranderen; I Ratoe is nu uw naam; uw oorspronkelijke naam zullen de menschen op 't drooge uitspreken; maar als er is (geboren) uw oudste zoon, dan zal zijn naam I Ratoe zijn. Over drie dagen, gaat men bij elkaar roepen opdat kome geheel onze familie; als al onze familie 't goed keurt, dan zullen wij u en I Lodoe laten trouwen."

Toen de menschen bij elkaar waren, raadpleegde men, allen tegelijk beraadslaagden. Toen men beraadslaagd had, zeiden zij: wat zou 't zijn; als vader 't toch zegt, ons aller vader.» En men slachtte en slachtte. De tijd van I Bokoe in 't hol der krokodillen was een maand.

De menschen op het drooge, de broeders van I Bokoe, zijn neven, zijn kleinkinderen, draaiden 't orakelsnoer, scheurden kuikens open, slachtten (karbouwen), slachttẹn (varkens), gingen hem zoeken in de riviermonding, in 't bosch; hij werd niet gevonden; men zag in kippendarmen, men zag in varkenslevers, de lijn liep naar boven.

Toen 't nu een maand geduurd had, zeiden de menschen op het drooge: zoo blijve 't maar, laten wij uitscheiden hem te zoeken met orakelsnoer en kippen; ga hem ook niet meer zoeken in de riviermonding; laat hem maar, totdat hij uit zich zelf terugkomt.

Toen men klaar was met slachten, zeide het familie-hoofd: "hoort allen, gij allemaal, mijn kleinkinderen, mijn kinderen, mijn neven, mijn zusters! als I Lodoe gegaan is naar den onbeweeglijken steen, het drooge land, vergeet haar niet, verlies haar niet, ga haar dikwijls opzoeken.»

En zij allen antwoordden en zeiden: "'t zou wat voor een moeite zijn, als wij tante eens gingen opzoeken! als wij gaan dan hebben wij maar te stappen".

Toen 't gaar was, aten al de door hem verzamelde menschen. Toen men klaar was, des nachts liet men ze trouwen. Toen 't zoo een tijd geduurd had, zeide I Bokoe: "daarom, omdat ik al zoo lang hier ben, laat mij nu gaan.» En zijn schoonvader antwoordde: "als dat zoo is, over twee dagen gaat dan." 
's Morgens vroeg, ving hij een varken, vervolgens nam hij één mand met massieve stukken (goud); en hij zeide: "neemt dit mee, als ik kleinkinderen krijg, zult gij 't onder hen allen verdeelen.» Maar I Bokoe antwoordde: "neen, zeide hij, als ik dit allemaal mee zou nemen, dat zou niet goed zijn; straks naderhand mijn kleinkinderen en uw kleinkinderen zouden er om vechten, omdat deze massieve stukken (goud) er zijn, zij zullen elkaar doodsteken en met 't kapmes houwen; alleenlijk vraag ik, doe mij wat in een kistje, een heel klein kistje maar».

En zijn schoonvader antwoordde: "welaan daar 't uw wensch is, zal ik u wat in een kistje doen; neem 't allemaal mee, zei ik u, maar gij wilt niet.» En hij nam hem een klein kistje, hij deed er wat in en 't andere liet hij; "daar ik dit in 't kistje gedaan heb, laat er niemand zijn, die 't kistje stuk breekt», zeide hij. Vervolgens omwond hij 't met koperdraad; toen hij er mee klaar was, plaatste hij 't bij den offer-paal; als gij thuis komt, leg 't niet neer in de voorgalerij, noch in huis op den vloer, breng 't rechtstreeks op 't zoldertje in 't bovenhuis; als gij 't er neergelegd hebt, kom dan weer naar beneden en zoek een jong varken, een mannetjes varken».

Men slachtte nu een varken; toen men er mee klaar was, zeide de vader van I Apoe Lodoe: "ha Lodoe, kom hier en hoor, hoe ik bid, overdenk 't en bewaar het.,

Toen stak hij over naar den hoogen vloer. Aldus bad hij: «I Woeja makalítoe, kaperi mara langoe, bescherm ons in 't opgaan, bescherm ons in 't nederdalen, doe onzen voet stooten tegen zilver, tegen goud, eveneens onze kleinkinderen, de menschen door u gemaakt, door u gevlochten; zij die zijn in 't water, eveneens ook zij, die verblijven boven op den beweeglijken steen, op 't drooge land; beantwoord mijn stem!»

Toen 't eten reeds gaar was, zeide de vader van I A poe Lodoe: "zoek koperen schotels, 4 stel, schept de offerrijst er op, brengt 't hier en plaatst het bij den offer-paal.» Vervolgens zeide de vader van I Apoe Lodoe: "ha Oemboe Ratoe, bid bij de offerrijst». Toen zeide I Bokoe: "ik heb iets aan vader te vragen: "als iedere kabisoe zijn naam noemt, wat moet men van hem zeggen?»

En zijn schoonvader zeide: "Wawang, zal men van hem zeggen, dat is, omdat hij uit 't water komt; daarom gaat 't naar beneden, gaat 't weer naar boven, het water; Wawang.» 
Toen ging I Bokoe bidden; toen hij klaar was met bidden, kreeg I Bokoe een stel der offerrijst, I A poe Lodoe één stel, en haar vader één stel, vervolgens gaf men één stel aan de menschen bij de stookplaats. Vervolgens reikte men rijst rond en toen zij allen wat hadden, aten zij.

Toen men gegeten had, zeide I Bokoe: "morgen heel vroeg vertrekken wij.» En zijn vader zeide: “zoo zij 't, vergeet niet het bidden van hier; als gij den Marapoe naar boven gebracht hebt, laat dan niemand onder de stookplaats komen, kippen, honden, paarden; bindt niets vast aan den offer-paal; als er iemand onder komt, sterven zij.»

Toen 't nu nacht was, zeide de vader: "als er jongens zijn die $\mathrm{u}$ komen bezoeken, dragen zij alleen roode kleeren en hun hoofddoeken zijn van rood goed.» En 's morgens vroeg vertrokken zij. Toen zij in de kampong waren gekomen, volgden zij de woorden van hun vader.

Toen zij er mee klaar waren, kwamen de broeders van I Bokoe, zijn kinderen, zijn neven, zijn zusters en zij zeiden tot hem: "hij zal wel dood zijn, hebben wij van u gezegd». Toen zeiden zij: waar is uw paard?» En I A poe Lodoe antwoordde: "hij heeft 't bij vader gelaten." Toen antwoordden sommigen: "mits 't maar zoo is, dat teruggekeerd is de priester, om nauwkeurig na te gaan met onze familie-leden; laten wij I Oemboe Ratoe teruggeven zijn ingewanden, zijn geest, opdat hij ons kunne beschermen, hij, die verblijf houdt op zijn schouder, boven op zijn hoofd. want de Marapoe heeft hem beklommen.»

Toen slachtte men (karbauwen), slachtte men (varkens). En men beschouwde de levers der varkens, de levers der karbauwen, de darmen der kippen; zij waren goed.

Aldus was de oorsprong van Ihi Wawang eertijds. 


\section{Na Tawoeroe.}

Toenanoe handăka na na pakiri na; nindja da anakeàda da mahalimoe ${ }^{1}$; na haätoe na ngara na, I Hadoe $\mathrm{Hina}$ ja; na haätoe na eri na, I Mada ja. Toenanoe ninja la hau koătăk na maremi, hiwăda: măla nda, talo'a patăngăroe ja na maremi. ${ }^{2}$ Toenanoe lakoe da nja ka; bada toăma ka la padoea ngarăngi'a, tăka hiwăna njoena I Mada: "ha aja, nindja da kataroe moeroe neloea la lihi ngarăngi'a, da meti be ka, na mbana ndja ka lodoe.»

Tăka hïwăna njoena I Hadoe Hina: "ha lakoe nda kata hikoe ha, kata ngăndi ha la mamaringoe, la mamaœ; djăka da meti kada meti.» Toenanoe bada hăla ka pabăndjăloe ha la mamaœ, la tana mbaha, lakoe da nja ka palo'a patăngăroe maremi.

Toenanoe ba taliœe da ka, tăka noeda da kataroe moeroe; ${ }^{3}$ da loeri beli ha. Toenanoe lakoe da nja ka la oema da, da peàka nja na ama da; wăda bada peàka: "ha ama, lăti meti be ma nja ka doema, bana paloe kăma tau; nindja da anakeăda da doea, hida piti kăma hida băndjăloe kăma la mamaœ, la tana mbaha».

Tăka na heàma njoena na ama da: "măla ndai tanda ha?» Tăka da heàma da anakeàda noeda: "ma tanda ha.» "Djăka

${ }^{1} \mathrm{da}$ mahalimoe $=$ jeugdig; jongeling. halimoe $=$ licht, niet zwaar.

${ }^{2}$ na maremi $=$ het feest. Een typisch gebruik van 't praefix ma.

De gewone beteekenis van maremi zou zijn: iemand, die feest viert; en niet zooals hier het feest zelre.

3 noeda da kataroe moeroe=die adders. 't Waren n.l. geen gewone adders, maar incarnatie's van „zielen”. Straks openbaren zij zich als njongelingen" en wat er verder in 't verhaal volgt.

Een dergelijke ontmoeting met „zielen", komt volgens 't animistisch geloof, wel meer voor. De „zielen" van een bepaalden stam, incarneeren en openbaren zich bij voorkeur in bepaalde diersoorten. In verband hiermee, heeft elke stam ook bepaalde "heilige" dieren.

Zoo zien de menschen van Ihi Wa wang (zie verhaal VIII) in krokodillen en slangen, een geschikte „woonplaats" voor de "zielen". De menschen van Karoenggoe Watoe (zie verhaal VI) b.v. duiven en apen.

Dèrgelijke dieren zal men niet zonder noodzaak dooden, evenmin als men een mede-mensch zonder oorzaak vermoorden zou. 
toenanoe, lo'a papandapoendja, kada lakoe li păkoe lai jehoe; wămi bai peàka: lakoe li, wăna nggămi i ama.»

Toenanoe lakoe da nja ka papandapoendja; da anakeàda noe kawai, da malo'a patăngăroe maremi, beli da nja ka hida lakoe li patăngăroe ha, la nge'a pabăndjăloe da ha ${ }^{1}$ da kataroe moeroe meti; tăka hi ndeda ita ha ${ } ;^{2}$ tăka hiwăda bada paní: "kanggini ha ka ihoe ná, da loeri ka năhoe», Tăka da anakeàda da mapandapoeng, da rongoe ha bada paní. ${ }^{3}$ Toenanoe da hili lakoe, hida djăngăpoe ha da anakeàda da mapandapoeng; tăka hiwăda da anakeàda da mapandapoeng: "ka ngga kămi nămoe loea.» Tăka da heàma da anakeàda, da maweli patăngăroe maremi: "njoema», hiwăda. "Lakoe li păkoe la oema, wăna i ama», hiwăda da anakeàda da mapandapoeng. Tăka da heàma da maweli patăngăroe maremi: "ai ha, oemboe, mamangădătoe doema palakoe li.» Tăka da heàma da anakeàda da mapandapoeng: "nde'a, lakoe li; djăka talakoe, măta kama mangiloe ka njoema; djăka tăka la ngaroe pindoe, ba ninja na ahoe mbeni, pangga ja $\mathrm{ka}$, dili ha da roekoe ma njoema, ka ămboe na mbeni na ahoe; na ahoe noena hama poăla mboeroeng bokoeloe na, kaboăta * ja na ngara na.»

Toenanoe lakoe da nja ka; tăka hiwăda da anakeàda da mapandapoendja: "djăka tăka tai, djăka na wŏnggai pahăpa mi la tanga mboăla bara, ămbi bihoe; tanga mboăla miri, ămbi bihoe: la kawinga, ămbi bihoe; la kaba kaliang, ămbi bihoe; tăngăroe ja na tanga mboăla papiti la tana kai hăpa ningoe. Koe wornggămi patoekoe lomboe, djăka wăna nggămi, ămbi

1 la nge'a pabăndjăloe da ha=de plaats, waarzij ze neergelegd hadden.

Het bijwoord van plaats "waar", wordt in relatieve zinnen-omsehreven met "nge' a' = plaats. Dit ${ }_{n}$ 'ge'a" eischt een verbaal-substantief constructie. De letterlijke vertaling zou dus luiden: „de plaats van hun neerleggen hen, de adders". vlg. Soemb. Gramatica pg. 55.

${ }^{2} \mathrm{i}=$ bijwoord, beteekenend: $;$ weer"; komt meestal voor in verbinding mèt "hili" = wederom: da hili ita ja $\mathrm{i}=$ wederom zagen zij hem weer.

Wordt ook gebruikt bij een beleefd verzoek: mai i nămoe $=$ kom eens hier.

3 da rongoe ha bada pani $=$ zij hoorden ben spreken.

Waar wij een infinitief-vorm gebruiken, wordt in 't Soemb. vereischt een constructie met 't voegwoord $\mathrm{b} a=$ terwijl.

koe ita ja bana mandapoe la oema=ik zag hem zitten in huis (terwijl hij zat).

Zoo dient ba ook tot 't vormen van een participium: hiwăda bada he à $\mathrm{ma}=$ antwoordende zeiden zij "(zij zeiden terwijl zij antwoordden)".

$4 \mathrm{kaboăta}=$ naam van een groot slangen-soort. 
bihoe; ndjara, ata, karămbo'a, kanataroe, ămbi bihoe; wămi bai heàma, didi jang na tawoeroe la lima kakiha moe, na pamboeha ma, wămi.» 1

Toenanoe bada tăka ka, hiwăda njoeda da anakeàda da mapandapoeng: "ha ama, nindja ka da tau da manamoe kăma.» Tăka na heàma njoena na ama da: "wŏnja pahăpa da.» $\mathrm{Na}$ panggănăp ndăba ha tanga mboăla bara, kawinga, kaba kaliangoe dắngoe tanga mboăla papiti la tana. Toenanoe hida piti ja na tanga mboăla miri papiti la tana hida hăpa ningoe.

Toenanoe bada hăla ka pahăpa, hiwăna njoena na ama da da anakeàda: "djăka ndai djeà kămi, oemboe, manamoe ha da ana nggoe, meti be da nja ka lăti; ndaningoe pa kawoekoe nggoe, ${ }^{2}$ meti măngoe didi nggoe nja ka lăti; batoenanoe koe wǒnggămi ndjara, ata, patoekoe lomboe, kanatar.» Tăka da heàma noeda da tau: "ndema bihoe». Tăka hiwăna na ama da da anakeàda: "măla pindi pamboeha mi. » Tăka da heàma noeda da tau: "didi jang na pamboeha ma, na tawoeroe la lima kakiha moe, kau wŏnggăma nja.»

Tăka na heàma njoena na ama da da anakeàda: « $\bar{e}$, djăka toema na ka noe, meti wăngoe ma nggoe nja ka; djăka ndai djeà kămi lăti, ba namoe ha da ana nggoe, ndaningoe pa kawoekoe nggoe lăti, djăka da meti pangalang ma ka lăti; djè batoenanoe, kē ja ka».

Tăka hina boetoehoe ja hina wŏndja ja na tawoeroe noena.

Toenanoe bana hăla ka pawŏnja, hi lakoe da nja. Toenanoe njoena I Hadoe $\mathrm{Hina}$ bana tăka ka la oema da, na jăpa ha da kambaniroe, da dedi ha kambaniroe ămăhoe rara; na jăpa

1 't Verkeer met de „zielen" eischt alle voorzichtigheid. Hadden zij b.v. sirih gekauwd uit een wit mandje, dan zouden zij een buit der "zielen" zijn geworden. Zoo ook met de geschenken, welke maar onheil zouden aanbrengen en in huis gebracht spoorloos weer zonden verdwijnen. De „ring", welken zij hier vragen moeten, is vasthouder van zielestof; daarom sterft de vader ook nadat hij hem weggegeren heeft.

In een volgend verhaal is 't een kip, welke als zoodanig dienst doet.

${ }^{2}$ ndaningoe pa kawoekoe nggoe $=i k$ zou geen nageslacht meer hebben. Voor elke animist 't verschrikkelijkste dat gebeuren kan, zonder kinderen te sterven.

kawoekoe= knoopen. aanknoopen.

ndaningoe pakawoekoe nggoe; zou echter beteekenen: er is door mij geen knoop gelegd, d.i. niets afgesproken, beloofd. (Door 't leggen van knoopen in een touw, spreekt men n.l. met elkander bepaalde dingen af.).

In den eersten zin is n.l. pa een adverbium $=n o g$, meer.

Dl, 68 , 
ha da mboăla, da mbeàka, da dedi ha ămăhoe rara; da hinggi na, da tera na, ămăhoe rara djoea ha.

Toenanoe hi ninja na poelangia na; haätoe na na ana na, kawini ja. Tăka hiwăna na poelangia na: "koe wŏnja tau ' na laleàba nggoe», hiwăna bana paní. Toenanoe hina paleàwa ja na ana na palo'a patoenja oehoe I Hadoe Hina. Toenanoe bada tăka ka, hiwăna njoena I Hadoe Hina: "ka nggăra wămi?» Tăka da heàma njoeda da tau kawini: "lo'a pangädăloe ja, wăna nggămoe i ama, ${ }^{2}$ lo'a patoenja ja na oehoe, wăna nggămoe i ama.» Tăka na heàma njoena I Ha do e Hina: "ka nggăra pawŏ ă nda nggămi ka?» Tăka da heàma njoeda da kawini: "ma ka nggăra pawŏ moe!»

Tăka njoena I Hadoe Hina na piti ha da oehoe, hina nggoeli $^{3}$ ha da likoe karăndi da. Toenanoe bana hăla ka patăngăroe ha, tăka hina karăndi pabeli ndja da oehoe noeda; tăka hiwăna: ngăndi beli ha da oehoe.

Tăka da heàma njoeda da kawini: măla ka. Toenanoe hida lakoe; bada tăka ka la oema, hida nggoeli ha da karăndi da da oehoe noeda; bada hăla ka panggoeli ha hida tăngăroe ha: ămăhoe rara djoea ha.

Tăka hiwăna njoena na poelangia na: "batoenanoe napa haromoe kata paleàwa nja tau, kata patamanja la koeroeng."

Toenanoe bana paleàwa nja ka tau hina lo'a njoena I Hadoe Hina. Toenanoe bana lakoe ka, ba hīna na tăka, dira matiki ${ }^{4}$ bana toboeng; na patamanja la koeroeng hamang. Toenanoe bana hăla ka patamang la koeroeng, bana mandai ki ka năhoe, toenanoe beli na nja ka la oema na, na kareànja na papaha na.

1 koe wŏnja tau =ik zal hem een mensch, geven.

Een vaste uitdrukking voor: ik zal hem een vrouw geven, n.l. tau. angoe=metgezel, dit tau angoe wordt echter zoowel voor den man als voor de vrouw gebruikt. Onjuist is dus wat b.v. iemand over Soemba schreef: de positie der vrouw is uiterst laag, wat vooral blijkt uit den naam, welke men aan zijn vrouw geeft, n.l. tau angoe, een mensch, dat er nog bijhoort of bijkomt. Hetzelfde zou men dus ook van de positie van den man kunnen verklaren!

2 wăna nggămoe i ama = zeide vader van u.

De datief wil niet alleen zeggen: aan iemand, tot iemand, maar ook: aangaande, in betrekking tot iemand.

s nggoeli=losmaken, loswikkelen, ivan een touw, dat ergens om heen is gewonden. Voor 't losmaken van een knoop zegt men "wăkăhoe".

"dira matiki= „uitscheiden met opnoemen", d.i. meer dan te zeggen is; verbazend veel. 
Toenanoe bana mandai ka, tăka hi ninja na djawa; ' tăka hiwăna njoena I Hadoe Hina: "ngăndi i ja na tawoeroe nggoe, kau toenja mata ${ }^{2}$ na, matembi kau toenja.»

Toenanoe ngăndi na nja ka na djawa. Tăka hoepapa bana toe ja ka la lima na, na jăpa ha da kambaniroe, da dedi ha ămăhoe rara; hamang da păti. Toenanoe hi ndena bihoe papabeli nja; na wŏnja tawoeroe hau, hiloe na.

Toenanoe ba nde djè ja pa na tawoeroe, I Hadoe Hina laloe handoeka ja na eti na: na mila beli ka; na mahoeroe na roedoeng, na lodoe, bana handoeka dănja na tawoeroe na. ${ }^{3}$

Toenanoe ba laloe handoeka ja na eti na na aja nggoe, wăna I Mada, hi lakoe na nja pawanda ja I Me'o. Tăka I Meo na wanda ja I Kalaoe. Toenanoe pala da nja ka la hapapa tana; bada tăka ka hida lakoe la hau oema hau oema; njoena I Me'o la koeroeng na tama loehoe, tama loehoe ndja hau oema hau oema; tăka njoena I Kalaoe na koeti măra hau ndja da păti.

Tăka I Kaka lakoe na nja ka pahimboe hama na. Toenanoe bana tăka ka la nge’a patăka na, hina hē ja la kapoeka ai. Tăka na lodoe noena, dje ja na răpa poeroe da la pahoămba ${ }^{4}$ da Me'o Roemba. ${ }^{5}$ Toenanoe bada tăka ka da Me'o Roemba la pingi na na ai na pahē na I Kaka, njoena I Kaka na kapăndi be ja la kapoeka ai. Toenanoe bada mătoe ka da Me'o Roemba, tăka hiwăda: ka ha ${ }^{6}$ nggiki nda ka, ha ngangoe nda nde $\mathrm{h}$ a ningoe, we $\mathrm{h}$ a bokoel nde $\mathrm{h}$ a ningoe.

$1 \mathrm{djawa}=$ vreemdeling; iedere vreemdeling is een $\mathrm{djawa}$, terwijl dan zijn landaard er apart wordt bijgevoegd, b.v. djawa ba ra =witte vreemdeling; $d j a$ w a a $a b=$ Arabier.

${ }^{2} \mathrm{mata}=$ oog. Een steen, of iets anders, in een ring gezet, noemt men "mata".

3 na handoeka dănja na tawoeroena $=$ hij was bedroefd over zijn ring.

Een typisch gebruik van dăngoe = met, en. (dăngoe $+j a=d a ̆ n j a$.$) .$

4 pahoămba $=$ offerplaats in 't veld, bij den mond der rivieren. Men offert er aan den Marapoe tana.

${ }^{5} \mathrm{Me}$ 'o Roemba=zijn een soort boschgeesten. Groote, zwaar behaarde gestalten. Als zij zich soms onder de menschen vertoonen zijn ze kenbaar aan hun witte tanden en doordat zij vreeselijk slokken, b. v. rijst met bord en al.

${ }^{6} \mathrm{ha}=$ dit telkens ingevoegd $\mathrm{ha}$ is bewijs dat ${ }^{\mathrm{t}}$ geesten zijn welke praten en geen menschen. Zoo spreekt ook b.v. I Apoe Kămi, welke in zoovele verhalen optreedt. 
Tăka hi ninja hau na na ana mongoe, hiwăna bana heàma: djăka ndaningoe pangangoe, djăka ndaningoe wē, toendoe ngga njoengga. Tăka hida toendoe nja; bada hăla ka patoendoe nja, oehoe, we e, karămbo'a, manoe, kamămbi, woeroe bokoel, woeroe băhi nggănăp ndăba.

Toenanoe manahoe da nja ka, hoendjoe da nja ka; ba memi ka, hamajang da nja ka. Toenanoe bada hăla ka pahamajang, da piti ha da wē, da hoăba măngoe he'au he'au ndja; oehoe la woeroeng, hoăba măngoe woeroe ndja.

Toenanoe bada hăla ka pangangoe, hiwăna njoena na ama bokoel Me'o Roemba: "ămbi ha ngara ha ngarangoe mi hoedita la kapoeka ha ai, ha anakeàda ha ngoerăkoe $\mathrm{h}$ a mata; ha ninja na ha rapoe ha tana hoedita la kapoeka ha ai.» Toenanoe ba hăla ka pawăna, mahoeroe ndăba da nja ka.

Toenanoe bada mahoeroe ka, tăka njoena I Kaka hina poeroe ja hina piti ja na ana mongoe hina ngăndi ja.

Toenanoe bana tăka ka la pădoea ngarăngia, hina hămboeroe nja haätoe na na tau, na madoekoe nimboe «koădja roekoe». ${ }^{1}$ Toenanoe hiwăna: "njoemoe na ana mongoe moe nggiki na?» "Djăka ndaningoe oehoe, djăka ndaningoe wē bokoel, oetoendoe nja, ka nggănăp ndăba be ă:»

Tăka na heàma na madoekoe nimboe: "njoengga djăka koe lakoe papatamang, djèpa nde'a mbăda lăpăhoe na, koe pangakoe nja, na meti be ă.» Tăka na heàma njoena I Kaka: "djăka toena, măla kata pandjèpang». Toenanoe hida pandjèpang; na kē ja njoena I Kaka I Koădja roekoe. Tăka hina wơnja ja na ana mongoe.

Toenanoe paheàwa da nja ka; bana marau ki ka hakoedoe, na mangăndi ana mongoe, tăka njoena I Kaka hina pangakoe nja I Koădja roekoe; meti na nja ka na mangändi ja na ana mongoe. Tăka njoena I Kaka na piti beli ja na ana mongoe, meha na ha ka I Kaka, ana mongoe, I Koădja roekoe.

Toenanoe hina ngăndi nja ha na oemboe na; hiwăna njoena I Kaka: "ha oemboe, djeà ndja ka, ana mongoe, koàdja roekoe ha $\mathrm{ka}$, hama dedi na na tawoeroe.» Tăka na heàma njoena I Hadoe Hina: "ndakoe bihoe, wăna, djè ma ja bădi na tawoeroe nggoe.»

\footnotetext{
1 koădja roekoe=steker van't spoor. De lans immers wordt opgeheven naar 't spoor van 't wild, dat voorbijgegaan is, en de dood volgt.
} 
I Me'o dăngoe I Kalaoe bada himboe ja na tawoeroe, loepa da hoenggoe ma ja. Toenanoe bada hoenggoe ja ka, hida piti ja. Toenanoe beli da nja ka; bada tăka ka la liboe moeroe, ' hiwăna njoena I Me'o: "măta kakoe kamang patoe ja la wŏ lima nggoe na tawoeroe.» Koe toe ja, wăna doe ka lăti, ${ }^{2}$ tăka hina kanaboe i na tawoeroe la liboe moeroe. Tăka I Kala oe hina roenoe nja, loepa na ita ma ja. Toenanoe bada tăka ka la mara, tăka hiwăna I Kala o e: "măta kakoe ngăndi ja ka njoengga.»

Tăka I Me'o: »nde'a, wăna, măta kakoe ngăndi ja ka njoengga.»

Tăka hina wŏnja ja; tăka la wăka tana, na panaboe ja i. Tăka njoena I Kalaoe hina ăki ja, na patoăma ma nja wai, hina măngoe pa'ita ja. Toenanoe bana ita ja ka, hina hē ngăndi ja; njoena I Kala oe na mangăndi ja.

Toenanoe bana tăka ka la I Hadoe Hina, hina wŏnja ja na tawoeroe noena; woeloe beli na nja ka, hama toena kawai la kawoenga na. Bana toe ja ka la wŏ lima na, na jăpa na oema na, ămăhoe ndăba; da hinggi ki na, ămăhoe ndăba. Na woeloe ndjara, karămbo'a, ata, mătoe maningoe-ningoe nja.

\footnotetext{
1 liboe moeroe='t groene diep; de volle zee.

${ }^{2}$ koe toe ja, wăna doe ka lăti=ik doe hem aan, zou hij zoo zeggen, d.i. hij zou hem aandoen. Veel gebruiktê Soemb. constructie met wăna. vlg. Soemb. Grammatica, pg. 62.
} 
IX. De Ring.

Aldus was vroeger 't begin er van; er waren twee jonge knapen; de naam van den een was I $\mathrm{Hadoe} \mathrm{Hina}$; de andere zijn jongere broeder heette I Mada. Er was nu feest in een kampong en zij zeiden: welaan laat ons eens naar 't feest gaan kijken. $\mathrm{Zij}$ nu gingen; halverwege den weg gekomen, zeide I Mada: "oudere broeder, er zijn adders daar aan de zijde van den weg, zij zullen wel dood gaan, door de hitte van de zon.» Toen zeide I Hadoe Hina: "laat ons gaan en ze (met een houtje) oppikken en ze brengen in de koelte, in de schaduw; als ze leven, laat ze leven; als ze dood zijn, laat ze dood zijn., Toen zij ze gelegd hadden in de schaduw, op vochtigen grond, gingen zij heen om 't feest te bezien.

Toen zij juist weg gegaan waren, keerden die adders weer in 't leven terug. Ze gingen naar hun huis en vertelden ' $t$ aan hun vader; sprekende zeiden zij: "vader, wij zouden zeker gestorven zijn, doordat iemand ons sloeg; er waren echter twee knapen, die namen ons op en legden ons in de schaduw, op vochtigen grond.» En hun vader antwoordde: "welaan kent gij ze niet?» Die knapen antwoordden: "wij kennen ze." "Als dat zoo is, ga ze dan opwachten, opdat ze hier eens aankomen; sprekende zult gij zeggen: kom eens aan, zegt vader tot u.,

En zij gingen hen opwachten; de knapen van zooeven, die naar 't feest gingen kijken, keerden nu terug, en zij gingen aan om te zien de doode adders, waar zij ze neergelegd hadden; maar zij zagen ze niet meer en sprekende zeiden zij: waar zouden ze nu toch zijn, ze zullen nu wel leven. En de knapen, die op den uitkijk stonden, hoorden hen spreken. Zij gingen wederom en kwamen tegen de knapen, die op den uitkijk stonden. En de knapen, die hen opwachtten, zeiden: "wie zijt gij daar ginds?, En de knapen, die terug kwamen van 't kijken naar 't feest, antwoordden: "wij», zeiden zij. "Kom toch aan in huis, zegt vader», zeiden de knapen, welke hen opwachtten. En zij die terugkwamen van 't kijken naar't feest, antwoordden: "ai ha, heeren, wij zijn bang om aan te gaan.» Maar de knapen die hen opwachtten, anțoordden; "neen, kom aan; als wij 
gaan, laten wij dan vooraan loopen; als wij komen bij de deur-opening - omdat er een nijdige hond is, stap dan en treed in onze voetstappen, opdat de hond niet nijdig worde; die hond is zoo groot als de stam van een go'ang palm, en zijn naam is Kaboăta.»

Zij nu gingen en de knapen, die hen opgewacht hadden, zeiden: "wanneer wij straks aankomen, wanneer men u uw sirih geeft in een wit mandje, moet gij niet willen; een vuil mandje, moet gij niet willen; op een bord, moet gij niet willen; op een koperen schaal, moet gij niet willen; kijk naar een mandje opgeraapt van den grond en kauw daaruit sirih. Ik zal u geven oude mamoeli's, als hij dat tot u zegt, moet gij niet willen; paarden, slaven, karbauwen, gouden kettingen, moet gij niet willen; antwoordende zult gij zeggen: alleenlijk de ring aan uw pink is onze begeerte, zult gij zeggen.»

Toen zij aangekomen waren, zeiden de knapen, die opgewacht hadden: "vader, de menschen, welke medelijden met ons hadden, zijn er.» En hun vader antwoordde: "geef hun sirih.» Men maakte alles voltallig: een wit mandje, een bord, een koperen schaal en een mandje opgeraapt van den grond. Maar hij nam 't smerige mandje opgeraapt van den grond en kauwde er sirih uit.»

Toen zij sirih gekauwd hadden, zeide de vader der knapen: *als gij 't niet geweest waart, heeren, die medelijden had met mijn kinderen, dan zouden zij wel gestorven zijn; ik zou geen nageslacht meer hebben gehad en zou gestorven zijn als een eenzame man; daarom zal ik u geven paarden, slaven, oude mamoeli's, gouden kettingen.» Maar die menschen antwoordden: "wij willen 't niet."

En de vader der knapen zeide: "welaan kiest, wat gij begeert. »

En de menschen antwoordden: "alleenlijk is onze begeerte de ring aan uw pink, dien zult gij ons geven.»

Maar de vader der knapen antwoordde: «e , als dat zoo moet, dan zal ik er van sterven; als gij 't niet geweest waart, die medelijden had met mijn kinderen, dan zou ik geen nageslacht meer gehad hebben, als zij heelemaal gestorven waren; daar dit zoo is - neem hem dan maar.»

En hij deed hem af en gaf hem dien ring. Toen hij dien gegeven had, gingen zij heen. I Hadoe $\mathrm{Hina}$ nu, toen hij bij hun huis was gekomen, greep de palen vast en 't werden 
gouden palen; hij nam de open manden, de gesloten manden, ze werden van goud; zijn slimoet, zijn hoofddoek, 't werd allemaal goud.

Er was nu een oom van hem; één kind had hij, een meisje. En zijn oom zeide: «ik zal mijn neef iemand (tot vrouw) geven, zeide hij sprekende. Zoo zond hij zijn dochter om wat rijst te brengen aan I Hadoe Hina. Toen zij daar gekomen waren, zeide I Hadoe Hina: "wat hebt gij te zeggen?» En die vrouwen antwoordden: "ga hem eens opzoeken, zeide vader van u, ga hem wat rijst brengen, zeide vader van u.» Toen antwoordde I Hadoe Hina: "wat zal ik u dan geven?» En de vrouwen antwoordden: "alwat gij maar geven wilt.».

I Hadoe Hina nam nu de rijst en maakte los de touwtjes, waar 't mee gebonden was. Toen hij 't bekeken had, bond hij die rijst wederom dicht; en hij zeide: "breng de rijst maar terug».

Toen antwoordden de vrouwen: 't is goed. En zij gingen heen; toen zij thuis gekomen waren, maakten zij los 't bindsel van de rijst; toen zij 't losgemaakt hadden, keken zij er in: 't was louter goud.

Toen zeide zijn oom: "daar dit zoo is, zullen wij hem morgen iemand zenden, opdat wij hem doen trouwen».

Toen men hem iemand gezonden had, ging I Hadoe Hina. Toen hij gegaan was en pas was aangekomen, siachtte men verbazend veel; toen hij trouwde, eveneens. Toen hij getrouwd was, en 't nu al een tijdje geduurd had, keerde hij naar zijn huis terug en nam zijn vrouw mede.

$\mathrm{Na}$ verloop van langen tijd, was er eens een vreemdeling en I Hadoe Hina zeide: "neem toch mijn ring en zet er een "oog» op, zet er een Engelsch pond op».

De vreemdeling nam hem nu mee. Maar overzee, toen hij hem aan zijn vinger deed, greep hij vast de palen en zij werden goud; eveneens de kisten. En hij wilde hem niet teruggeven; hij gaf een anderen ring in de plaats.

En daar deze niet meer was de ring, was I Hadoe $\mathrm{Hina}$ zeer bedroefd; hij werd weer arm; hij sliep des nachts en des daags, daar hij bedroefd was over zijn ring. Daar mijn oudere broeder zoo bedroefd is, zeide I Mada, zoo ging hij heen en riep de Kat te hulp. En de Kat riep de Muis te hulp. Zij nu staken over naar 't land aan de overzijde; de Kat ging 
uit en in de kamers van elk huis; en de Muis krabbelde tot in alle kisten één voor één.

Ook de Kakatoe ging zoeken een gelijke er van (van den ring).

Toen hij gekomen was, waar hij komen wilde, klom hij in den top van een boom. En die dag was juist de tijd, waarop de Boschkatten naar de offerplaats kwamen.

Toen de Boschgeesten gekomen waren bij den boom, waar de Kakatoe in geklommen was, verborg zich de Kakatoe in den top. Toen de Boschgeesten voltallig waren, zeiden zij: "hoe hebben wij 't, ons eten is er niet, een groot varken is er niet.»

Er was nu een gong en die zeide antwoordende: als er geen eten is, als er geen varkens zijn, sla dan op mij. En zij sloegen er op; toen zij geslagen hadden: rijst, varkens, karbauwen, kippen, geiten, groote potten, ijzeren potten, alles was compleet.

En zij kookten en zij slachtten; toen 't gaar was, ging men bidden. Toen men gebeden had, namen zij de varkens en ieder stak er één in zijn mond; de rijst in de potten, staken zij met pot en al in den mond. Toen zij gegeten hadden, zeide 't hoofd der Boschgeesten: "gij moogt niet telkens opzien naar den top van den boom, knapen jong van oog; de Marapoe tana is boven in den top.» Toen hij dit gezegd had, gingen zij allen slapen.

Toen zij nu sliepen, klom de Kakatoe naar beneden en pakte de gong en nam die mee. Halverwege gekomen ontmoette hij een man, die lans "Steker» droeg. En hij zeide: "gij met uw gong, hoe is 't daarmee?» "Als er geen rijst is, als er geen groot varken is, moet gij er op slaan en dan is alles zoo maar compleet.»

En hij, die de lans droeg, zeide: "ik, als ik ga jagen, al is ('t wild) ook al reeds voorbij gegaan, ik hef haar dreigend op en 't sterft zoo maar». En de Kakatoe antwoordde: "als 't zoo is, laten wij dan ruilen ". $Z$ ij nu ruilden; de Kakato e nam de "Steker». En hij gaf hem de gong. Zij gingen nu van elkaar; toen hij, die de gong droeg, een eindje weg was, hief de Kakatoe dreigend den "Steker» tegen hem op; dood ging hij, die de gong droeg. En de Kakatoe nam de gong weer terug; alleen in zijn bezit had de $\mathrm{Kak}$ a to e nu, de gong en de "Steker».

Hij bracht ze nu aan zijn heer, en de Kakatoe zeide: "heer, deze hier, zijn de gong en de "Steker», van denzelfden oor- 
sprong als de ring." I $\mathrm{Had}$ oe $\mathrm{Hina}$ antwoordde: "ik wil ze niet, zeide hij, 't moet mijn ring zijn."

De Kat en de Muis zochten den ring, totdat zij hem vonden. Toen zij hem gevonden hadden, namen zij hem.

En zij keerden terug; midden op zee gekomen, zeide de $\mathrm{K} a t$ : "laat ik eens probeeren den ring aan mijn vingers te doen». Hij wou hem er aan doen, maar daar viel de ring in zee. De $\mathrm{Mu}$ is echter dook er naar, tot hij hem zag: Toen zij nu aan land waren gekomen, zeide de Muis: «laat mij nu hem maar brengen.» Maar de Kat: neen, zeide hij, laat mij hem brengen.»

En hij gaf 't hem; maar bij een aardspleet gekomen, liet hij hem weer vallen. De Muis echter ging aan 't graven: hij deed 't tot aan 't water toe, toen pas zag hij hem. Toen hij hem gezien had, bracht hij hem naar boven; 't was de Muis, die hem nu bracht.

Toen men bij I Hadoe Hina gekomen was, gaf men hem dien ring; wederom rijk werd hij, evenals vroeger de eerste maal.

Toen hij hem aan zijn vinger gedaan had, greep hij zijn huis, 't werd allemaal goud; zijn slimoets, allemaal goud. Hij werd rijk in paarden, karbauwen, slaven, van alles had hij. 
X. Ana Manoe.

Ninja haätoe na na tau, nde'oekoe mila ma ja; hinggi na, tera na ndena toăma ja; ${ }^{1}$ da manindja la lima na: doea ngioe dang ${ }^{2}$ da bai manoe pa'ana; he'au he'au da ana da, pihoe ngioe da. La mbaroe na doekoe ha da bai manoe pa'ana, ${ }^{3}$ na ngăndi ha la woăka; na maling ka na lakoe ja la koătăk, na doekoe ha da bai manoe. Toe-toe ă na hau mbaroe hau maling năhoe bana doekoe ha da bai manoe.

Toenanoe la mbaroe na piti ha da bai manoe hina doekoe ha. Tăka la padoea ngarăngi'a hina ita ha da koemboe lai, doea ngioe da, da pawitoe dăngga angoe da, da pakiloeng-kiloeng.

Tăka njoena na madoekoe bai manoe hina băndjăloe ha da bai manoe, hina boeti ndja bada pawitoe. Toenanoe bana oela ja ka paboeti ndja hini piti ja na hoepoe tera na, na makarē, hina hira ja hina măra hakadipoe ndja he'au he'au, hiwăna bana paní, bana ndoeha ndja ja na tera: "rongoe ná, djăka oemboe kămi, djăka rămboe kămi, ămbi pahănggang doe, paheàwa wa.» Toenanoe hida paheàwa; da koemboe lai lakoe da nja ka doeda; ndena pindja pange’a da. Tăka njoena na madoekoe ha da bai manoe, hina piti ha da bai manoe hina doekoe ha.

Toenanoe bana tăka ka la woăka, na bǒwa ndja da manoe; lakoe na nja ka paboeta roemba. Toenanoe bana tama ka na lodoe hina lakoe ja la oema; bana tăka ka la oema, na tăngăroe ha da manoe, mbăda tama da ka la katanga da.

1 tera na ndena toăma ja=zijn hoofddoek bereikt hij niet; d. w. z. hij was niet in staat zijn noodige kleeren te koopen.

't Verbum toăma wordt dikwijls in die beteekenis gebruikt= bereiken, in staat zijn, tot stand kunnen brengen, bij machte zijn.

2 doea ngioe dang=twee slechts. De nasaal ng schijnt hier de beteekenis van "slechts" te hebben. Zoo zegt men ook: nindja hakoedoe dang da loea a $\mathrm{i}=$ er waren slechts weinig aardvruchten.

hama mboăla jang bokoeloe na='t was maar zoo groot als een mandje.

didi jang = alleenlijk, slechts.

3 manoe pa'ana $=$ kip met kuikens. Een typisch gebruik van 't praefix pa. 
Toenanoe hina răpitoe ka; bana hăla ka parăpitoe ha hina kanð̌ama hina doekoe ha da manoe na.

Bana tăka ka la padoe'a ngarăngí'a, la nge'a pa'ita na ha kawai da mapawoē, toenanoe hina hamboeroe ha da doea da anakeàda, anakeàda mini ha. Toenanoe hiwăda nja: "ha oemboe neloea madoekoe bai manoe! băndjăloe ha kadiroe da bai manoe; mai $i$, wăna $i$ ama. Tăka hina heàma na madoekoe bai manoe: "ai ha, ndakoe bihoe; na jăpa ă ha i doekoe me'o da manoe nggoe.» Tăka da heàma njoeda da anakeàda: "djăkau băndjăloe ha lai jehoe da manoe moe, ndaningoe ă mapoetoe ha.»

Toenanoe hina băndjăloe ha; lakoe kareà da nja ka; tăka hiwăda njoeda da anakeàda: rongoe ja na papaní ma njoema: tai djăkau tăka, djăka na wŏnggau pahăpa moe i ama, ămboe hăpa ha da mangé'angoe la tanga mboăla bara, hăpa ni ha la tanga mboăla papiti la tana, tanga mboăla pawoeloe ahoe.» A'a, hiwăna. "Djăka na karai nggau, i ama, hiwădanja, nggăra pamboeha moe, djăka wăna nggau, didi jang na ana manoe la jarang, ${ }^{1}$ wămoe bau paní; patoekoe lomboe, djăka, wăna nggau, watoe ha; kanatar, djăka wăna nggau, loeloe a na la loe ha; ămăhoe miting, djăka wăna nggau, loeloe kăroe kapoe ${ }^{2}$ ha; ndjara, karambo'a, djăka wăna nggau, ămboe bihoe, djăkau kē ha noeda, kahodoekoe ha, ngginggi ha; didi jang noena na papapeàka ma njoema, na ana manoe la jarang. Tai djăka ta tăka la ngaroe pindoe, dili ma ha da roekoe ma, da dangoe da ahoe mbeni.»

Tăka njoena na tau na kikoenja na papaní da da anakeàda.

Toenanoe bana tăka ka hina wŏnja pahăpa na; na tanga mboăla bara ndena bihoe; na katoetoe ni ja na tanga mboăla miri, na papiti la tana, hina hăpa. Toenanoe bana hăla ka pahăpa, hiwăna njoena na ama da da anakeàda noe kawai:

\footnotetext{
$1 \mathrm{jarang}=$ een offerrekje, aangebracht rechts boven de deuropening.
}

Daar vertoeft gewoonlijk de Marapoe, nederdalend van zijn plaats boven in huis. Hier brengt men zijn offers aan den Marapoe, bij 't bespreken van "zaken", waar hij dan zit als ongeziene getuige.

2 loeloe kăroe kapoe, evenals loeloe ana laloe zijn soorten van lianen.

Wanneer de man, door begeerlijkheid gedreven, goud en beesten zou vragen, dan zou hij ze wel krijgen, maar straks zouden ze weer veranderd worden in nuttelooze voorwerpen.

Met geschenken van geesten, moet men steeds zeer voorzichtig zijn! 
«djăka nde djeà kau lăti, oemboe, mapaheàwandja da ana nggoe, meti doe wiki da lăti; djeà batoenanoe, koe palohoe nggămoe; nggăra pamboeha moe?»

Tăka na heàma njoena na tau: "njoemoe bădi, kakoe rongoe păkoe la ngaroe moe.» Tăka hina peàka nja na ama da da anakeàda: "koe wŏnggau patoekoe lomboe, kanatar, mamoeli, ndjara, karămbo'a, ata.» Tăka na heàma njoena: "ndakoe bihoe ha noeda da papeàka moe.» Tăka hina heàma na ama da da anakeàda: "măla, nggăra ja na pamboeha eti moe; ămboe mangădătoe.» Tăka hiwăna njoena na tau na mapaheàwa ndja da anakeàda: "na pamboeha eti nggoe, didi jang na ana manoe noedita la jarang.» Tăka hina heàma na ama da da anakeàda: "djăka toe ma na ka noe, oemboe, meti nggoe nja ka, ba djeà ma ja ka na kalada nggangga nggoe, ' ' na pakarai moe.»

Toenanoe hina piti nja ja na ana manoe noena, hina wŏnja ja. Toenanoe bana ke ja ka, hiwăna njoena na tau na mapaheàwang: "măta kakoe lakoe, oemboe!» Na heàma na ama da da anakeàda: "lakoe na lodoe jeàna ă, bata papoeloe dăngoe; djăka taliœ moe ka, meti ma doe nggoe nja i doekoe.»

Toenanoe lakoe na nja ka na tau na papa paní na $;{ }^{2}$ mandai ki ka hakoedoe, meti ma na nja na ama da da anakeàda.

Toenanoe bana tăka ka la woăka hina piti nja watăroe, hina toe nja; bana hăla ka patoe nja watăr, na piti nja wai, na toe nja. Toenanoe bana hăla ka patoe nja wai, hina boeta ha da roe ihi na dăngoe da woeloe kiri na dăngoe da woeloe kăpa na, hina toe ha la mboăla. Toenanoe bana hăla ka paboeta ha hini piti ha da woeloe manoe noeda hina ngăndi ha la hambeli oăka hina wéwăroe ndja. Bana hăla ka pawéwăroe ndja, da dedi ha ndjara, karămbo'a, kamămbi, wē. ${ }^{3}$

${ }^{1} \mathrm{na}$ kalada ngangga $\mathrm{nggoe}=$ dat is mijn strottenhoofd.

't Kuiken is dus zijn ,geconcentreerde" zielestof. Geeft hij 't weg, dan moet hij sterven. Evenals in een der sprookjes, waar 't "hart" van den reus in een ei is verborgen; breekt dat ei, dan sterft de reus.

vlg. verhaal IX, pag. 193.

${ }^{2}$ na tau na papa pani na $=$ de man, zijn mede-spreker.

papa $=$ de (andere) helft. Bij 't bespreken van een zaak, zijn er altijd vaste woordvoerders der beide partijen. De een noemt dan den ander zijn "papa pani", zijn tegenpartij in 't spreken.

3 De "geconcentreerde" zielestof van 't kuiken, bezielt dus nu andere dingen. Alles moet sterven of vergaan, maar de zielestof kan niet sterven, bezielt telkens op nieuw andere wezens en andere voorwerpen, in eeuwigdurende kringloop. 
Toenanoe bana hăla ka pawéwaroe ndja hawiang, hina ngăndi ha la oema hawiang. Bana tăka ka la oema hina wéwăroe ndja la talora, da dedi ha tau, ata, mamoeli, patoekoe lomboe; mboendăba na na nggănăp ndăba, ndaningoe pamandjaka na.

Toenanoe bana mătoe ndăba $\mathrm{ka}$, na ana manoe noena na meti ka. Bana meti ka hina piti nja hinggi komboe, na kawoehoekoe ja hina taninja; ${ }^{1}$ toe nja ihi ngaroe na, na toboenja dănga na, ndjara, karămbo'a, wē, kamămbi; na wau na tana.

Toenanoe toera na nja ka paraing, marămba bokoeloe ja ka; hau marămba hau marămba tangara ndăba lai njoena.

${ }^{1}$ hina $\operatorname{taninja}=$ en hij begroef het (kuiken).

Hij geeft aau 't kuiken een begrafenis als aan een mensch; stopt 't een geldstuk in den mond (ihi ngaroe), slacht beesten ter begeleiding in 't hiernamaals (dăngra). 
X. Het Kuiken.

Er was eens een man, welke buitengewoon arm was; zijn slimoet, zijn hoofddoek bereikte hij niet; wat in zijn hand was: slechts twee hennen met kuikens; ieder had zeven kuikens. Des morgens droeg hij de hennen met kuikens en bracht ze naar den tuin; als 't avond was ging hij naar de kampong en droeg de hennen (terug). Zoo deed hij nu iederen morgen en iederen avond, dragende de hennen.

Op zekeren morgen nam hij de hennen en droeg ze. Halverwege gekomen, zag hij twee hagedissen, welke elkander aan 't bijten waren, zij rolden en rolden over elkaar. En hij, die de hennen droeg, zette de hennen neer en keek naar hen, terwijl ze vochten. Toen hij er genoeg van had naar hen te kijken, nam hij een stukje van zijn hoofddoek, welke vol gaten was, en scheurde 't in tweeën en gaf elk (der hagedissen) ieder één stuk, en hij sprekende zeide hij, terwijl hij 't stukje goed naar hen toewierp: "hoort daar! hetzij gij heeren, hetzij gij dames zijt, zijt niet toornig op elkaar, gaat toch uit elkaar.» En zij gingen van elkaar; de hagedissen gingen heen, hij wist hun verblijfplaats niet. En hij, die de hennen droeg, nam de hennen op en droeg ze.

Toen hij in den tuin gekomen was, maakte hij ('t mandje) open voor de kippen; en hij ging onkruid wieden. Toen de zon ondergegaan was, ging hij naar huis; bij 't huis gekomen, keek hij naar de kippen; zij waren reeds in hun mandje gegaan. Hij sloot 't dicht; toen hij 't dichtgedaan had, maakte hij zich klaar en droeg zijn kippen. Halverwege gekomen, op de plaats, waar hij zoo even hen had zien vechten, ontmoette hij twee knapen, jongelingen waren het. En zij zeiden tot hem: "o heer daar, die hennen draagt! zet de hennen eens even neer; kom toch, zegt vader.» Maar hij, die de hennen droeg, antwoordde: "ai ha, ik wil niet; een kat zal misschien mijn kippen grijpen.» En de knapen antwoordden: "als gij hier uw kippen neerzet, zal niemand ze oprapen.»

En hij zette ze neer; zij gingen met hem mee; de knapen zeiden: "hoor onze woorden; als gij straks aankomt, en als 
vader u sirih geeft, kauw dan geen sirih van hetgeen is in een wit mandje, kauw sirih uit een mandje opgeraapt van den grond, een beschimmeld mandje.» Ja, zeide hij. "Als vader u vraagt, zeiden zij tot hem, naar uwe begeerte, als hij dat tot u zegt: alleenlijk 't kuiken op 't offerrekje, zult gij sprekende zeggen; oude mamoeli's, als hij 't u zegt, 't zullen steenen zijn; gouden kettingen, als hij 't u zegt, 't zullen boom-lianen zijn; koperen kettingen, als hij 't u zegt, het zullen boom-lianen zijn; paarden, karbauwen, als hij 't u zegt, moet gij niet willen; als gij die aanneemt, 't zullen mieren zijn en spinnen; alleenlijk wat wij gezegd hebben, 't kuiken op 't offerrekje. Als gij straks bij de deur-opening komt, treed dan in onze voetsporen, er zijn vele nijdige honden.»

En de man volgde 't gesprokene door de knapen. Toen hij er gekomen was, gaf men hem zijn sirih; 't witte mandje wilde hij niet; hij richtte zich naar 't vuile mandje, opgeraapt van den grond en kauwde sirih. Toen hij sirih gekauwd had, zeide de vader der knapen van zooeven: "als gij 't niet geweest was, heer, die mijn kinderen gescheiden had, zoo zouden zij zelf gestorven zijn, daarom, ik zal u een vergoeding betalen; wat is uwe begeerte?»

En de man antwoordde: "dat moet gij (weten), ik zal wel luisteren naar uw mond.» En de vader der knapen sprak tot hem: «ik zal u geven oude mamoeli's, gouden kettingen, gewone mamoeli's, paarden, karbauwen, slaven.» Maar hij antwoordde: «ik wil niet datgene, wat gij opnoemt.» En de vader der knapen antwoordde: "welaan, wat is de wensch van uw hart; vrees niet.» En de man, die de knapen gescheiden had, zeide: "de begeerte van mijn hart is alleenlijk 't kuiken, daarboven op 't offerrekje.» Toen antwoordde de vader der knapen: "als dat zoo zijn moet, heer, dan zal ik sterven, want dat is mijn strottenhoofd, wat gij vraagt.»

Vervolgens nam hij voor hem dat kuiken en gaf 't hem.

Toen hij 't aangenomen had, zeide de man, die (hen) gescheiden had: "Laat ik heen gaan, heer!» De vader der knapen antwoordde: "ga dezen dag maar heen, daar wij nu met elkaar gesproken hebben; als gij pas zijt vertrokken, dan zal ik toch sterven.»

En de man, zijn mede-spreker, ging heen; na korten tijd stierf de vader der knapen. 
Toen hij in den tuin was gekomen, nam hij mais en gaf 't het (kuiken); toen hij 't mais had gegeven, haalde hij 't water en gaf 't het (kuiken). Toen hij 't water gegeven had, trok hij uit de veeren, de staartveeren en de vleugels van het (kuiken) en deed ze in een mand.

Toen hij ze uitgetrokken had, nam hij die kippenveeren en bracht ze buiten de omheining en strooide ze uit.

Toen hij ze uitgestrooid had, werden het paarden, kar= bauwen, geiten, varkens.

Toen hij (zoo) een gedeelte had uitgestrooid, bracht hij 't andere gedeelte naar huis. Thuis gekomen, strooide hij ze uit op de open ruimte (voor 't huis), 't werden menschen, mamoeli's, oude mamoeli's; van alles was er compleet, er ontbrak niets.

Toen alles zoo voltallig was, stierf het kuiken. Toen 't gestorven was, nam hij een gekleurde slimoet voor het (kuiken) wikkelde het er in en begroef het; hij deed 't "geld" in den mond, hij slachtte 't dooden-offers, paarden, karbauwen, varkens, geiten; de aarde stonk. Vervolgens stichtte hij een kampong, hij werd een groot vorst; alle vorsten gehoorzaamden allen aan hem. 
XI. Paraing Madita.

Toenanoe ninja hau na na paraing; ba hīna na toera ja, laloe dangoe ha da oelăroe, oelăroe bokoeloe djoea. Toenanoe hiwăna na tau: "djăka ndaningoe oelăroe na, na hămoe păkoe na na paraingoe jeàna.»

Tăka hi ninja he'au na na oelăr, na pambeli ja tau, hiwăna: "woeloe nja ka bădi oema, djăka wămoe, toboenja karămbo'a rara; lo'a pangădăloe ja na mange'ang la ngaroe mananga, na ratoe bokoel.»

Tăka hiwăna na tau: "ndeta pinja, djăka nggăra ratoe ja; ninja na ratoe, wămoe nda ka, nde pa'ita nja i tau na, nde pa'ita nja i oema na.» Tăka na heàma na oelăroe: "pa'aunja, hiwănggoe, pajépoe nja ba nde pa'ita nja tau na.»

Toenanoe hina beli ja na tau la oema, hina lakoe pahimboe

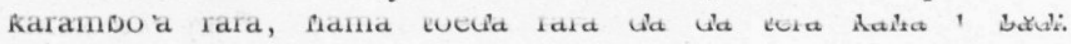
Toenanoe ndena hoenggoe ndokoe; oela na nja ka, na pălăkoe ${ }^{2}$ la hau paraing hau paraing. Tăka hina beli ja la oema hina hili lo'a, hiwăna: "ndewa paraing pawoewang wiki moe!»

Toenanoe hina pawoewang wiki na, hama toena na tau.

Toenanoe bana ita ja ka, hiwăna: "ndakoe hoenggoe karămbo'a rara.» Tăka hiwăna na oelăr: "djăka toenanoe ba ndau hoenggoe, oe mai kau, kau ngăndi wē dăngoe kamămbi, ba ndau toăma ${ }^{3}$ ja na papeàka nggoe; djăkau hăla ka pahoendjoe, kau woeloe nja oema na; djăkau hăla ka pawoeloe nja oema na, kakoe peàka ndja da ahoe nggoe, kada pajilang dăngoe njoengga, kakoe lakoe la hau kandjoănga, kakoe pamaœngoe + ningoe. Koe peàka nggau njoengga na hoeri na na paraingoe jeàna; djăka madau moe nja: " $\mathrm{madau} \mathrm{nggoe} \mathrm{nja}$ ", ămboe wămoe - "na malara na nggoroe nggoe», wămoe be

\footnotetext{
1 tera $\mathrm{kaha}=$ rood goed. Dit $\mathrm{kaha}$ is een verbastering van Makassar, dat een Soembanees uitspreekt als Makaha.

${ }^{2}$ pálăkoe= van de eene kampong naar de andere kampong trekken, van landschap tot landschap.

3 toă $\mathrm{ma}=$ vergelijk aanteekening 1 verhaal $\mathrm{X}$.

4 pamaøngoe = zich in de schaduw ophouden (gelijk slangen bij voorkeur doen).
} 
$a^{5}$. Djăkau hăla ka pa'oenoeng wai: "djăka nggoe ka» ămboe wămoe - "na pa tai», wămoe be ă.

Djăkau ngangoe, djăkau mbihoe ka: "koe mbihoe ka», ămboe wămoe - "napa kadirce», wămoe; "koe mbihoe ka», djăka wămoe bau hăla pangangoe, na woendoe haní na na kamboe moe.

Maweling la tehik, ijang, ămboe wămoe - "malara», wămoe. "Malara», djăka wămoe, na hămoe be; "ijang», djăka wămoe, bau tiki ndja tamoe da, da pambeli ha kataroe moeroe.

Na mehing - kapoe, wămoe nja; na kapoe - hihoe, wămoe nja. Kapoe, djăka wămoe nja, na pambeli ja tana koemboer. Djeà ja, hiwănggae nggau, ămboe maroămbanja: hinggi komboe, ămboe tinoeng lai jehoe; djăkau tinoeng ka, da oelăroe da mareni, da woendjoeloe nggămoe; hinggi bara dăngoe hinggi miting kau tinoeng. Hau ndaung ămboe maroămbanja pa'oehoe ${ }^{6}$ ja na paraing: wē mbălang dăngoe manoe hoerătoe. Djăka ningoe mamai pabera kau, ămboe na măka.»

Toenanoe paheàwa da nja ka; lakoe na nja ka la oema; na kanandi ma nja na papeàka na na oelăroe. Toenanoe hina woeloe nja oema na; bana hăla ka pawoeloe nja oema na, hina pa'oehoe ja hau ndaung hau ndaung.

Toenanoe hi ninja na Mahoe, na mamai pabera ja; bana tăka ka la paraingoe noena, bana tăka la pindoe, da kapătang da mata na mboendăba na na tau. Tăka hina beli ja; bana beli ja, ndena pinja ngarángi'a na, na tama ja la oămang; bana tama ja ka la oămang, na napa ja oelăroe, na woendjoeloe nja, na pamboeta ma ja; ndaningoe haätoe mabeli.

Toenanoe mahări ja, hiwăna nja; na ngara na Parai Madita.

s Dit verwisselen van namen, bij verschillende volkeren meer voorkomend, wordt hier ontleend aan 't bevel van den kampong-geest, die in een slang geïncarneerd is. Door zijn woorden op te volgen, zal men er rustig en zonder schade kunnen leven.

't Verwisselen van de hier genoemde woorden vindt men ook te Wai mbidi in Mahoe. Deze menschen komen oorspronkelijk van Parai Madita. Tegenwoordig laat men echter veel van die dingen na en gaat kalmpjes zijn gang.

Een algemeen gebruik is echter bij ,'t dorschen van de padi, als men de rijst in de manden doet en 't dan opneemt, mag men niet zeggen : mbotoe (zwaar), maar moet men zeggen: "n a mbădi" ('t jeukt.).

${ }^{6} \mathrm{pa}$ ' o ehoe= rïst geven, offeren. 
XI. Paraing Madita.

Er. was eens een kampong; toen men die pas stichtte, waren er zeer veel slangen, uitsluitend groote slangen. Toen zeiden de menschen: "als er hier geen slangen waren, zou werkelijk goed zijn deze kampong.»

Er was nu een slang, hij veranderde in een mensch en zeide: "men moet hem een huis bouwen, als gij dat zegt, slacht dan een roode karbauw; ga opzoeken hem, die woont bij de riviermonding, den grooten priester.»

Maar de man zeide: "wij weten niet, wat voor priester 't is; de priester is er, zegt gij ons, maar zijn lichaam wordt niet gezien, zijn woning wordt niet gezien.»En de slang antwoordde: "roep hem, zeg ik, wenk hem (met de handen), daar zijn lichaam niet gezien wordt.»

De man keerde nu terug naar huis en ging zoeken een roode karbauw, 't moest rood zijn, als 't rood van Makassaarsch goed.

$\mathrm{Hij}$ vond 't echter heelemaal niet; hij had er genoeg van, te bezoeken elke kampong. Toen keerde hij terug naar huis en hij ging wederom en zeide: "geest der kampong vertoon u zelven.»

En hij vertoonde zich zelven, gelijk een mensch. Toen hij hem zag zeide hij: "ik heb geen rooden karbauw gevonden." En de slang zeide: "als 't zoo is, dat gij 't niet vindt, kom dan en breng varkens en geiten, daar gij mijn bevel niet kunt volbrengen; als gij geslacht hebt, maak hem dan zijn huis; als gij hem zijn huis gemaakt hebt, dan zal ik mijn honden bevelen dat zij en ik op zij gaan, dan zal ik gaan naar een ander dal en er in de schaduw vertoeven. Ik zal u nu zeggen de adat van deze kampong: als gij dorst hebt: "ik heb dorst», moogt gij niet zeggen: "mijn keel is brandend heet», moet gij maar zeggen.

Als gij water gedronken hebt: «ik heb genoeg», zult gij niet zeggen; "strakjes», moet gij maar zeggen. Als gij eet en verzadigd zijt: "ik ben verzadigd", zult gij niet zeggen; "wacht even», zult gij zeggen; "ik ben verzadigd», als gij dat zegt na 't eten, dan zal uw buik voortdurend opgezwollen zijn. 
Wat uit de zee komt, zult gij geen "visch» noemen; "brandend heet», zult gij zeggen. Wanneer gij zegt: "brandend heet», dan zal 't goed zijn; maar als gij "visch» zegt, terwijl gij hun namen opnoemt, dan zullen zij veranderen in adders.

Tot 't "zout», zult gij "kalk» zeggen; "kalk» zult gij "schelp» noemen. Wanneer gij 't "kalk» noemt, zal 't veranderen in stof. Dit is 't, zeg ik u, vergeet 't niet: gekleurde slimoets zult gij hier niet weven; als gij ze zult weven, zullen de slangen nader bij komen en u omkronkelen; witte slimoets en zwarte slimoets zult gij weven. Telken jare zult gij niet vergeten aan de kampong te offeren: een gevlekt varken en een bonte kip. Wanneer u iemand komt beoorlogen, zal hij niet vermogen.»

Zij gingen nu van elkaar; hij ging naar huis; hij overdacht 't gesprokene door den slang. Hij maakte hem zijn huis; toen hij hem zijn huis gemaakt had, offerde hij hem ieder jaar.

Er waren eens -menschen van Mahoe, die hem kwamen beoorlogen; toen zij bij die kampong gekomen waren, genaderd bij de deur, werden verduisterd de oogen van al die menschen. Men keerde terug; toen men terug keerde, wist men den weg niet meer; men ging een bosch in; toen men 't bosch ingegaan was, wachtten hen de slangen op, zij omkronkelden hen, zij maakten ze allen dood; niet één keerde terug.

't Is een heilige plaats, zeide men er van; haar naam is Paraing Madita. 


\section{Ndéwa rândjang.}

Nindja da tau madoea; haatoe kawini, haatoe mini; hida pa'ana ndja da anakeada mini, madoea haattoe da. Toenanoe híwăna na ama da, bada matoea ${ }^{1}$ ka: "nínja na pingi ai na ndewa rằndjănggoe ${ }^{2}$ njoengga, kai lo'a pajăpa ja, kana wơnggămi pambiha wăngoe.

Toenanoe hina paleàwa woenga ja na mama'aja, lakoe panapa wănja roedoeng. Toenanoe hina lakoe; bana tâka ka la pingi ai, mbăda maling na ka. Toenanoe hina pawăla ja bana dai ja; na oela ja papateànja; ndaningoe ndokoe makatikoe. 3 Mahoeroe na nja ka, loepa harí na. Toenanoe bana hari ka, hi lakoe na nja la oema; bana tăka ka la oema hiwăna na ama na: smála ndau pawăla kamodoe 4 la mandalora?s 5 Tăka na heàma na ana na: "oela nggoe papateànja, ndakoe rongoe ndokoe makatikoe; toenanoe hikoe mahoeroe loepa harí na, hi pamai nggoe nja nămoe. Tăka na heàma na ama na: «ndau patoetoeng na papeàka nggoe, tama kau la loemboe mboămang ».

Toenanoe na hili paleàwa ja na haätoe; hina lakoe. Toenanoe bana tăka ka la pingi ai noena, roedoeng na ka; na pateà dira dira nja, laloe tătikoe ja; mahoeroe na nja ka loepa harí na. Toenanoe bana harí ka, lakoe na nja ka la oema. Toenanoe

1 matoea =oud; den huwbaren leeftijd bereikt hebben; rijp zijn (van vruchten.).

" ndewa răndjăng, is 't best te vertalen door "geleide-geest", welke speciaal over iemand waakt. Uit dit verhaal blijkt, dat 't hier de ziel van zijn overleden vader is, de grootvader der kinderen. Hij wordt echter genoemd Meo $\mathrm{Roemba}$, waaronder men verstaat een soort bosch-geesten, in ruw behaarde mensehen-gestalten zich soms vertoonende.

Een eigenaardige vermenging van geest en ziel dus.

${ }^{3} \mathrm{katikoe}=$ ritselend, knappend geluid.

$4 \mathrm{kamodoe}=$ gepasseerde nacht.

Dit "modoe" komt nog voor in doea modoeng=over twee dagen (nachten), tiloe modoeng etc.

In verschillende dialecten is mă doeng 't gebruikelijke woord voor "nacht", in 't Kamberaasch "roedoeng".

${ }^{5} \mathrm{mand}$ alora $=$ middernacht.

Men vindt nog: "talora"=open ruimte tusschen de huizen. In 't verwante Savoeneesch is tĕlora $=$ midden, midden in. 
bana tăka nja na ama na: măla! Na heàma na ana na: "oela nggoe papawăla ja, kē mandalora tătikoe nggoe nja ka, hikoe mahoeroe; bana harí ngga ka, pamai nggoe nja ka nămoe; nde nggăra parongoe nggoe, nde nggăra pa'ita nggoe. » Hiwăna na ama na: "ndau pawăla la marai romoe marau?» 1 "Nde'a!». "Ndau patoetoeng bakoe papeàka nggau, batoenanoe tama kau la loemboe mboămang dăngoe aja moe; măta kakoe paleàwa ja na haätoe.»

Toenanoe hina paleàwa ja na haätoe, na mama'eri. Toenanoe lakoe na nja ka la maling; bana tăka ka lai noe, bana roedoenja ka, tăka hina pawăla ja, na piti weli hoe kálitoeng ${ }^{2}$ loepa marai romoe marau ja. Toenanoe bana marai romoe marau ja ka hina poeroe ja na Meo Roemba; bana poeroe ja ka, na napa ja, na jăpa ma ja. Hiwăna njoena na $\mathrm{Meo}$ Roemba: "nggamoe kau ka năhoe mapajăpa?» Na heàma na anakeàda : "njoengga! oemboekoe moe ngga, padeàkam ${ }^{3}$ ămang, ba hīna koe dedi.»

Toenanoe hiwăna na Meo Roemba: poeli ngga. Na heàma njoena na anakeàda: nde'a, wăna. Tăka na heàma na $\mathrm{Meo}$ Roe mba, hiwăna: "nggara pakarai moe?» "Wongga pambiha wăngoe» "Kanggiki nggoe bakoe wŏnggau?» Na heàma na anakeàda: "wăngoe pakokoeroe ${ }^{4} \mathrm{ka}$, kana kadjilăkoe ndăba na ihi nggoe, hama toena na ămăhoe rara.»

Toenanoe hina kokoeroe ja; bana hăla ka pakokoeroe ja, hiwăna njoena na Meo Roemba: "djăka ningoe na mapameti kau, koe lo'a papahada beli nggau.» Toenanoe harí na nja ka, hina măngoe papoeli nja. Toenanoe lakoe na nja ka la oema; tăka na ama na, talănga mandapoe na la bangga, hi ita be na nja ana na, hama toena na handoărăkoe na na epi. Toenanoe

1 marai romoe mara $u=a l s$ de morgenstond nog verre is.

rai=zijn, (in West-Soemba.). rai malé=tegen den avond. romoe vindt men in haromoe= morgen.

${ }^{2} \mathrm{ká}$ litoeng = avondschemer, vóór 't geheel donker is.

't Voorgevoegde hoe duidt een beweging aan; evenals in hoedita $=$ naar boven; hoewaw a = naar beneden.

${ }^{3}$ deàka $=$ 't raden van een naam voor een pas geborene.

De zielen der voorouders zijn daarbij ongeziene getuigen en noemen bij elken naam, welken de menschen raden, een voorspelling of bedreiging, duidende op 't lot dat den pas-geborene wacht.

${ }^{4}$ kokoeroe=klappernoot; iemand met klappernoot inwrijven. (een geliefkoosde Soembaneesche gewoonte.) 
bana ita ja ka, hina palai ja, hina hamboeroe ja, hina loenggoe ja, hina hē ngăndi ja la oema, hina pawălăhoe nja topoe kamba, ${ }^{1}$ hina pamandapoe ja, hina karai ja: măla, nggăra pa'itam?

$\mathrm{Na}$ heàma na ana na: "haätoe na na makaweàda, ba hīna na poeroe, hama toena na doeroe epi; na loendoeng la tana, na moenang.» Toenanoe bana moenang ka, mandai ki ka hakoedoe, hama toena na dandăk ${ }^{2}$ bokoeloe na; tăka hikoe jăpa weli lima nja; bakoe jăpa ja ka hiwăna: "ka nggamoe kau năhoe mapajăpa ?» Koe heàma doekoe njoengga, hiwănggoe: "njoengga, oemboekoe moe.» Toenanoe ba wănggoe nja ka: poeli ngga, hiwăna. Koe heàma doekoe njoengga, hiwănggoe bakoe paní: "wŏngga kadiroe pambiha wăngoe.» Tăka na heàma doena njoena: "kanggiki hama wŏnggoe nggau pambiha wăngoe?»

Hiwănggoe bakoe heàma nja: "kokoeroe ka, kana kadjilăk ndăba na ihi nggoe, hiwănggoe nja.» Toenanoe hina kokoeroe ka; toăma na nja ka na harí; tăka hikoe pahăla nja hikoe pamaingoe nămoe.»

Na heàma na ama na, hiwăna: "hau mini kau, bau patoetoeng na papeàka nggoe njoengga; djăka nida păkoe, da mange'ang la loemboe mboămang, ndeda patoetoenja na papeàka nggoe njoengga; ba toenanoe pangangoe ămboe worndja, wai ămboe wŏndja, măta kada meti rimbang.»

Mandai-ndai ba laloe mandjoé ha ka, hida palai ha la woekoe oămang. Toenanoe bada palai ka, tăka njoena na mama'eri na ita ndjăpoe ka bada palai; ${ }^{3}$ tăka njoena hina poeroe ja, hina kikoendja. Toenanoe bana kikoendja ka, tăka la woekoe oămang, hiwăna njoena: "ha aja, napa ta doeta, ămboe palai wăroe nda.» 4 Toenanoe hida napa ja; bada napa ja ka hida jăpa ja, da poeha ja la hoemoer.

Toenanoe palai da nja li la hau kandjoănga. Tăka noena

1 topoe $\mathrm{kamba}=$ eigenaardige samenstelling van topoe=mat, en $\mathrm{kamba}=$ kapok; men bedoelt er mee een kleine bultzak.

2. dandăk=een van rottan gevlochten mand, 土 1.50 M. hoog en soms van zoo'n omvang, dat geen drie mensehen 't omspannen kunnen. Men bewaart er maïs of padi in.

s na ita ndjăpoe ka bada palai $=$ hij zag 't pas, toen zij al gevlucht waren. (ndjăpoe = geëindigd.)

4 ămboe palai wăroe $\mathrm{nda}=$ vluchtende laat mij niet alleen.

Een dergelijke samenstelling is meti wăroeng=door den dood achterlaten. 
na anakeàda na loeri beli ja; na namătoe ha, na ita marau ha; tăka hiwăna: "ha aja, napa ta.»

Toenanoe hida napa ja; bana toăma ndja ka, hida jăpa ja, hida hondoe ha da wihi na, da lima na; hida boeta nja roemba, ${ }^{1}$ hida paboendoenja, hida toenja epi. Toenanoe bada hăla ja ka, palai da nja ka; noena na anakeàda na kăra mboe-mboehoe la epi. Toenanoe bada marau $\mathrm{ka}$, hina hadang beli na anakeàda; na hili namătoe ha; bana ita marau ha, hiwăna: "ha aja , napa ta.»

Toenanoe hida napa ja; bana toăma ndja ka, hida danda ndja, da ndoeha ja la keàla; ${ }^{2}$ meti na nja ka na anakeàda. Tăka njoeda palai da nja ka la hau kandjoănga.

Toenanoe bada marau ka, tăka na nja ka na ăpoe na, na mawŏnja pambiha wăngoe, hina pahada beli nja.

Toenanoe bana hadang ka, lakoe kareà na nja ka. Toenanoe bana ita marau ha, hiwăna: "ha aja, napa ta.»

Toenanoe hida napa ja; na makaweàda ndeda ita ja, didi jang na anakeàda na pa'ita da. Toenanoe bana toăma ndja ka, hiwăda: "măta kata jăpa ja, kata hondoe ja, kata pakădăki nja la pingi ai, kata măta nja.»

Toenanoe hida jăpa ja; bada hondoe ja la pingi ai, tăka na makaweàda hina jăpa ha da anakeàda noeda da makadjălikoe eti da, hina hondoe ha. Toenanoe bana hăla pahondoe ha, hina ndoeha ha la hoemoer. Tăka hina beli ja hina wăkăhoe ja na anakeàda noena na pahondoe da. Toenanoe bana hăla ja ka pawăkăhoe ja, hina kareà beli nja la pange’a pakokoeroe na nja. Tăka hiwăna nja: "lakoe wa la oema.»

Toenanoe hina lakoe la oema; bana tăka ka la oema, na hē la bangga, hiwăna: "ha ina!» Ndaningoe maheàma.

Tăka na hē la kaheli: "ha ama!» Ndaningoe maheàma. Toenanoe hina poeroe beli ja; lakoe na nja ka hina tama la patóe na. ${ }^{3}$

1 hida boeta $n$ ja roemba= zij rukten gras uit, met ' $t$ oog op hem, voor hem. (Een datief-constructie veel voorkomende).

${ }^{2}$ keàla $=$ de steile helling van een ravijn; ook 't ravijn zelf.

${ }^{3}$ na tama la pat ó e na $=$ hij verdween voor altijd.

Een verklaring van "la patoé na" is mij onbekend.

Men gebruikt deze uitdrukking steeds van menschen welke spoorloos verdwijnen. Hun verdwijnen schrijft men dan toe aan geesten, want anders had men tenminste toch een spoor moeten kunnen ontdekken! 
XII. De geleide-geest.

Er waren eens twee menschen; één vrouw, één man; en zij baarden drie jongens. En hun vader zeide, toen zij groot geworden waren: "er is een boom van mijn geleide-geest, gaat hem vangen opdat hij u wondermacht geve.»

Hij zond nu eerst den oudste om hem des nachts op te gaan wachten. Hij ging en bij den boom gekomen, was 't reeds avond.

En hij bleef wakker, terwijl hij oppaste; hij had genoeg van 't wachten; er was heelemaal niets dat bewoog, Slapen ging hij, totdat 't licht werd. Toen 't nu licht geworden was, ging hij naar huis; thuis gekomen, zeide zijn vader: "welaan was gij van nacht ter middernacht wakker?» Maar zijn zoon antwoordde: "ik had genoeg van 't wachten, ik hoorde heelemaal niets bewegen; aldus ging ik maar slapen tot 't licht werd en ik kwam hier." Maar zijn vader antwoordde: "gij hebt niet gedaan, wat ik gezegd heb, ga onder 't huis!

Wederom zond hij een ander; en hij ging. Bij den boom gekomen, was 't al donker; hij wachtte zonder einde, hij werd zeer slaperig; en hij sliep tot 't licht werd. Toen 't licht geworden was, ging hij naar huis. Toen hij bij zijn vader gekomen was (zeide deze): welaan! Zijn zoon antwoordde: «ik had genoeg van 't wakker blijven, 't was ongeveer middernacht dat ik slaperig werd en ik sliep; toen 't mij licht was geworden, ben ik hierheen gekomen; er is door mij niets gehoord en niets gezien.» En zijn vader zeide: "was je niet wakker van morgen heel vroeg?» "Neen.» "Gij gebt niet gedaan wat ik je gezegd heb, daarom ga onder 't huis bij je broeder; laat mij den andere zenden.

En hij zond den andere, den jongste. Hij ging des avonds heen; daar gekomen, terwijl 't reeds nacht was, bleef hij wakker, hij deed 't van toen 't pas donker werd tot 't heel vroeg in den morgen was. Toen 't nu heel vroeg in den morgen was, kwam de Meo Roemba naar, beneden; toen hij naar beneden kwam, wachtte hij hem op en greep hem vast. En de Meo Roemba zeide: "wie zijt gij nu, die mij vast 
grijpt?» De knaap antwoordde: "ik! ik ben uw kleinzoon, door u een naam gegeven, toen ik pas geboren werd.» En de Meo Roemba zeide: "laat mij gaan.» De knaap antwoordde: neen, zeide hij. En de Meo Roemba antwoordde en zeide: "wat wordt door u gevraagd?» "Geef mij wondermacht.» "Hoe zal ik 't u geven?» De knaap antwoordde: "door mij in te wrijven, opdat geheel mijn lichaam schittere als goud.

Hij wreef hem in; toen hij hem ingewreven had, zeide de Meo Roemba: "als er iemand is, die u doodt, zal ik u weder komen opwekken.» 't Was nu licht, geworden en toen pas liet hij hem gaan. Hij ging nu naar huis; en zijn vader zat juist in de voorgalerij en hij zag zijn zoon, als 't schitterend schijnsel van vuur. Toen hij hem zag, liep hij snel en ging hem tegemoet en omarmde hem en bracht hem in huis en spreidde voor hem een matras en deed hem neerzitten en vroeg hem: welaan, wat hebt gij gezien.

En zijn zoon antwoordde: "een oude man, toen hij pas naar beneden kwam, was hij als de vlam van 't vuur; hij kwam geheel op den grond en hij verdween. Toen hij verdwenen was, na verloop van korten tijd, was hij zoo groot als een groote mand; toen greep ik hem bij zijn hand; toen ik hem gegrepen had, zeide hij: "wie zijt gij nu, die mij vast grijpt?» Ik antwoordde en zeide: "ik, uw kleinzoon.»

Toen ik 't hem gezegd had: laat mij gaan, zeide hij. Maar $\mathrm{ik}$ antwoordde en sprekende zeide ik: "geef mij eerst wondermacht.» Maar hij antwoordde: "hoe moet ik u wondermacht geven?" Hem antwoordende zeide ik: "wrijf mij in, opdat mijn geheele lichaam schittere, zeide ik tot hem.» En hij wreef mij in; hij deed 't tot het licht werd; vervolgens liet ik hem los en kwam hier.»

Zijn vader antwoordde en zeide: "je bent een kerel, daar gij gedaan hebt, wat ik gezegd heb; maar wat dezen betreft, die daar onder 't huis zijn, zij hebben niet'gedaan, wat ik zeide; daarom geef hen geen eten, geef hen geen water, laat ze van honger omkomen.»

$\mathrm{Na}$ langen tijd, daar zij ergen honger hadden, vluchtten zij naar 't dichtte van 't bosch. Toen zij vluchtten, zag de jongere broeder, terwijl zij reeds gevlucht waren; vervolgens ging hij naar beneden en volgde hen. Toen hij ze gevolgd had en gekomen was in 't dichtte van 't bosch, zeide hij: broeders, 
wacht toch op mij, laat mij door uw vlucht niet alleen.»

$Z_{i j}$ wachtten op hem; toen zij op hem gewacht hadden, duwden zij hem in een put.

Weer vluchtten zij naar een ander dal. Maar die knaap kwam weer in 't leven terug; hij speurde ze na en zag ze van verre; en hij zeide: "broeders, wacht mij.»

$Z_{\text {ij }}$ wachtten op hem; toen hij hen bereikt had, grepen zij hem en bonden zijn voeten en zijn handen; en zij trokken voor hem gras uit en stapelden 't voor hem op en staken 't in brand. Toen zij dat gedaan hadden, vluchtten zij heen; die knaap was geheel verschroeid en verbrand in 't vuur. Toen zij ver weg waren, stond de knaap wederom op; hij speurde ze wederom na; toen hij ze van verre zag, zeide hij: «broeders, wacht mij.»

En zij wachtten op hem; toen hij ze bereikt had, namen zij hem op en wierpen hem in een afgrond; de knaap stierf. Maar zij vluchtten heen naar een ander dal. Toen zij ver weg waren, kwam daar zijn grootvader aan, die hem wondermacht had gegeven en hij deed hem weer opstaan.

Toen hij opgestaan was, ging hij met hem mede. Toen hij ze van verre zag, zeide hij: "broeders, wacht mij.» En zij wachtten op hem; den oude zagen zij niet, alleen de knaap werd door hen gezien. Toen hij hen bereikt had, zeiden zij: «laten wij hem grijpen en hem binden en hem vast maken aan een boom en hem achterlaten»

En zij grepen hem; toen zij hem aan den boom gebonden hadden, greep de oude die knapen, stout van hart en bond ze. Toen hij ze gebonden had, wierp hij ze in een put. Toen keerde hij terug en maakte dien knaap, door hen gebonden, los. Toen hij hem losgemaakt had, bracht hij hem weer naar de plaats, waar hij hem ingewreven had. En hij zeide tot hem: "ga maar naar huis."

Hij ging naar huis; thuis gekomen klom hij in de voorgalerij en zeide: "ha moeder!» Niemand antwoordde. Hij klom in huis: "ha vader!» Niemand antwoordde. Hij klom nu weer naar beneden; hij ging heen en verdween voor altijd. 
XIII. Na tandánoe.

Toenanoe na pakiri na; handăka na nindja da ata marămba, da doea; ana mamila ha. Toenanoe hiwăna ndja: lakoe wa la woăka, kai boeta roemba; djăkai hăla ja ka, kai beli kămi la paraing.

Toenanoe lakoe da nja ka; bada tăka ka la woăka hida tăngăroe ja na woăka, hiwăda: kanggiki boeta nda nja jeà na roemba, ba laloe timbi ${ }^{1}$ ma ja; hakamboeloe roedoeng ndedi ta hăla ja, wăda bada paní; 'djăka toenanoe, măla kata palai, talakoe lai toeja hoepapa la hapapa tana».

Tăka hina heàma na kareà na: "ka nggăra wăngoe teàna kata hē?» Tăka na heàma na haätoe: "kakoeta kăloé, kata lo'a patarăba ja, kata ngăndi ja la wai; djăka ta băndjăloe la wai, djăka na halinding, kata hē nja kata mandapoe pahămoe hămoeng la koeroe ${ }^{2}$ na.»

Toenanoe hida lakoe hida ita ja hareti na na kăloé, na mabidi wili; hida piti ja na hawăla. Toenanoe bada piti ja ka hida ngăndi ja; bada tăka ka la lokoe hida băndjăloe ja la wai; na halinding. Hiwăna na haätoe: "ná, ba wănggoe, ai ha, koe mbiha ka i doekoe, ai!»

Toenanoe hē da nja ka; bălang da ndaningoe. Toenanoe na mili-mili na kakoeta kăloé, loepa na tăka la tehikoe; bada tăka ka la tehikoe, na toengoe na ngiloe dăngoe na ngaling, na tiki patamboeloe ${ }^{3}$ ka ă mang.

Toenanoe hi ninja na tandanoe ${ }^{4}$, hama toena na noeha; bada ita marau ja, hiwăda: "pareànggang bata boehi, kata toăma ja na noeha noena.» Toenanoe hida boehi; bada toăma ja ka hida pahadiding wiki da, ${ }^{5}$ hida hē. Toenanoe bada he

1 timbi=dik; dicht op. elkaar.

${ }^{2}$ koeroeng $=$ een afgesloten ruimte; kamer; kajuit.

${ }^{3}$ na tiki patamboeloe $=$ zij zou bijna gezonken zijn.

tiki= bijna iets doen.

"tandanoe= walvisch; eigenlijk "potvisch"; wordt soms op 't strand gespoeld.

s hida pahadiding wiki da=zij brachten zich langs zij.

hadidi=zijde, kant. 
ka, na kakoeta na pakaliti da, na mili ka; na ngeri marau-rau; tăka hiwăda: "kanggiki ă nda ka, na mili ka na teàna nda? ta ngeni, wănda, ndeta pingoe pangeni.

Toenanoe mandai ki ka hakoedoe, tăka hiwăda: "meti rimbang nda nja ka njoeta.» Tăka hina heàma na tandánoe, hiwăna; "tăba la karaha nggoe, ningoe oehoe tai; tăba la papoe nggoe, na dedi toloe we tai.» Toenanoe hida tăba la karaha na, tăka hida hili tăba ja na papoe na, na dedi ja oehoe, na dedi ja toloe wē. Toenanoe ngangoe da nja ka; bada hăla ka pangangoe hiwăda: "na noeha jeàna na pingoe papaní, na mbiha mboe, djeà ningoe be ja mamemi.»

Toenanoe ba hăla ka pawăda, ${ }^{1}$ lakoe na nja ka na tandánoe; tăka hiwăda: na opoeng, djeà ngga mo! Ba hăla ka pawăda, ndena păndjang ndokoe, la-lakoe be na nja na tandánoe hau roedoeng hau lodoe na. Toenanoe hiwăda: "é ha, meti mboeta ${ }^{2}$ nda nja ka, ba tandánoe be ja, na hoăba hăla ta ka.» Tăka na heàma na kareà na: "măla wa njoena, meti ki ka doena, pakarai ma nda nja.»

Toenanoe mandai ka năhoe hida ita ja hau na na noeha, hiwăda: "mili Marapoe ki, ${ }^{3}$ kana palakoe li nda, kana papoeroe ni nda lai ni.» Toenanoe palăngang hau lodoe hau roedoeng, tăka na nja ka la ngaroe mananga, hiwăna njoena na tandánoe: «ba tăka dimi nja lai jehoe, poeroe wa». Toenanoe hida poeroe, bada poeroe ka, hiwăda: "ha ăpoe tandanoe, pangama ndaningoe.» $\mathrm{Na}$ heàma na tandanoe: "hē haätoe kana lindi ngga * kada loehoe oehoe la karoeng. " 5 Toenanoe hina hē hina lindi nja. Bana beli ja ka, mbăda ninja ka oehoe la karoeng la mamara.

1 ba hăla ka pawàda = toen zij 't gezegd hadden.

wăda = hun zeggen; 't verbaal substantief wordt geconstrueerd als zuiver verbum met $\mathrm{pa}$, afhankelijk van 't voorgaande verbum $\mathrm{hăla}=$ met iets klaar zijn.

$2 \mathrm{meti} \mathrm{mboeta}=$ sterven zonder nageslacht.

$\mathrm{mboeta}=$ uitgerukt; uitgeroeid.

3 mili Marapoe $\mathrm{ki}=$ als 't een Marapoe is (beschermgeest en geen gewone walvisch!)

De walvisch is de incarnatie van één der voorvaderen, welke aldus zijn nageslacht helpt en rijk maakt. Gelijk ook blijkt uit hun aanspraak: ăpoe tandánoe= grootvader walvisch!

4 kana lindi $\mathrm{ngga}=$ in de lengte over mij heen loopen; mij als een lindi d.i. brug, verbindingsweg gebruiken.

${ }^{5}$ oehoe la karoeng = rijst in een zak; een zak rijst.

Zoo zegt men ook: oehoe la mboăla=en mandje rijst.

Het woord "karoeng" is ontleend aan "karong" $=$ zak. 
Toenanoe hiwăna na tandanoe: "măta kakoe lakoe wa doekoe la pange'a nggoe». Toenanoe lakoe na nja ka.

Tăka da tau noeda hiwăda: "nggăra ka ihoe la hau karoeng, ndjăra-ndjăra i da bakoe mandapoe ndja?» Tăka hiwăna na angoe na: "măla pa kata tăngăroe ha, djăka nggăra ha.»

Toenanoe hida loăla ja na ngaroe na na karoeng hida ita ka noedaloe: ămăhoe rara ha hawiang, ămăhoe bara ha hawiang.

Tăka hiwăda: "oera ma nda, la oera ana manoe, ${ }^{1}$ eti ma nda, la eti ana wē, bata ngalang marara, mabara: ta woeloe ka haromoe, nggăra pakarai nda pa.»

Toenanoe hi ninja haätoe na na tau, na malo'a padjala, ${ }^{2}$ hiwăna ndja: "kai jeà, nggi lakoe nlngoe mi nja?» Tăka da heàma njoeda: "lakoe ma nja lai toeja ${ }^{3}$ Tăka na heàma njoena na tau: "ka nggamoe toeja?» Tăka da heàma njoeda: "lai toeja Lăki andoeng.»

Tăka na heàma njoena na tau, na malo'a padjala: «lai toeja Lăki andoeng, wămi?» Tăka da heàma njoeda: "wŏ hí! lai toeja Lăki andoeng, wăma doe.» Tăka na heàma njoena na tau: "njoengga jeà, ana na I Lăki a ndoeng ka». Tăka da heàma njoeda: "mădja ka toena, djăka ama doe moe nja, măla wa kata kareàngoe la oema» .

Toenanoe kareàngoe da nja $\mathrm{ka}$; da doekoe ha da banda da.

Toenanoe bada tăka ka la oema, hiwăna măngoe oemang: "nggamoe ha heàna?» Tăka na heàma njoena na makareàndja "tau la hapapa tana ha.» "Ka nggăra padangga da?»

Da heàma njoeda: "nde'a, nda nggăra ă padangga ma ; pamaingoe ma nja lai toeja, wăma.» Hīna ka, hina poeroe la

1 oera ma nda, la oera ana manoe='t was onze lijn, in de lijnen van een kuiken.

oera = zenuw, pees, lijn, voorteeken. Uit de lijnen van darm en lever makt men iemands lot op; daaruit leest men de toekomst, welke den mensch te wachten staat.

Deze uitdrukking, evenals de volgende „eti ma nda"... wil dus zeggen: 't was ons bestemde lot, onze goede fortuin, dat wij zouden vinden 't roode (goud) en 't witte (zilver.)

${ }^{2}$ na malo'a padjala $=$ die ging visschen met een werpnet.

$\mathrm{djala}=$ werpnet.

${ }^{3}$ to eja $=$ oom, vader van mijn moeder.

De adat eischt dat iemand trouwt met een kind van zijn toeja. Heeft deze geen kinderen, dan moet hij toch uithuwelijken de kinderen van zijn zuster. 
bangga njoena I Lăki andoeng, hiwăna: "ka ngga kămi jeà ?»

Toenanoe da tau madoea: I Pinang ${ }^{1} \mathrm{ka}$, wăna ka na haätoe; na haätoe hama. Hiwăna I Lăki andoeng: «djeà ja na ngara na na ama nggoe, heàna na patiki moe.» Toenanoe hiwăna: "mili toedoe na nja njoena, kai pamaingoe lai jehoe; djăka ningoe doe nggoe, koe ndăni kămi ka la mboăla, koe tapoe kămi ka la tera; ${ }^{2}$ palérangoe ka woăka, wănggoe nggămi ka doena, la pambeli ndaung, la pandjiloe woelang* ${ }^{3}$

1 I Pinang = wij zouden zeggen: N.N.

2 koe ndăni kămi ka la mboăla,

koe tapoe kămi ka la tera...=manden zal ik voor u op elkar zetten en goed op elkaar leggen.

Hij heeft vroeger zijn zuster (hun moeder) uitgehuwelijkt. (manden met goudwerk en kleedingstukken gegeven). Hetzelfde zal hij nu ook doen voor haar kinderen.

3 la pambeli ndaung,

la pandjiloe woelang =als 't jaar verandert, als de maan verwisselt; d.w.z. na verloop van tijd; een volgend jaar. 
XIII De walvisch.

Aldus was 't begin; vroeger waren er eens twee slaven van een vorst; 't waren weezen. En hij zeide tot hen: ga maar naar den tuin en wiedt onkruid; als gij er mee klaar zijt, komt dan terug naar de kampong.

$\mathrm{Zij}$ gingen heen; in den tuin gekomen, bekeken zij den tuin eens en zij zeiden: hoe moeten wij dit onkruid wieden, want 't is veel te dicht; wij zijn er nog niet mee klaar in tien jaar, zeiden zij sprekende; als 't zoo is, laat ons vluchten, laten wij gaan naar oom in 't overzeesche land.

Maar zijn metgezel antwoordde: "wat voor schuit zullen wij gebruiken, om er in te gaan?» De andere antwoordde: "de bloem van een pisang; wij zullen die van de bast ontdoen en naar 't water brengen; als wij die in 't water leggen en als die drijft, zullen wij er in klimmen en heel goed zitten in haar kamer.

$\mathrm{Zij}$ gingen en zagen een pisangboom, welke pas bloeide; zij namen een bloem. Toen zij die genomen hadden, namen zij die mee; bij de rivier gekomen, legden zij haar in 't water; ze dreef. En de een zeide: "daar, ik heb 't wel gezegd, ai na, wat ben ik toch alvermogend, ai!,

Zij klommen er in; reis-voorraad hadden zij niet. De pisangbloem dreef maar steeds af, totdat ze kwam in zee; in zee gekomen, sloegen wind en golven tegen haar aan; zij zonk bijna.

Er was nu een walvisch, evenals een eiland; toen zij dien van verre zagen, zeiden zij: "laten wij vlug roeien om dat eiland te bereiken.» En zij roeiden; toen zij 't bereikten, brachten zij zich langs zij en klommen er op. Toen zij er op geklommen waren, dreef de pisang-bloem, door hen beklommen, met den stroom af; langzaam ging ze verder, en zij zeiden: wat moeten wij nu, onze schuit is afgedreven? wij zullen zwemmen, zeggen wij, maar wij kunnen niet zwemmen.»

$\mathrm{Na}$ korten tijd zeiden zij: "wij zullen van honger sterven.» Maar de walvisch antwoordde en zeide: "sla op mijn zijde, en straks zal er rijst zijn; sla op mijn wang, straks ontstaat er Dl. 68 . 
varkensvleesch.» En zij sloegen op zijn zijde en wederom sloegen zij op zijn wang, er ontstond rijst, er ontstond varkensvleesch. $\mathrm{Z}_{\mathrm{ij}}$ aten nu, toen zij gegeten hadden, zeiden zij: "dit eiland kan praten, 't is ook alvermogend, gekookt eten is er maar zoo.,

Toen zij dit gezegd hadden, ging de walvisch vooruit; en zij zeiden: er is aardbeving - daar heb ik 't nu al! Toen zij dit gezegd hadden, hield 't heelemaal niet op, hij ging maar steeds door, de walvisch één nacht en één dag. En zij zeiden: "é ha, wij zullen heelemaal dood gaan, want 't is een walvisch, hij zal ons heelemaal opslokken.» Maar zijn metgezel antwoordde: "laat 't maar zoo zijn, laat 't maar sterven zijn, want dat hebben wij gevraagd.

Toen 't nu lang geduurd had, zagen zij een eiland en zij zeiden: "als 't een Marapoe is, dan zal hij ons daar doen aangaan en ons hier doen afstijgen.» Nadat één dag en één nacht voorbij was, kwam men in de riviermonding, en de walvisch zeide: "daar gij hier gekomen zijt, klimt er maar af.» En zij klommen er af; toen zij er afgeklommen waren, zeiden zij: "Nu grootvader walvisch, wij hebben geen eten» De walvisch antwoordde: "laat één er op klimmen en over mij heen loopen, dan zullen er zakken rijst uitkomen.» En hij klom er op en liep er over heen. Toen hij terugkeerde, was reeds een zak rijst op 't drooge.

Toen zeide de walvisch: "laat mij nu maar gaan naar mijn plaats.» En hij ging heen.

En die menschen zeiden: "wat zou er toch wel zijn in dien eenen zak, 't klinkt zoo, terwijl ik er op zit?» $Z_{i j n}$ makker zeide: "welaan dan, laat ons kijken wat 't is." En zij sneden overlangs open den mond van den zak en zagen er in: gedeeltelijk was 't goud, gedeeltelijk was 't zilver. Toen zeiden zij: "'t was onze lijn, in de lijn van 't kuiken; 't was onze lever, in den lever van een varkentje, dat wij verwerven 't roode, 't witte; wij zullen morgen rijk zijn; wat hebben wij nog meer te vragen.»

Er was nu een man, die ging visschen en hij zeide tot hen: "gijlieden daar, waar gaat gij heen?» En zij antwoordden: wij gaan naar oom. En de man antwoordde: "wie is oom?» $\mathrm{Zij}$ antwoordden: naar oom Lăki andoeng.

En de man, die ging visschen, antwoordde: "naar oom Lăki andoeng, zegt gij?» Zij antwoordden! «ja hoor!» naar 
oom Lăki andoeng, zeggen wij toch.» En de man antwoordde: «ik hier, ik ben een zoon van Lăki Andoeng». Zij antwoordden: "laat 't zoo zijn, als 't uw vader is, welaan laten wij medegaan naar huis.»

En zij gingen met hem mee; zij droegen hunne bezittingen.

Bij 't huis gekomen, zeide de heer des huizes: "wie zijn dat daar?» En die hen begeleidde, antwoordde: 't zijn menschen van 't overzeesche land.» "Wat komen ze verkoopen?, Zij antwoorden: neen, wij hebben niets te verkoopen; wij gaan naar onzen oom, zeiden wij. » Toen eerst kwam Lăki Andoeng naar beneden in de voorgalerij en hij zeide: "wie zijt gij dan?» En zij beiden: N. N. ben ik, zeide de een; de ander eveneens. En Lăki andoeng zeide: "dat is de naam van mijn vader, welken gij daar noemt." Toen zeide hij: "mits 't aldus maar is, dat gij hier gekomen zijt; als ik wat heb, zal ik ook u uithuwelijken; maak maar een grooten tuin; zeg ik u toch, 't andere jaar, de andere máan.» 


\section{Na woeja.}

Toenanoe handăka na, ninja haätoe na na tau; laloe kaborangoe ja la kawini, kawini mangoăma; la ndjara manganga; ${ }^{1}$ na poetoe ndăba ja na pabăndjăloe tau, ndaningoe na pahili na.

Toenanoe hi ninja haätoe na na kawini, laloe manándangoe ja, ${ }^{2}$ hina pa’ănga ja, hiwăna nja: “măla noe rămboe! djăka ta karai ja na tawoeroe la lima moe, ndau pamădja nja?”

Tăka hina heàma na kawini: "năhoe, bau kăli rongoe ka, koe kăli dánggangoe ma tawoeroe?» Tăka hina heàma na tau mini, hiwăna: "nde’a njoena, napa hioe dangga ă nja, wănggoe, hikoe toroe mbení ${ }^{3}$ pakarai ja».

Tăka hina heàma na kawini: "ndakoe kambănga, djèpa ndau nggeli wăngga patoekoe lomboe ${ }^{*}$ kanatar.» Tăka na heàma na tau mini: "ka nggiki ă nda, wămoe?" Na heàma na tau kawini: "djăka ta pakoetang ${ }^{5}$ ă, koe bihoe be njoena, paha loepa ja, djăka wămoe, ndakoe bihoe.» Tăka na heàma na tau mini: "mădja ka toena, peàka ngga rehi, djăka nggini tapahamboeroe ningoe.» Tăka hiwăna na kawini: "napa tai, djăka na kálitoe ka, kata patoămangoe, ka lai noe.» $\mathrm{Na}$ heàma na tau mini: "măla ka". Toenanoe paheàwa da nja ka.

Toenanoe bada paheàwa $\mathrm{ka}$, njoena na tau kawini, lakoe na nja ka la oema na, nde papinja na pange'a na. Toenanoe bana

1 la ndjara manganga = wat betreft gestolen paarden.

Vaste nitdrukking voor "gestolen paarden", hoewel men pamanganga zou verwachten, evenals b.v. djạra pake $=$ gekochte paarden.

2 laloe manándangoe ja= zij was zeer schoon.

laloe=zeer; eischt steeds de vorming van een bijzin: er was een zeer wild varken $=\operatorname{ninja}$ he'au na na wé, laloe mbeni ja.

3 toroe mbeni=durven; moed vatten.

toroe $=$ uithouden, verdragen, $\mathrm{mbeni}=$ dapper.

4 djèpa ndau nggeli wăngga patoekoe lomboe=al zoudt gij mij willen overhalen met oude mamoeli's.

Eigenaardig dat wăngoe $=$ met (alleen instrumentaal gebruikt.) 't object tot zich trekt, en niet 't instrument, waarmee de handeling verricht wordt. na paloe wăngga iwi = hij slaat mij met een rottan.

${ }^{5}$ pakoetang = met elkaar sirih kauwen.

Dit zegt men van menschen, die niet wettig getrouwd zijn en maar met elkaar leven; natuurlijk tegen de adat in. 
toăma ka na rehi, bana kálitoe ka, lakoe na nja ka na tau mini. Toenanoe bana lakoe $\mathrm{ka}$, hina ita ja haätoe na na kawini, tăka hiwăna bana karai ja: "djeà kau ka năhoe». Na heàma na kawini: "djeà doe ka». Toenanoe hiwăna: nggini ta lakoe ningoe patodoe». Tăka na heàma njoena na tau kawini: "mai kau, kikoengga njoengga".

Toenanoe hina kikoenja; hina ita ja hau na na ana oema; hida tama lai noe. Toenanoe bada tama ka lai noe, mandai ki ka hakoedoe, na oema na pambeli ja wai. Tăka na kawini na pambeli ja woeja. ${ }^{1}$ Toenanoe jăpa na nja ka na tau mini, hina kaœ ja, ndena pameti ja, la wihi na, la lima na, na ihi dana ${ }^{2}$ na manoea ndăba. Tăka hiwăna na woeja: "măla noe, pădang doe ka malara?» Na heàma njoena na tau: "pădang ka.» Na heàma njoena na woeja: "măla bau pădang ka, ndau mandjare'a ?» ${ }^{3} \mathrm{Na}$ heàma njoena na tau: "mandjare'a weli nggoe năhoe, loepa koe meti.»

I na pambeli ja woeja= zij veranderde in een krokodil.

De zielen der voorouders, treden niet alleen zegenend en helpend op, gelijk in 't vorig verhaal, maar ook straffend; want zij zijn de wachters over de adat, en kunnen niet dulden, dat die overtreden wordt.

${ }^{2} \mathrm{na}$ ihi dana $=$ 't geheele lichaam.

In 't dialect van Kambera komt dit d a n a alleen voor in deze uitdrukking. In West-Soemba (Laura, Wadjewa, Lauli) is 't een praepositie, met de beteekenis van te, in, naar; en wordt steeds gevoegd achter' $t$ nomen: b.v. wa'è oema dana $=$ hij is in huis.

${ }^{3}$ mandjare'a = berouw hebben; iets niet meer zullen doen; zich bekeeren van een slechten daad. 
XIV. De Krokodil.

Vroeger was er eens een man; hij was erg slecht wat vrouwen betreft, getrouwde vrouwen; (slecht) wat gestolen paarden betreft; hij raapte alles op, wat iemand neergelegd had, niets liet hij liggen.

Er was nu een vrouw, zeer schoon was zij en hij misleidde haar en zeide tot haar: hoe is 't rămboe, als ik den ring van uw vinger vraag, staat gij 't dan niet toe?» Maar de vrouw antwoordde: "nu, hebt gij 't dikwijls gehoord, dat ik dikwijls ringen verkoop?»

En de man antwoordde en zeide: "dat niet, maar misschien verkoopt gij hem wel, zeide ik, daarom had ik den moed 't te vragen.»

Maar de vrouw antwoordde: "ik ben niet dom, al wilt gij mij overhalen met oude memoeli's en gouden kettingen.» De man antwoordde: "hoe moet ik dan, naar uw gedachten?" De vrouw antwoordde: "als wij slechts "sirih-kauwen» met elkaar dan wil ik wel, maar geheel trouwen, als gij dat zegt, wil ik niet.» En de man antwoordde: "laat 't zoo zijn, zeg mij den tijd, waar wij elkaar zullen ontmoeten.» En de vrouw zeide: "straks dan, als 't avond-schemer is, zullen wij daar naar toe gaan.» De man antwoordde: "dat is goed». En zij gingen van elkaar.

Toen zij van elkaar gegaan waren, ging die vrouw naar haar huis, haar woonplaats was onbekend. Toen de bestemde tijd was aangebroken en 't avond-schemer was, ging de man er heen. Toen hij er heen ging, zag hij een vrouw en vragende zeide hij: "zijt gij 't nu? De vrouw antwoordde: "dat ben ik.» En hij zeiden: "waar zullen wij gaan overnachten? De vrouw antwoordde: "kom en volg mij maar."

En hij volgde haar; en hij zag een klein huisje en zij gingen daar binnen. Toen zij er binnen gegaan waren, na korten tijd slechts, veranderde 't huis in water. En de vrouw veranderde in een krokodil. Toen greep zij den man en' beet hem, zij doodde hem niet, in zijn voeten, in zijn handen, zijn geheele lichaam was heelemaal gewond. En de krokokil zeide: "welaan, 
gevoelt gij nu brandende pijn? De man antwoordde: «ik gevoel het.» De krokodil antwoordde: welaan nu, daar gij 't gevoelt, zult gij u niet bekeeren?» De man antwoordde: "ik zal mij bekeeren van nu af aan, totdat ik sterf.» 


\section{I Dai Karămbo'a.}

Toenanoe handăka na, nindja da doea; da ngara da: na mama'aja I Hadoe ja, na haätoe I Hina ja. Toenanoe hidoe manggări na nja na ama da; hiwăna ndja na ama da: «lo’a pamoeti ${ }^{1}$ nda roe djărikoe.» Toenanoe hi lakoe da nja; bada tăka ka la pingi djărikoe, tăka hi ninja haätoe na na tau bokoel, ndena paheàndja pamoeti roe djărikoe. Laloe mangădătoe ha da anakeàda. Toenanoe da beli djoe'a ${ }^{2}$ ha, ndeda ngăndi roe djărikoe; bada tăka ka la oema, hiwăna na ama da: "ka nggini ha da roe djărikoe?» Da heàma da anakeàda: "ai ha, ama, ninja haätoe na na tau bokoel la pingi ai djărikoe, laloe mangădătoe ma nja.»

Tăka hiwăna na ama da: "măta kata lo'a papameti ja.»

Toenanoe hida lakoe; bada tăka nja ka na tau noena ndena mbeni, na kandí ${ }^{3}$ be la pingi djărikoe, nde nggăra ehi na ${ }^{4}$. Toenanoe hida jăpa ja; hida ngăndi ja la oema, hida hondoe ja la loemboe mboămang.

Toenanoe bada hăla ka pahondoe ja, hi lakoe na nja papatoăma na ama na la hau koătăk. Ba taliœ na ka, da ana na didi hang la oema; padjoeloe da nja la kaheli, padjoeloe wăngoe maka hau nang ${ }^{5}$. Toenanoe hina kanaboe na maka; tăka njoena na tau bokoel hina piti ja na maka. Tăka hiwăna njoena na eri na: "wŏngga nja na maka nggoe.» Tăka na heàma na aja na: "kanggiki nda nja ka ni tai, ba mbăda piti na nja na tau bokoel, na pahondoe?» Tăka hina heàma na tau bokoel: "pahăla ka kakoe wŏnggămi nja na maka.» Tăka hiwăna njoena na haätoe na aja: "djăka ta pahăla ja, tai na mbeni i ama.» Tăka na heàma na eri na: "pahăla ja, wăna.» Tăka na heàma na aja na: "koe mangădătoe nja i ama, wăna.»

Toenanoe hina hī na eri na, hina párahoeng wiki na. Toe-

1 moeti $=$ met een mesje afsnijden; oogsten van de rijst.

' djoe'a = ledig; zonder iets.

${ }^{3} \mathrm{k}$ andi=zich niet bewegen; zwijgen.

4 nde nggăra ehi na =er ontbreekt niets aan; er is niets bijzonders.

${ }^{5}$ maka hau nang $=$ slechts één tol.

vlg. Aanteek. 2, Verhaal X. 
nanoe hina poeroe hina nggoeli ja hina pahăla ja; bana hăla ka papahăla ja hina pabeli nja na maka. Toenanoe lakoe na nja ka; mandai ki ka hakoedoe hina tăka na ama da; bana tăka ka, hiwăna bana karai ha: "ka nggini ja na tau bokoel?» "Mapahăla ja ka.» "Ka ni hi pahăla ja ?» Da heàma da anakeàda: "na kanaboe na maka na i eri, toenanoe hikoe pahăla ja.» Tăka hiwăna na ama da: "koe pameti ndăba kămi, ndakoe djăma nggămi. ${ }^{1}$ »

Tăka njoena na ama da hina pa'aunja I Kaka, ata na: "kareàndja da anakeàda jeàda, kau pameti ha la oămang; ngăndi katoendoel, kau toe wăndja da wai ria da, kau ngăndi ngga ha kakoe ita ha.» Toenanoe lakoe da nja ka. Tăka njoena I Kaka hina lakoe li pajăpa kamămbi he'au hina iroe ja. Toenanoe bana tăka ka la hau kandjoănga, tăka hiwăna njoena I Kaka: lai jehoe pameti ni kămi. Da heàma da anakeàda: "lakoe marau ki, djăkau pameti ni kămi lai jehoe, na kăli mai patăngăroe ndjara i ama; djăka na ita ha da reti ma, na hambai ${ }^{2}$ nggăma pahàpa ma.»

Toenanoe da hili lakoe; tăka la hau kandjoănga, hiwăna njoena I Kaka: lai jehoe pameti ni kămi. Da heàma da anakeàda: "lai jehoe pada ndjara na i ama ja, djăka na mai pangadoe $^{3}$ ndjara, na ita ha da reti $\mathrm{ma}$, na hambai nggăma pahăpa ma.»

Toenanoe da hili lakoe; tăka da nja ka la oămang bokoel.

Tăka hiwăna njoena I Kaka: lai jehoe pameti ni kămi.

Tăka da heàma njoeda da anakeàda: pameti kăma ka lai jehoe. Tăka hiwăna njoena I Kaka: pameti lănga tăka kămi? "Pameti lănga tăka kăma.» Tăka hiwăna njoena I Kaka: batoenanoe măta kakoe hambăli ja na kamămbi. Toenanoe hina pa'ihi ndja wai ria kamămbi la katoendoel ba dămboe; bana hăla ka pahambăli ja hina lakoe; hiwăna ndja da anakeàda: "măta kakoe lakoe wa.» Da heàma da anakeàda: "lakoe wa».

Toenanoe lakoe na nja ka; bana tăka ka la oema: "jeàna wai ria na $\mathrm{I} \mathrm{Hadoe}$ ja, jeàna wai ria na $\mathrm{I} \mathrm{Hina}$ ja.»

\footnotetext{
${ }^{1} \mathrm{ndakoe}$ djăma nggămi = ik laat 't er niet bij; ik vergeef 't u niet.

${ }^{2} \mathrm{hambai}=$ offeren van sirih en pinang op een grafsteen.

Men mag 't graf van een familielid niet voorbijgaan, zonder hem wat sirih aan te bieden, bij wijze van groet, gelijk men 't een "levend" familielid ook zou doen.

3 pangadoe = van boven at naar beneden zien; op een heuvel staande over 't weideveld heen zien.
} 
Na ama da hiwăna: "pameti lănga tăka doe ha?» Na heàma I Kaka: "koe pameti lănga tăka ha.» "Na hămoe ka na eti nǵgoe, hiwăna na ama da.

Toenanoe mandai-ndai ki ka, hi ninja na tau na malo'a pahoeloe rawa ' lai noe; ba hīna na lo'a, ndedi na ita ha pa.

Toenanoe na hili lo’a pandoe'angoe wăngoe; hina hoeloe ja na rawa hina kanaboe toeba ndja. Toenanoe hida piti ja, tăka hiwăna njoena na mama'eri: "ha aja, njoengga ja na wihi kawana na, njoemoe ja na wihi kalai na.» $\mathrm{Na}$ heàma na aja : «nde'a, njoengga ja na kawana na, njoemoe ja na kalai na.»

Tăka na heàma na eri na: "nde’a, njoengga ja na kawana na.»

Tăka na heàma na aja na: "napa tai, njoemoe ja na kawana na

Toenanoe bada hăla ka patoenoe ja, hina hoăwăkoe ja. Tăka hiwăna nja na aja na, bana hăla ka pahoăwăkoe ja: djè nja ka wihi kawana na, njoengga ja na wihi kalai na.»

Toenanoe ngangoe da nja ka; bada hăla ka pangangoe, lakoe na nja na aja na.

Toenanoe hina ita ja na tau bokoel; tăka hiwăna na tau bokoel bana paní meha: "ai ha, oera ma nggoe, ${ }^{2}$ na ana nggoe.».

Toenanoe karèa na nja ka la paraing. Tăka la paraing na hoendjoe wē, toboeng karămbo'a, tondoeng ana mongoe, na doenda ndăba nja na tau; lo'a parémi ba djeà ja na ana marămba, na makanaboe weli ditang la awang, ana marămba, na makanaboe weli ditang la awang, ana marămba londoeng. 3 Toenanoe nde'oekoe rémi ma ja; hau lodoe na rémi, hau lodoe na rémi, ndena păndjang ndokoe.

Tăka njoena na eri na, na himboe ja na aja na. Toenanoe hina ita ja hau na na oema; na oema noena, didi jang na tau kawini. Tăka na tau angoe na ndaninja.

Tăka hiwăna na tau kawini: "napa ja ka tai na tau angoe nggoe bana tăka, kau paní nja.» Toenanoe hiwăna na anakeàda: "ka nggi lo’a na nja? "Hoedita la paraing, wăna na tau

1 rawa =een groot soort, groene duiven.

${ }^{2}$ oera ma nggoe $=$ 't is mijn goed fortuin.

vlg. Aanteekening, verhaal XIII.

3 ana marămba londoeng =een echte, volbloed vorstenzoon.

Een radja moet steeds uit een bepaald stamhuis zijn voornaamste vrouw halen. Een zoon vit dit huwelijk is pas een "ana marămba londoeng". Zonen zijner andere vrouwen, hoe voornaam ook, zijn alleen maar „ana marăm ba". Zonen bij slavinnen, tellen niet mee. 
kawini. "Kanggiki na hina remi, hiwăna na anakèada. Tăka hiwăna nja na tau kawini: "ninja na ana marămba, na pa'ita na na marămba la paraingoe; djeà ja hina remi; na ngara na I Hadoe ja.»

Tăka na heàma njoena na anakeàda: "hama djeà $\mathrm{i}$ ja na ngara na na aja nggoe, " hiwăna nja. Tăka na heàma na tau kawini: "ha, ămboe paní ă ănga ka; marămba noedita djăka na rongoe kau, na paloe kau.»

Toenanoe tăka na nja ka I Mbata Roekoe; tăka hina pa'aunja na tau angoe na: "ha nedita, poeroe kau, kaú piti ha da ngăndi nggoe.» 1 Toenanoe hina poeroe ja; bana hăla ka papiti ha da pangăndi na, tăka hina pa'aunja na anakeàda: "ha anakeàda newawa, hē kau la kaheli.,

Toenanoe hina hē; tăka hiwăna I Mbata Roekoe: "ka nggamoe ana da nggămoe?» Tăka na heàma njoena: "da ina nggoe da ama nggoe ndakoe pindja.» Tăka hiwăna na tau kawini: "anakeàda pawăroeng kăma la woekoe oămang, bakoe rongoe hama djeà $\mathrm{i}$ ja na ngara na na aja nggoe, noedita la paraing.»

Tăka na heàma I Mbata Roekoe: "ha, ămboe paní ă ănga ka, na rongoe kau na marămba, na paloe kau; ana marămba londoeng ja, wăna i doena; tăka njoemoe, aja nggoe nja, wămoe be ka njoemoe.» "Ka nggamoe ja na ngara moe?» Tăka na heàma njoena: "I Hina ja na ngara nggoe.» Tăka na heàma I Mbata Roekoe: "ndena hămoe na ngara moe, napa koe pandjiloe nja na ngara moe, I Dai Wē kămoe; haromoe la mbaroe pamama ha da wē, kau toe ndja oehoe da; weli ndja la oăka, djăka da hăla paramoekoe.» ${ }^{2}$

Toenanoe hadang ka la mbaroe, njoena I Mbata Roekoe, lakoe na nja ka la paraing; tăka njoena $1 \mathrm{Dai} W \bar{e}$; dai na ha ka da wē. Toenanoe hina weli ndja da wē, lakoe ngăndi ha la ramoek; bada ramoekoe ka, hina hē ja la mara njoena bana hăla pa'ihoe, hina mandapoe, hina kamibi ndja da wē; da meti hăla da wē, ndaningoe maloeri he'au.

Toenanoe lakoe na nja ka la oema, hina peàka nja na rămboe na: "ha rămboe nedita, kanggiki nda ha i pa da wē, da meti

1 da ngăndi nggoe=mijn brengen; wat ik meebreng.

De meer gewone constructie zou zijn: da pangăndi nggoe=wat door mij gebracht wordt.

2 ramoekoe= stilstaande plas; buffelwed; zich in de modder wentelen. 
hăla ma.» "Kanggikina hida meti, » hiwăna na tau kawini. Tăka hiwăna na anakeàda: "kau pindja ka, djăka nggăra maroekoe ndja!» ${ }^{1}$ Tăka na heàma njoena na tau kawini: "meti moe nja ka njoena tai, djăka na tăka na oemboe moe.»

Toenanoe bana tăka ka na oemboe na, hiwăna na oemboe na: "ha Dai Wē nedita, mai kau kē ha da toloeng.» 2 Toenanoe hina poeroe ja, hina $k \bar{e}$ ha: ngăndi nja ha na rămboe moe kana pahămoe ha.

Tăka hiwăna njoena na tau kawini; "ha Dai Wē, mai kau padoekoeloe ja na epi, kau wotoe ja na woeroeng la epi.»

Toenanoe hina lo'a, hina padoekoeloe ja, hina toenja wai na woeroeng, hina wotoe ja la epi. Toenanoe bana hăla ka pawotoe ja hina pala ja la kaheli bokoel, ${ }^{3}$ hina kamibi nja na woeroeng. Toenanoe bana kamibi nja ka, na mbongoe na wai, na mbăda mboe na epi. Tăka hiwăna na tau kawini: ha Dai We e, mai kau padoekoeloe ja na epi.» Toenanoe hina riki, na wai la woeroeng ni beli nja, na epi na doeroe beli. Toenanoe na rămboe na manahoe pangangoe; bada memi ka da pangangoe, bada hăla ka pangangoe, hiwăna na oemboe na: "ha $D$ ai $W \bar{e}$. măla da wē la oăka ha ka?» Tăka na heàma njoena na tau kawini: nggăra i pa ná, bada meti hăla ka da wē.»

Tăka hiwăna I Mbata Roekoe: "ndena hămoe na oera moe, djăkau dai we ; I Dai Kamămbi kau, pandjiloenja na ngara moe; ‘ haromoe' la mbaroe kau tăngăroe ha da kamămbi. »

Toenanoe hadang ka la mbaroe, hi lakoe na nja ka I Mbata Roekoe la paraing, tăka noena na anakeàda I Dai Ka mă-

1 djăka nggăra maroekoe ndja= wat de oorzaak van hun dood is geweest.

roekoe=spoor, teeken. Zoo zegtmen: ,nggăra roekoe hina meti" = door welke oorzaak stierf hij ? roekoe nimboe=door een lans.

2 da toloeng = het vleesch; de stukken vleesch.

3 la kaheli bokoel= de groote zitplaats.

In huis, rechts als men binnen komt, is over de geheele breedte van 't huis een groote zitplaats aangebracht. Daar zitten de gasten, eten en slapen zij.

${ }^{4}$ pandjiloenja na ngara moe $=$ verwissel, verander uw naam.

't Nauw verband tusschen iemands naam en iemands wezen, iemands zielestof, is welbekend. Met den naam is ook iemands aard omschreven. De aard van den knaap was niet geschikt, was een vijand ( $p$ a p a gelijk 't verder genoemd wordt) van 't geiten hoeden. Daarom 't telkens veranderen of hij ook den juisten naam, passend bij zijn aard, bij zijn zielestof (n dew a, o era) kan vinden. 
mbi weli na ndja ka da kamămbi; na ngăndi ha la marăda. Toenanoe bana tidoeng ka na lodoe, na lo'a papa'oenoe ndja wai da, bana hăla ka papa'oenoeng wai, bada hē ha ka la mara da kamămbi, tăka njoena I Dai Kamămbi hina kamibi ndja da kamămbi, da meti hăla ha, ndeda bingoe kanănda da.

Toenanoe lakoe na nja ka la oema; bana tăka ka la oema, hiwăna: "ha rămboe, da kamămbi da meti hăla ma, ndaningoe he'au maloeri; meti nggoe nja ka njoena tai, djăka na tăka i oemboe?.

Tăka na heàma njoena na tau kawini: "ămboe handoeka nja lai noe, napa ta peàka pahămoe nja ka na oemboe moe, ka ămboe na mbeni. »

Toenanoe bana tăka ka, hiwăna: «ha Dai Ka mămbi nedita, mai kau kē ha da pangăndi nggoe da toloeng, kau wornja ha na rămboe kana pahămoe ha».

Toenanoe hina hē hina wŏnja ha na rămboe na da toloeng, wăna na rămboe: "ha Dai Kamămbi, padoekoeloe ja na epi, kau piti ja na woeroeng, kau toe nja wai na, kau wotoe ja la epi.» Toenanoe hina padoekoeloe ja na epi, na wotoe ja na woeroeng; bana hăla ka pawotoe ja hina pala ja la kaheli bokoel hina mandapoe hina kamibi nja na epi dăngoe na woeroeng; na woeroeng na panggoeboeloeng, na epi na mbăda. Tăka hina pa'aunja: "ha Dai Kamămbi, kanggikina ka na woeroeng na panggoeboloeng be ka, na epi na mbăda mboe, mai kau padoekoeloe ja na epi.» Toenanoe na lo'a hina riki nja na wai dăngoe na woeroeng dăngoe na epi; na epi na doeroe beli, na woeroeng na ndeàlang, hama toena kawai bana wotoe ja. Toenanoe manahoe da nja ka da toloeng; bada memi ka hida ngangoe.

Toenanoe bada hăla ka pangangoe, tăka hiwăna njoena I Mbata Roekoe: "ha Dai Kamămbi!» Tăka na heàma njoena na tau kawini: "I Dai Ka mămbi, wămoe, wămoe nja ka, ba mbăda hăla da ka pameti da kamămbi!» "Kanggikida hida meti?»

Tăka na heàma njoena na tau kawini: "kau pindja ka, karai ja I Dai Kamămbi.» Tăka na heàma I Dai Kamămbi : "hīna koe hăla ha papa'oenoe ndja wai, djeà meti be da.» Tăka na heàma I Mbata Roekoe: "djăka toenanoe ndena hămoe na ndewa moe, djăka I Dai Kamămbii kau; napa ta pandjiloe nja na tamoe moe; I Dai Bimbi kau, hiwăna njoena 
I Mbata Roekoe, haromoe la mbaroe, kau lo'a patăngăroe ha da bimbi, lo'a papa'oenoe ndja wai da, lakoe ngăndi ha la padang kau pawa ndja.»

Toenanoe ba hadang ka la mbaroe, njoena I Mbata Roekoe lakoe na nja ka la paraing; I Dai Bimbi lakoe ngăndi ha la marăda da bimbi. Toenanoe bana tidoeng ka na lodoe hina lo'a papa'oenoe ndja wai da; bada hăla ka pa'oenoeng wai, tăka njoena I Dai Bimbi hina kamibi ndja, da meti ndăba da bimbi, ndaningoe he'au maloeri.

Toenanoe hi lakoe na nja la oema; bana tăka ka la oema hiwăna: "ha rămboe, da meti ka da bimbi.» Tăka na heàma na rămboe na: "napa tai kata peàka pahămoe nja ka na oemboe moe, ămboe na mbeni.»

Toenanoe bana tăka ka I Mbata Roekoe na roedoeng ma nja ka; hiwăna bana pa'aung: "ha Dai Bimbi nedita, mai kau kē ha da ngăndi nggoe.» Toenanoe hina poeroe, na kē ha da ngăndi na; hiwăna njoena I Mbata Roekoe: wotoe ha hoedita la kaheli, kai manahoe ha.»

Tăka hiwăna na rămboe na: "ha anakeàda, boeri nja wai na na woeroeng, kau padoekoeloe nja epi na.»

Toenanoe hina padoekoeloe ja na epi, bana hăla ha papadoekoeloe ja, bana doeroe ka, tăka hina lakoe ja, tăka hina lakoe ja la kaheli bokoel, hina kamibi nja na woeroeng; na epi na mbăda, na woeroeng na panggoeboeloeng. Tăka hiwăna na rămboe na: "ha $\mathrm{Dai} \mathrm{Bimbi}$, mai kau padoekoeloe ja na epi, na mbăda ka ni.» Toenanoe hina riki, na epi na doeroe beli ja. Toenanoe manahoe da nja ka pangangoe; ba memi ka, takoe da nja ka, ngangoe ndăba da.

Toenanoe bada hăla ka pangangoe hiwăna njoena I Mbata Roekoe: "ha Dai Bimbi, da bimbi patama ndja ka la oăka?" Tăka na heàma njoena na tau kawini: "da meti hăla,» wăna. "Kanggiki da ihoe hida meti?». "Lănga tăka ma na ndja papa da hida meti.» Tăka hiwăna njoena I Mbata Roekoe: "djăka toenanoe pandjiloenja na ngara moe; I Dai $\mathrm{Ndjara} \mathrm{kau,}$ djăkau hăla ka papa'oenoe ndja wai da, patama ndja la oăka.»

Toenanoe hadang ka la mbaroe, njoena I Mbata Roekoe lakoe na nja ka la paraing; tăka njoena I Dai Ndjara hi lakoe na nja papawandja da ndjara. Toenanoe bana tidoeng ka na lodoe, hina pa'oenoendja wai da, hina welindja hina patamandja la oăka. Tăka hina lakoe la oema, na hē ja la 
bangga, hina mandapoe hangga ndja da ndjara, hina kamibi ndja. Toenanoe bana hăla ka pakamibi ndja, da ndjara da meti hăla.

Tăka hina pa'aunja na rămboe na: "ha rămboe, mai kau tăngăroe ha da ndjara la oăka, da meti i ka ni!» Tăka hina poeroe hina tăngăroe; lănga tăka, hiwăna na rămboe na, napa tai djăka na tăka na oemboe moe, bakoe ita ma doe ha i doekoe. ${ }^{1}$

Toenanoe bana roedoeng ka, tăka na nja ka I M bata Roekoe, wăna bana pa'aung: "ha Dai Ndjara, mai kau kē ha da ngăndi nggoe! Toenanoe hina poeroe ja hina kē ha da ngăndi na hina wŏnja ha na rămboe na; tăka hiwăna na rămboe na: "padoekoeloe ja na epi, ta manahoe kata ngangoe." Toenanoe hina padoekoeloe ja na epi; bana hăla ja ka hina pala ja la kaheli bokoel, na mandapoe hina kamibi nja na woeroeng na panggoeboeloeng, na epi na mbăda. Toenanoe bana ita ja ka na rămboe na bana mbăda na epi: "ha Dai Ndjara, mai kau padoeroe ja na epi.»

Toenanoe hina riki, na doeroe na epi; hida manahoe, pangangoe, hida ngangoe; ba hăla ka pangangoe hiwăna I M b a ta Roekoe: "ha Dai Ndjara, da ndjara nggi ha ka?"

Tăka hiwăna na rămboe na: "bada meti kawai, koe ita ma ha; na patamandja ka la oăka, djeà ti-tila be da hida meti.» Tăka hiwăna njoena I Mbata Roekoe: "ndena hămoe na ndewa moe; ta pandjiloenja na ngara moe: I Dai Karămbo'a kau ka i njoena; haromoe la mbaroe kau lo'a patăngăroe ha da karămbo'a, na tidoeng na lodoe weli ndja la ramoekoe kada ramoekoe.»

Toenanoe hadang ka la mbaroe, njoena I Mbata Roekoe lakoe na nja ka la paraing; tăka njoena I Dai Karămbo'a, lakoe na nja padai ha da karămbo'a. Toenanoe bana tidoeng ka na lodoe, na weli ndja la ramoekoe; bada tăka ka la ramoekoe, bada tama ka la ramoekoe da karămbo'a, hina kamibi ndja, da meti hăla la ramoekoe da karămbo'a.

Toenanoe lakoe na nja ka la oema, hiwăna bana tăka: * ha rămboe, da karămbo'a da meti hăla la ramoekoe, ndaningoe

I bakoe ita ma doe ha i doekoe=daar ik 't nu toch ook gezien heb.

Wat een opeenvolging van enclytische woordjes! ma, doe ter versterking van 't verbum; i=ook; doe hoort bij ik, ik zelf. 
ndokoe he'au maloeri.» Tăka hiwăna na rămboe na: "da meti ki ka doeda, lănga tăka ma na ndja papa da hida meti.»

Toenanoe tăka na nja ka I Mbata Roekoe: "ha Dai Karămbo'a, kau kē ha da ngăndi nggoe.» Tăka hina poeroe hina kē ha da ngăndi na, hina ngăndi nja ka na rămboe na, hina wŏnja ha. Toenanoe hiwăna na rămboe na: "padoekoeloe ja na epi, kau wotoe nja wai na woeroeng kata manahoe toloeng." Toenanoe hina padoekoeloe ja na epi hina toe nja wai na na woeroeng hina wotoe ja; bana hăla ja ka hina pala la kaheli bokoel, hina kamibi nja na woeroeng dăngoe na epi; na epi na mbăda, na woeroeng na panggoeboeloeng. Tăka hiwăna na rămboe na: "ha Dai Karămbo'a na epi na mbăda ka.» Tăka njoena I Dai Karămbo'a hina riki nja na epi, na epi na doeroe beli, na woeroeng na tindjang beli. Toenanoe manahoe da nja ka pangangoe.

Toenanoe bana memi ka hida ngangoe; bada hăla ka pangangoe, tăka hiwăna njoena na oemboe na: "ha Dai Karămboa, da karămbo'a, mbăda patama moe ha ka la oăka?" Tăka na heăma njøena na tau kawini: "mbăda meti hăla da ka,» wăna. Tăka hiwăna njoena I Mbata Roekoe: "măta kau padjoeloe djoea ka, ămboe nggăra padai moe; wăna na marămba: lo'a hoepapa la hapapa tana, wăna; măta kakoe kareànja ka I D a i Karămbo'a, wanggoe nja na marămba bakoe peàka nja; wǒ'a hiwăna, lo’a pahimboe nja papaha na na ana marămba, na makanaboe weli ditang la awang, haromoe lo'a da nja patăngăroe ja na teàna.»

Toenanoe bada lo'a ka patăngăroe ja na teàna, bada hăla ja ka pakadoedoe ja, na hămoe ka. Tăka hiwăna I Mba ta Ro e koe: «I Dai Karămbo'a, ămboe na lo'a.» Tăka njoena I Dai Karămbo'a hina kamibi nja na teàna noena, na mbera beli. Tăka njoena I Mbata Roekoe hiwăna bana paní: «I Dai Karămbo'a kareànja.». Tăka njoena I Dai Karămbo'a hina riki nja na teàna, na hămoe beli.

Toenanoe hida parehing: doea modoeng, hiwăda. Toenanoe bana toăma ja ka na rehi, lakoe da nja ka; bada tăka ka la hapapa tana, da paleàwa ja palo'a papiti epi I Dai Karămbo'a. Toenanoe bana lo'a ka papiti epi, na napa ja djawa; na pătoe ma ja: djeà ja na ana marămba, wăda.

Toenanoe da pateà-teànja, ndeda ita ndokoe ja; da himboe ja, ndeda ita ndokoe ja. Njoena I Dai Karămbo'a mbăda 
kanoăma na nja ka I Rămboe $\mathrm{Kahi}$, mbăda tiloe mboea roedoe na ka mandai na.

Toenanoe hiwăda : lo'a papa'aunja I D a i Kară m bo'a kata lakoe.

Toenanoe hida pa'aunja, na kareà mboe nja na papaha na; bada tăka ka la teàna hida hē ha; bada hăla ka pahē hida pamaingoe ha. Tăka la padoea liboe moeroe hida dandanja I Dai Karămbo'a, hida ndoeha ja la wai; na napa ja iœ, na kawăloekoe nja hina ngăndi ja la hingi wara, la toeba na na pange'a na, hina moeta beli nja.

Toenanoe bana moeta beli nja ka hina lakoe ja la makaweàda, na makapoăla; didi ă i jang la oema na, ndaningoe ana na. Toenanoe bana tăka ka lai noe, hiwăna: "ăpoe, wŏnda tangangoe, laloe mandjoé ka.» Toenanoe hina wornja hina ngangoe; bana hăla ka pangangoe, tăka hiwăna njoena na maka- · weàda: "ămboe lakoe ănga ănga doe, padaingoe ka lai jehoe.» Tăka hiwana I Dai Karămbo'a: wǒ, hiwăna.

Toenanoe mandai-ndai ki ka hakoedoe, hau woelang mapalăngang, tăka hiwăna njoena I Dai Karămbo'a: "ha ăpoe, na marămba noedita la paraing, djăkau ngăndi nja wăla woenga, laloe mboehangoe ja; kau lo'a pakarai hambakoe, koeta, winoe.»

Toenanoe hina lo'a paketoe ${ }^{1}$ ha da wăla woenga, hina toe ha la ana mboăla. Tăka hiwăna njoena I Dai Karămbo'à: "ha ăpoe, ămboe toe ha la ana mboăla repi, toe ha la ana mboăla roăwang; toe păkoe nja oeta la kiri, kau măngoe patoe ha da wăla woenga la pinoe.»

Toenanoe bana hăla ha ka, hi lakoe na nja ka la paraing; bana tăka ka la paraing, hiwăna njoena I Rămboe Kahi: "ha ăpoe, jehoe kămoe, nggăra ha da pangăndi moe.» Na heàma njjoena na makaweàda: "wăla woenga ă ha.» Tăka na heàma njoena I Rămboe $\mathrm{Kahi}$, hiwăna: «tau hămoe kămoe, ăpoe, bau ngăndi ngga wăla woenga.» Na wŏnja koeta, na wŏnja winoe, na wŏnja hambakoe.

Tăka hiwăna I Rămboe Kahi: "hili ngăndi ki nda wăla woenga.» $\mathrm{Na}$ heàma njoena na makaweàda: "măla ka, napa koe hili mai. »

Toenanoe lakoe na nja ka; palăngang patoe, lima, na hili lo'a; na ngăndi wăla woenga. Na wǒnja hambakoe, na wŏnja koeta, na wŏnja winoe. Tăka hiwăna njoena I Rămboe Kahi:

${ }^{1}$ ketoe $=$ met een haak, met een stok naar zich toe halen.

Dl. 68 . 
"hili ngăndi ki nda wăla woenga.» Na heàma njoena na makaweàda: "măta kakoe hili mai ka.»

Toenanoe lakoe na nja ka na makaweàda; palăngang patoe, lima, tăka hiwăna njoena I Dai Ka rămboa: "ha ăpoe, djăkau hili lo'a patoe nja wăla woenga na marămba, peàka păkoe ngga.» Tăka na heàma na makaweàda: wŏ.

Toenanoe hina lo'a papăpoe wăla woenga; bana hăla ka papăpoe ha, hina ngăndi nja ha, hina wŏnja ha. Toenanoe bana hăla ka pawŏnja ha, hina boetoehoe ja na tawoeroe la wŏa lima na, hina toe ja la angoe wăla woenga.

Toenanoe lakoe na nja ka na makaweàda la paraing; bana tăka ka lai noe, hiwăna njoena I Rămboe Kahi: "ha ăpoe, jehoe kămoe, nggära ha da pangăndi moe?» Na heàma njoena na makaweàda: "wăla woenga ha.» Toenanoe hini piti ha; bana piti ha ka, tăka hina hoenggoe ja na tawoeroe; na tanda ja ba tawoeroe na njoena ja. Toenanoe bana hăla ka papiti ja, hina kawini parăpoe-răpoe ja. ${ }^{1}$

Tăka hina piti nja hambakoe, winoe, koeta; hiwăna: "hili ngăndi ki nda wăla woenga haromoe la mbaroe.» Tăka na heàma njoena na makaweàda: măla ka.

Toenanoe lakoe na nja ka na makaweàda. Bana hadang ka la mbaroe, hina palai njoena I Kahi, na kakikoenja na oeta, loepa na tăka la oema na na makaweàda.

Toenanoe bana tăka ka la oema, na napa ja njoena I Dai Karămbo'a, na kawininja. Tăka da tau la paraing da lo'a pahimboe ja, ndeda ita ndokoe ja. Palăngang hakamboeloe roedoeng hida kakikoenja na oeta noena. Toenanoe bada kakikoenja ka na oeta noena, tăka hida ita ha la bangga be ă, bada mandapoe. Tăka hina mai măngoe papahang; ${ }^{2}$ nde’oekoe karaœ ma ja na eti na.

Toenanoe hiwăna njoena I Dai Karămbo'a: "djăka na karaœ na eti moe, mandapoe kadiroe, kata paní.» Toenanoe hida mandapoe hida paní. Tăka hiwăna njoena I Dai Karămbo'a: "ha aja, toe păkoe na na pakiri na, na ana hoedoe, ${ }^{3}$ na pamata păkoe na na ana djala: ămang hidoe manggări

1 na kawini parăpoe-răpoeja=zij verborg hem zorgvuldig.

răpoe=nauw opeen gesloten.

2 măngoe papahang=de eigenaar der getrouwde.

Wanneer iemand met een vrouw getrouwd is (paha) 'dan is ze zijn eigendom, zijn bezit. (măngoe=eigenaar, bezitter.)

3 na pakiri na na ana hoedoe='t begin van 't schepnetje.

Een overdrachtelijke uitdrukking voor: 't begin der zaak. 
na nja i ama.

en dan komt 't verhaal, totdat zij de duif opeten en I Hadoe verdwijnt .

Toenanoe bata hăla ka panganja na rawa noena, mandai ki ka hawoetoe, mboelang doe moe nja ka. Toenanoe koe lakoe lo'a ka dija, koe lakoe lo'a ka loeroe, bakoe pa'aunggămoe, bakoe himboe kămoe; noe njoengga lakoe hoăra nggoe nja ka. Toenanoe hikoe hoenggoe ja hau na na oema, hi haätoe na na tau kawini, tau mini ndaningoe; tăka hiwăna ngga: nggi weli ni moe, ha anakeàda. Tăka hiwănggoe bakoe heàma: himboe nggoe nja na aja nggoe, I Hadoe ja na ngara na. Toenanoe tăka doe na nja ka na mini lē na, tăka hiwăna: ka nggi anakeàda ni kau, hiwăna ngga. Tăka hiwănggoe bakoe heàma: "himboe nggoe nja na aja nggoe; noedita la paraing hama djcà i ja na ngara na na aja nggoe njoengga.» Tăka hina heàma njoena I Mbata Roekoe: "ha, ămboe paní ă-ănga ka, na rongoe kau na marămba, paloe pameti doe kau; ana marămba makanaboe weling la awang ja, wăna i doena; tăka njoemoe: aja nggoe njoengga ja, wămoe i kai doemoe.» Hiwăna ngga. "Ka nggamoe ja na ngara moe?»

Tăka koe heàma njoengga: I Hina ka, hiwănggoe. Tăka na heàma njoena: "ndena hămoe na ngara moe, I Dai K a mămbi, wăna ngga, na pakiri na; I Dai Wē, wăna ngga; I Dai Bimbi, wăna ngga; I Dai Ndjara, wăna ngga; I Dai Karămbo'a, wăna ngga; na nimbihoe ndăba ngga ha da ngara makajidikoe, ${ }^{1}$ da papáwa wăngoe tau.

Toenanoe bakoe rongoe pala la djawa I Mbata Roekoe, tăka hiwănggoe njoengga: koe pala mboe njoengga. Na heàma I Mbata Roekoe: măla ka. Toenanoe hina pala; bakoe tăka la djawa, hina paleàwa ka palo'a papiti epi. Toenanoe bakoe tăka ka la nge’a patăka nggoe, hina pătoe ka. "Djeà ja na ana marămba londoeng, wăna ngga, hina patama ka la koeroeng, na kawini jeàna na pahimboe nggoe, bawămoe.»

Toenanoe bana rongoe ja ka njoena I Hadoe, bana paní i eri na, tăka hina hadang hina rohoe nja na eri na, laloe hī ja.

\footnotetext{
1 da ngara makajidikoe= de namen van al wat zich beweegt.

Typisch dat men geen woord voor "dier" heeft, men moet 't dus altijd omschrijven. Ook zegt men wel: banda loeri=levende goederen, tegenover banda meti=doode goederen.
} 
XV. De Karbauwen-hoeder.

Eertijds waren er eens twee menschen; hun namen: de oudere was I $\mathrm{Hadoe}$, de andere was I $\mathrm{Hina}$. Hun vader was ziek van een bloedzweer; en hun vader zeide tot hen: "ga mij djeroek-bladeren plukken.» $Z_{i j}$ gingen heen; bij den djeroek-boom gekomen, was daar een groote man, hij liet hen niet toe djeroekbladeren te plukken. De knapen waren zeer bang. En zij keerden ledig terug, zij brachten geen djeroek-bladeren; thuis gekomen, zeide hun vader: "waar zijn de djeroek-bladeren!» De knapen antwoordden; "ai ha, vader, er was een groote man bij den djeroek-boom, zeer bang waren wij.»

Maar hun vader zeide: "welaan, laat ons hem gaan dooden.»

En zij gingen; bij dien man gekomen, was deze niet woest, hij stond maar stil bij den djeroek-boom, er was niets bijzonders. Men greep hem en bracht hem naar huis en men bond hem onder 't huis.

Toen men hem er gebonden had, ging hun vader een andere kampong bezoeken. Toen hij vertrokken was, waren zijn kinderen alleen in huis; zij speelden op den vloer (in huis), zij speelden met één tol maar. En de tol viel; de groote man nam den tol op. De jongere broeder zeide: "geef mijn tol.» Maar zijn oudere broeder zeide: "wat zal ons straks hier overkomen, daar de groote gebonden man hem reeds heeft opgeraapt?» En de groote man antwoordde; "laat mij los en ik zal u den tol geven.» Maar de een, de oudere, zeide: "als wij hem loslaten, is vader straks nijdig." Maar zijn jongere broeder antwoordde: "laat hem los», zeide hij. Maar zijn oudere broeder antwoordde: "ik ben bang voor, vader», zeide hij.

Toen huilde zijn jongere'broeder en rolde zich zelven over den grond.

Hij ging nu naar beneden, wond hem los en liet hem los; toen hij hem los gemaakt had, gaf hij den tol terug. Hij ging nu heen; na korten tijd, kwam hun vader er aan; toen hij aangekomen was, zeide hij, hen vragende: "waar is de groote man?» "Wij hebben hem losgelaten.» "Waarom hebt gij hem losgelaten?" De knapen antwoordden: "de tol van den jongeren 
broeder viel en toen heb ik hem losgelaten.» Maar hun vader zeide: "ik zal je allemaal dooden, ik vergeef 't je niet."

En hun vader riep I Kaka, zijn slaaf: "neem deze kinderen mee, en dood ze in 't bosch; neem bamboe water-kokers mee om er hun bloed in te doen, breng ze mij opdat ik 't zie.» En zij gingen heen. Maar I Kaka ging ergens aan om een geit te halen en trok die aan een touw mee. Toen zij in een dal gekomen waren, zeide I Kaka: hier zullen wij u dooden. De knapen antwoordden: "ga wat verder, als gij ons hier doodt, komt vader dikwijls de paarden bezien; en als hij onze graven ziet, offert hij ons onze sirih.»

Wederom gingen zij; in een ander dal gekomen, zeide I Ka ka: hier zullen wij u dooden. De knapen antwoordden: "hier is 't weideveld der paarden van vader, als hij komt zien naar de paarden, ziet hij onze graven, en offert hij ons onze sirih.»

Wederom gingen zij; zij kwamen in een groot bosch. En I Kaka zeide: hier zullen wij u dooden. De knapen antwoordden: dood ons maar hier. Maar I Kaka zeide: "zal ik u werkelijk dooden». "Dood ons werkelijk.» Maar I Kaka zeide: "daarom laat mij de geit slachten.» Toen vulde hij 't bloed der geit in de twee bamboe water-kokers; toen hij haar geslacht had, ging hij heen en zeide tot de knapen: "laat mij heen gaan. De knapen antwoordden: ga maar.

En hij ging heen; toen hij thuis gekomen was, zeide hij: dit is 't bloed van I Hadoe, dit is 't bloed van I Hina. Hun vader antwoordde: "hebt gij ze werkelijk gedood?» I Kaka antwoordde: "ik heb ze werkelijk gedood.» "Mijn hart is nu gerust», zeide hun vader.

$\mathrm{Na}$ verloop van korter of langer tijd was, er een man, die aldaar duiven ging schieten; toen hij pas ging, zag hij ze nog niet. Wederom ging hij ten tweede male, en hij schoot een duif en die viel juist voor hen neer. $\mathrm{Zij}_{\mathrm{ij}}$ namen haar op en de jongere zeide: «broeder, ik de rechterpoot, en gij de linkerpoot. De oudere broeder antwoordde: "neen, ik de rechter en gij de linker. Maar de jongere broeder antwoordde: "neen, ik de rechter.» En zijn oudere broeder antwoordde: "nu straks, gij de rechter." Toen zij haar geroosterd hadden, sneed men haar open. En zijn oudere broeder zeide tot hem, toen hij haar had opengesneden: "dit is haar rechter poot, ik haar 
linkerpoot.» En zij aten; toen zij gegeten hadden, ging zijn oudere broeder heen.

Toen zag hij den grooten man; en de groote man zeide, sprekende bij zich zelf: "ai ha, mijn goed fortuin, mijn zoon!" En hij nam hem mee naar de kampong. In de kampong gekomen slachtte hij varkens, slachtte hij karbauwen, sloeg op de gongs, riep alle menschen bij elkaar; zij gingen feestvieren ter oorzake van den vorstenzoon, welke boven uit den hemel was gevallen, een echte vorstenzoon. Buitengewoon feest vierde men; elken dag vierde men feest, men hield heelemaal niet op.

Zijn jongere broeder nu, zocht zijn ouderen broeder. En hij zag een huis; dat huis, er was alleen maar een vrouw. Maar haar man was er niet. En de vrouw zeide: "wacht maar als straks mijn man komt, praat dan met hem.» De knaap antwoordde: "waar is hij heen gegaan?" "Naar boven naar de kampong," zeide de vrouw. "Waarom viert men feest, zeide de knaap. En de vrouw zeide tot hem: "er is een vorstenzoon, gezien door den vorst in de kampong; daarom viert men feest, zijn naam is $\mathrm{I} \mathrm{Hadoe}$.»

Toen antwoordde de knaap: "dat is gelijk aan den naam van mijn oudere broeder, s zeide hij tot haar. Maar de vrouw antwoorddc: "ha, praat toch geen onzin; als de vorst daar boven je hoort, zal hij je slaan.»

En daar kwam I Mbata Roekoe aan; hij riep zijn vrouw: "ha daar boven, kom naar beneden, neem aan wat ik meebreng." En zij kwam naar beneden; toen zij 't door hem meegebrachte had aangenomen, riep zij den knaap: "nu knaap daar beneden, klim eens in huis.»

En hij klom naar boven; toen zeide I Mbata Roekoe: «van wie zijt gij een zoon?» Hij antwoordde; "ik ken mijn ouders niet." Toen zeide de vrouw: "wij zijn kinderen, weggeworpen in 't bosch, naar ik hoorde is dat dezelfde naam als mijn broeder, daar boven in de kampong.» Maar I Mbata Roekoe antwoordde: "ha, praat toch geen onzin, de vorst zal je hooren, hij zal je slaan; 't is een echte vorstenzoon, zeide hij toch; maar gij: 't is mijn oudere broeder, zegt gij daar maar." "Hoe is je naam?» en hij antwoordde: "I Hina is mijn naam.» Maar I Mbata Roekoe antwoordde: «je naam is niet goed, ik zal je naam verwisselen, I Dai Wē (varkenshoeder) moet gij heeten; morgen vroeg, roep de varkens bij 
elkaar, geef hun hun eten, drijf ze in de omheining, als zij klaar zijn met wentelen in de plas.»'s Morgens opgestaan zijnde ging I Mbata Roekoe naar de kampong; maar I Dai We e (varkenshoeder) paste op de varkens. En hij joeg de varkens bij elkaar en bracht ze naar de plas; terwijl ze aan 't wentelen waren, klom hij weer op 't drooge, nadat hij gebaad had en zette zich neer en trok een mond tegen de varkens; al de varkens stierven, niet één bleef leven.

Hij ging nu naar huis en hij zeide tot zijn meesteres: "ha ramboe, daar boven, hoe heb ik toch nu met de varkens, zij zijn allemaal dood.» "Waaraan zijn ze dood?» zeide de vrouw. Maar de knaap antwoordde: "weet gij 't soms, wat de oorzaak voor hen is?» En de vrouw antwoordde: "gij zult straks wel dood gaan, als je heer komt.

Toen zijn heer nu kwam, zeide zijn heer: "ha $\mathrm{Dai} W \bar{e}$ daar boven, kom 't vleesch aannemen.» En hij kwam naar beneden en nam 't vleesch aan: breng 't aan je meesteres, dat zij 't opberge. Toen zeide de vrouw: "ha Dai We, kom 't vuur eens oprakelen en zet den pot op 't vuur.» Hij ging en rakelde 't vuur op en deed water in den pot en zette dien op 't vuur. Toen hij ze opgezet had, stak hij over naar de groote zitbank en trok een mond tegen den pot. Toen hij er een mond tegen trok, stortte 't water er uit en ook ging 't vuur uit. En de vrouw zeide: "ha Dai We e, kom 't vuur opstoken.» Toen lachte hij; 't water was weer terug in den pot en 't vuur vlamde weer op, De meesteres kookte eten; toen 't eten gaar was en zij gegeten hadden, zeide zijn heer: "ha $\mathrm{Dai} W \overline{\mathrm{e}}$, welaan zijn de varkens in de omheining?" Maar de vrouw antwoordde: "wat zou er nog zijn, daar de varkens allemaal dood zijn.»

Toen zeide Mbata Roekoe: "uw lijnen zijn niet goed, als gij varkens hoedt; je moet I Dai Kamămbi (geitenhoeder) zijn; verander je naam; morgen vroeg kijk dan naar de geiten.

's Morgens vroeg opgestaande zijn, ging I Mbata Roekoe naar de kampong, en die knaap I D a i Ka mă mbi (geitenhoeder) dreef de geiten bij elkaar; hij bracht ze naar de grasvlakte. Toen de zon boven zijn hoofd (12 uur) was, ging hij ze hun water te drinken geven; nadat hij ze gedrenkt had en de geiten weer op 't drooge geklommen waren, trok I Dai $\mathrm{Ka}$ mămbi een mond tegen de geiten, ze stierven allen, zij bewaarden hun overblijfsel niet.

En hij ging naar huis; thuis gekomen, zeide hij: ha ramboe, 
de geiten zijn allemaal dood, er leeft er niet één; ik zal straks wel sterven, als de heer komt.»

Maar de vrouw antwoordde: "maak je daarover maar niet bezorgd, we zullen het straks wel goed vertellen aan uw heer, opdat hij niet nijdig is.»

Toen hij nu aangekomen was, zeide hij: " ha Da i Ka mămbi daar boven, kom eens aannemen, wat ik meebreng, de stukken vleesch, en geef ze aan je meesteres, dat die ze bewaart.»

En hij klom naar boven en gaf 't vleesch aan zijn meesteres; de meesteres zeide: "ha Dai Kamămbi stook 't vuur op en neem den pot en doe er 't water in en zet hem op 't vuur.» Hij stookte 't vuur op en zette den pot op; toen hij dien opgezet had, stak hij over naar de groote zitplaats en zette zich neer en trok een mond naar het vuur en den pot; de pot keerde ten onderste boven, 't vuur ging uit. Toen riep zij hem: "ha $\mathrm{Dai} \mathrm{Kamambi}$, hoe is 't, dat de pot ten onderste boven gekeerd is, 't vuur is ook uit, kom en stook 't vuur op, " Hij ging en hij lachte tegen 't water en den pot en 't vuur; het vuur vlamde weer op, de pot stond overeind; evenals zooeven toen hij dien opzette. Zij kookten nu 't vleesch; toen 't gaar was, aten $\mathrm{zij}$,

Toen zij gegeten hadden, zeide I Mbata Roekoe: "ha Dai Kamămbi!» Maar de vrouw antwoordde: „I Dai Kamămbi, zeidet gij, moest men tegen hem zeggen; terwijl de geiten allemaal dood gegaan zijn!» "Hoe is 't, dat zij dood gegaan zijn?» Maar de vrouw antwoordde: "weet gij 't soms? vraag 't aan I Dai Kamămbi.» Toen antwoordde I Dai Kamămbi: "pas had ik ze water laten drinken, zoo maar dood waren ze." Toen antwoordde I Mbata Roekoe: "als 't zoo is, dan is je zielestof niet gerust, als je I Dai Kamămbi zijt; laten we je naam verwisselen; I Dai Bimbi (schapenhoeder) zult gij zijn, zeide I Mbata Roekoe; morgen vroeg ga de schapen bezien, ga ze drinken geven, breng ze naar de grasvlakte en weid ze aldaar.»

Toen hij 's morgens opgestaan was, ging I Mbata Roekoe naar de kampong; I Dai Bimbi (schapenhoeder) bracht de schapen naar de grasvlakte. Toen de zon boven zijn hoofd stond, ging hij ze hun water laten drinken; toen zij gedronken hadden, toen trok I Dai Bimbi een mond tegen her, al de schapen gingen dood, niet één bleef er leven.

Hij ging nu naar huis; thuis gekomen, zeide hij: «ha meesteres, 
de schapen zijn dood.» Toen antwoordde zijn meesteres: "wacht we zullen 't straks goed aan je heer vertellen, opdat hij niet boos zij."

Toen I Mbata Roekoe kwam, was 't al nacht; roepende zeide hij: "ha Dai Bimbi daar bóven, kom eens aannemen hetgeen ik meegebracht heb.» Hij kwam naar beneden, nam 't gebrachte aan; en I Mbata Roekoe zeide: breng 't naar boven in huis en kook het.

En zijn meesteres zeide: "ha knaap, giet 't water in den pot en stook 't vuur op.»

Hij stookte nu 't vuur op, toen hij 't opgestookt had en 't vlamde, ging hij naar de groote zitplaats en maakte een mond tegen den pot; 't vuur ging uit, de pot keerde onderste boven. Toen zeide zijn meesteres: "ha Dai Bimbi, kom 't vuur eens opstoken, 't is al uit hier.» Hij lachte, 't vuur vlamde weer op. $\mathrm{Z}_{\mathrm{ij}}$ kookten nu eten; toen 't gaar was, schepten zij 't op en aten allen.

Toen zij gegeten hadden zeide I Mbata Roekoe: ha Dai Bimbi, hebt gij de schapen in de omheining gebracht?» Maar de vrouw antwoordde: "zij zijn allemaal dood», zeide zij. "Hoe is 't toch, dat zij dood zijn?" "Hij is werkelijk hun vijand, dat zij dood gegaan zijn.» Toen zeide I Mbata Roekoe: "als 't zoo is, verwissel je naam: I Dai Ndjara (paardenhoeder) zult gij zijn; als gij ze hun water hebt laten drinken, breng ze dan binnen de omheining.»

's Morgens opgestaan zijnde ging I Mbata Roekoe naar de kampong; en I Dai. $\mathrm{Ndj}$ a ra (paardenhoeder) ging op de paarden passen. Toen de zon boven zijn hoofd stond, liet hij ze water drinken, en hij dreef ze bij elkaar en bracht ze binnen de omheining. Toen ging hij naar huis, hij klom in de voorgalerij en zette zich neer recht voor de paarden en hij trok er een mond tegen. Toen hij er een mond tegen getrokken had, stierven alle paarden. En hij riep zijn meesteres: "ha ramboe, kom eens kijken naar de paarden in de omheining, daar zijn ze dood gegaan!» En zij kwam naar beneden en keek; werkelijk, zeide zijn meesteres; wacht strakjes als je heer komt, daar ik 't nu toch zelf ook gezien heb.

Toen 't avond was, kwam I Mbata Roekoe er aan en roepende zeide hij: "ha Dai Ndjara, kom eens aannemen hetgeen ik meegebracht heb.» Hij kwam naar beneden en nam 
't gebrachte aan en gaf het aan zijn meesteres; vervolgens zeide zijn meesteres: "stook 't vuur op, wij-zullen koken om te eten." En hij stookte 't vuur op; toen hij er mee klaar was, stak hij over naar de groote zitplaats, hij zette zich neer en trok een mond tegen den pot; de pot keerde onderste boven, het vuur ging uit. Toen zijn meesteres zag, dat 't vuur uit was: "ha Da i Ndjara, kom 't vuur eens doen ontvlammen.» Hij lachte, 't vuur vlamde op; en zij kookten eten en zij aten; toen zij gegeten hadden, zeide I Mbata Roekoe: "ha Dai Ndjara, waar zijn de paarden?»

Maar zijn meesteres zeide: "toen zij zooeven stierven, heb ik 't ook gezien; hij bracht ze de omheining binnen, toen schopten en trapten zij maar en gingen dood.» Toen zeide I Mbata Roekoe: "uw zielestof is niet goed, wij zullen je naam verwisselen, je moet maar I Dai Karămbo'a zijn; morgen vroeg ga dan naar de karbauwen kijken, als 't 12 uur is drijf ze naar 't buffelwed, opdat zij zich rondwentelen.»

's Morgens opgestaan zijnde, ging I Mbata Roekoe naar de kampong; en I Dai Karămbo'a (karbauwen-hoeder) ging op de karbauwen passen. Toen 't nu 12 uur was, dreef hij ze naar 't buffelwed; toen zij bij 't buffelwed gekomen waren en de karbauwen in de plas waren gegaan, stak hij zijn mond er tegen uit, zij stierven allemaal in de plas, de karbauwen.

Hij ging nu naar huis en zeide toen hij er aan kwam: "ha ramboe, de karbauwen zijn allemaal dood gegaan in de plas, er is heelemaal geen één, die leeft. En zijn meesteres zeide: «laten ze maar dood gegaan zijn, werkelijk is er hun vijand, dat zij zijn gestorven.

Toen kwam I Mbata Roekoe: "ha Dai Karămbo'a, neem eens aan, hetgeen ik meebreng.» Hij kwam naar beneden en nam aan, hetgeen hij meebracht, en bracht 't aan zijn meesteres, en gaf 't haar. En zijn meesteres zeide: "stook 't vuur wat op, doe wat water in den pot, opdat wij 't vleesch koken.» Hij stookte 't vuur op en deed water in den pot en zette dien op; toen hij er mee klaar was, stak hij over naar de groote zitplaats en hij maakte een mond tegen den pot en tegen 't vuur; 't vuur ging uit, de pot keerde onderste boven.

Toen zeide zijn meesteres: "ha Dai Karămbo'a, 't vuur is al uit.

Maar I Dai Karămbo'a lachtte tegen 't vuur, 't vuur 
vlamde weer op, de pot stond weer recht over eind. Zij kookten nu het eten.

Toen 't gaar was, aten zij; toen zij gegeten hadden, zeide zijn heer: "ha Dai Karămbo'a, hebt gij de karbauwen reeds in de omheining gebracht?» Maar de vrouw antwoordde: "zij zijn reeds allen dood, zeide zij. Toen zeide I Mbata Roekoe: "welaan speel jij maar slechts, laat er niets meer door je opgepast worden; de vorst zeide: ga naar 't overzeesche land, zeide hij; laat mij I Dai Kară mbo'a meenemen, zeide ik tot den vorst, met hem sprekende; ja, zeide hij, ga een vrouw zoeken voor den vorstenzoon, die boven uit den hemel is gevallen; morgen gaat men kijken naar een schuit.»

Toen zij gingen kijken naar een schuit en zij die gebreeuwd hadden, was die in orde. Toen zeide I Mbata Roekoe: "I Dai Karămbo'a, mag niet gaan.» Maar I Dai Karămbo'a makkte een mond tegen de schuit, ze was weer kapot. Toen zeide I Mbata Roekoe, terwijl hij sprak: «I Dai Karambo’a gaat mee. Toen lachte I Dai Karămbo'a tegen de schuit en ze was weer in orde.

Toen spraken zij een tijd af: over twee dagen, zeiden zij. Toen de bestemde tijd was aangebroken, gingen zij heen; gekomen bij 't land aan de overzijde, zonden zij I Dai Karămbo'a 'om vuur te gaan halen. Toen hij nu vuur ging halen, wachtten de vreemden hem op; men hicld hem vast: dat is de vorstenzoon, zeiden $\mathrm{zij}$. $\mathrm{Zij}$ nu wachtten en wachtten, maar zagen hem heelemaal niet; zij zochten hem, maar zij zagen hem heelemaal niet. I Dai Karămbo'a was nu reeds getrouwd met I Rămboe Kahi, 't was reeds drie nachten geleden.

Toen zeiden zij: ga I Dai Ka rămbo'a roepen, wij zullen vertrekken. $\mathrm{Zij}$ riepen hem, hij nam ook zijn vrouw mee; toen zij bij de schuit gekomen waren, stegen zij in; toen zij er in gestegen waren, gingen zij. Gekomen midden in volle zee, namen zij I Dai Karămbo'a op en wierpen hem in 't water; een haai wachtte hem op, slokte hem naar binnen, bracht hem aan den rand van 't strand, juist voor zijn woonplaats en spuwde hem weer uit.

Toen deze hem weer uitgespuwd had, ging hij naar een oude vrouw, die vol wonden was; zij was alleen slechts in haar huis, zij had geen kinderen. Toen hij daar gekomen was, zeide 
hij: "grootmoeder, geef mij te eten, ik heb zoo'n honger.s En zij gaf hem en hij at; toen hij gegeten had, zeide de oude vrouw: "ga niet overal heen, blijf steeds hier.» Toen zeide I Dai Karămbo'a: ja, zeide hij.

Toen nu na zekeren tijd, een maand was er voorbij gegaan, zeide I Dai Karămbo'a: "grootmoeder, de vorst daar boven in de kampong, als gij hem toeri bloemen brengt, heeft hij dat zeer gaarne, ga dan vragen tabak, sirih, pinang.»

Zij ging nu toeri bloemen haken (met een stok) en zij deed ze in een mandje. Toen zeide I Dai Karămbo'a: "grootmoeder, doe ze niet in een dichtgevlochten mandje, maar doe ze in een open gevlochten mandje; gij moet er zemelen onder in doen en dan pas de toeri bloemen er boven op doen.»

Toen zij er mee klaar was, ging zij naar de kampong; in de kampong gekomen, zeide I Ramboe Kahi: "grootmoeder, kom hier, wat brengt gij daar!» De oude antwoordde: «'t zijn toeri bloemen.» Toen antwoordde I Ramboe $\mathrm{Kahi}$ en zeide: «je bent een goed mensch, grootmoeder, dat gij mij toeri bloemen brengt.» $Z_{i j}$ gaf haar sirih, zij gaf haar pinang, zij gaf haar tabak.

Toen zeide I Ramboe $\mathrm{Kahi}$ : "breng mij nog maar eens toeri bloemen." De oude antwoordde: "dat is goed, ik zal nog eens terug komen.: En zij ging heen; na verloop van 4 à 5 (dagen) ging zij wederom en bracht to e ri bloemen. Zij gaf haar tabak, zij gaf haar sirih, zij gaf haar pinang. Vervolgens zeide I Ramboe Kahi: "breng mij nog eens toeri-bloemen.» De oude antwoordde: "welaan ik zal nog eens komen.»

De oude nu ging heen; na verloop van vier à vijf (dagen) zeide I Dai Karămbo'a: "grootmoeder, als gij wederom toeri-bloemen gaat brengen aan den vorst, moet gij 't mij zeggen.» En de oude antwoordde: ja.

Zij ging nu toeri-bloemen plukken; toen zij ze geplukt had, bracht zij ze hem en gaf ze hem. Toen zij ze hem gegeven had, trok hij af den ring van zijn vinger en deed dien in de to e ri-bloemen.

De oude ging nu naar de kampong; toen zij daar gekomen was, zeide I Ramboe Kahi: "grootmoeder, kom hierheen, wat brengt gij?» De oude antwoordde: «'t zijn toeri-bloemen.» En zij nam ze; toen zij ze genomen had, vond zij vervolgens den ring; zij herkende hem, dat 't de ring van hem was. Toen 
zij hem genomen had, verborg zij hem zorgvuldig. Toen haalde zij haar tabak, pinang, sirih; en zij zeide: "breng mij wederom maar toeri-bloemen, morgen vroeg.» En de oude antwoordde: "'t is goed."

De oude nu ging heen. Toen zij 's morgens was opgestaan, vluchtte I Kahi, zij volgde de-zemelen, totdat zij kwam aan 't huis van de oude. Toen zij bij 't huis gekomen was, wachtte I Dai Karămbo'a haar op en verborg haar. En de menschen in de kampong gingen haar zoeken, zij zagen haar heelemaal niet. Na verloop van 10 nachten, volgden zij de zemelen. Toen zij die zemelen volgden, zagen zij hen, terwijl zij in de voorgalerij zaten. Toen kwam de eigenaar van de getrouwde; buitengewoon nijdig was hij.

Maar I Dai Karămbo' a zeide: "als gij nijdig zijt, ga dan eerst zitten, opdat wij wat praten. $\mathrm{Zij}$ gingen zitten en spraken. Toen zeide I Dai Karămbo'a: "oudere broeder, aldus was toch 't begin van 't schepnetje, het mazen maken toch ('t knoopen) van het werpnetje: eertijds was vader ziek van een bloedzweer ........ en dan komt het verhaal, totdat zij de duif opeten en I Hadoe verdwijnt . . . . . . .

Toen wij die duif gegeten hadden, korten tijd er na, waart gij toch verdwenen. En ik ging stroomop en ik ging stroomaf, terwijl ik je riep, terwijl ik je zocht; daar liep ik als een dwaas maar heen. Toen vond ik een huis, en één vrouw, de man was er niet; en zij zeide tegen mij: "waar komt gij van daan, knaap?» En ik zeide, terwijl ik antwoordde: "ik zoek mijn ouderen broeder, I Hadoe is zijn naam. En daar kwam haar echtgenoot aan en hij zeide: "een kwaap waar vandaan zijt gij, zeide hij tot mij.» Maar ik zeide antwoordende: "ik zoek mijn ouderen broeder; daar boven in de kampong is er iemand van denzelfden naam als mijn broeder.» Maar I Mbata Roekoe antwoordde: "ha, praat toch geen onzin, de vorst zal je hooren en zal je dood slaan; een vorstenzoon uit den hemel gevallen is hij, dat zegt hij; en gij: 't is mijn oudere broeder, dat zegt gij daar maar zoo.». En hij zeide tot mij: "hoe is uw naam?» Toen antwoordde ik: ik ben I Hina, zeide ik. Maar hij antwoordde: "uw naam is niet goed, I D a i K a r ă m bo ' a (karbauwenhoeder), zeide hij tot mij; dat was 't begin; I Dai We (varkenshoeder) zeide hij tot mij; I Dai Bimbi (schapenhoeder) zeide hij tot mij; I Dai $\mathrm{Ndjara}$ (paardenhoeder) zeide 
hij tot mij; I Dai Karămbo'a (karbauwenhoeder) zeide hij tot mij; hij ging ze allemaal voor mij langs, de namen van wat zich beweegt en door menschen gehoed wordt.

Toen ik hoorde dat I Mbata Roekoe naar 't vreemde land zou oversteken, toen zeide ik: ik steek ook over. I Mbata Roekoe antwoordde: 't is goed. En men stak over; in 't vreemde land gekomen, zond men mij uit om vuur te halen; toen ik gekomen was, waar ik aankwam, hield men mij vast. "Dit is de echte vorstenzoon, zeide men van mij, en men deed mij trouwen, deze vrouw, die gij zegt te zoeken.»

Toen I Hadoe nu zijn jongeren broeder hoorde spreken, stond hij op en omarmde zijn jongeren broeder, hij weende zeer.

Van de volgende verhalen wordt alleen de Hollandsche vertaling gegeven, daar de Soembaneesche tekst niet geheel in orde is. Er zijn heel wat verhalen van I Ramboe $\mathrm{Kahi}$ en I Oemboe Ndiloe in omloop. Vooral de jeugd vermaakt er zich mee en weet telkens nieuwe bijzonderheden er in te voegen. Men zal hetzelfde verhaal nooit met dezelfde bijzonderheden hooren vertellen. Telkens is 't weer iets anders. 
XVI. I Rămboe Kahi, die een varken baarde.

I Domoe Woelang was de vader van I Rămboe Kahi; haar moeder was I Harabi Loda. Haar moeder ging nu naar 't bosch hout sprokkelen en I R. K. huilde, want zij wilde gaarne met haar moeder mee. Toen nam haar moeder haar mede; in 't bosch gekomen, ging de moeder hout sprokkelen. Maar I R. K. dronk de urine van een wild varken uit een holte in een steen, want zij had dorst. Toen haar moeder hout had gesprokkeld, keerden zij naar huis terug.

Thuis gekomen werd I R. K. na verloop van tijd zwanger. ${ }^{1}$ Haar vader en haar broeder zagen dat I R. K. zwanger was en zij vroegen haar. Maar I R. K. zwoer van niets te weten. Toen haar maand was aangebroken, baarde I R. K.; een varken was haar kind.

$\mathrm{Al}$ de menschen waren verbaasd, want nog nooit is er iemand geweest, die aldus baarde - nu voor 't eerst is 't I R. K. , die alzoo baart.

Toen zeiden haar vader en haar broeder I Oemboe Ndiloe: "wij moeten die Kahi maar dooden, daar zij nu toch een varken gebaard heeft». Maar I Oemboe Mada, de jongere broeder, zeide: "dood haar niet; laten wij haar in 't bosch gaan brengen.» Toen ging I Mada zijn zuster wegbrengen, met haar varken, in 't bosch beneden de kampong. Maar I Oemboe Ndiloe zag haar en wilde haar dooden. Toen grepen de menschen I Ndiloe vast. Wederom nam nu I Mada

${ }^{3}$ In 't Animisme van Alb. C. Kruyt, pg. 48 lezen wij: „Veelvuldig zijn de verhalen in den Indischen Archipel, waarbij dieren worden bezwangerd met menschen, doordat zij de urine van een man hadden opgelikt, en ook planten of boomen, die ran menschen zwanger worden, omdat een man er tegen heeft geurineerd."

Dergelijke verhalen heb ik op Soemba niet kunnen vinden. Wel 't omgekeerde. Een vrouw, drinkt bij vergissing de urine van een dier (varken, duif.) en baart dan straks zoo'n dier. Dit dier-mensch verandert dan tenslotte in een schoone jongeling, welke trouwt met I Ramboe Kahi.

Als type van een dergelijk verhaal zie ook: Schets van een Soemb. Gramatica. Bat. Gen. v. K. en W. 1910, pg. 100.

Vergel. ook: Kruyt Animisme, pg. 122. 
zijn zuster en deed haar verhuizen naar een huis, waarin geen menschen waren, midden in een bosch. Als zijn ouders eten gaven aan I Mada, dan wikkelde hij 't in en bracht 't aan zijn zuster. Hij liet 't niet zien aan zijn ouders. Omdat hij veel van zijn zuster hield, deed I Mada aldus elken dag, wanneer zijn moeder hem eten gaf. I Mada at 't zelf niet, maar bracht 't aan zijn zuster.

Toen zag I R. K. wat spaansche peper-struiken en andere soorten groenten en zij zeide: "als ik maar een scherf van een pot had, dan zou ik die groenten daar plukken, ik zou ze koken en bij mijn eten gebruiken», zeide zij, sprekende tot zich zelf. Toen antwoordde 't varken en knorde: "moeder, daar ginds is een platte pan, neem die en kook er mee.» En zijn moeder nam 't en plukte groenten en kookte. Toen zeide I R. K.: «ik heb geen lepel.» Maar 't varken zeide knorrend: "moeder, daar boven in de alang alang is een lepel gestoken.» En zijn moeder nam den lepel van de plaats, waar die tusschen gestoken was.

Wederom zeide I R. K.: "dit hier is mijn klapperdop, om uit te eten, maar wat moet ik doen, als de groente gaar is?» Wederom knorde 't varken: "er zijn klapperdoppen daarboven op 't zoldertje.»

Wederom zeide zijn moeder: "als er maar was een kapmes, dan zou ik 't bosch hier vellen en kalabassen planten en maïs, opdat ik wat kippen zou krijgen.» En 't varken hoorde het en zeide knorrend: "moeder, daarboven is een kapmes ergens tusschen in gestoken.» Toen nam zijn moeder 't en begon 't bosch te vellen om een tuin te maken. $Z \mathrm{ij}$ verbrandde nu 't bosch, door haar omgehakt, 't Was goed schoon, toen zij er naar keek. En I R. K. zeide: "als ik maar wat maïs en kalabassen had, dan zou ik ze mij wel planten.» Het varken hoorde het en hij zeide knorrend tot zijn moeder: "moeder daar boven is maïs op 't zoldertje en pitten van kalabassen heeft men daar in de alang alang verborgen; neem ze en plant ze.»

En zijn moeder nam 't en plantte. De maïs en de kalabassen groeiden; buitengewoon mooi waren ze. Wederom zeide I R. K.: "als ik maar wat padi had, en als ik ze plantte, dan zou ze even mooi worden als deze maïs.»'t Varken hoorde haar en zeide knorrend: "moeder, daar boven op 't zoldertje is padi in een pot, neem 't en plant het.» En zijn moeder nam 't en plantte. 
$\mathrm{Na}$ vele dagen en vele nachten, was de padi hoog en ook de maïs; de kalebassen hadden ook reeds vruchten. Toen zeide knorrend 't varken: "moeder zijn de kalabassen nog niet groot?» En zijn moeder zeide: "de eerste vrucht is al rijp. «Ga en pluk ze, met blaren een handvol en ga het brengen aan oom Mada in de kampong.

Zijn moeder ging van de kalabas vrucht plukken en één handvol bladeren en ging 't brengen aan I O emboe Mada in de kampong.

En 't varken zeide, terwijl hij sprak tot zijn moeder: "als gij in de kampong komt, zeg dan tegen oom $\mathrm{Mada}$, dat hij de bladeren van de kalabas niet buiten mag leggen, hij moet ze in een gesloten mand doen.»

En als hij de kalabasvrucht wil stuk snijden; om aan de varkens te geven, laat hij 't dan niet doen op den vloer, maar hij moet-'t op een mat doen.» Ja, zeide zijn moeder.

Wederom werd I R. K. gezien door I Oemboe Ndiloe: "hallo! daar is ze weer», zeide hij en hij stond op en nam lans en kapmes. Hij wilde haar gaarne dooden, maar vele menschen grepen I O e mboe $\mathrm{Ndiloe}$ vast. En $\mathrm{F}$ R. K. ging weer naar 't bosch. In den tuin gekomen, zeide 't varken: "zijt gij daar aangekomen, moeder?» "Ja, zeide zijn moeder, 't scheelde maar weinig of ik was in de kampong gedood door I Oemboe $\mathrm{Ndiloe}$, als vele menschen hem niet vast gegrepen hadden.» En 't varken zeide: "laat hem maar, want hij is zoo overmoedig, want hij is toch een vorst; en gij gaat niet naar hem toe, maar naar hem, die even arm is als wij.»

Toen 't avond geworden was, sneed. I O emboe Mada de kalabas vrucht stuk op den vloer. Hij dacht er niet meer aan 't op een matje te doen. En onder 't huis vielen nu de gouden ponden, de rijksdaalders, de gouden kettingen, de gouden oorhangers, uit de kalabas-vrucht, door hem in stukken gesneden. Hij klom nu naar beneden om ze op te rapen van onder 't huis en hij deed ze in een mandje. ${ }^{1}$

Toen zeide I Oemboe $\mathrm{Mada}$ tot zijn dochter $\mathrm{Kahi}$ : "ga eens kijken daar in 't mandje met kalabas-bladeren, door uw

1 Volgens de adat begint $\mathrm{I} \mathrm{O}$ emboe $\mathrm{Ndiloe}$ varken nu reeds aan zijn oom een gedeelte van den bruidschat te betalen, opdat hij straks diens dochter tot vrouw kan krijgen. Men begint soms al te betalen als 't kind pas geboren is.

Dl. 67. 
tante gebracht, en geef 't aan uw moeder, opdat zij ze kooke.» En I Kahi ging 't mandje openmaken, 't was vol met koperen gevlochten kettingen.

Wederom zond 't varken zijn moeder en zijn moeder ging kalabas-vruchten en bladeren plukken. En 't varken zeide, sprekend tot zijn moeder: "als gij in de kampong komt, vraag dan aan oom Mada om I Kahi, opdat gij hier iemand bij u hebt.» Ja, zeide zijn moeder en ging heen. In de kampong gekomen en nadat zij sirih gekauwd had en gegeten had, vroeg zij om I Kahi aan I Oemboe Mada. Haar vader stemde toe en zij werd door haar tante meegenomen naar den tuin in 't bosch.

"Zijt gij daar weer aangekomen, moeder?» zeide 't varken. Ja, zeide zijn moeder. En wederom vroeg hij aan I R. K. : «hebt gij I Kahi niet mee hierheen gebracht? " $\mathrm{Zij}$ is er», zeide zijn moeder. Men sneed padi en plukte maïs; voortdurend waren zijn moeder en I Kahi, de dochter van zijn oom, aan 't oogsten. En 't varken was voortdurend bezig het huis grooter te maken, de omwanding, de vloeren waren in orde. Des avonds kwam zijn moeder thuis van 't oogsten en I Kahi, de dochter van zijn oom, zeide: "tante, zooeven was ons huis maar een vervallen huis, en dit nu is een prachtig huis en dit is zoo groot. Haar tante zeide: "wees stil, en spreek er niet van.

Wederom den volgenden morgen, gingen zij oogsten, na 't oogsten gingen zij dorschen en brachten 't naar huis. 't Huis was nu vol met kippen, zoo waren zij toegenomen. Zij legden eieren zelfs op den grond.

I O. Ndiloe hakte palen voor zijn huis en I Oemboe Mada, ging zeggen aan I R. K. zijn zuster en aan I Kahi, zijn dochter: "komt morgen met mij de huispalen van I O e m b o e Ndiloe, trekken», zeide hij. Maar I R. K. zeide: "ik ben bang voor hem.» En I Mada zeide: "wees niet bang voor hem, want ik ben er toch ook." "Als 't zoo is, zal ik gaan», zeide I R. K. Toen 't morgen was geworden ging I R. K. om den huispaal te sleepen. Er waren tweehonderd menschen aan 't sleepen, maar zij waren er heelemaal niet toe in staat. Daarom lieten zij den paal maar liggen, omdat zij heelemaal niet in staat waren dien te sleepen. $\mathrm{Al}$ de menschen keerden naar huis terug, daar 't nu toch avond was. 
Wederom toen 't licht werd, gingen alle menschen, tweehonderd en I R. K. ook. Z $\mathrm{ij}$ kwamen bij 't hout, zij probeerden te trekken, maar steeds nog waren zij er niet toe in staat. Toen 't avond was, keerden al de menschen naar huis terug.

Toen I R. K. in huis was gekomen, vroeg 't varken: "zijt gij daar aangekomen, moeder?» Ja, zeide zijn moeder. En 't varken vroeg: "waart gij in staat 't hout te trekken? "Neen, zeide zijn moeder, 't blijft nog op de plaats, waar 't gehakt is.»

Toen 't wederom licht was, ging I R. K. wederom. Al de menschen probeerden te trekken, maar steeds waren zij er niet toe in staat.

Toen I. R. K. in den tuin kwam, vroeg het varken: "zijt gij gekomen, moeder?» Ja, zeide zijn moeder. "Waart gij in staat 't hout te trekken», zeide hij tot zijn moeder, haar vragende. Maar zijn moeder zeide: "wij waren heelemaal niet in staat om te s!eepen, werkelijk zeer zwaar was 't.»

Toen 't wederom licht werd, ging zijn moeder, met IKahi, de dochter van I Oemboe Mada. En I Oemboe Ndiloe varken kwam nu achteraan.

$\mathrm{Al}$ de menschen waren reeds bij den boom gekomen, toen pas kwam 't varken, dat veranderd was in een mensch. Zijn rijpaard was 't rijstblok; de lans in zijn rechterhand was een stuk suikerriet; de sirih-tasch aan zijn schouder was een kippenmandje; de belletjes aan zijn paard, waren djarak-pitten. Hij had een prachtig gekleurde slimoet om zijn lendenen gewikkeld en er een over zijn schouders geslagen, Hij had een hoofddoek van rood en groen doek.

Gekomen bij den paal, door I Oemboe Ndiloe gehakt, was 't varken buitengewoon prachtig, zijns gelijke was er niet. Toen bleef hij te paard en stil staan, en al de menschen, waren verbaasd dat hij er zoo prachtig uitzag. Toen zeide I O emboe $\mathrm{Ndiloe}$ varken, hen vragende: "hebt gij soms zooeven mijn paarden hier niet gezien, heeren en dames?» "Neen», zeiden zij. "Ik heb al meer dan genoeg er van ze te zoeken», zeide hij. "Stijg dan maar van uw paard, Oemboe, en kauw wat sirih!» "Ei, neen, ik kom er niet af; ik ben mijn paarden aan 't zoeken.» $Z_{i j}$ hielden maar steeds aan, dat hij er af zou komen. En hij kwam er af. Men gaf hem sirih en hij reikte zijn sirih-tasch over en zeide: "leg "den vergeten 
echtgenoot ${ }^{1}$ niet op den grond. Nadat zij sirih gekauwd hadden, gaven zij hem te eten, maar zij herkenden hem niet, waar hij vandaan kwam.

Nadat hij gegeten had, zeiden I Oemboe Mada en I Oemboe Ndiloe: "sleep toch met ons een weinig den huispaal, Oemboe!

Maar I O. Nd. varken zeide: "mijn meester zal straks boos zijn, dat ik de paarden niet zie." "Al sleept gij maar een beetje met ons, Oemboe, straks kunt gij dan heengaan.» Toen sleepte I O. Nd. varken met zijn ooms. $Z$ ij waren nu er toe in staat, één paal. Wederom sleepten zij nog drie palen naar buiten. Zoo hadden zij in 't geheel vier palen naar buiten gesleept.

"'t Is al avond, laat ik heengaan», zeide I O. Nd. varken, "mijn meester zal straks nijdig zijn.» Hij besteeg zijn paard en ging heen. Voortdurend sloeg hij zijn paard met een rottan. Bij 't huis gekomen, rolde terstond 't rijstblok op den grond en 't kippenmandje en 't suikerriet. En I O. Nd. varken wroette al weer onder 't huis.

Toen kwamen zijn moeder met I Kahi, de dochter van zijn oom en I O. Nd. varken zeide knorrend: "moeder, zijt gij daar gekomen?» Ja, zeide zijn moeder. En I Kahi, de dochter van zijn oom, zeide: "wat is er toch dat gij daar ligt te knorren onder 't huis; ik zou maar zwijgen, want gij kunt toch niet spreken als die man van zooeven, door mij en tante gezien; buitengewoon mooi was hij, die met ons hout sleepte.» Toen zeide knorrend I O. Nd. varken: "hoe mooi die man, zooeven door u gezien, moge zijn, laat hem maar mooi zijn.» "Zijns gelijke is er niet», zeide I Kahi, de dochter van zijn oom.

Toen 't wederom licht was geworden, kookten zij kleefrijst en eieren, éér mand, om mede te nemen naar 't hout. Toen de rijst en de eieren gaar waren, gingen zij heen om hout te sleepen.

Toen besteeg I O. Nd. varken 't rijstblok-paard; hij hing over zijn schouder 't sirihtasch-kippenmandje; hij nam in zijn

1 Een Soembanees geeft aan dieren en voorwerpen, waaraan hij zeer gehecht is, bijzondere namen. Net bijzondere toespeling wordt hier zijn sirihtasch genoemd: "de vergeten echtgenoot"; want volgen's de adat is hị de aangewezen echtgenoot voor I Kahi. Zoo noemt hij straks zijn paard: „de weggeworpen neef." 
rechterhand de suikerriet-lans en hij ging heen. Bij 't hout gekomen, zeide I O. Nd. varken: "ai, mijn paarden, Oemboe, zoek ik sinds gisteren, maar ik zie ze heelemaal niet. De menschen, die aan 't hout sleepen waren, zeiden: "kom er eerst maar even af, Oemboe, en kauw sirih.» En I O. Nd. kwam er nu af en zijn moeder hield 't paard vast. Toen zeide hij: "gij moet hem niet binden den "weggeworpen neef " en mijn sirihtasch hier "de vergeten echtgenoot», mag niet op den grond gelegd worden.»

Toen men sirih gekauwd had, gaf men hem eten. Nadat hij gegeten had, gingen zij hout sleepen; zij brachten zes stuks naar buiten. 't Was avond toen men naar huis terug. keerde.

I O. Nd. varken besteeg zijn paard en galoppeerde maar steeds door. Bij 't huis gekomen, rolde hij het rijstblok op den grond, legde hij neer het kippenmandje en de suikerriet-lans, en hij wroette al weer onder 't huis. Toen kwamen zijn moeder en I Kahi, de dochter van zijn oom. En I O. Nd. varken zeide knorrend: "moeder, zijt gij daar gekomen?" Ja, zeide zijn moeder. Toen zeide I Kahi, de dochter van zijn oom: "wat hebt gij daar toch te knorren, jij daar onder 't huis ; zwijg me toch stil.» En hij zweeg stil.

Toen 't wederom licht was geworden, kookten zij kleefrijst en eieren. En zij gingen heen om hout te sleepen. I O. Nd. varken maakte zich nu ook klaar. Hij besteeg zijn rijstblokpaard en hing over zijn schouder het sirihtash-kippenmandje en hield in zijn rechterhand de suikerriet-lans. Toen hij klaar was ging hij heen. Bij 't hout gekomen, zeiden zij: «Kom er af en kauw sirih.»

Maar I O. Nd. varken zeide: "ai, neen, Oemboe, ik ben heelemaal nog niet naar huis gegaan, omdat ik de paarden nog niet gezien heb. Ik ben bang voor mijn meester. »

"Kom er maar af, kauw eerst wat sirih en ga dan heen."

En I O. Nd. varken kwam er af. Men gaf hem sirih; nadat hij sirih gekauwd had, gaf men hem eten. Nadat hij gegeten had, kauwde hij sirih en I Oemboe Ndiloe zeide: "Kom eerst even en sleep met ons hout.» En hij ging met hem sleepen. $\mathrm{Al}$ 't hout kregen zij er nu uit. Toen 't avond geworden was keerden allen naar huis terug. En I O. Nd. varken besteeg zijn paard en rende naar huis.

Bij huis gekomen, rolde hij zijn rijstblok-paard op den grond, 
legde zijn sirihtasch-kippenmandje, en zijn suikerriet-lans neer en hij zelf ging wroeten onder 't huis.

Toen kwamen zijn moeder en I Kahi, de dochter van zijn oom. Terwijl zij gingen, spraken zij op den weg: «ik wil wel met hem trouwen,» zeide I Kahi, haar nicht. Ja, zeide haar tante. Thuisgekomen, zeide knorrend het varken: "zijt gij daar gekomen, moeder.»

Ja, zeide zijn moeder. Maar I Kahi, zeide: "wat hebt gij toch te knorren, jij daar onder 't huis; mijn man moet zoo. zijn als hij, door mij en tante zooeven gezien; buitengewoon mooi was hij.» Wat voor moois zou er toch aan hem zijn!" zeide I O. Nd. varken.

Toen 't wederom licht was geworden, gingen zij eten; nadat zij gegeten hadden, gingen zij heen. Toen zag hen de oude Kămi: "ha, gij beide Kahi's», riep zij. "Kom evens even hier aan, Rămboe Kahis, zeide de oude Kămi wederom, terwijl zij hen riep. Maar de beide Kahi's zeiden: "wij willen niet aankomen, want gij stinkt.» "Blijft gij dan boven den wind en ik zal beneden den wind blijven. "Wat wilt gij tot ons zeggen?» «Kom dan hier.»

Toen zeide de oude Kămi: "'t is I O. Nd.varken; iederen dag gaat hij met u hout sleepen.» "Gij houdt ons voor den gek», zeide 't R. K.

"Als ik u voor den gek houd, moogt gij mij doodslaan, daar ik toch al ziek ben; probeer eens u te verbergen en kijk dan hoe I O. Nd. varken in een mensch verandert. 't Rijstblok verandert in een paard; 't kippenmandje verandert in zijn sirihtasch; suikerriet verandert in een lans. »

Toen verborgen zich I R. K. en I Kahi, haar nicht. Zij zagen, dat I O. Nd. varken te paard steeg. En zij zeiden

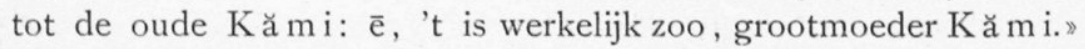
Toen ging I O. Nd. varken heen. En de oude Kămi zeide: "ga weg, want hij zal niet lang wegblijven, daar hij u straks niet ziet. $\mathrm{Zijn}$ omhulsel heeft hij onder een kooksteen gestopt; ga dien oplichten en neem het en kook het en doe ' $t$ in een schotel. Als hij straks terugkomt, giet 't dan over hem uit. Als hij bewusteloos neervalt, til hem op en breng hem in huis, loop driemaal over hem heen en hij zal weer in 't leven terugkeeren.»

Toen keerde I O. Nd varken terug naar huis. Bij 't huis 
gekomen, wilde hij van zijn paard afstijgen, toen goten zij over hem uit, "t water in den schotel. Hij viel flauw en zij namen hem op en brachten hem in huis. Drie maal liep men over hem heen en I. O. Nd. varken leefde weer. En I Kahi, de dochter van zijn oom, zeide: "wat zijt gij toch een listig man, Oemboe Ndiloe!» "Hoe zou ik listig zijn! Gij zelf zijt listig, daarom ben ik toch zoo», zeide I. O. Nd.

Toen 't avond was, trouwde I O. Nd. met I Kahi, de dochter van zijn oom. Toen 't licht geworden was, schoot men geweren af en sloeg op de gongs. En zoo ontstonden slaven, paarden, karbauwen, van alles ontstond er door I O. Nd. Een prachtige kampong werd er door I $\mathrm{O} . \mathrm{Nd}$. gemaakt midden in 't bosch. 't Was geen bosch meer, zoo mooi was alles.

En I O emboe Mada, zijn oom, hoorde 't geluid der gongs en der geweren van uit 't bosch. Toen zeide I Oemboe Mada: "waar zouden die geweren toch zijn en die gongs? Buitengewoon feest schijnt men daar te vieren.» Toen ging I Oemboe Mada eens kijken. Zij waren 't, die feest vierden. En I Oemboe Mada keerde terug naar de kampong en de menschen vroegen hem. Toen zeide hij: "'t is I Ndiloe varken, die veranderd is in een mensch.»

En I Oemboe Mada verzamelde en ging brengen paarden en karbauwen, om te slachten: "want mijn neef is veranderd in een mensch», zeide hij. Zoo slachtte men karbauwen en varkens.

En I O. Nd. varken zeide: "laat I Oemboe Ndiloe, mijn oom, niet komen. Want hij is een vorst en zeer slecht. Gij alleen kom maar, want wij zijn even arm, wij zijn maar als slaven. Eeuwigdurende vijanden zijn ik en I Oemboe Ndiloe.»

En arm werd nu I Oemboe $\mathrm{Ndiloe}$, terwijl hij vroeger zoo rijk was geweest. En 't was I O. Nd. varken welke nu buitengewoon rijk in bezittingen werd. 


\section{I Rămbòe Kahi en I Mili Kămi.}

I Loemba Babang en I Ndjoroe $\mathrm{Ndjara}$ waren de moeder en de vader van I Ră mboe Kah i. Haar ouders gingen iederen dag naar den tuin. Maar I Ră mboe Kahi ging iederen dag naar 't bosch om te vragen een sarong, van haren geweven, aan de Meo Roemba. ${ }^{1}$ En I Meo Roemba zeide tot I R. K.: "wat zult gij mij geven?" Toen zeide I R. K.: "er zijn mijne ouders, die zal ik u geven.» En I Meo Roemba gaf haar een sarong, van haren geweven. Toen zeide I Meo Roemba: "wanneer zal ik komen?" "Over vier dagen», zeide I R. K. terwijl zij haar een tijd bepaalde.

I R. K. keerde terug naar huis. Toen zij twee dagen in huis geweest was, slachtte zij een varken en zij gaf ze allemaal te eten: de huispalen, de balken, de sparren, de latten, de alang alang, de voorgalerij, de deuren, de omwanding, de vloer, de stijlen, de potten, de kruiken, de lepels, de deksels, de hangende mandjes, de zoldertjes, de ladders, de lansen, de kapmessen, de messen, de schotels, het vuur, de matten, de kook-steenen, de offersteen, de rijststampers, de rijstblokken, de grond, de kampong-deur, de steenen omheining, de cactusomheining, de boomen, het gras, de gongs, de trommen, de trommelstokken - alleen de naalden, werden door haar vergeten en werden door haar niet te eten gegeven.

Zij met haar slaven hakten nu in tweeën een kalabas-vrucht; en zij gingen naar de zee en bestegen de kalabas, zij en haar slavin I Jăkoe Dangga. Zij gingen naar I Oe mboe Ndiloe overzee, een neef van haar vader.

Zoo kwam nu de vierde dag; 't was de dag om te vertrekken. En toen kwam I Meo Roemba bij 't huis van I R. K. Bij de deur gekomen, vroeg zij aan de deur: "is I R. K. thuis?"

1 Meo Roemba zijn een soort boschgeesten, groot en ruw. Zij vertoonen zich soms onder de menschen. Maar zijn dan spoedig hieraan kenbaar, dat zij 't eten met schotel en pot en al doorslikken. Ook zijn hun tanden wit. De manlijke Meo Roemba rooft gaarne een meisje, en omgekeerd een vrouwelijke Meo Roemba rooft gaarne een jongeling, om er mee te trouwen.

In dit verhaal is 't een vrouw, I Mili Kămi geheeten. 
zeide zij tot de deur. Maar de deur antwoordende zeide: "dat weet ik niet, ik heb van nacht niet geslapen, want duizendpooten, schorpioenen en tjitjaks klommen tegen mij op.»

Daarop vroeg zij 't wederom aan de steenen omheining; 'de steenen omheining zeide echter: "ik weet 't niet, ik heb van nacht niet geslapen, want slangen en hagedissen klommen tegen mij op.»

Wederom vroeg zij het aan de cactus; maar de cactus zeide: "ik weet 't niet; ik heb van nacht niet geslapen, want de wind liet $\mathrm{mij}$ niet toe van nacht te slapen.»

En wederom vroeg zij 't aan de boomen: "is I R. K. thuis?» Maar de boomen zeiden: "wij weten 't niet."

Wederom vroeg zij 't aan den offersteen vóór 't hūis, maar de offersteen zeide: "ik weet 't niet; ik heb van nacht niet geslapen, de varkens hebben voortdurend om $\mathrm{mij}$ heen gesnuffeld.

Wederom vroeg zij 't aan den grond: «is I R. K. thuis?» zeide I Mjeo Roemba. Maar de grond antwoordde: "ik weet 't niet; ik heb van nacht niet geslapen, want menschen, honden, varkens trapten op mij.»

Zoo kwam zij in de voorgalerij en I Mili Kămi vroeg het aan de voorgalerij. Maar de voorgalerij zeide: "ik weet 't niet, de honden hebben van nacht voortdurend op mij gesprongen.»

Zoo bereikte zij de deur van 't huis en wederom vroeg zij: "is I R. K. thuis?" "Ik weet 't niet, de honden hebben tegen mij gekrabbeld tot 't licht werd», zeide de deur.

En zij vroeg alle mogelijke dingen, welke in huis waren; maar er was niemand die 't wist. Zij had er nu genoeg van en ging slapen op de groote zitplaats, En toen viel daar de naald op haar borst en zij vroeg: "waar is I R. K. ?» Toen zeide de naald, 't vertellende aan I Meo Roemba: "zij is al vertrokken naar de zee, zij besteeg een kalabas-schuit; zij gaat naar I Oemboe $\mathrm{Ndiloe}$, een neef van haar vader in 't overzeesche land», zeide de naald; $\ldots$. allen hebben hun deel gehad, alleen ik werd door haar overgeslagen.»

I Meo Roemba ging haar nu opsporen en hij zag haar van verre en riep en hij zeide: "als gij niet terugkeert, zal ik de schuit breken en doen zinken en ik zal u opeten.

Toen keerde I R. K. terug. "Wij zullen met ons beiden er in gaan», zeide I Meo Roemba. Hij ging er in, terwijl zij 
haar begeleidde. En I R. K. ging en de schuit ging voort. Toen zeide I Meo Roemba: "mijn hoofd wordt er duizelig van "vrouwelijk schaamdeel», zeide zij, haar scheldende; laat mij maar eens zingen.»

En toen zong I Mili Kămi; maar toen ging de schuit heelemaal niet meer. Toen zeide zij: "ha zing jij maar, Rămboe Kahi; de schuit wil heelemaal niet gaan, als ik zing.»

Daarop zong I R. K. en de schuit vloog, buitengewoon snel was het, terwijl de schuit vloog. Wederom schold zij op I R. K., en wederom zong I Mili Kămi, en de schuit wilde niet meer vooruit gaan. "Zing gij maar, Rămboe Kahi, de schuit gaat heelemaal niet, als ik zing.» Toen zong I R. K. en de schuit ging weer vooruit.

In 't overzeesche land gekomen, in de riviermonding, werd I R. K. door I Mili Kămi ingewreven met 't zwartsel van een pot. "Ik zal haar tot mijn slavin maken», zeide zij en daarna wreef zij haar in met 't zwartsel van een pot.

Toen ging I R. K. aan land en zij legde haar mooie kleeren op 't drooge, terwijl zij in de rivier afdaalde om te baden met haar slavin I Jăkoe Danga. Toen nam I Mili Kămi de kleeren van I R. K. weg, de gouden ring, de gouden kam, de gouden armband.

De armband stak zij als een ring aan haar vinger, omdat I Mili Kămi zoo groot was; den ring stak zij op 't topje van haar pink; en de kam deed zij op haar hoofd.

En I R. K., de eigenares der kleeren, bleef naakt in de rivier met haar slavin. $\mathrm{Zij}_{\mathrm{ij}}$ vroeg haar kleeren aan I Mili Kămi: «ik zal je straks opeten», zeide I Mili Kămi. En I R. K. was bang; zij en haar slavin bleven maar stil in de rivier.

Toen hoorde I Oemboe Ndiloe van iemand: "I R. K. is er van Soemba, de dochter van den oom van I Oemboe Ndiloe», zeide men, terwijl hij 't hoorde. En I O. Nd. ging eens kijken en hij werd gezien door I Mili Kămi. Toen zeide I Mili Kămi: "gij hoort van ons en gij komt niet naar ons kijken. Ik heb een neef in 't overzeesche land, zeide mijn vader, daarom is 't, dat ik kom.»

I O. Nd. ging nu de familie bijeen roepen. «'t zal werkelijk wel I R. K. zijn", zeide I O. Nd. En zij kwamen om haar naar de kampong te halen. In de kampong gekomen, zetten zij I Mili Kămi op de groote zitplaats. Maar I O. Nd. sliep op zijn 
eigen plaats en I Mili Kămi bleef op de groote zitplaats, met al de menschen.

$\mathrm{Na}$ ongeveer tien nachten, zeide I Mili Kămi: "I O. Nd. doet mij heelemaal niet op den grond nederdalen.» ${ }^{1}$ Toen 't wederom licht was geworden, ging I O. Nd. de karbauwen bij elkaar drijven. "Zij wil gaarne op den grond nederdalen", zeide hij. En I O. Nd. wilde de karbauwen vangen, maar hij kon ze heelemaal niet in bedwang houden. Toen kwam I Mili Kămi naar beneden, en zij greep de karbauwen vast, zoodat de hoornen er uitschoten. Vervolgens bond men ze met touwen.

Den volgenden dag, ging men ze slachten, terwijl I Mili Kămi op den grond nederdaalde. Toen ging I Mili Kămi naar de stookplaats. Maar I O. Nd. bleef alleen slapen, en ook I Mili Kămi sliep alleen. Toen zeide I Mili Kămi: "wat is er toch met I O. Nd., dat hij niet met mij slaapt! hij blijft maar alleen slapen!»

En zij nu, I R. K. bleef maar naakt in de rivier met. haar slavin, terwijl zij zongen tot haar tante in den hemel. Toen hoorde haar tante in den hemel; en haar tante bracht naar beneden verschillende kleederen voor I R. K. en haar slavin. "Welaan ga mee naar den hemel», zeide de tante tot I R. K. Maar I R. K. wilde niet.

En zij ging nu naar 't boom-huisje in den tuin van I. O. Nd. Aldaar gekomen in 't boomhuisje, veranderde dat boomhuisje in een huis van zink. Eén paal slechts had dat huis.

Iederen morgen gingen zij baden in de rivier en zij sloegen met een stokje de bladeren af, van de sirih-boomen van I O. Nd. En nu kwam I O. Nd. uit de kampong eens zien naar zijn sirih en pinang-boomen. En hij vroeg de oude Kămi, welke den tuin bewaakte; "wat is er met deze sirih, dat ze heelemaal geen bladeren hebben, en deze pinang, dat ze geen bloesemranken hebben? ze liggen maar op hoopjes op den grond!»

1 poeroe la tana=op den grond neerdalen. Wanneer de bruid in 't huis van den bruidegom is gebracht, viert men eenige dagen feest. De bruid moet in huis blijven en mag niet op den grond neerdalen. Na afloop der feesten, laat men haar, na een heelen nacht gedanst te hebben, 's morgens uit 't huis nederdalen en moet zij baden in de rivier. Dan eerst neemt zij de positie van "huisvrouw" in.

Daar 't voor de bruid zelve wat vervelend is, zoolang in huis te moeten zitten, heeft zij een plaatsvervangster, de an a mamóha. Dit jonge meisje representeert de bruid, welke zelve vrij rond loopt. 
Maar de oude Kămi antwoordde: «ik weet niet, wie ze er afgeslagen heeft.» En I. O. Nd. ging heen naar de kampong. Juist was I. O. Nd. vertrokken naar de kampong, of daar kwamen wilde varkeus zijn tuin binnen; er waren wel twintig varkens, terwijl zij opaten de maïs van $\mathrm{I} O \mathrm{O}$. Toen kwam I R. K. midden in den nacht naar beneden en zij ging midden in den tuin staan en zij schreeuwde tegen de varkens en al de varkens stierven.

Toen 't licht geworden was kwam de oude Kămi kijken ; de varkens lagen allen dood op één hoop opgestapeld. En de oude $\mathrm{Kămi}$ nam er één en deed dien in een mand en zij plukte meloen bladen en legde die er boven op. Toen zette zij de mand op haar hoofd en ging naar I. O. N d. in de kampong. In de kampong gekomen, vroeg I. O. Nd.: "waar is dat varken van daan?» zeide hij. En de oude $\mathrm{Kămi}$ zeide: "er waren varkens, welke binnen kwamen om maïs te eten van nacht en toen ik van morgen eens ging kijken, waren ze allemaal dood; toen heb ik er één genomen en kom dien nu brengen; de anderen zijn opelkaar gestapeld blijven liggen in den tuin ginds. »

Nadat de oude Kămi gegeten had, keerde zij terug naar den tuin. In den tuin gekomen, vroeg I R. K. haar: "waar komt gij vandaan, grootmoeder $\mathrm{K} \breve{a} \mathrm{mi}$ ?» «Ik kom van de kampong, en heb een wild varken weggebracht, dat van nacht dood gegaan is.»

I. R. K. liet nu eten voor de oude $\mathrm{Kămi}$ naar beneden zakken, allerlei soort gekookte groenten; op gouden borden deed zij 't eten, en gaf 't aan de oude Kămi. Maar zij deed de rijst echter over in een mandje, want zij was bang te eten uit een etensbord van een vorst.

Wederom liet I. R. K. nu sirih, pinang en tabak naar beneden zakken in een gouden sirih-mandje. De oude Kă mi nam 't aan en reikte 't sirih-mandje weer terug, nadat zij de inhoud er uit genomen had. Toen zeide I. R. K tot de oude Kămi: "zeg 't aan niemand, dat ik hier ben.» "Ja», zeide de oude Kămi,

's Avonds en 's morgens gaf I R. K. eten aan de oude Kă mi; alleen witte rijst gaf zij. En de varkens kwamen weer in den tuin; toen ging I R. K. midden in den nacht nąar beneden en zij stond midden in den tuin. $\mathrm{Al}$ de varkens stierven. Toen 't weer licht was geworden, ging de oude $\mathrm{Kămi}$ door den 
tuin wandelen en zij zag de doode varkens. Zij nam er één en deed dien in een mand; toen plukte zij jonge meloen bladeren en deed die er boven op. Toen de oude $\mathrm{K}$ ămi in de kampong kwam, zag I O. Nd. het varken en hij zeide: "wat is toch de oorzaak, dat de wilde varkens zoo dood gaan?» Maar de oude Kămi zeide: "buitengewoon veel zijn er in den tuin, welke dood zijn.»

Toen zeide I O. Nd.: "welaan ik zal eens met je gaan kijken.»

En I O. N d. ging nu naar den tuin en hij ging even kijken naar de sirih: steeds waren er nog geen bladeren, want IR. K. met haar slavin sloegen ze er steeds af. Toen vroeg I O. Nd.: "hoe is dat met deze sirih, ze krijgen heelemaal geen jonge spruiten!» Maar de oude Kămi zeide: "wie weet 't! ik weet niet, wat de oorzaak er van is.s

Vervolgens ging I O. N d. kijken naar de varkens, welke dood in den tuin lagen. Hij zag de wilde varkens. "Hei, werkelijk buitengewoon veel varkens zijn er gestorven», zeide I O. Nd. tot de oude $\mathrm{K}$ ămi.

Toen zag hij de witte rijst en veel sirih bij de oude Kămi; en I. O. Nd. vroeg: "waar hebt gij die witte rijst vandaan gekregen, Kămi?»

"Ik heb ze van de menschen gevraagd», zeide de oude Kă m i. En zij kookte nu eten om 't aan I O. Nd. te geven. Toen 't gaar was, schepte zij 't eten op en gaf het aan I O. Nd. Toen I O. Nd. gegeten had, vroeg hij wederom aan de oude $\mathrm{Kămi}$ : "gij moet 't zeggen, grootmoeder $\mathrm{Kămi}$, wie u de witte rijst gegeven heeft.» «'t Is mij door iemand gegeven, wien ik er om gevraagd heb, heb ik toch gezegd.» "Wie is 't die 't $u$ gegeven heeft? heeft die dan geen naam soms? Maar de oude Kămi zweeg en antwoordde niet aan I O. N.d., want zij was bang voor I. R. K.: «zeg 't aan niemand», had zij tot haar gezegd.

Toen ging I. O. Nd. eens naar buiten en hij keek op naar het boomhuisje. 't Was veranderd in een zinken huis. "Dit boomhuisje, was een huis van alang alang toch, toen ik 't makkte! En nu is er een huis met zink en heeft 't een ijzeren paal! Wie heeft dat voor-u gemaakt? Als gij 't niet zegt, zal ik je dooden», zeide I O. Nd.

Toen zeide de oude Kămi: "de sirih, waarvan de bladeren op hoopjes op den grond lagen, waarvan gij hebt gesproken; 
die heeft I R. K. daar boven er af geslagen; dat is haar huis, dat daar boven. En wat haar in de kampong betreft, van wie gij zegt: dat is I R. K. van Soemba; dat is ze niet, maar 't is een Meo Roemba, en haar andere naam is I Mili Kămi.

Toen ging I O. $\mathrm{Nd}$. onder 't huis van I R. K. zitten zingen. En I R. K. daar boven antwoordde, terwijl zij ook zong. Zij bleven antwoorden en zingen dag en nacht, totdat I O. Nd. in 't zingen overwon. Toen liet I R. K. een ladder zakken, opdat I O. Nd. naar boven zou' klimmen. En I O. Nd. klom naar boven in 't boomhuisje.

Geruimen tijd daarna ging I O. Nd. naar de kampong. In de kampong gekomen, vertelde I O. Nd. 't nog niet aan de menigte, alleen aan I Ndiloe van de overzijde, en aan zijn ouders vertelde hij 't fluisterend, opdat I Mili Kămi 't niet zou hooren.

Toen I Mili Kămi I O. Nd. zag, zeide zij tot hem: "waarom, Oemboe Ndiloe, gaat gij u verbergen in den tuin? gij komt heelemaal niet in mijn kamer.» Maar I Ndiloe, van de overzijde, zeide tot I Mili Kămi: "dat is, omdat gij uw tanden nog niet zwart gemaakt hebt; maak die eerst zwart en laat ze afvijlen, dan pas zal I O. Nd. in uw kamer komen.» Toen zeide I Mili Kămi: "ik wil gaarne mijn tanden zwartmaken en afvijlen. Wanneer zullen wij gaan?»

Toen 't den volgenden dag licht was geworden, gingen zij naar een woendoetoe-boom. En die boom was op den rand van een ravijn. Toen klom I Mili Kămi er een eindje in, en zeide: "tot hier." "Neen", zeide I O. Nd. Wederom klom zij een beetje hooger. Maar I Ndiloe, van de overzijde, zeide: "klim nog wat hooger, totdat gij den top bereikt hebt.» Daar ging zij zitten en bladeren kauwen.

En zij bleef maar bladeren kauwen. Voortdurend hakte men nu tegen den boom; de bijlen gingen gelijk op en neer. Toen zeide I Mili Kămi: "waarom kapt gij daar in den boom?" En I O. Nd. zeide: "opdat gij er straks in kunt stappen, als gij naar beneden komt.» Steeds door bleven zij hakken. 't Scheelde maar weinig of de boom zou vallen. Toen zeide I Mili Kămi: "wat is er toch? 't kraakt!» Maar I O. Nd. zeide: "kauw gij daar maar; 't is de wind, die hem heen en weer schudt.»

Steeds door bleven zij hakken, totdat de boom in 't ravijn 
viel. En I Mili Kămi stierf. De rijststampers en rijstblokken, stukken van borden en stukken van potten; van alles kwam er uit haar buik.

Toen I Mili Kămi dood was, ging I O. Nd. naar de kampong om de familie bij elkaar te roepen. Vervolgens kwamen zij bij elkaar om I R. K. te halen en naar de kampong te brengen. De geheelé menigte ging uit de kampong om I R. K. te halen. Men slachtte van af de kampong, totdat men bij den tuin kwam.

$\mathrm{Nu}$ namen zij I R. K. mee naar de kampong. Men slachtte van af den tuin, tot men in de kampong kwam. Onafgebroken vierde men feest, toen I R. K. uit den tuin in de kampong kwam. 
XVIII. I Rămboe Kahi, zonder hoofd.

Oemboe Hadoe Hina en I Lingga Wăndăl, waren de vader en moeder van I Rămboe Kahi. Haar moeder I Lingga stierf en zij bleef alleen met haar vader. I Rămboe $\mathrm{Kahi}$ was nog een klein kind, toen haar moeder stierf, zij kende nog niets, zij was nog een heel klein kind, maar haar vader voedde haar op.

$\mathrm{Z}_{\mathrm{ij}}$ werd ouder, zij kon loopen. Langzamerhand werd I Rămboe Kahi ouder en ouder.

Op zekeren dag ging haar vader om een tuin te maken; hij nam I Rămboe Kahi mee en liet haar niet in huis. Toen de regentijd was gekomen, gingen zij planten. Hij nam mee eten voor I Rămboe $\mathrm{Kahi}$ en ook water in een kleine kalabasflesch.

Toen hij onkruid ging wieden, nam hij haar ook mee en zette haar bij een pisang-boom. Toen 't avond werd keerde zij en haar vader terug naar huis. Wederom des 's morgens, ging zij naar den tuin met haar vader. In den tuin gekomen, zeide haar vader: "ha Rămboe, drink niet telkens veel water, als je keel maar vochtig is, want 't water is ver.» Ja, zeide I R ămboe Kahi.

Na verloop van korten tijd zeide I R. K. : vader, ik heb dorst. Haar vader zeide: "drink dan een beetje, maar drink niet al te veel, want 't water is ver.» Maar I R. K. deed niets dan water drinken; telkens en telkens dronk zij, tot 't water op was.

Zij wachtte even en riep haar vader: "vader, ik heb dorst", zeide I R. K. "Drink dan een beetje», zeide haar vader. "Er is niets meer, 't is op», zeide I R. K. Toen zeide haar vader: "wat heb ik je zooeven gezegd, 't water is ver, heb ik je zooeven gezegd.» "Vader, vader», zeide I R. K., terwijl zij hem riep, totdat haar vader opstond; en hij nam de kleine kalabasflesch en hij maakte los 't touw van zijn kalk-zakje en bond er de kalabas-flesch aan en haar vader zeide: "wacht maar op mij hier, ik zal water gaan zoeken.» Ja, zeide I R. K.

Haar vader ging heen; na korten tijd kwam hij terug van 't water scheppen en I R. K. dronk. Haar vader ging weer 
onkruid wieden. Toen 't avond werd, keerden zij terug naar huis. Wederom wakker geworden toen 't licht werd en nadat zij gegeten hadden, zeide haar vader: "gij moet maar niet meer gaan naar den tuin.» "Ik ga, vader», zeide I R. K.

Maar haar vader zeide: "ik wil straks wat onkruid wieden, maar gij laat mij niet toe te wieden, gij maakt mij moede met water te laten scheppen. Maar I R. K. zeide: "neen, vader», en zij huilde maar. Toen zeide haar vader: "als 't zoo is, ga dan vullen daar die kalabas-flesch met water, opdat wij heengaan.»

$\mathrm{Zij}$ deed nu water in de kalabas-flesch en zij gingen naar den tuin.

In den tuin gekomen, zette haar vader haar neer bij een pisangboom en hij ging onkruid wieden. Na korten tijd zeide I R. K.: "vader, laat mij wat water drinken." En haar vader zeide: "dat was 't zooeven, dat ik zeide: kom niet; drink dan maar een beetje water. Onophoudelijk dronk nu I R. K., totdat 't water op was.

Na korten tijd: "vader, ik heb dorst», zeide I R. K., terwijl zij haar vader riep. "Drink dan maar een beetje water», zeide haar vader. Maar I R. K. antwoordde aan haar vader: "'t water is op, vader." Toen zeide haar vader: "dat was 't toch, kom niet, zeide ik je zooeven; buitengewoon boos is mijn hart, dat gij zoo doet. Haar vader maakte nu los 't touw van zijn kalkzakje en bond 't aan de kalabas-flesch. "Laat mij maar water gaan scheppen», zeide zij tot haar vader. Maar haar vader zeide: "gij moet niet gaan, gij valt straks in den put. Maar I R. K. zeide: "ik ga.» En haar vader zeide: «laat ' $t$, je zult straks in den put vallen.» Maar antwoordende zeide I R. K. tot haar vader: "neen, ik zal niet vallen.» Toen zeide haar vader: "als dat zoo is, ga dan maar."

En zij ging naar den put. Bij de put gekomen, liet zij de kalabas-flesch naar beneden zakken; 't touw strikte om haar hals: knap, zei haar hoofd, terwijl 't in den put viel. Haar lichaam bleef boven bij den put. En haar vader wachtte en wachtte op haar, maar hij zag I R. K. heelemaal niet wederkeeren van den put. Toen ging hij kijken naar den put; daar was haar lichaam alleen maar, terwijl hij 't zag boven bij den put. En hij bracht 't naar de kampong om 't te begraven. Onbeschrijflijk droef was haar vader. Eten at hij niet, sirih kauwde hij niet, totdat de vader van I R. K. geheel en al mager was. DI. 68 
$\mathrm{Na}$ korten tijd werd de put ondiep en werd een plas. En I Oemboe Mada, de jongere broeder van I Oemboe Ndiloe, dreef de paarden bij elkaar, om ze te laten drinken in de plas. Toen de paarden dicht bij de plas waren gekomen, schreeuwde I R. K.: "tja paarden, tja paarden, je trapt straks boven op mij. De paarden keerden van angst terug, door 't schreeuwen van I R. K.

Toen zeide I Oemboe Mada: "wat zou er toch in die plas zijn, dat de paarden bang zijn; een mensch, zou ik zeggen, maar er is geen mensch te zien.» En I O emboe Mada keerde maar terug.

Wederom kwam I Oemboe Mada op een anderen dag; hij dreef de paarden bij elkaar om ze te laten drinken in de plas. De paarden kwamen bij de plas en wederom schreeuwde I R. K.: "tja paarden, tja paarden, je zult straks op mij trappen." Toen zeide I Oemboe Mada: "als gij daar, een man zijt, of als gij daar, een vrouw zijt, laat dan tenminste u zelven zien, doe 't dan maar aan de andere zijde (van de plas.)" "Ai ha, de paarden zullen mij trappen, zeg ik jou daar, zeide I R. K. tot I Oemboe Mada.»

Naar huis terug keerde I Oemboe Mada; de paarden hadden nog geen water gedronken. Toen kwam I Oemboe Ndiloe terug van de kampong en hij zag dat de paarden mager waren en hij vroeg aan I Oemboe Mada: "buitengewoon mager zijn de paarden, ga je ze geen water laten drinken.» En I Oemboe Mada zeide: "hoe zou ik niet gaan? maar er is iemand die de paarden wegjaagt, daar beneden in de plas.» Toen zeide I Oemboe Ndiloe: "wat zou daar beneden in de plas toch kunnen zijn? je praat maar onzin.» "Hoe zou ik onzin praten; welaan laat ons dan samen gaan», zeide I Oemboe Mada tot I Oemboe Ndiloe. "Ga dan maar! als ik straks niets zie»!

En I Oemboe Mada ging de paarden bij elkaar drijven en hij ging met I Oemboe Ndiloe. De paarden kwamen bij de plas. En I R. K. schreeuwde: "tja paarden, tja paarden, je zult straks op mij trappen.» Toen hoorden 't I Oemboe Ndiloe en I Oemboe Mada.

En I Oemboe Mada zeide: "wat heb ik zoo even gezegd! je praat onzin, wou je tegen mij zeggen. $\gg$ Toen,zeide I Oemboe Ndiloe: "welaan Rămboe, als gij daar, een Rămboe zijt; welaan Oemboe, als gij daar, een Oemboe zijt: ga wat aan 
de andere zijde, opdat de paarden een beetje kunnen drinken.

«Wat zou ik anders zijn, ik ben een Rămboe! een Rămboe ben ik», zeide I R. K. terwijl zij antwoordde. Toen zeide I Oemboe Ndiloe: "welaan toch, de paarden drinken heelemaal geen water; vertoon u zelven.»

"Hoe kan ik mij zelf vertoonen, daar gij een metgezel bij u hebt. »

Toen beval I Oemboe Ndiloe aan I Oemboe Mada heen te gaan.

En I Oemboe Mada ging heen; toen zeide I Oemboe Ndiloe: "vertoon u zelven nu! Maar I R. K. zeide: "daar ik alleen maar hoofd ben, zult gij mij misschien straks dooden.

"Neen, als gij u ten minste maar vertoont , zeide I Oemboe Ndiloe. Toen vertoonde I R, K. zich; en zij zeide tot I Oemboe Ndiloe: neem mij toch, stop mij in uw sirih-tasch; laat mij op mij nemen te bewaken uw tuin, uw kippen.»

Toen nam I O. Nd. haar en stopte haar in zijn sirih-tasch. En sprekende zeide hij tot haar: "praat hier nu niet straks, als ons iemand ontmoet; ik zou beschaamd over u zijn, daar gij enkel maar hoofd zijt.» En I R. K. zeide: "neen, ik zal straks niet praten.»

Toen gingen zij heen en zij ontmoetten iemand op den weg en die man zeide: "geef mij toch, Oemboe, sirih te kauwen uit uw sirih-tasch.» Maar I R. K. antwoordde: "ga! ziet gij soms dat I O. Nd. terug komt van sirih en pinang halen, dat gij sirih en pinang aan hem vraagt; hij komt toch terug van 't drinken geven aan de paarden!» De man ging heen en zij gingen heen.

Toen zeide I O. Nd.: "praat hier niet, heb ik zooeven tegen u gezegd; en toch praat gij maar; ik ben beschaamd over u, daar gij enkel hoofd zijt.» Maar I R. K. zeide: "niet meer, ik zal straks niets zeggen.»

$\mathrm{Z}_{\mathrm{ij}}$ gingen verder en wederom ontmoetten zij iemand, en hij vroeg tabak. Wederom antwoordde I R. K. : "ziet gij soms, dat I Oemboe Ndiloe terug komt van 't tabak snijden, dat gij hem tabak vraagt?» Vervolgens ging die man maar heen.

Zij gingen nu naar den tuin van I O. Nd. en hij zette I R. K. neer op een tomaten-struik. Daarop ging I O. Nd. naar de kampong. Er was nu iemand, die sirih kwam stelen; hij werd gezien door I R. K. en zij riep hem. De dief hoorde haar 
en vluchtte. $Z$ ij zag de roofvogels, die kuikens wilden rooven; zij verjoeg ze en al de roofvogels vielen dood.

I O. Nd. kwam nu in den tuin en vroeg aan de oude $\mathrm{Kămi}$ : "hoe is 't?" Maar I R. K. antwoordde: "iemand heeft al uw sirih gestolen.» Toen ging I O. Nd. er naar kijken: netjes opgestapeld lag de sirih. Toen nam I O. Nd. ze op en ging heen.

Na twee à drie dagen kwam I O. Nd. wederom in den tuin; en hij vroeg aan de oude $\mathrm{Kămi}$ : is er iemand bij de sirih geweest? De oude Kămi antwoordde niet. 't Was I R. K. die antwoordde: "ben ik 't niet, die op mij nam er naar te kijken, dat gij 't aan de oude Kămi vraagt, of er iemand bij de sirih is geweest!

Toen ging I O. Nd. naar de kampong. $\mathrm{Na}$ verloop van drie dagen, kwam I O. Nd. wederom in den tuin. Vervolgens vroeg hij aan de oude Kămi, maar I R. K. antwoordde: "hoe is."t, dat deze uw slaaf, door u gevraagd wordt, maar ik, die uw sirih bewaak, wordt door u niet gevraagd? En I R. K. zeide tot I O. Nd., terwijl zij hem vroeg: "wat voor feest is er boven in de kampong?" Toen antwoordde I O. Nd.: "men viert een huwelijk." Toen zeide I R. K.: "neem mij mee om naar't feest te gaan zien." Maar I O. Nd. zeide: "ik heb er genoeg van u mede te nemen, gij praat toch te veel; ik ben bang voor mijn vrouw I Tèngga W r roe.» "Ik zal straks geen geluid geven», zeide I R. K. Toen zeide I O. Nd.: »dat is 't maar, geef straks geen geluid, als gij in de kampong komt; 't is iemand, die overspel met hem bedrijft, zal straks misschien I Tèngga Wor roe zeggen.» Wederom zeide I R. K.: "als wij straks bij huis komen, steek mij dan achter de omwanding, en zoo niet achter de omwanding, steek mij dan in een spleet van een paal.»

Thuis gekomen ging I O. $\mathrm{Nd}$. recht door naar de kamer; maar zijn vrouw I Tèngg a Woroe zei: "hoe is 't, dat gij zoo recht door naar de kamer gaat? brengt gij mij eens niet uw sirih-tasch? misschien is er wel wat sirih door u meegebracht uit den tuin», zeide zij.

"Laat mij eerst mijn buikgordel losmaken», zeide I. O. Nd. Toen hij zijn buik-gordel had losgemaakt, ging hij uit de kamer naar zijn vrouw bij de stookplaats. Toen kauwde I Tèngga sirih. Zij beval haar, slavin en die schepte eten op en gaf't aan 
I O. Nd. Daarop ging I O. Nd. eten; toen hij gegeten had, kauwde hij sirih.

- Toen sloegen zij op de gongs, de menschen die feest vierden in 't andere huis. Hij vroeg nu aan zijn vrouw hem met klapper in te wrijven.

"Daar is nog wat in de klapperdop overgebleven, 't overschot van toen gij uw kind hebt ingewreven», zeide zijn vrouw. Daarop gaf hij 't haar en zij wreef hem in. Toen zij hem met klapper had ingewreven, ging I O. Nd. zich aankleeden.

Pas daalde I O. Nd. af in de voorgalerij of I R. K. begon gillend te schreeuwen, in de spleet van een paal, totdat I O. N d. de trom bereikte en danste; steeds bleef I R. K. gillend schreeuwen. En I Tèngga hoorde het en zeide: "misschien is er iemand, meegebracht door $\mathrm{I} \mathrm{O} . \mathrm{Nd}$ ? Zij ging de kamer in, met een licht; zij zag niets. Zij rolde al de matten open, ze naziende, ook achter de omwanding, maar hij zag niets. Toen zeide I T èngga tot I O. N d.: "is er iemand door u verborgen in de kamer?" "Er is niemand", zeide I O. Nd. "Hoe is 't dan, dat men zoo gillend schreeuwt!» «Er is niemand , zeide I O. Nd.

Wakker geworden toen 't licht werd, begon I T èngga met een gloeiend hart te zoeken, totdat zij haar vond in de spleet van een paal. Toen pakte zij haar beet en wierp haar op den grond. Maar I. O. Nd. was niet in huis; hij was in 't andere huis een bezoek gaan brengen.

Toen hij in huis terug keerde, vroeg I Tèng g a aan I O. N d. : "er is niemand, hebt gij mij gezegd; ga dan nu maar eens kijken boven op de cactus. Toen riep I R. K. tot I. O. N d. : "Kom toch, neem mij en ga mij brengen naar den tuin; uw vrouw is niet wijs! zij heeft mij in de cactus geworpen.»

Toen nam I O. Nd. de schacht van een lans en stak uit 't hoornen ondereind en prikte er I R. K. op en ging haar naar den tuin brengen. Hij zette haar weer in de tomaten struik.

Juist was I O. Nd. terug gegaan naar de kampong, of I R. K. veranderde in een mensch; veel slavinnen waren er, die zingend achter haar liepen naar de rivier. De oude Kămi sloeg haar gade, toen zij gingen baden. Toen kwam I O. Nd. van de kampong en de oude Kămi zeide: "Kom hier heen, oemboe!» Maar I. O. N d. zeide: "neen, want 't stinkt zoo dicht bij je.» "Blijf dan boven den wind en ik zal beneden den wind blijven; ik heb u wat te zeggen. 
I O. Nd. ging nu. "Kauw mij een sirih pruim», zeide de oude $\mathrm{K}$ ă mi.

"Ei, ei!» zeide I. O. N d. "Buitengewoon mooi was I R. K. toen ik haar gisteren zag», zeide de oude Kămi. "Als gij mij voor den gek houdt, zal ik je dooden!» "Neen», zeide de oude Kămi.

En I O. Nd. bleef overnachten, terwijl hij op den loer stond. De nacht was reeds ingegaan, terwijl hij op de wacht stond bij de tomaten struik. Daarop ging I R. K. baden, terwijl veel slavinnen op een rij achter elkaar liepen en zongen. Toen nam I O. Nd. 't omhulsel en verbrandde 't in 't vuur, nadat hij 't geweekt had in een schotel met water. Toen keerden zij terug van de rivier en hij goot 't water uit op I R. K. Allemaal vielen zij bewusteloos neer, I R. K. met haar slavinnen. Toen tilde I O. N d. haar op en bracht haar in huis. In huis gekomen, kwam I R. K. weer tot bewustzijn. En zij zeide tot I O. Nd.: "gij kent heel wat listen, Oemboe Ndiloe!» Maar I. O. Nd. zeide: "dat kent gij toch, Rămboe Kahi!"

Maar I. R. K. zeide: "neen, ik ken heelemaal geen listen."

Toen trouwde I. O. N d. met I R. K. Vervolgens nam I R. K: een waaier en zij ging er mee waaien. En toen ontstond er een gouden huis. Wederom waaide zij en er ontstonden veel slaven, 't huis propvol.

$\mathrm{Na}$ vijf à zes dagen zond I Tèngga een slaaf uit de kampong: "ha $\mathrm{Kawau}$, ga eens kijken naar I O. $\mathrm{Nd}$. in den tuin. $\mathrm{Hij}$ is er al wel tien nachten. Ik ga eens naar den tuin, zeide hij wel tot mij, maar ik zie hem heelemaal niet terugkeerens, zeide I Tèngg a. Daarop ging I Kaw a u naar den tuin, om naar I. O. Nd. te zien. In den tuin gekomen: "wat is er, Kawau? vroeg I. O. Nd. aan I. Kawau. "De meesteres heeft mij gezonden: ga eens even kijken naar den meester in den tuin, zeide zij tot mij, en daarom kom ik.» Maar I. O. Nd. zeide tot I Kawau: ga maar.

En I Kawau keerde terug naar de kampong. In de kampong gekomen, vroeg I Tèngga aan I Kawau: «is uw meester in den tuin», zeide zij. En I Kawau zeide: "hij is in den tuin en er is ook een vrouw van hem. "Toen vroeg I Tèngga: "wie is die vrouw van hem?» En I Kawa u zeide: "Kahi enkel hoofd.» Toen zeide I Tèngg a: "zij! 't is best te begrijpen, dat I. O. N d. buitengewoon lang wegblijft. En zij zond I K a w a u 
en I Kaka om het varken onder 't huis te vangen en te brengen naar de echtgenoote van I O. Nd. : de onvergelijkelijke moet al de ribben van 't varken er uit halen, er mag geen haartje uitgetrokken zijn, niet één, en 't varken mag niet sterven.

I Kaka en I Kawau droegen 't varken op hun schouders en brachten 't varken naar den tuin. En zij kwamen in den tuin. "Hier is 't varken», zeiden zij tot I R. K. "Waarom is't, dat gij een varken hierheen brengt», zeide IR. K. tot I Kawa u en I Kaka. "Breng 't haar, opdat zij de ribben er uithale, de haren mogen er niet uitgetrokken zijn en 't mag ook niet dood zijn, zeide de meesteres tot ons. "Hoe' is 't, een toovenares, zegt zij van $\mathrm{mij}$, dat $z$ ij $\mathrm{mij}$ zegt de ribben er uit te halen? Wie kan de ribben er uit halen? Hak 't open, dan pas kan ik de ribben er uit halen.

En I R. K. beval haar slavin: ga en maak eten klaar voor I Kawau en I Kaka. Zij gingen eten koken. En I R. K. bracht 't varken binnen in de kamer en zij waaide met den waaier, terwijl zij er de ribben uithaalde. Toen I K a wa u gegeten had, riep I R. K. hem: "Komt en draagt 't varken terug naar de kampong.» En I R. K. zeide tot I Kawau: "ik ben geen toovenares, al kan ik de ribben van een varken er uit halen, moet gij goed aan uw meesteres zeggen. »

Daarop ging I Kawa u naar de kampong, terwijl zij 't varken droegen. I Kawau kwam in de kampong en zij legden het varken in de voorgalerij. "Heeft zij de ribben er uit gehaald?» zeide I T èngga, terwijl zij 't vroeg. " $Z$ ij heeft 't klaar», zeide I Kawau. En I Tèngga ging 't varken over 't geheele lichaam knijpen.

«Ga en leg 't onder 't huis, zeide I T èngga tot I Kawau. Zij gingen en brachten 't onder 't huis.»

Toen zij wederom wakker werd, toen 't licht was, zeide zij: "vang één geit, breng 't haar wederom, opdat zij alle beenderen er uit hale.»

Daarop gingen I Kawau en I Kaka de geit wegbrengen. Zij kwamen in den tuin en I Kawau zeide: "er is weer wat, rămboe, een geit! ga die brengen opdat zij er al de beenderen uithale, zeide zij tot ons.» $\mathrm{Zij}$ nam de geit aan en waaide met den waaier; zij haalde al de beenderen er uit. Toen zij er de beenderen had uitgehaald, gaf zij ze aan I Kawau, om ze weg te brengen. 
I Kawa u ging nu naar de kampong. In de kampong gekomen, legden zij de geit in de voorgalerij. En I T èngga kwam naar beneden, terwijl zij de geit overal betastte. Toen zij ze geheel betast had: ga haar maar loslaten, zeide I Tèngga.

Wederom ving zij nu een haan en zond I Kawau om dien te brengen en er de beenderen uit te halen. Toen gingen I $\mathrm{Kaw}$ au en I Kaka den haan wegbrengen. Zij kwamen er aan en wederom haalde zij de beenderen uit den haan. Nadat zij ze er uitgehaald had, gaf zij hem terug en zij gingen heen. I $\mathrm{Kaw}$ a u en I Kaka in de kampong gekomen, legden den haan weer in de voorgalerij. I T èng g a kwam naar beneden, terwijl zij den haan kneep, maar zij voelde nergens één been meer. Toen zeide zij: ga hem maar in huis brengen.

Wederom wakker geworden toen 't licht was, nam zij een mand en deed er katoen in; zij drukte 't stevig vast en riep I Kawau en I Kaka: "gaat 't brengen, zij make terstond op dezen dag nog een gekleurde slimoet en een gekleurde rok; breng 't nu terstond.»

I Kawau en I Kaka gingen heen en zij kwamen in den tuin. Toen vroeg I R. K. : wat heb je daar, Kawau?" «'t is katoen; breng 't, opdat zij er terstond heden een gekleurde slimoet en een gekleurde rok van make en 't ook terstond afmake.» $Z_{i j}$ nam 't aan en werkte en maakte 't terstond af en gaf ze aan I Kawau. En I Kawa u nam ze aan en bracht ze naar de kampong. "Breng 't, Kawau! zij hier beneden kan heelemaal niet werken, zult gij tot haar zeggen», zeide I R. K.

En I Kawau kwam in de kampong en zij legden ze neer in de voorgalerij. I T èngga kwam naar beneden en zij keek naar de gekleurde slimoet en de gekleurde rok, een mand vol en zij bracht ze in huis. "Oe! zoo gaat 't niet! telkens loop ik er in; wat ik zeg, zij doet 't telkens.»

Wederom wakker geworden toen 't licht werd, ging zij naar haar toe, en zij kwam bij 't huis van I R. K. "Kom naar beneden », zeide I T èngg a tot I R. K. Maar I R. K. riep haar slavin: "breng haar sirih», zeide zij. Maar I T è ngg a wilde geen sirih kauwen. Toen kwam I R. K. naar beneden. Zij sloeg naar I R. K., maar raakte haar niet. I R. K. raakte haar echter wel, terwijl zij haar sloeg, totdat de oogen en 't lichaam van I Tèngg a gezwollen waren.

I Tèngga keerde nu terug naar de kampong. Maar I O. Nd. 
ging het zeggen aan haar ouders. Toen I O. N d. in de kampong kwam, wachtte I Tèngga hem op en schold hem uit. Toen werd I Tèngga geslagen door I O. N d. en hij joeg haar uit huis. $\mathrm{Zij}$ keerde weer terug naar 't huis van haar vader en broeders.

Zijn ouders gingen nu naar den tuin en de heele kampong kwam bij elkaar om I R. K. te halen, men slachtte, beginnende boven in de kampong, totdat men den tuin bereikte. En I R. $\mathrm{K}$. zond haar slaven, om haar schoonvader en schoonmoeder tegemoet te gaan.

Toen haar schoonouders bij 't huis gekomen waren, werden zij in huis gedragen. Den volgenden morgen kwamen al haar slaven om haar schoonouders te dragen. Men droeg haar in eens, met huis en al. Men slachtte, beginnende bij den tuin, totdat men in de kampong kwam. In de kampong gekomen, vierde men buitengewoon feest. Men sloeg op de gongs; de vrouwen dansten, de mannen dansten, men hield spiegelgevechten.

Toen hoorde het de vader van I R. K. Zijn oogen, welke blind waren geworden van 't huilen, werden weer geopend, daar I R. K., die in de put was gevallen, weer terug was gekomen, naar hij hoorde. Toen zij van de menschen hoorde, dat haar vader er was, liep zij haar vader tegemoet. Toen zag I R. K. haar vader; buitengewoon blijde was I R. K., toen zij hem zag. $Z$ ij kuste zijn handen en zijn voeten. En haar vader ook weende, omdat hij dacht aan zijn dochter, dat zij nu weer in 't leven was terug gekeerd. 
XIX. I Rămboe Kahi, met den boschhaan.

I Ndjoroe Ndjara, was de vader van I Rămboe Kahi; haar moeder was I Loemba Babang; haar broeders waren I Pila Ndiloe en I Mada. Iederen dag sliepen haar ouders en haar broeders in den tuin, terwijl zij onkruid wiedden in den tuin. Alleen I R. K. was 't, die in de kampong bleef, daar zij moest weven. Toen haar ouders in den tuin gingen slapen, zeiden zij tot haar: "wees vlijtig en breng ons eten.» Ja, zeide I R. K. En haar moeder zeide tot haar: "weef wat vlug, opdat gij 't afmaakt en kom dan naar ons om onkruid te wieden in den tuin.» Ja, zeide I R. K.

En haar ouders en haar broeders vertrokken nu naar den tuin. Den volgenden morgen, bracht I R. K. haar weefgetouw naar beneden en begon te weven. En een boschhaan hoorde haar, het dreunend geluid dat I R. K. maakte bij 't weven. De boschhaan kwam nu dichter bij en zette zich neer op 't kopstuk van 't weefgetouw van I R. K. Toen zeide de boschhaan kakelende: "ho Rămboe Kahi, kauw mij een sirih-pruim voor rooden mond, kauw mij klapper voor glimmend gezicht. ${ }^{1}$

En I R. K. kwam naar buiten en rolde haar weefgetouw op. Zij pakte den boschhaan op en klom er mee in huis en deed hem in een kamer. Toen ging zij eten klaarmaken en toen 't eten gaar was, schepte zij 't op en gaf 't hem om te eten, met kippen eieren.

En de boschhaan zeide kakelend tot I R. K.: "ga gij naar buiten en laat mij alleen eten.» Toen ging I R. K. naar buiten. En de boschhaan at. Nadat hij gegeten had, nam I R. K. de schotels weg en gaf hem sirih om te kauwen. Wederom nam zij hem op en bracht hem in de voorgalerij. Toen vloog de boschhaan, weggaande, heen. Daar 't avond was geworden, bracht zij haar weefgetouw in huis.

1 kapoe nda pahăpa rara ngaroe,

njama nda kokoer ili mata $=$ kauw mij sirih voor rooden mond, kauw mij klapper voor glimmend gezicht.

Een gewone uitdrukking voor iemand, die een liefdesverklaring aflegt an een meisje. Wil voor mij doen, wat een goede huisvrouw voor haar man doot. 
Toen 't wederom licht werd, bracht I R. K. haar weefgetouw weer naar beneden. Terwijl zij aan 't weven was, kwam de boschhaan er wederom aan, daar hij 't gedreun van 't weefgetouw hoorde. En hij zeide wederom: "ho Rămboe Kahi, kauw mij een sirih pruim voor rooden mond, kauw mij klapper voor glimmend gezicht.»

En I R. K. kwam naar buiten, terwijl zij haar weefgetouw oprolde. Eveneens kookte zij eten voor den boschhaan. Toen 't eten gaar was, schepte zij 't op en gaf 't hem om te eten. Nadat hij gegeten had, gaf zij hem sirih. Wederom droeg zij hem naar beneden in de voorgalerij. In de voorgalerij gekomen, ging de boschhaan heen. Zoo gebeurde het iederen dag met den boschhaan en I R. K. bekommerde zich niet om 't weefgetouw.

Toen kwam I Pila Ndiloe uit den tuin en zeide tot zijn zuster, haar vragende: "hebt gij uw weefgetouw al af?» "Nog niet», zeide I R. K. Wat voert gij hier dan uit, dat gij 't weefgetouw heelemaal nog niet af hebt gemaakt? Kom ons eten brengen, hebben wij u gezegd, en gij komt ook niet. Morgen gaat gij eten brengen aan vader en moeder.»

En I R. K. ging nu naar den tuin. Juist was I R. K. heen gegaan, of I Pila Ndiloe bracht 't weefgetouw naar beneden en begon te węven. Dreunend klapte 't weefgetouw. Toen kwam de boschhaan er aan en zette zich neer op 't weefgetouw. En I Pila Ndiloe nam de klop-bamboe en sloeg den boschhaan. Deze stierf nu en hij nam hem en roosterde hem. I Pila $\mathrm{Ndiloe}$ at de eene helft op en hij bewaarde voor I R. K. de andere helft. Toen kwam I R. K. terug van den tuin.

"Daar is wat kippenvleesch in 't mandje in uw kamer; ik sloeg een kip dood, die in de asch hier zat te krabbelen", zeide I Pila Ndiloe. Toen nam I R. K. 't mandje en maakte 't open en keek er in: 't was niet als 't vleesch van kip uit huis. $\mathrm{Zij}$ rolde haar weefgetouw op en ging er mee naar 't bosch. In 't bosch gekomen, bond zij haar weefgetouw aan een boom en begon te weven, terwijl zij zong: "waar zijt gij toch hiẹr, Oemboe Ndiloe kip; in 't verwarde struikgewas, in de dicht neergetrapte alang alang?

Wederom rolde zij haar weefgetouw op, wederom ging zij heen en kwam in een ander bosch. $\mathrm{Zij}$ maakte haar weefgetouw open en zong. 't Was hetzelfde, als zij zooeven gezongen had: 
"waar zijt gij toch hier, Oemboe $\mathrm{Ndiloe} \mathrm{kip?"} \mathrm{zeide} \mathrm{zij}$ zingende. Maar I Oemboe Ndiloe kip was aldaar niet.

Wederom ging zij naar een ander klein bosch; wederom zong I R. K., maar zij zag I Oemboe Ndiloe kip aldaar niet. Wederom rolde zij haar weefgetonw op en ging naar een ander bosch. Wederom bond zij 't weefgetouw aan een boom en weefde en zong. Toen hoorde haar de boschhaan en hij antwoordde kakelend: "hier ben ik! ga naar den bruinen waringin-boom, naar den vasten wonderkrachtigen steen. ${ }^{1} \mathrm{Ndiloe}$ uw broeder was 't, die mij sloeg en roosterde, zeide I O. Nd. kip tot I R. K.

En I R. K. ging naar hem toe. Toen veranderde I O. $\mathrm{Nd}$. $\mathrm{kip}$ in een mensch. De bruine waringin-boom veranderde in een huis. En zij bleven er wonen, terwijl I Oemboe Ndiloe trouwde met I R. K.

Toen het ongeveer een maand geleden was, ging haar broeder I Pila Ndiloe zoeken naar I R. K. Hij vond haar aldaar en I O. Nd. kip zag I Pila Ndiloe, en goed gezond was weer zijn hart, toen hij zijn zwager zag, en niet meer boos was hij op hem, die hem doodgeslagen had.

Men kookte eten voor hem en gaf hem te eten. Na ongeveer tien nachten, trouwde I O. Nd. kip; daar zijn zwager er nu was. En men gaf hem goud en mamoeli's en paarden. Toen keerde I Pila Ndiloe terug naar zijn huis.

1 la pingi ai wanggarara,

la watoe $\mathrm{ngoedoe} \mathrm{mbiha}=$ naar den bruinen waringin boom, naar den onbeweeglijken wonderkrachtigen steen; d. i. een heilige plaats, door geesten bewoond. 
I Rămboe Kahi, en de uien.

I Rămboe Kahi, was de dochtervan I Domoe Woelang en haar moeder was I Lingga Wăndăloe. Haar dorp was in Kambera. En nu kwam I Oemboe Ndiloe zijn vrienden bezoeken in Kambera; in Taboendoeng was de kampong van $\mathrm{I} \mathrm{O}$ emboe $\mathrm{Ndiloe}$. Hij kwam geen vriendschapsbezoek brengen bij andere menschen, want I $\mathrm{Hadoe} \mathrm{Hina}$ was zijn oom. Hij zag I Rămboe Kahi en vroeg haar. De ouders van I Rămboe Kahi zeiden: ja. Haar ouders verzamelden nu de menschen en men sloeg op de gongs, terwijl men feest vierde. En I Oemboe Ndiloe trouwde. Haar vader slachtte onzegbaar veel, paarden, karbauwen, toen I O. N d. trouwde. Eveneens de manden en de slaven, welke zij meebracht (als bruidschat). En I O. Nd. gaf paarden, karbouwen, oude mamoeli's en gouden kettingen.

Ongeveer één jaar bleef I $\mathrm{O} . \mathrm{Nd}$; toen ging hij naar zijn eigen kampong. Hij was juist vertrokken naar Taboendoeng, toen I Kahi, van de overzijde, en I Loda gingen roepen naar I Rămboe $\mathrm{Kahi}$, de vrouw van I $\mathrm{O}$. Nd., om hout te gaan sprokkelen in 't bosch, terwijl zij een listig plan hadden. I Kahi en I Loda hadden gaarne I. O. Nd. als man gehad, daarom smeedden zij een listig plan tegen I Rămboe Kahi, de vrouw van I O. Nd.

In 't bosch gekomen, werd I Rămboe Kahi door I Kahi, van de overzijde, en door I Loda, op den rug geworpen en zij raspten de borst open van I Rămboe $\mathrm{Kahi}$, met een klapper-rasp. Tegen den avond keerden zij terug. 't Eerst kwamen I Kahi en I Loda, en toen vroeg de moeder van I Rămboe $\mathrm{Kahi}$ : "waar is toch uw naamgenoot?" zeide de moeder van I Rămboe Kahi. "Zij komt er nog aan; zij sprokkelde geen hout, zij speelde maar wat.» Korten tijd daarna kwam I Ră $\mathrm{mboe} \mathrm{Kahi}$ en zij ging regelrecht door naar haar kamer. Haar moeder zeide: "kom toch eten." "Wacht nog even», zeide I Rămboe Kahi.

$\mathrm{Na}$ langen tijd, kwam zij er uit en ging eten. Nadat zij 
gegeten had, ging zij heen om te slapen. Zij zeide niets tegen haar moeder van haar pijn.

Wederom wakker geworden toen 't licht was, riepen zij haar wederom om hout te gaan sprokkelen. Zij ging, toen zij haar riepen.

In een dal gekomen, wierpen zij haar op den rug en raspten de borst van I Rămboe Kahi. 't Was avond toen zij wederkeerden. En ook nu kwamen I Kahi en I Loda 't eerst aan. "Waar is uw naamgenoot? zeide de moeder van I Rămboe Kahi. "Zij komt er al aan», zeiden zij.

$\mathrm{Na}$ korten tijd kwam I Rămboe Kahi; zij ging regelrecht naar haar verblijfplaats om te slapen. "Wat zou er toch zijn met I Rămboe Kahi? misschien heeft zij wel de koorts.»

En haar moeder ging naar haar toe in de kamer, om naar haar te zien. Toen zag haar moeder, wat haar pijn deed, de teekenen van 't raspen door I Kahi en I Loda. Maar zij zeide tegen haar moeder: "als ik sterf, begraaf mij dan bij den offersteen van 't huis. De uien. overgeschoten van 't eten van I. O. $\mathrm{Nd}$., welke onder mijn hoofdblok liggen, neem die en plant ze bij mijn voeten en bij mijn hoofd.

Toen 't wederom licht werd, stierf I Rămboe Kahi. Toen I Rămboe Kahi gestorven was, weende haar moeder meer dan te zeggen is. Toen 't avond werd, begroef men I R ămboe Kahi. En haar moeder nam de uien, waarvan zij tot haar moeder gesproken had, en plantte die, één bij het hoofd, één bij de voeten.

I O. Nd. nu bleef drie maanden in Taboendoeng; en hij keerde terug. Buitengewoon veel pinang en sirih bracht hij te paard mee uit Taboendoeng. Toen I O. Nd. aangekomen was, bracht haar moeder voor hem sirih naar beneden, om te kauwen. En haar moeder vertelde aan I O. Nd., dat I Rămboe Kahi gestorven was. "Daar is haar graf», zeide zij.

Toen brachten ook I Kahi en I Loda sirih aan I O. Nd., maar hij wilde niet kauwen. Hij gaf niets om haar beiden. Hij ging liggen boven op 't graf van zijn vrouw. Op zekeren nacht, terwijl I O. Nd. sliep op 't graf van zijn vrouw, bewoog zich de ui, juist voor zijn voeten; eveneens de ui, bij zijn hoofd.

Nadat drie nachten voorbij gegaan waren, leefde I Ră mboe $\mathrm{Kahi}$ weer. Toen nam I O. Nd. haar op en bracht haar in de voorgalerij en legde haar op zijn knieën. 
Maar I Kahi, van de overzijde, en I Loda, daalden heelemaal niet neer uit hun huis, daar zij bang waren voor I O. Nd. "Laten wij hem trouwen, zeiden zij van $\mathrm{u}$, daarom doodden zij mij , zeide I R. K. het vertellende aan I O. $\mathrm{Nd}$. Toen I O. $\mathrm{Nd}$. dat hoorde, nam hij zijn kapmes en ging naar I Kah i en I Loda toe. En hij doodde ze allen, den vader, de moeder, de familie. En hij stak hun huis in brand en verbrandde ze allen op eenmaal.

$\mathrm{Na}$ twee à drie maanden, zond hij iemand om het aan zijn ouders te gaan vertellen. $\mathrm{Zijn}$ ouders kwamen met een groot gevolg om hem terug te halen naar Taboendoeng. Toen zij allen uit Taboendoeng aangekomen waren, slachtten zij karbauwen en varkens, ook danste men, terwijl men feest vierde.

Na korten tijd werd I Rămboe Kahi zwanger. Toen haar maand was gekomen, baarde zij een jongen. Hij kreeg den naam van den vader van I O. Nd. Langzamerhand werd I Domoe Woelang, de zoon van I O. Nd., groot. Hij kon al loopen. Toen maakte men zich gereed. Men slachtte karbauwen en varkens. De vader van I Rămboe Kahi gaf haar de bruidschat en zij gingen heen naar Tabòendoeng. 